


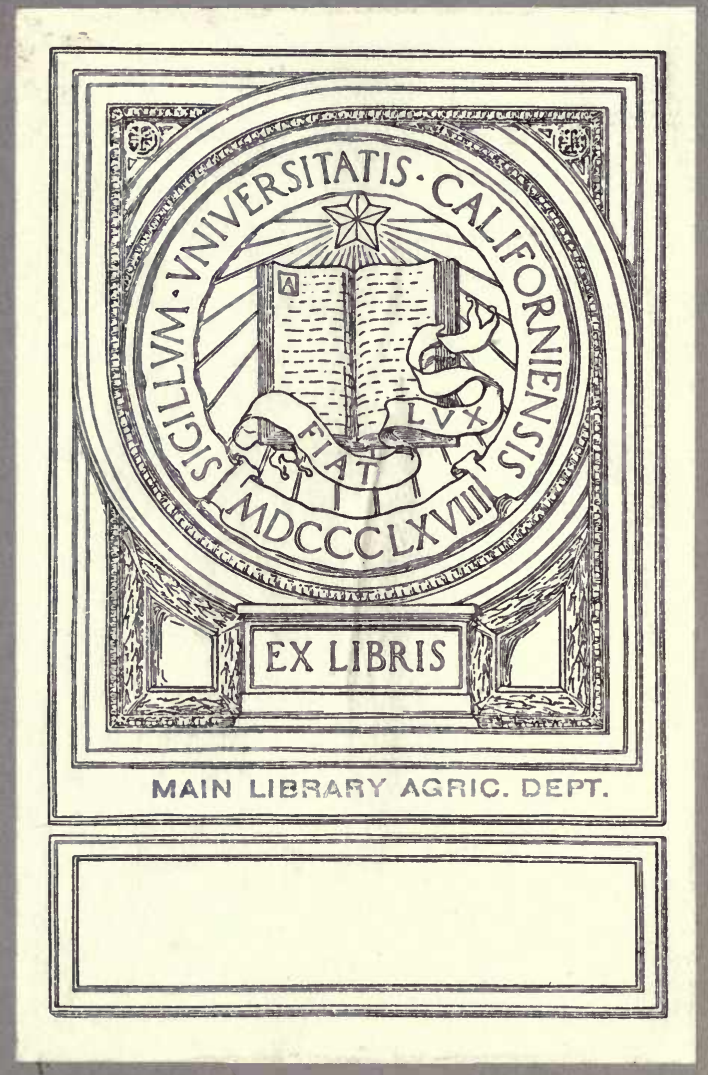







\section{THE PRACTICAL BOOK OF GARDEN ARCHITECTURE}





\section{THE PRACTICAL BOOK OF GARDEN ARCHITECTURE}




\section{THE \\ PRACTICAL BOOKS}

EACH HANDSOMELY BOUND

AND IN A SLIP CASE

8VO. $\$ 5.00$ NET, POSTPAID $\$ 5.25$

\section{THE PRACTICAL BOOK OF} ORIENTAL RUGS

By DR. G. GRIFFIN LEWIS

20 illustrations in color, 93 in doubletone, 70 text designs in line. Folding chart of rug characteristics and a map of the Orient. 8vo.

THE PRACTICAL BOOK OF GARDEN ARCHITECTURE By

PHEBE WESTCOTT HUMPHREYS With frontispiece in color, designed title and 125 illustrations from actual examples of garden architecture

\section{THE PRACTICAL BOOK OF PERIOD FURNITURE By}

HAROLD DONALDSON EBERLEIN AND ABBOT MCCLURE

IN ADVANCED PREPARATION

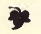

UNIFORM IN SIZE, STYLE, AND PRICE

THE CURIOUS LORE OF PRECIOUS STONES

By GEORGE FREDERICK KUNZ, PH.D., A.M., D.Sc.

With 86 illustrations in colors, doubletone and line.

J. B. LIPPINCOTT COMPANY PUBLISHERS PHILADELPHIA 



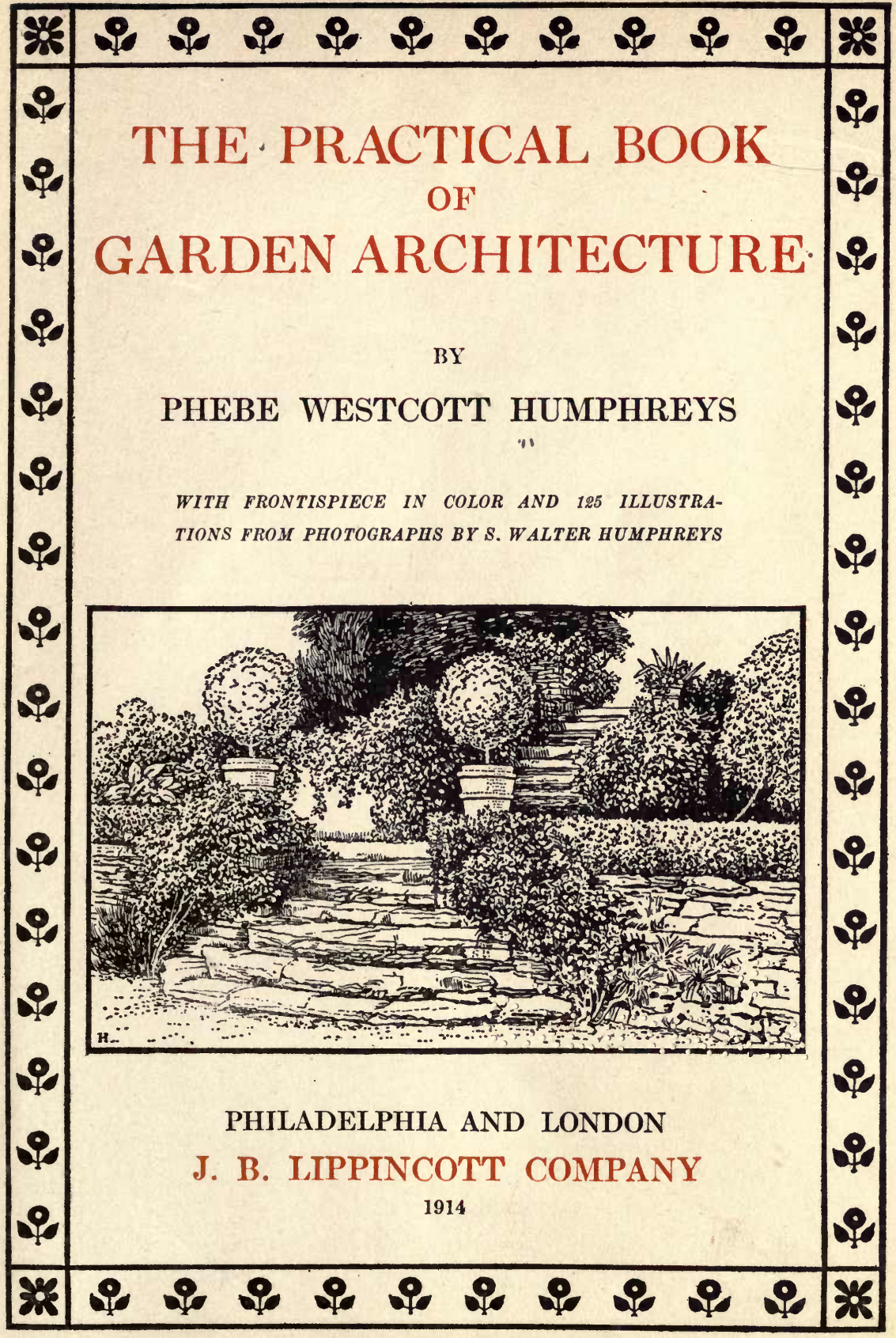


WAIN LIBRARY A - D CULTURE DEFY. Spa Agni e. Bubbler COPYRIGHT, 1914, BY J. B. LIPPINCOTT COMPANY

PUBLISHED MARCH, 1914

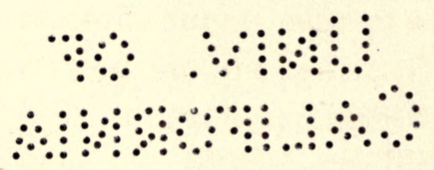

PRINTED BY J. B. LIPPINCOTT COMPANY AT THE WASHINGTON SQUARE PRESS PHILADELPHIA, U. S. A. 


\section{PREFACE}

THE preparation of this book has resulted from years of delightful study of art and architecture in connection with a regular college course, and the art course at the Philadelphia School of Design; from an early developed love for outdoor life; and from an intimate study of beautiful home surroundings in the form of garden architecture during extensive travels in various European countries and throughout the United States.

Over twenty of the chapters have been written especially for this book, and, with over a hundred of the illustrations, have never appeared in magazines or other publications.

Thanks are due to "American Homes and Gardens," "Suburban Life," and "House Beautiful," for the release of certain of my articles and photographs which form portions of ten chapters. Thanks are due also to "Country Life in America" and "House and Garden" for help and inspiration in the study of various water features, engine power, wall treatments, etc. Suggestions and guide-clippings from these magazines have led to the best results in visiting famous gardens for illustrating interesting types of garden embellishment. It has been impossible to give individual credit for all the 


\section{PREFACE}

quoted extracts, especially pertinent, as the source of inspiration was lost in some instances after a round of photographic journeys.

With a husband-chum eager for travel and photography as the most restful and interesting form of recreation from the arduous duties of an extensive manufacturing business, it has been possible to secure the best form of illustration for every phase of garden architecture.

The numerous details of practical construction, and the intricasies of introducing and developing water supplies, and other requirements for home betterment and adornment have been carefully chronicled under the expert supervision of this same dependable assistant. Manufacturers of hydraulic rams and the different forms of engine power have vouched for the reliability of all of my statements in this connection. This work is accordingly offered to the public with the hope that it will prove an inspiration in creating a love for outdoor life, a reliable source of encouragement and inspiration in the equipment and decoration of open-air living rooms, and in establishing harmonious relations between the house and its surroundings.

P. W, H.

February, 1914 


\section{CONTENTS}

CHAPTER

PAGE

I. InTRODUCTION........................ 1

II. Types of Gates and Gateways .............. 9

Effective Barriers of Wood, Stone, Iron, Brick and Concrete, for Insuring Home Privacy.

III. Walk Paving. .......................... 19

Stepping Stones, Methods of Ramping, and Quaint Terrace Treatment for Picturesque Walks.

IV. The Walled Garden and Ins Advantages ......... How to Construct the Decorative Barrier that will Keep out Intruders, and Encourage Outdoor Living

V. Terrace Walls and Their Treatment................ The Function of the Retaining Wall in Relation to Garden Development.

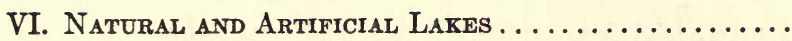
How to Convert Unsightly Swamp and Marsh Land into Beauty Spots and Control Objectionable Features.

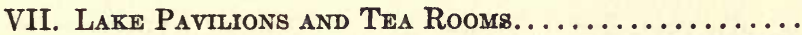

Novel Water Features Devised for Dispensing Hospitality.

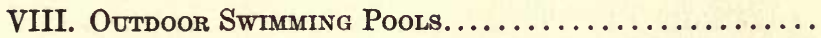

Natural and Artificial Water Supplies Form an Architectural Feature Capable of Wide Adaptation.

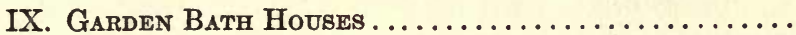

Quaint Rustic Shelters and Highly Ornate Structures Are Being Built in Harmony with the Adjoining Swimming Pool.

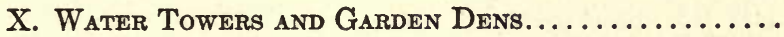

The Water Supply of the Country Home may Prove an Inspiration as well as an Essential.

XI. Decorative Wrndmils.................... 114

How They May be Made to Give Distinctive Character to Suburban Places, and How Satisfactory Tanks May be Built. 


\section{CONTENTS}

XII. Crows'-nests and Tree Houses . . . . . . . . . . . . 123

Secluded Retreats Ideal for Securing Rest and Inspiration.

XIII. Arches and Pleaching

English and Continental Types Suitable for American Gardens.

XIV. Dependable Bird Houges. ............... 138

Where the Feathered Songsters Find Practical Nesting Places and Protection from Their Enemies.

XV. Bird Basins and Feeding Tables ............. 150

An Interesting Form of Garden Decoration Urged by Audubon Societies and State Grange Committees.

XVI. Transforming Garden Buildings .............. 161 An Architecture Study in Utilizing Historic Structures.

XVII. The Japanese Garden in America ............ 167 Quaint Accessories Combined with Unusual Landscape Features.

XVIII. French Furnishings for the Formal Garden...... 179 Practical Accessories Well Adapted to Formal Composition.

XIX. An Undestal Woods Garden................. 190

A Place of Surprises at Every Bend of the Winding Woodland Roadway.

XX. Nover Spring Houses. . . . . . . . . . . . . . . . . . . 197

Varied in Type to Fit Requirement and Situation.

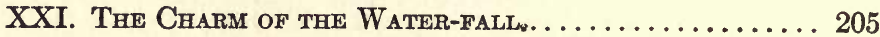

How to Build and Maintain This Fascinating Garden Feature.

XXII. Appropriate Bridges................... 215

Garden Streams Aid Considerably in Perfecting the Picture of Harmonious House Surroundings.

XXIII. Practical Garden Fountains.

The Combination of Sculpture and Water Plays an Important Part in the Decorative Scheme of the Outdoor Living Room.

XXIV. Revival of the Wall Fountain............... 234

A Suggestion from the Villas of Ancient Rome for Beautifying American Gardens. 


\section{CONTENTS}

XXV. The Practical Side of the Tennis Court........ 240 The Best Materials for a Durable Court and Appropriate Architectural Features.

XXVI. Espalier Walls and Trellises............. 252

A Practical Horticultural Hobby Developed into an Ornamental Garden Feature.

XXVII. Pergolas and Arbors .................... 264

The Use and Abuse of Adapting the Italian Pergola to American Ideas.

XXVIII. The Popdlar Porch Pergola ............... 271

Combined with the Tiled Terrace It Forms an Ideal Open-air Living Room.

XXIX. The Quaint and Durable Thatched Roof........ 276 An Inexpensive Form of Garden Handicraft that is Easily Executed.

XXX. Temples and Belvederes ................. 288

Appropriate Situation and Green Background are Important.

XXXI. Decorative Garden Lanterns. . . . . . . . . . . . 297

Illuminating Conveniences for the Home Grounds that are Practical, Inexpensive and Ornamental.

XXXII. Ornamental Wells and Well Houses............ 306

Many are Purely Decorative; Others Combine Their Beauty with Utility.

XXXIII. Attractive Garden Stairways.............. 315

Clever Designs for Climbing Terraces and for Securing Pictorial View-points in Outdoor Living Rooms. 



\section{ILLUSTRATIONS}

A Wall Fountain with Appropriate Surroundings at "Thorn Hedge," the H. H. Battles Estate, Newtown Square, Pennsyl-

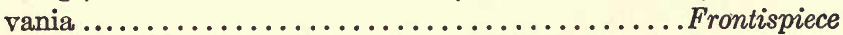

Gate-posts of Brick Panelling after an Old English Design at Ger-

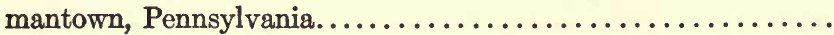

A Dignified Triple-arched Gateway in Harmony with a Formal Garden................................... 10

A Terrace Gateway Complete without a Gate............ 12

The Stone Wall Forming the Gate-posts of a Germantown Home 12

A Practical Metal Gate for an Arbor Walk................ 14

Entrance to "Old Gate," Farmington, Connecticut........... 14

A Covered Gateway through a Well-built Wall ............. 16

Coral Enclosing Wall at the Florida Home of Mr. George B. Cellon 16

An Attractively Paved Walk on the Pilling Estate at Lansdowne,

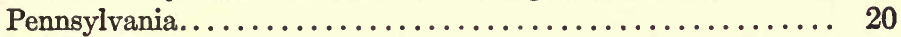

A Combination of Brick and Concrete Paving on a Terrace Slope 24

Foot-holds on the Declines of a Winding Terrace Walk......... 24

A Novel Walk of Small Cedar Branches, Quaintly Enclosed, where a Garden Walk Extends into Pasture Land...............

Walls of Concrete and Field Stone about Bermuda Gardens......

A Combination of Low Wall before the House and a High One

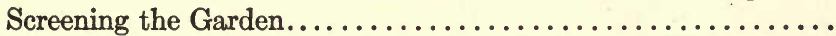

The Interesting Treatment of the High Wall of a Hill Garden at "Krisheim".

Giant Box Bushes Overtopping the High Wall in the Garden of Haddon House, Haddonfield, New Jersey................

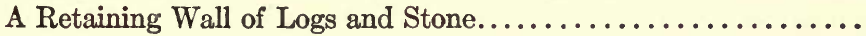

Terrace Bowlders Draped with Trailing Plants at "Lynnwood Hall," the Widener Estate at Elkins Park................

The Famous Garden Wall on the Woodward Estate at Chestnut Hill, Pennsylvania........................... 48

A Terrace Wall Bordering a Lake in a Florida Garden near Miami 53

A Spring-fed Lake with Stepping Stones and a Bed of Watercress at the Overflow at "Twickenham Farm," Glenside, Pennsylvania

A Lake Attractively Screened by Willows, with Floating Plants to

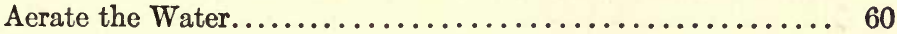

A Lake Tea Room Giving Beautiful Reflections.............. 66 


\section{ILLUSTRATIONS}

A Lake House at "Erdenheim" in the Whitemarsh Valley....... 66

A Charming Lake Pavilion at "Swastika," the Matheson Estate, Southern Florida........................... 71

A Pool with the Intake End Bordered with a High Rim of Concrete 76

A Pool Screened by a Tall Privet Hedge............... 76

A Pool with Good Planting at Garden City, New York........ 79

A Pool with High Coping Keeping the Surrounding Soil Free from

Dampness.................................. 79

A Rustic Bath House with Railed Roof ............... 88

An Attractive Bath House Set among Large Trees at the Pool's

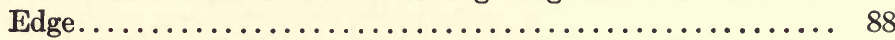

A Bath House Well Situated and Reflected in the Pool.......... 95

A Long Bath House with Six Dressing Rooms at "Spring Dell

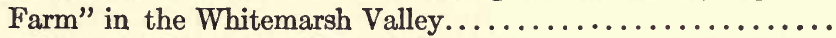

The Famous Water Tower on the Aldrich Estate, Rocky Point, Rhode Island............................... 98

A Bermuda Watershed, Cistern, and Tower............... 98

Water Tower at "Rose Valley Farm," the Home of Mr. Charles T.

Schoen, Moylan, Pennsylvania.................. 111

Tower with Winding Stone Stairway - a Quaint Feature in Southern

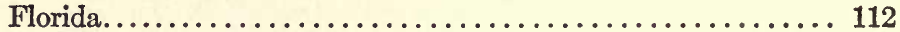

A Massive Water Tower on the Matheson Estate at Cocoanut Grove, Florida.

A Quaint Holland Windmill on a Rotterdam Dyke.......... 116

A Charming Play House for the Children Built at the Base of a

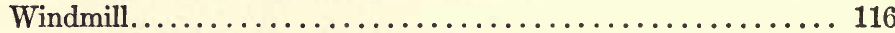

Thatched Windmill with Spacious Rooms and Porch, "Lyndanwalt," Abington, Pennsylvania................... 119

Dutch Windmill at Rotterdam...................... 119

A Crow's-nest Extending from Tree to Tree with Cosy Landings.. 124

A Two-story Tree House Serving as a Commodious Play House for the Children............................ 126

A Tree Room with Vine-clad Stairway................ 129

A Crow's-nest Built by Boys near Baltimore............... 129

A Pleached Arch over a Garden Seat at Garden City, New York.. 132

A Succession of Arches Leading through the Garden from Front to Back Entrance........................... 135

A Series of Rose Arches Forming a Continuous Bower.......... 135

A Bird Box Forming an Appropriate Apex to a Summer-house ... 138

A High-placed Bird House in the Chicago Suburbs.......... 145

A Keg Bird House with Thatched Roof and Circular Platform.... 145 


\section{ILLUSTRATIONS}

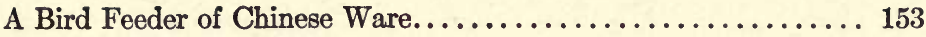

An Antique Bird Basin at "Lyndanwalt"............... 153

Front View of Dilapidated Building at "Lyndanwalt" before

Remodelling............................ 162

The Garden Studio into Which the Above Was Transformed .... 162

Back View of the Ancient Structure before Remodelling. ........ 164

Back View of the Well-lighted Garden Studio.............. 164

A Japanese Garden of True Oriental Design on the Burk Estate at Olney, Pennsylvania........................ 168

A Wooden Lantern in an Appropriate Setting of Japanese Maples on the Pilling Estate at Lansdowne, Pennsylvania.......... 171

Water-worn Rocks and Dwarf Trees Covering a Miniature Island 175 An Exquisite Japanese Lantern in a Secluded Spot........... 175 Attractive, Modest Homes along the Canals of Suburban Paris .. 180 One of the Narrow and Crooked French Streets with Blooming Plants Overhanging the Wall................... 180

A Water Basin in the Wall on the Woodward Estate at Chestnut Hill, Pennsylvania, Resembling Those of France........... 183

A Rustic Bridge Placed where the Drive Crosses a Woodland Stream at "Thorn Hedge"....................... 191

An Ox-team as a Distinctive Feature of the Garden Grove...... 193 An Old Spring House Converted into a Woods Tea Room by

Extending Roof and Porch....................... 193

A Typical Old-time Spring House Dating from Revolutionary Days 198 Interior of the Ryers Spring House, Brick Floor, Concrete Walls, and Cooling Channel.......................... 198

An Inexpensive Spring House of Local Field Stone and Home-made

Construction................................. 202

The Historic Andalusia Spring House Walled on but One Side... . 202

A Picturesque Fall over a Broad, Low Dam of Logs and Puddled Clay.....................................206

A Dam of Logs and Rocks in the Blue Ridge Mountains........ 208

A Water-fall with Much Stone-work Adding to its Vigorous Beauty 208

A Broad, Rugged Dam and Attractive Spillway for the Lake..... 211

A Steep Grade with Stone Steps Forming a Water-fall in the Springfed Stream at the Intake of a Lake, Merion, Pennsylvania..... 213

A Flat Bridge on a High Stone Foundation. Picturesque Treatment at "Compton," the Morris Estate............... 216

An Appropriate Bridge Leading to the Old Mill at Ogontz....... 216

A Steeply Arched Bridge over a Narrow Stream Subject to Sudden Freshets.................................... 


\section{ILLUSTRATIONS}

An Oblong Terrace Fountain with Spouting Figure Poised on the Rim and Shrubbery Background................... 222

Fountain of Roman Type, Feeding Others in the Sunken Garden. 222

A Circular Fountain in the Centre of a Sunken Garden of Italian Style................................... 224

A Tall, Elaborate Fountain with the Advisable Background of Foliage.................................... 230

A Simple Iron Fountain, Easily Installed and Attractive........ 230

A Series of Fountain Basins in a Terrace Wall on the Kolb Estate

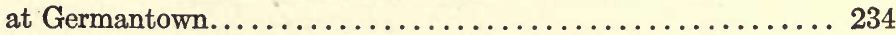

A Dignified Wall Fountain of Classic Design with Dolphin Mouth Piece................................... 236

Heavy Timbers Used to Hold a Fountain in Place Are Afterwards Covered with Plaster......................... 236

A Wall Fountain of Italian Design on the Clark Estate, "Kate's Hall," at Chestnut Hill......................... 238

A Well-laid Tennis Court with Back Net in Decorative Pergola Form at "Lindenhurst," the Wanamaker Estate at Wyncote, Pennsylvania.............................. 240

A Low, Ornamental Terrace about a Tennis Court............ 245

A Long Flight of Steps to a Low-placed Court.............. 245

A Door in the Back Net and Steps Giving Convenient Access to a Tennis Court............................... 248

An End of a Tennis Court Developed into a Pergola Tea Room. . 250 Fan-shaped Peach Trees on a South Wall with Overhanging Glass Roof, on the Laughlin Estate..................... 254

Vase-shaped Espalier Frames of Wire Supporting Unusual Trees at "Thorn Hedge"................................. 254

Espaliers on Wire Frames Occupying Little Space in the Garden. . 259 The Court between Two Pergolas and Roman Well Head at

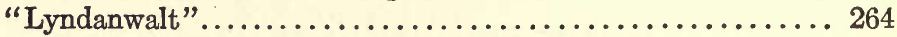

A Section of the Double Pergola at "Lyndanwalt," the Hering Estate at Abington, Pennsylvania.................. 264

The Long Pergola at "Rose Valley Farm," Moylan, Pennsylvania; of Good Design with Attractive Paving................ 267

A Pergola with Circular Centre and Rose Trellises............. 268

A Rugged Pergola of Home-made Concrete Construction......... 268

A Stately Pergola at "Fox Hill," the Ellis Estate at Bryn

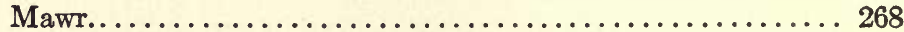

A Long Porch Pergola Added to an Old Homestead at "Kathaleen Farm" on Bethlehem Pike....................... 272 


\section{ILLUSTRATIONS}

A Porch Pergola Surrounding the House of Dr. John Griffith,

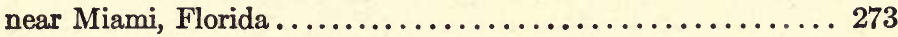

A Side Porch Pergola, with Concrete Floor Connecting with the Front Porch.............................. 273

A Combination Porch and Pergola Supported by Massive Concrete

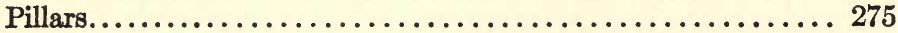

A Tightly Bound, Rope-finished Apex to a Thatched Roof....... 278

A Good Apex, but Poor Thatching, the Roof Being too Flat...... 278

A Thatched Roof at Rotterdam, Holland, Showing Thorough,

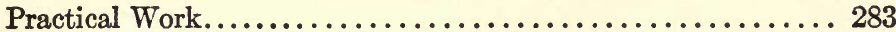

A Stately Temple on the Van Rensselaer Estate, "Camp Hill Hall," Overlooking the Whitemarsh Valley................... 288

A Lake Temple, Grecian in Design, at "Compton," the Morris Estate at Chestnut Hill........................... 290

A Grecian Type of Garden Temple with Many Columns ........ 293

A Simple and Well-placed Temple at Old Orchard, Maine....... 293

A Stout Tree Trunk Supporting a Driveway Lamp............ 298

A Picturesque Setting for the Garden Lantern Post............ 298

A Stable-wall Lantern with Background of Ampelopsis Vine...... 303

A Simple Form of Water Power for Generating Electricity ....... 303

A Rose-decorated Pump House of Considerable Attraction and Little Cost. ................................ 306

An Italian Well, Fitted with Iron Windlass, Chain, and Bucket .. 309

A Treasured Roman Well Head with Practical Appliances at "Druim Moir," the Houston Estate at Chestnut Hill......... 312 An English Method of Decorating Rocky Stairs with Alpine Plants 316 An Ideal Form of Crossing a Stream to Climb the Garden Terrace 316 An Arched Entrance to a Hillside Stairway................ 321 A Stone Stairway Winding among Shrubbery ............... 321 



\section{THE PRACTICAL BOOK OF GARDEN ARCHITECTURE}

\section{I \\ INTRODUCTION}

Whether the owner of a property supervises its ornamental development or places the work in the hands of a professional, the requirement of a practical book on the subject is equally great. If the first need is the more obvious, the second is quite as real, for how shall an owner be able intelligently to consider the plans and suggestions of his garden architect unless he himself has some adequate knowledge of the subject? Much waste of good money, much upheaval of work done and not liked, much dissatisfaction with the final effect have resulted simply from the lack of such knowledge as is compendiously given in this volume.

For the man or the woman who is supervising the actual work done, or perhaps even doing it with his or her own hands, this book will be found to supply practical directions of a specific character.

At this very beginning of the volume the author wishes, too, to say a word regarding the city "yard" 
:PRAGTICAL BOOK OF GARDEN ARCHITECTURE

- too often either neglected or overdone. The principles and the helps given will be found as useful here as for the property out of town.

It should be mentioned that, throughout, the word garden has been used in the most elastic sense, it being necessary to embrace both the smallest nook of ground and the large estate.

Of the first importance in any artistic work, simple or complex, is the correct point of view. The garden that is lived in and loved, whose architectural treatment has developed naturally in response to the growing demand for art out of doors, and in harmony with the house and its surroundings, will achieve far greater success than the "show garden" in which the architect has slavishly followed some prescribed canon of formal or naturalistic treatment. Repose and harmony must be the fundamental principles in blending the numerous accessories with picturesque and comfort-dispensing features in the little garden living rooms surrounding suburban homes, as well as in the landscape designs of spacious country seats.

In preparing this practical book on architectural embellishment the author has endeavored clearly to demonstrate that garden beauty and harmony need not necessitate lavish expenditure. The most attractive features are shown to be within the means of the 


\section{INTRODUCTION}

modest owner. The expense of building and maintenance has been materially lessened during recent years by many labor-saving devices unknown to the famous craftsmen of old-world gardens. It is, for instance, now possible to secure in cement excellent reproductions of fountains, temples, garden-seats, steps, balustrades, etc., formerly executed in marble; and, with the numerous labor-saving devices, their manufacture is within the capabilities of the average garden-craftsman. On the other hand, the wealthy proprietor who wishes to import genuine antiques of such objects or to have them specially designed will find among the illustrations excellent examples for his guidance.

Another important object in the preparation of this book is the warning against an overcrowding of supposedly desirable accessories. There are numerous American properties (including even some of those which are given as models in household journals) which are "horrible examples" of overdoing and incongruity. We must not overlook our natural trait - the average American wants too much, wants everything in one small stretch of territory. If it doesn't "belong," he will nevertheless force it in, especially if it happens to be the fad of the moment. Satisfactory results can be obtained only when each architectural feature admitted to the garden beauti- 


\section{PRACTICAL BOOK OF GARDEN ARCHITECTURE}

ful so fits into its surroundings that, however new it may be, it will when completed look as if it not only belonged there, but had always been there. There is no better test than this of good and bad forms of garden development. It means restfulness and repose instead of the uneasiness of effect too frequently encountered in the treatment of house surroundings.

While advocating the effect of restfulness, which is secured only by appropriateness to surroundings and by congruity of detail, it has seemed unwise in the various chapters treating of distinct characteristics of garden architecture to make repeated mention of faults. The frequent warning against the several offenses, never permissible though often encountered, has not appeared in each chapter; therefore the author desires here to sound emphatic warning against the most glaring of these offenses, those of mixture of styles, mixture of materials, overcrowding, and overloading.

In the first offense-the mixture of styles-the garden builder is cautioned against any form of garden architecture which does not agree with the architecture of the house, or with the general type of neighboring properties-the offense of mixing Tudor houses and Greek temples, French châteaux and Holland windmills, Swiss chalets and Japanese 


\section{INTRODUCTION}

gardens, and various other inappropriate and inexcusable combinations. In the second offense-the mixture of materials-it is here pointed out that stone work, brick work, concrete work, rustic work, etc., should not be allowed to appear on the same property. Not that it is necessary that absolutely everything should be of stone or brick, or of any one sort of material, but that too much variety only breeds discord. That there should be harmonious relations between the various forms of garden embellishment and utility when it is desirable to use more than one kind of material. In considering the third offense-overcrowding-it is evident that a small place may be made as much of a gem as a large one, but it will be by the selection of just the right features which are suitable to it, and not by attempting to put everything in landscape gardening and garden architecture upon one small property. Selection is here the keynote; and if a few of our wealthy people with large estates would also bear this in mind, the result would be simpler and far more pleasing. There is no excuse for the owner of a spacious garden, lawn, and woodland to overcrowd; neither should the owner of the small place attempt to display in compendium form a sample of every kind of scenery and accessory that his fertile brain can conjure to decorate his limited acres. In the 


\section{PRACTICAL BOOK OF GARDEN ARCHITECTURE}

fourth offense-overloading-it has been considered wise to caution against the introduction of accessories which are larger and more ornate than the principal things. A handsome wall of cut stone, for instance, should not be erected around a brick or frame house. Neither should the front gateway be so large and ornate that it will dwarf the residence and garden surroundings to which it gives entrance. One special feature of embellishment should not be allowed to give others the appearance of inferiority. $N o$ accessory should be too heavy and imposing for the house itself.

But the rules of art are reasonable and not arbitrary, as many misapprehend: the Greek temple, so called, does not harmonize with a Tudor or Moorish house, but it will, if simple, go with a Colonial one; because both are classical in spirit. Many individual features of the garden beautiful that would clash when carelessly placed in juxtaposition will prove entirely appropriate when intervening shrubbery screens them from one another. In woods gardens and various forms of surprise gardens where distinctive vistas are screened from one another, the owner may exercise his hobby in some quaint type of old-world treatment without interfering with the general characteristics surrounding the house. While it is generally understood that Japanese land- 


\section{INTRODUCTION}

scapes and various forms of Oriental gardens are incongruous with any Occidental house, they have been introduced with pleasing results and have served as attractive studies of garden composition when so separated from the house by space and foliage that the two are not visible at the same time.

In the chapters where it has been necessary to describe and illustrate various forms in brick, stone, concrete, and rustic work, to show the distinctive designs pertaining to each type of garden architecture, an attempt has been made to present a wide range of choice to fit the requirements of every form of garden. It has been taken for granted that no one will make the mistake of assuming the responsibility of mixing these various types in any one garden, no matter how large and well screened. In treating of pergolas and similar features of garden architecture that have been extensively overdone in many localities, the caution has been especially emphatic against using them where they do not belong, and only where there is some reason for their existence. In portraying good examples of cobble walls, various effects in rough field stone, bark-covered logs, slab furnishings, and similar forms of rusticity, it has been shown that they are most attractive when used in the most rugged surroundings. In dealing with quaint and unusual types and fads in garden furnishings, an ef- 


\section{PRACTICAL BOOK OF GARDEN ARCHITECTURE}

fort has been made to keep them in their appropriate places. For instance, among the various thatched roofs described for picturesque effects, an example is given of the best form of thatching housesillustrated by a house photographed in Holland. But this does not indicate that the author would encourage the thatching of dwelling houses in this country, or that it is necessary to delve into the possible unsanitary and fire-breeding problems that might arise should thatched houses become popular. The thatching is considered simply as a pleasing type of roofing for rustic and picturesque features far removed from the dwelling house. The charm of simple, dignified treatment has been set forth as desirable for every form of garden. With the house as the dominant object in the home picture, all the various features of the architectural treatment of the grounds have been made subservient to it. This rule applies alike to the little garden enclosure in or out of town and to the spacious country estate. 


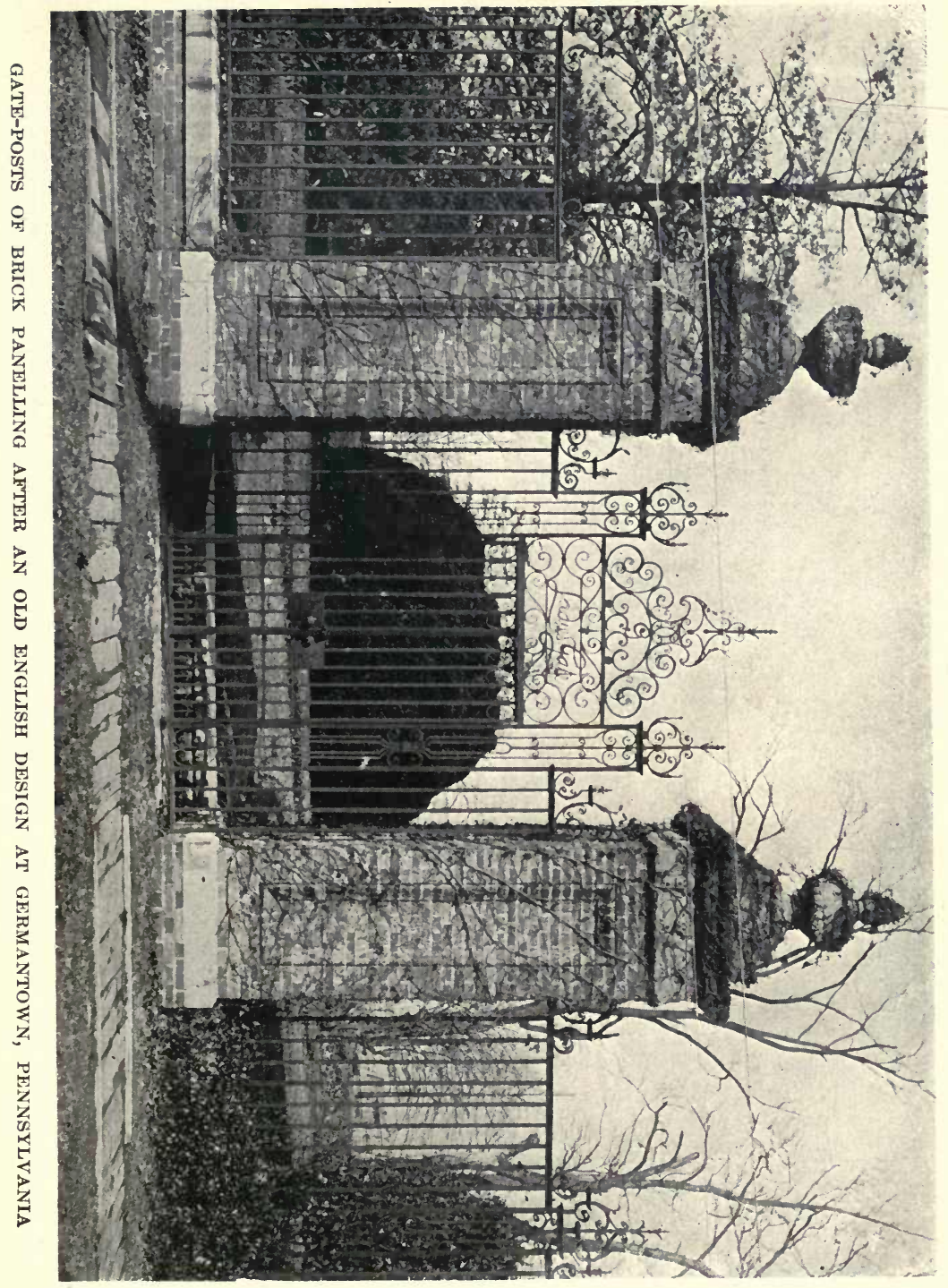


$\because \because \because \quad \because \because \vdots \vdots \vdots \vdots$

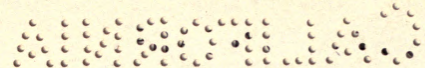




\section{II}

\section{TYPES OF GATES AND GATEWAYS}

EFFECTIVE BARRIERS OF WOOD, STONE, IRON, BRICK AND CONCRETE, FOR INSURING HOME PRIVACY

WE are following the good old traditions of domestic privacy when we erect a barrier about our gardens and construct a gateway in harmony with its surroundings. We are contributing to the elevation of the public taste when we consider suitability and simplicity, such as, for instance, characterize the entrance gates of the old Colonial gardens of New England. What is still more to the point with some outdoor architects, we are strictly in the fashion now in giving thoughtful consideration to our gateways; for some sort of barrier that will keep the public from making common property of our lawns and gardens has become very sensibly "fashionable" - with a wide range in the desirable types.

The treatment and design of the gateway will depend largely upon the enclosure of the garden - whether it is a stone, brick, or concrete wall, a wooden fence in rustic design, iron fencing, a typical New England picket fence, or one of the many sorts of durable hedges. When the enclosure is a combination of rustic or iron fencing, with a thick hedge 


\section{PRACTICAL BOOK OF GARDEN ARCHITECTURE}

planted just within the protective boundary, the gate and gate-posts should be in harmony with the fencing, without introducing a third type.

Without the hedge, a combination of iron fencing and gate, with brick posts, is a popular type, where it is desirable to shut out dogs and flower- and fruitstealing youngsters. It may even be made effective in keeping out chickens when the iron work is of close pattern and there is a coping or low stone wall in close contact with it, instead of the usual space below the iron rods. This type of enclosure is exceedingly ornamental, it serves as an effective barrier, and it has the advantage of expressing a sort of free hospitality in sharing the beauties of flower attractions and landscape designs of front lawns and gardens, while reserving the right to entire privacy and seclusion by hedging or walling in the open-air living-rooms of the back and side gardens.

An arched and trellised gateway, with a simple form of iron or picket gates and vine-covered fencing of iron or wire, forms a picturesque entrance to a cottage home. It may be in narrow arbor or pergola form, or simply two or more arches, set close together and connected by arbor strips; or it may be in rustic form, of bark-covered logs and branches. In every case this form of gateway is at its best when screened by vines that drape without entirely cover- 


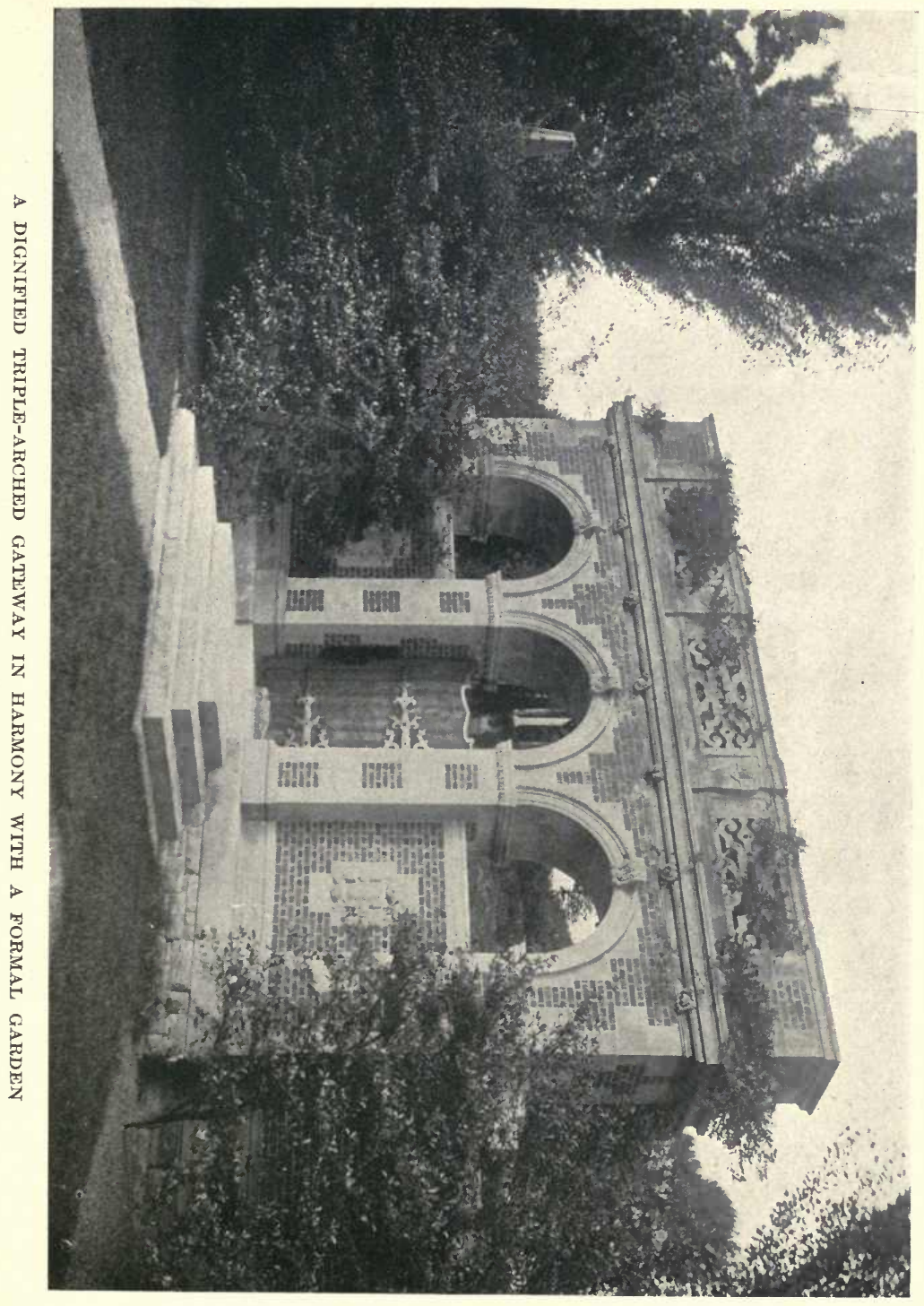




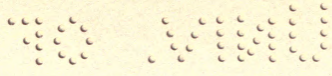

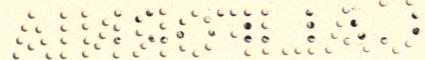




\section{GATES AND GATEWAYS}

ing the attractive design. The rustic gate set within the stone wall may also have a vine-covered arch or roof of rustic design over the entrance-way and several feet of the walk.

- When gate-posts of brick or stone are used to provide a staunch finish to the gateway entrance of a privet hedge, care is necessary in building the posts -much greater than when they are the continuation of a wall. There are few objects more unsightly and depressing than uncertain, leaning gate-posts. They give an air of neglect and general dilapidation to the entire place, no matter how thoroughly the lawns and gardens beyond may show care and attention. A straight, trim, stately gate-post, on the other hand, will impart an air of general neatness to the entire garden. To bring about this desirable effect, it is important to have the stone- or brickwork extend at least three feet below grade, beyond the reach of frost. No matter how heavy the big square posts, nor how carefully the material is laid in one-third cement mortar, the least suspicion of frost heaving will give the appearance of crookedness that is the death-blow to all real beauty in gateposts of masonry. They cannot be pushed back and driven down into place, as may be possible with some forms of wooden posts. Once crooked, the only remedy is to pull down and rebuild. 


\section{PRACTICAL BOOK OF GARDEN ARCHITECTURE}

Foot-stones, projecting from four to five inches on all sides of the stone-work, should be placed beneath the gate-posts of stone, brick, or concrete. With a depth of three feet below grade, and with the careful placing of the foot-stones, the most stately and dignified of decorative gate-posts can be built without the least fear of frost heavings or any form of leaning or pushing out of plumb. The drywall gate-post, or one with the stones placed without mortar, is not desirable unless it is a continuation of the wall laid in the same fashion. The upright stonework at the entrance-way, built to provide sufficient height for swinging the gate, should be made especially firm for the insertion of the iron for hinges and fastenings; but beyond this the dry-wall finish may continue from the wall to the top of the post. Dainty Alpine and other rock-loving plants will flourish in the soil-pockets in the larger crevices and grow to the top of the posts. For the mortarfinished stone-work, there must be no attempt to leave crevices for the small particles of earth required to grow the sedums and other rock plants. Only dry-wall effects will allow this treatment for gate-posts. For the staight, firm, mortar-finished posts it is important to have good cement mortar where it is exposed to the weather. In the use of rough field stones, care should be taken to have the 


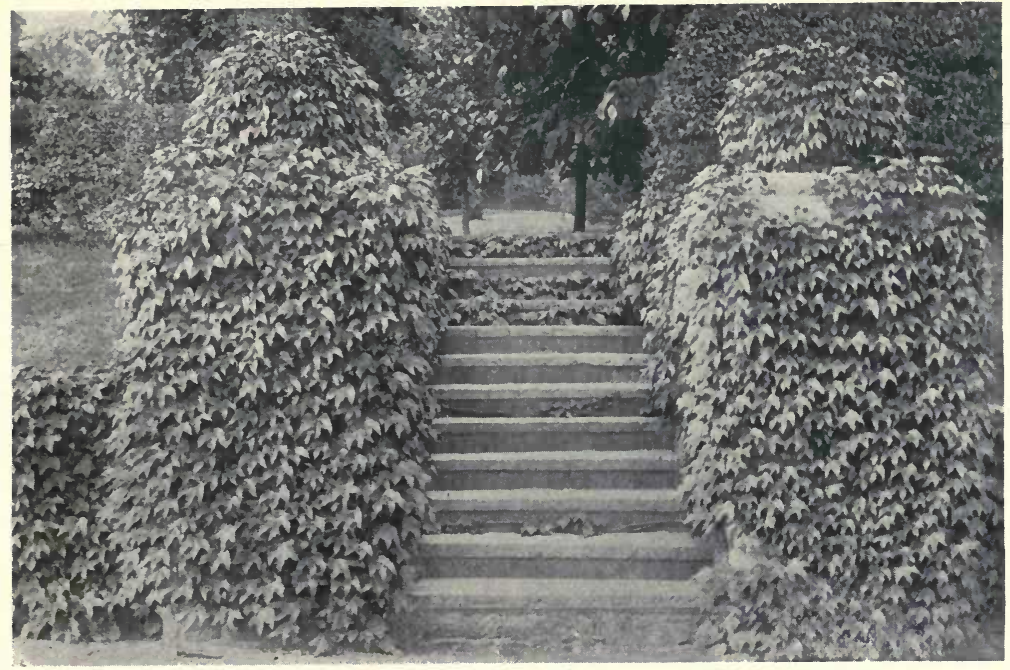

A TERRACE GATEWAY COMPLETE' WITHOUT A GATE

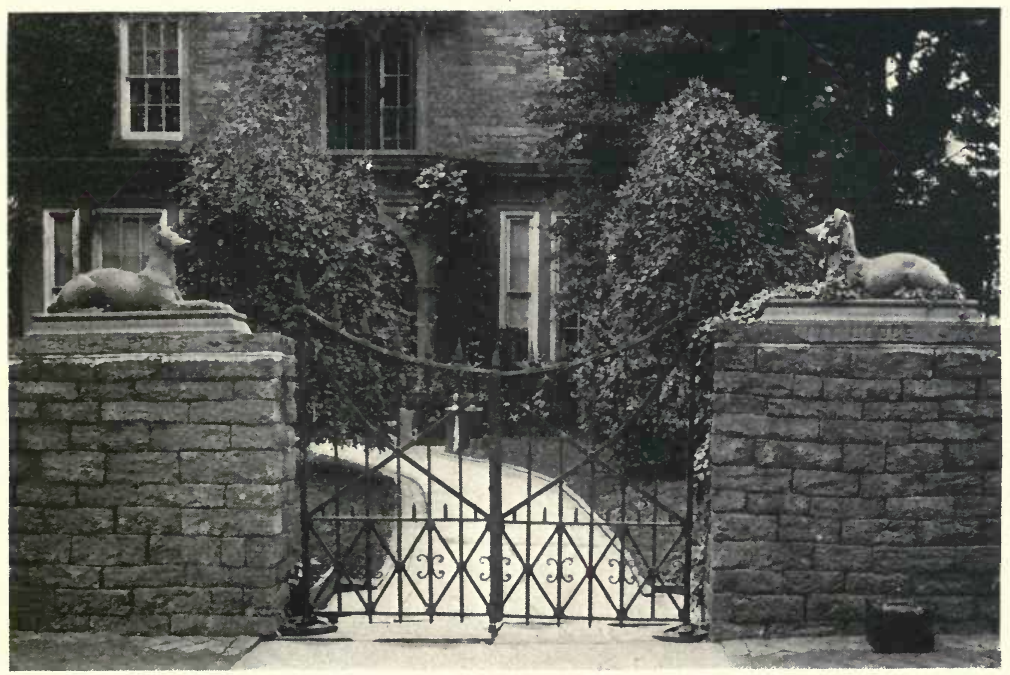

THE STONE WALL FORMING THE GATE-POSTS OF A GERMANTOWN HOME 


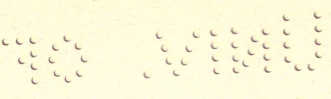

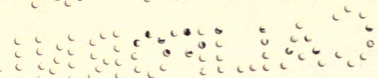




\section{GATES AND GATEWAYS}

joints "weather-struck," to prevent the water from running into the wall.

Cap-stones are quite as important as foot-stones for gate-posts of brick- or stone-work. A single capstone of the right size to project an inch or two on all sides beyond the faces of the wall may be laid nearly flat, if desired, without ornamental top. This will be the best finish when it is desirable to place a flower-box on the gate-posts during the summer months, with only the plain flat finish during the winter. The flatness should be in appearance only. There should be a slight pitch to any sort of flat stone capping the top, whether it is of slate stone or a heavy granite slab. The double cap-stone and ball will prove especially attractive for big square posts of brick.

Where stone walls continue to the iron or picket gate without tall posts, they are of sufficient height to take the hinges of the gate. The ornamental finish in this instance is developed in a variety of forms. When the long cap-stone of the wall is of the apparently flat but slightly pitched type, a square or oblong stone is placed above it, supporting the figure of a lion, a dog perhaps, or a big, square flower vase. A good example of this design is found at "Ivy Lodge"' estate in Germantown, Pennsylvania. When the capstone is cut to pitch slightly in both directions, 


\section{PRACTICAL BOOK OF GARDEN ARCHITECTURE}

like a comparatively flat roof, the ornamental finish at the gate may be formed into a square receptacle for flowers, with a broad coping brought down over the wall at this point after joining the cap-stone.

Gateways of concrete and stucco, like those that are built in harmony with Spanish and Moorish types of houses in California and in tropical islands, are finished in many novel forms. In square, circular, or octagon form, these huge posts sometimes extend as high as the doorway, where the entrance gate to the service yard is close to the kitchen door, or where the gate to the court or patio garden is close to the side entrance. Big plant tubs, holding curious growths of immense cactus plants, are the favorite finish, where the climate will allow these plants to remain outside all the year round, as in California and Florida.

Another favorite California type is the thick wall of concrete, stucco, or cobbles, sloping up to the top of the gate-post, although only two to three feet in height in the lower levels surrounding the garden. The concrete cap-stone with the pitch both ways covers the top of the wall, but on reaching the top of the gate-post the pyramid or conical form is assumed,-sometimes finished with a ball,-all carried out in the same design of concrete or stucco. With the flat-topped wall and the tall square gate-post not 

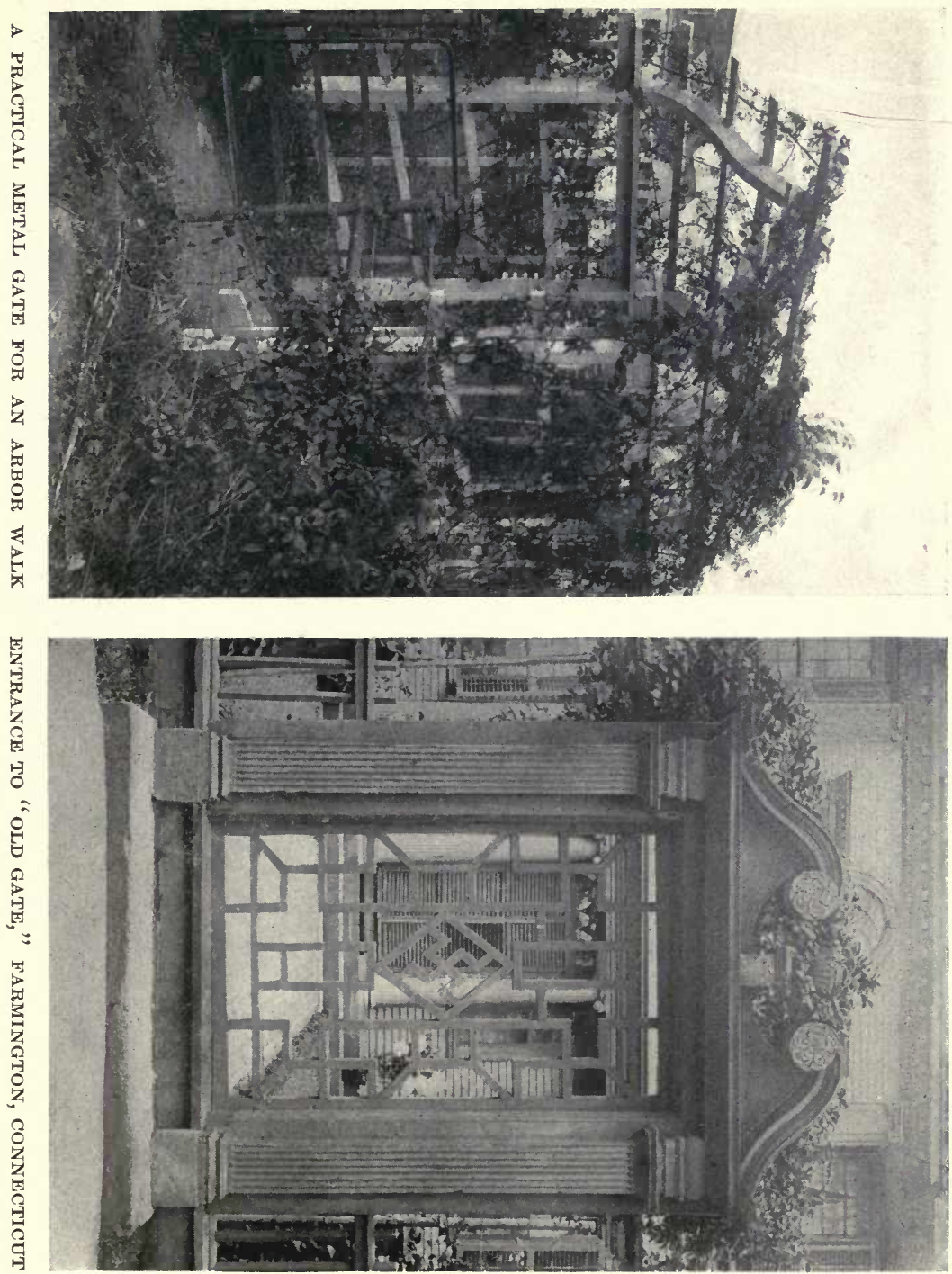


\section{GATES AND GATEWAYS}

intended for other ornamentation except the smooth white finish-a popular type in the Bermuda Islands -the heavy cap-stone of the posts shows the four-1 sided slope with a slight elevation in the centre, with no further ornament to interfere with the stately simplicity.

Gate-posts without gates are sometimes encountered on large estates, where there is a formal parked effect among adjoining country seats. The posts serve merely as an ornamental finish, and, unless the formal idea is carried out in other details, the posts without gate may seem an absurdity. We should not approve of a doorway in the house or garden building without a door, except for very special designs; then, why should the gate-post entrance look complete without a gate? It can be left open if desired, but its mere presence saves from giving the impression that the entire enclosure of the grounds has been rendered useless because of the absence of the gate. Especially is this noticeable at the entrance to a broad driveway. The tall, square posts of stone or brick erected as a gateway boundary for the privet hedge will appear bare and unfinished unless ornamental gates are swung back against the shrubbery.

Probably the one exception to this rule is the narrow entrance to a garden walk, where there is a 


\section{PRACTICAL BOOK OF GARDEN ARCHITECTURE}

steep flight of steps leading up the terrace just within the stone gate-posts. It would be unwise to have the gate swing out to obstruct the public roadway or walk, and impossible for it to swing in, because of the steps. Drop chains, or some other attractive form of barrier, are sometimes used to give the effect of privacy. When the big gateposts are covered with ivy or ampelopsis vines, it is not unusual to find the vine trained about the chains swung between the posts. The pliable tendrils of the vines are not injured by repeated using, and the effect is that of a thick rope of living green to enclose the entrance. A single drop chain is sometimes used for the stately tower gate-posts giving entrance to a formal garden. Naturally, this finish does not present a real barrier to trespassers, but it preserves the dignity of a barrier, which is sufficiently effective.

Carved and molded woodwork forms the favorite gateway of the old Colonial gardens of New England. Providence and Middleton, Marblehead and Salem, are the towns of Rhode Island, Connecticut, and Massachusetts where the best types may be found. At the historic estate of Commodore Cowles, at Farmington, Connecticut, is a prominent type where the quaintly designed gate stands close to the house, providing a barrier for the typically narrow front dooryard of the old house facing the village 


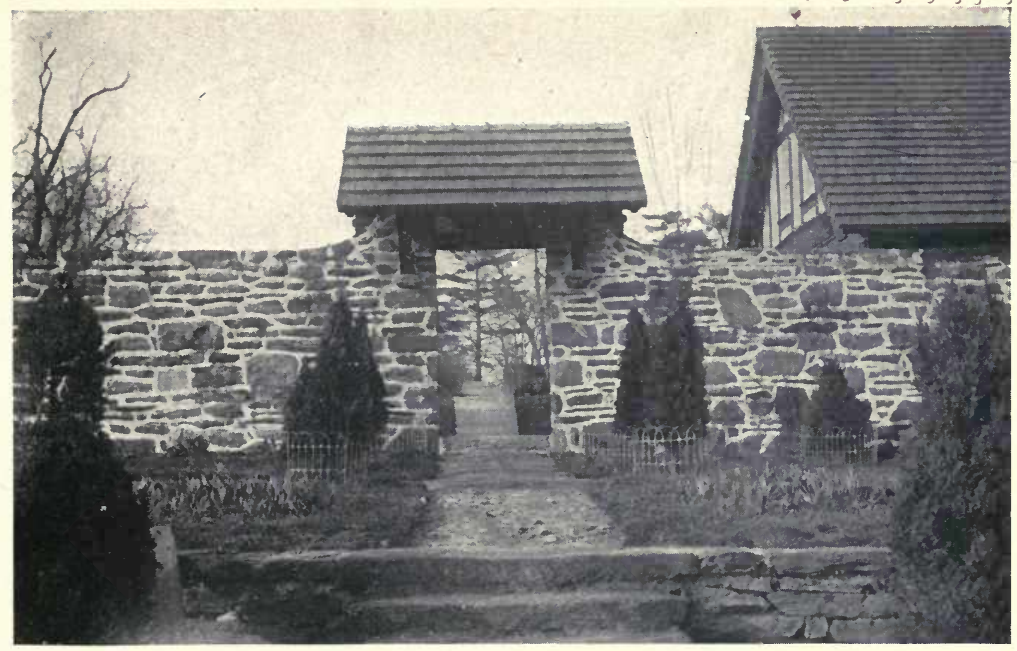

A COVERED GATEWAY THROUGH A WELL-BUILT WALL

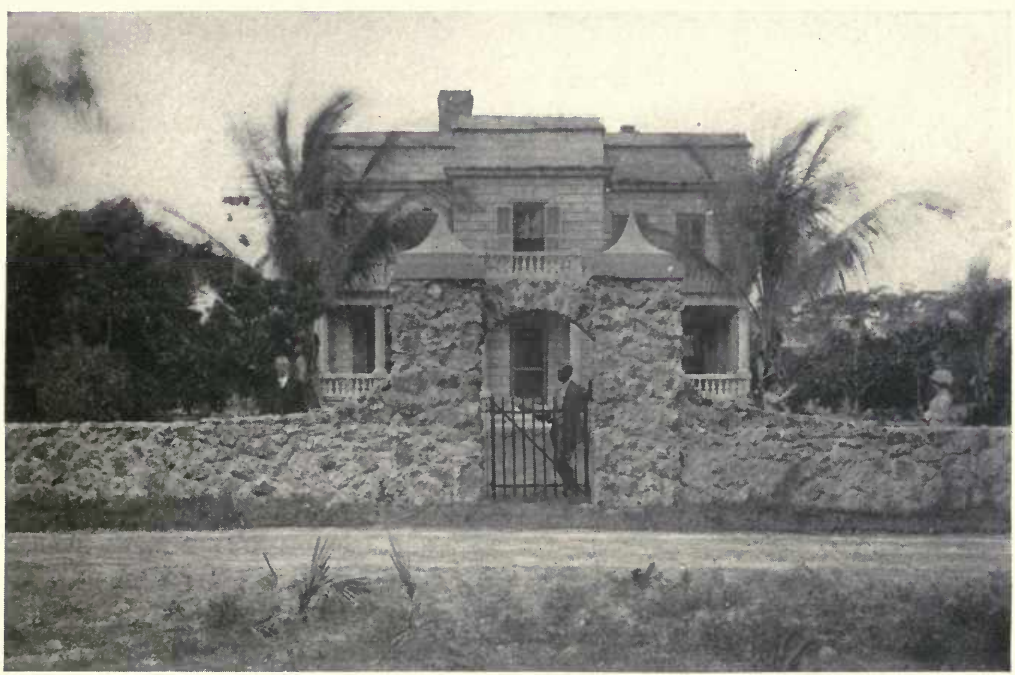

CORAL ENCLOSING WALL AT THE FLORIDA HOME OF MR. GEORGE B. CELLON In photographing the size of gateway has been somewhat exaggerated 


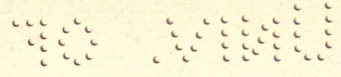

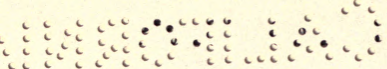




\section{GATES AND GATEWAYS}

street. Here the closely guarded entrance-way has given the name "Old Gate" to the estate. The picket fences and gates of these New England homes are at their best when flanked by panelled gate-posts, with conical and ball cappings.

Among the beautiful winter residences of northern architects at Palm Beach and Miami, Florida, the gate-ways that give entrance to the lawns and gardens richly decorated with luxuriant palms and tropical fruits are invariably attractive because they are attuned to their environments. At the home of the famous "Fruit Wizard," Mr. George B. Cellon, near Miami, is a characteristic type that has been pleasingly evolved. The entire enclosure to the spacious grounds of the Cellon estate has been formed of rough coral rock dug from the garden. Square posts, similar to the smaller gate-posts, are set at intervals along the wall; while at the front entrance to the home the high posts of coral rock are built far above the gate, with an arch of the rock just below the cap-stones. The entire effect has been so skilfully carried out, and is so entirely in harmony with its surroundings, that the celebrated fruit culturist (who has become the "morethan-Burbank" to tropical fruits) may also be justly famous for the decorative accessories of his charming home. Had the long wall and the numer- 


\section{PRACTICAL BOOK OF GARDEN ARCHITECTURE}

ous gate-posts and enclosures been built of costly marble, or of any material not found in this tropical climate, they might have appeared overdone.

When a gate-way expresses a combination of home protection, privacy, and embellishment, without unnecessary display, it will be truly beautiful, no matter what the material used for its construction. But, naturally, the material close at hand will serve best. Quaint round cobbles and flat field stones are equally effective when found in rocky gardens and grounds. Rustic types for the woodland cottage and Colonial designs for historic homes express the same idea. 


\section{III}

\section{WALK PAVING}

STEPPING STONES, METHODS OF RAMPING, AND QUAINT TERRACE TREATMENT FOR PICTURESQUE WALKS

THE average garden builder is inclined to lay too much stress upon the position and the utilitarian aspect, in constructing walks, and to neglect the picturesque qualities and space economies, which are equally important.

It is true that certain well-defined principles concerning their general layout must be adhered to before one can exercise ingenuity in making them attractive. They should invariably have some reason for their existence, and be so placed that the reason is immediately apparent. For instance, if they do not lead directly from the gateways to the entrance to the home or garden buildings, they must lead to an arbor, a pond, or a seat overlooking a garden vista.

Of equal importance is the use of good judgment in deciding whether they shall lead in a reasonably and comfortably direct line from the gateway to their destination or whether curved and winding walks will be better for completing a well-proportioned garden picture. Extremes in either direc- 


\section{PRACTICAL BOOK OF GARDEN ARCHITECTURE}

tion should be carefully avoided. The "straight and narrow path" has its advantages in architectural as well as in moral character building. But there is danger in overdoing the direct line so that it becomes monotonous and uncompromisingly stiff. There is still greater danger, on the other hand, in leaving the puritanical "straight and narrow" of deviating widely in the opposite direction, forming silly, meaningless bends and curves.

There is a happy medium between the straight, prim, unadorned walk and the one which wabbles uncertainly and irritatingly from its beginning to its end. When the walk shows but a slight modification from the direct route, and a definite reason for its turns and curves (for the purpose of going around a fine old tree, or leading by a side path to an arbor or garden seat screened by shrubbery) one question of its decorative success is practically assured. Then will come the problem of appropriate materials and attractive features for constructing the walks for both level and terraced positions.

- Concrete, gravel and brick paving are the most common forms for garden walks and all are worthy of consideration for flat grade and for terrace levels. For climbing the rising grades of slight terraces, more picturesque treatments are desirable, 


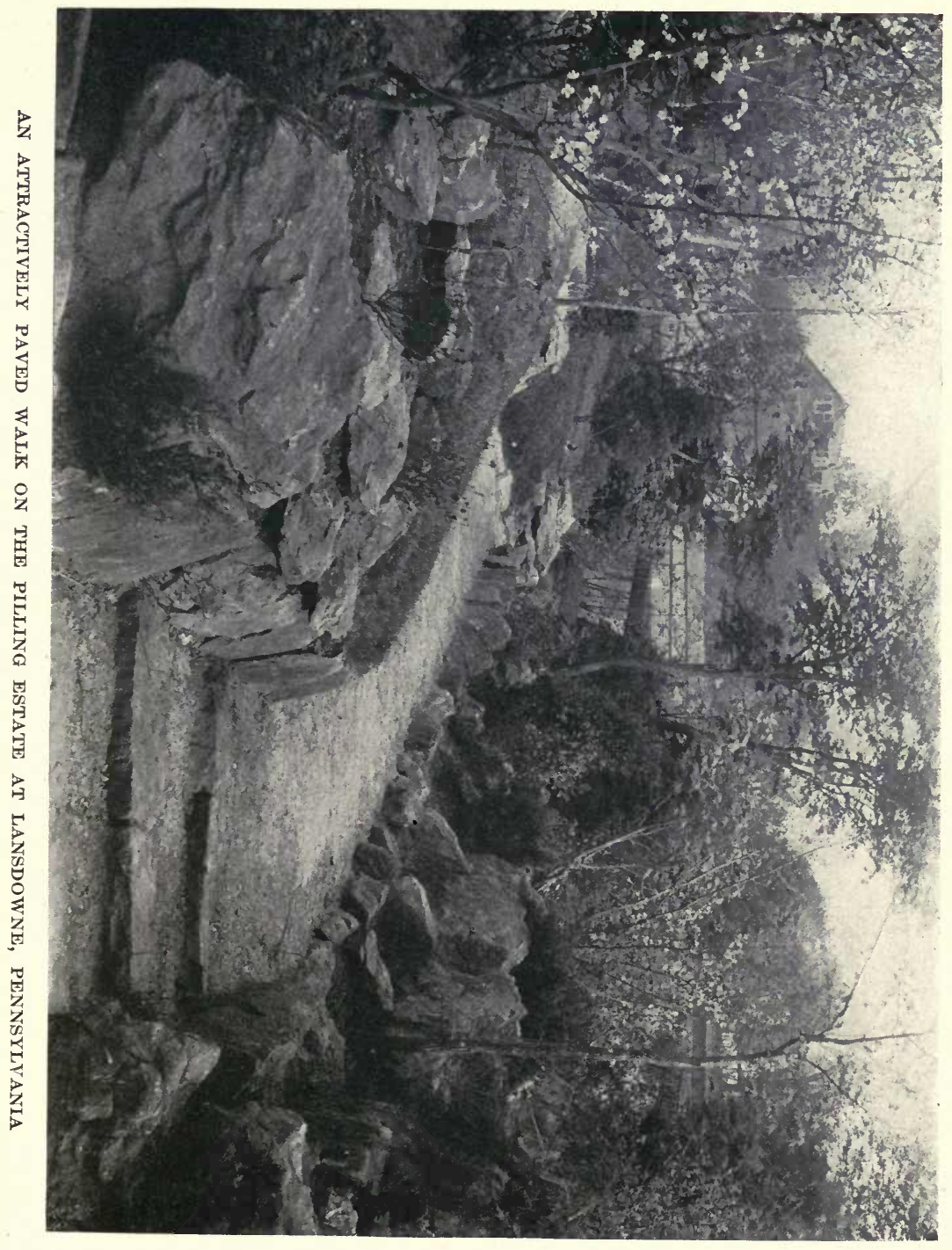




\section{WALK PAVING}

both in the material used and in the planning of the walk to prevent washouts.

Stepping stones have of late years become exceedingly popular for a quaint, serviceable and inexpensive paving in certain sections of the garden. This method is supposed to have been introduced into this country by the Japanese landscape artists, who have developed many characteristic types of oriental gardening on occidental country seats. Walks of stepping stones have also been widely used in old English gardens, where economy of space is as carefully considered as the desire for unusual and decorative paving. The work is then done with the snug, trim, painstaking thoroughness which is one of the greatest charms of English garden-building. The paving is regularly laid, with stones of sufficient weight and breadth to stay in place when once carefully embedded in the ground. The upper surfaces are smooth enough to make walking easy; and they are set at the right distance apart to avoid strain or unnatural stepping in passing along the picturesque walk. They are also set so evenly in the surface of the soil that the lawn-mower passes over them in the grass cutting; and leaves an even surface of closely trimmed sod about each large stone.

This care in the laying is not only a great economy of time (as there is no trimming of irregular 


\section{PRACTICAL BOOK OF GARDEN ARCHITECTURE}

walk edges when a single sweep of the lawn-mower trims the sod and outlines the stepping stones) but also in the saving of space and paving material. With such a walk no space is required for cutting into the lawn for the usual types of broad walk paving. The flat stepping stones set at convenient intervals in the sod are scarcely noticeable from the different view-points in the garden and, when discovered, their picturesque value is invariably appreciated., Another point in their favor is their indefinite duration when once carefully placed, and the avoiding of such troubles as resetting bricks, resurfacing gravel, and the replacing of boards.

In following Japanese methods of paving garden walks with stepping stones, greater variety is at one's command. Instead of the big stepping stones being set directly in the soil and surrounded by closely clipped sod, the large stones are outlined in various quaint ways by many small stones, forming paths that are decidedly picturesque, but which have the disadvantage of requiring considerable time to keep in good condition. This type of paving requires a deep foundation of clay, gravel or cement mixture to hold the stones of various sizes in place and to give the effect of quaint tiling. When set directly in the sod, the presence of the small stones is soon lost to view by being covered by the grass, 


\section{WALK PAVING}

and as those of large size are the only ones in evidence, the walk is now practical without the outlining.

Another method of Japanese paving, more practical and decidedly decorative, is the use of long narrow slabs with a smooth upper surface, laid at regular intervals, with intervening spaces of smaller tile-like stones forming squares or circles. The entire paving is set on a level with the sod, so that the grass can be cut without touching the stones. This will form a practical and decorative form of paving for any garden when the large slabs are carefully compacted in hard earth and the intervening spaces have the small stones laid in durable pockets of concrete.

A mistake too frequently made in stepping-stone paving is the placing of the stones at somewhat regular intervals through the centre of a gravelled walk or pathway. All sense of utility is immediately lost and the stepping stones become an absurdity. Placed directly in the sod, the stones will serve to protect the feet from dampness when the grass is dewy or rain-soaked; and when properly placed they will also prevent a footpath from being worn through the grass.

For the shallow stream flowing through the home grounds, without sufficient depth or turbulence to re- 


\section{PRACTICAL BOOK OF GARDEN ARCHITECTURE}

quire bridging, stepping stones are ideal. Such stones should form the walk leading down to the little stream; then with miniature bowlders lead across, and continue the walk along the bank and up the sodded slope on the other side. The decorative effect will be as fully appreciated as the dry footing, when one is visiting this bit of garden enchantment.

For gravel, brick, and concrete walks that require special arrangement because of slightly rising lawn slopes, there are various pleasing methods of treatment. Gravel is seldom satisfactory except on level walks, where there is little danger of washouts. Even in the right locations it must be carefully laid. Good binding gravel should be used for paving, and care should be taken to secure it from a gravel pit comparatively free from clay. After removing the top soil of the walk to a depth of eight to ten inches (if there is a good solid bottom this will be sufficient), rake out, or screen out, the larger stones from the gravel and fill in first with these stones. The addition of cinders may be required to bind the subgrading when the soil is loose or of a sandy nature. Fill in with the screened gravel to a depth of four or five inches, and wet and roll the walk thoroughly, until it is smooth and compact. It should be filled in and rolled to a slight slope on the sides, and well 


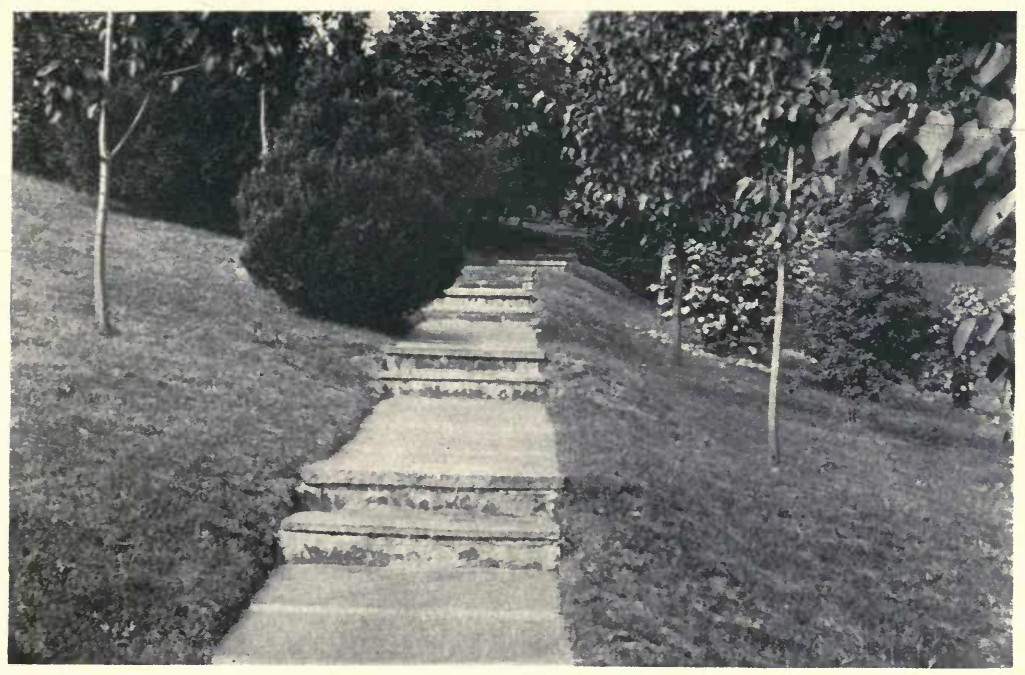

A COMbINATION OF BRICK AND CONCRETE PAVING ON A TERRACE SLOPE

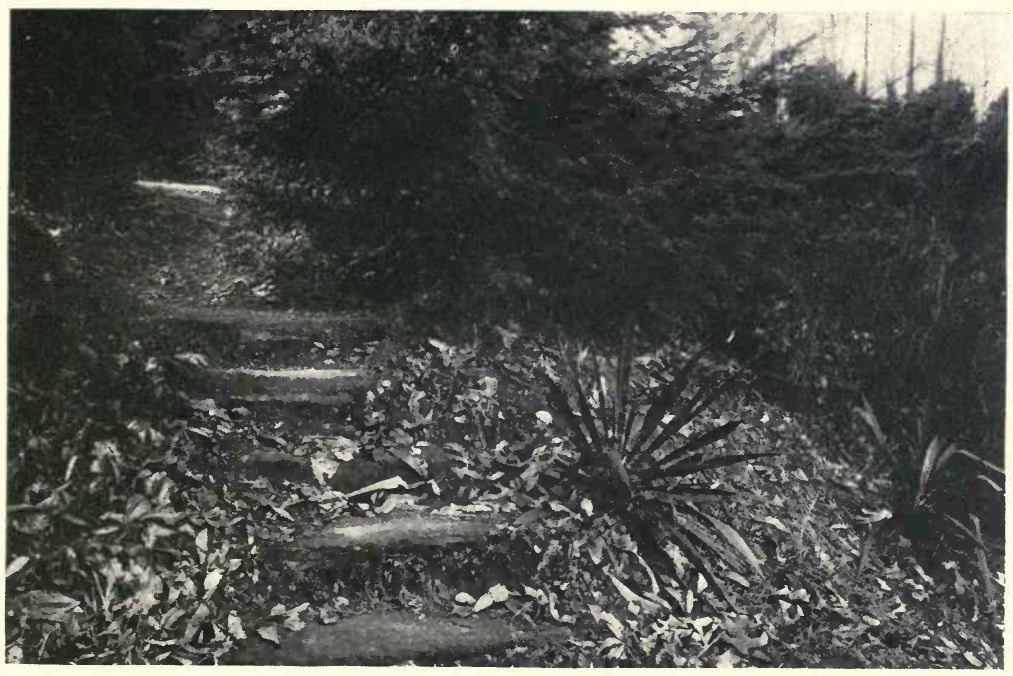

FOOT-HOLDS ON THE DECLINES OF A WINDING TERRACE WALK 
$\because \because y \quad \because \because \vdots \because \vdots \vdots$

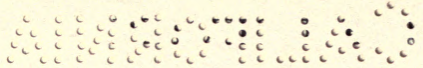




\section{WALK PAVING}

rounded in the centre. When the gravel walk outlines a terrace, or follows a slight rise in the ground, its borders may be attractively treated by laying a rock boundary on the upper side, over which trailing plants are trained. Where the gravel walk borders a garden pond or lake, a jutting of rocks and broken stones will be the most appropriate border. A quaint treatment is found at "Roselea," in the Meadowbrook section of famous country seats, where a double row of jutting border stones are set about a foot apart along the margin of the lake. The spaces between the stones form pockets of rich earth, in which nasturtiums and other profusely blooming plants make a brilliant border between the walk and the lake during the summer. Ivies and other evergreen trailers form a border of green after the flowers fade.

For brick and concrete walks, a firm, smooth border of sod is more pleasing than any fanciful or fussy attempt to outline them with flowers. Not only are these durable walks desirable in straight levels, but they are also especially appropriate for broken and rising surfaces that climb broad, slight terrace slopes.

When the incline is very slight, gravel or cinder walks may be used, with single long stones forming the shallow steps at well-proportioned intervals. 


\section{PRACTICAL BOOK OF GARDEN ARCHITECTURE}

These flat, shallow stones serve as footholds or steps in the gravel, and at the same time prevent washouts. The wash and wear of swift-flowing water in times of storm may also be prevented by laying this form of walk on a curve, when it can be harmoniously arranged in this form among the trees and shrubbery. Instead of the stone steps, heavy logs, after the order of railroad ties, with a smooth upper surface, may be imbedded in the gravel at long intervals for the comparatively level walk. When a steeper grade demands rising steps, set closer together, long, narrow slabs of stone will be more appropriate and durable. The weight of these stones probably will be found sufficient to keep them firmly in place, and it will not be necessary to provide them with cement or other foundation. Simply imbed them in the gravel, with the front forming the step, and the top on a level with the upper surface.

When the lawn slope is sufficiently steep to require two steps at each rise-with broad levels between each set of steps-the paving may be made decidedly picturesque. The risers may be made of brick, set on edge, and held in place with mortar or cement, while the treads and the broad level paving adjoining are of brick or flag-stones. When of concrete, the walk may have the step, risers, treads, and intervening levels all of the same material. 


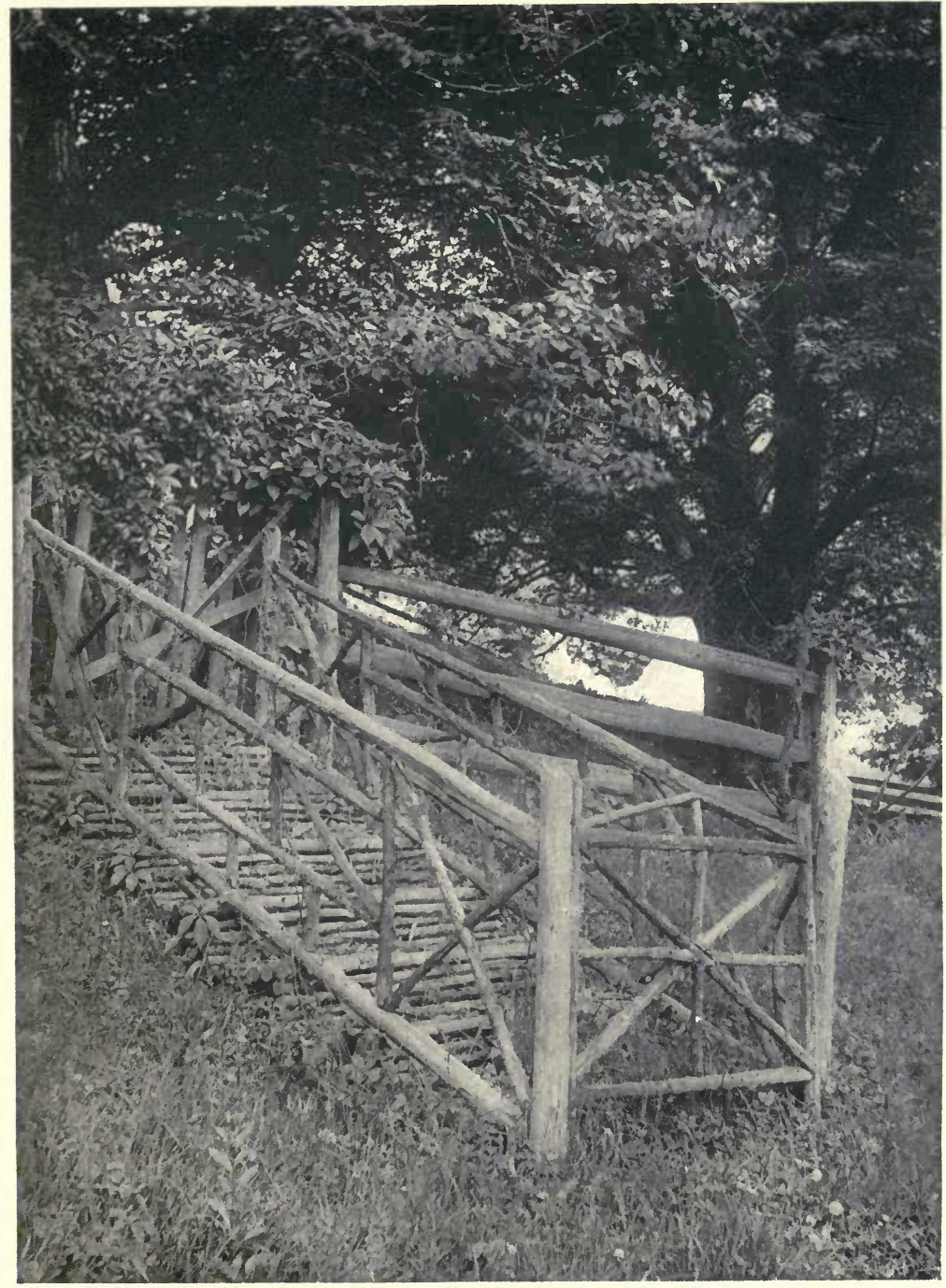

A NOVEL WALK OF SMALL CEDAR BRANCHES, QUAINTLY ENCLOSED, WHERE A GARDEN WALK EXTENDS INTO PASTURE LAND 


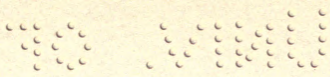

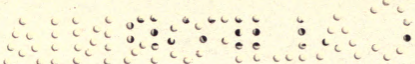




\section{WALK PAVING}

An ingenious device known as "ramping" was resorted to in old Italian gardens for making walks and steps of lawn slopes easy to climb. By its use steep slopes are no more fatiguing than level walks. During recent years ramped steps, after the approved Italian type, have been introduced in various sections of this country. Ramping consists of giving the surface of the treads a slight incline downwards towards the bottom of the slope. It is a simple device, and its value is not understood or appreciated as it should be. The inclination of the ramped steps should be so slight that it will not be noticeable to the eye, but only to the feet and muscles in making the ascent.

The old-time board walks are seldom seen where it is desirable to have attractive paving. Durable cedar branches, like miniature logs, are imbedded in gravel, and these form picturesque walks. They prevent the muddy surface which sometimes forms in spots, thereby making an old gravel walk objectionable. With the short-length imbedded cedar logs, one is sure of a firm surface; where one may pass without slipping and dry-shod after a storm.

These short lengths of cedar limbs and branches are also used in a novel and attractive manner for forming steps, or footholds, for the walk leading down a steep slope. When the slope leads from the 


\section{PRACTICAL BOOK OF GARDEN ARCHITECTURE}

lawn or garden to an orchard or pasture land, where animals graze, a unique method of paving and decorating the slope is accomplished by removing a section of the fence leading into the orchard or pasture, laying the log walk down the incline, and having it outlined with a rustic railing of sufficient height to form a fence for excluding the animals from the walk and the upper garden. The railing is finished with a rustic gate at the bottom of the incline. The width of paved walks may vary from three to six feet, according to the importance of their position and their location in the garden. Less than three feet will seldom prove satisfactory. 


\section{IV}

\section{THE WALLED GARDEN AND ITS ADVANTAGES}

HOW TO CONSTRUCT THE DECORATIVE BARRIER THAT WILL KEEP OUT INTRUDERS, AND ENCOURAGE OUTDOOR LIVING

To those of us who have travelled extensively among old-world gardens, the suggestion of high walls for enclosing spacious open-air living rooms will recall fascinating visions of charming English estates, and call up glimpses of fairyland set apart from the commonplace world. In such a place members of the family and their favored guests can spend the greater part of the time, can rest and dine and enjoy the exchange of hospitalities, entirely free from curious intruders and prying eyes. Possession of a walled garden is not the exclusive prerogative of old English estates, however. American architects are awake to its possibilities. We have learned that it is not necessarily an indication of snobbishness to desire privacy and seclusion for our outdoor living rooms. We are not considered undemocratic and exclusive because we insist that our indoor dining rooms and living rooms be shut away from the public and there is no reason why we should 


\section{PRACTICAL BOOK OF GARDEN ARCHITECTURE}

not claim the same privilege in regard to our openair living rooms.

The reason why high wall enclosures have fallen into disfavor in suburban sections is because of lack of consideration for our neighbors. It is unwise to carry the wall idea to extremes and erect barriers about the front gardens which are unsightly and objectionable. The owner of a beautiful country estate with entrance-ways and front lawns far off from neighboring gardens, may feel privileged to enclose any portion with screens of hedges, shrubbery and walls of brick or stone; in the suburban section, or the village street, however, the residents should observe the prevailing desire for decorative street parking. The broad sweep of open lawn, the low hedges, and iron fence enclosures, or Colonial types of stately wooden fences, when necessary to shut out garden prowlers, may all find favor, and with shrubbery and flower planting will blend harmoniously with adjoining lawns and gardens. But beyond the spaces devoted to what is now popularly termed "street parking," the side and back yards should be reserved for family privacy. Even the smallest place may have its outdoor living room enclosed by high walls. No other form of enclosure will give such durable pleasure, and no other feature can be made more decorative than the high wall 


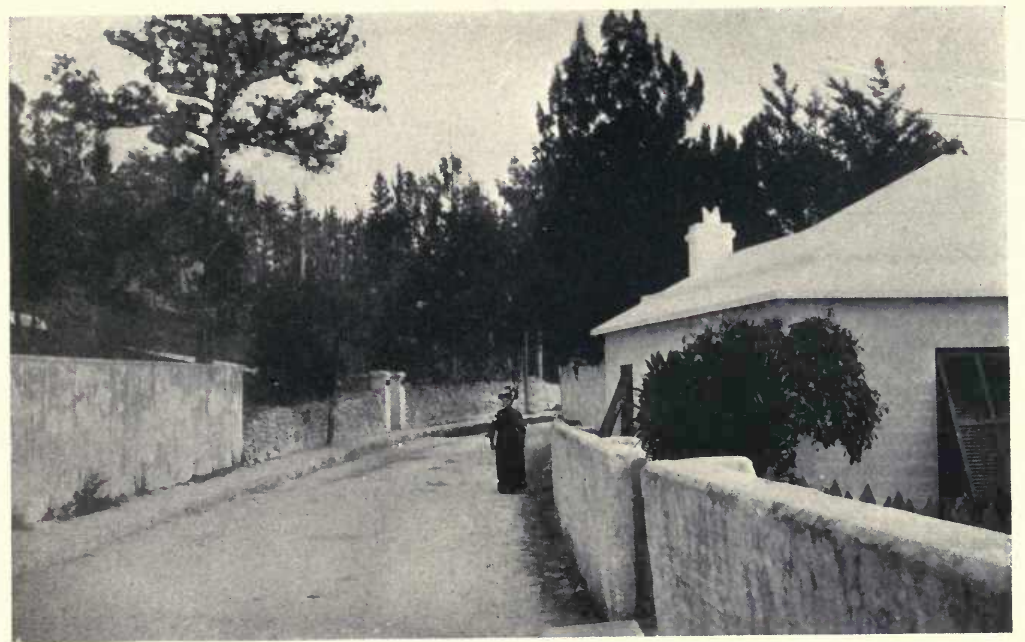

WALLS OF CONCRETE AND FIELD STONE ABOUT BERMUDA GARDENS

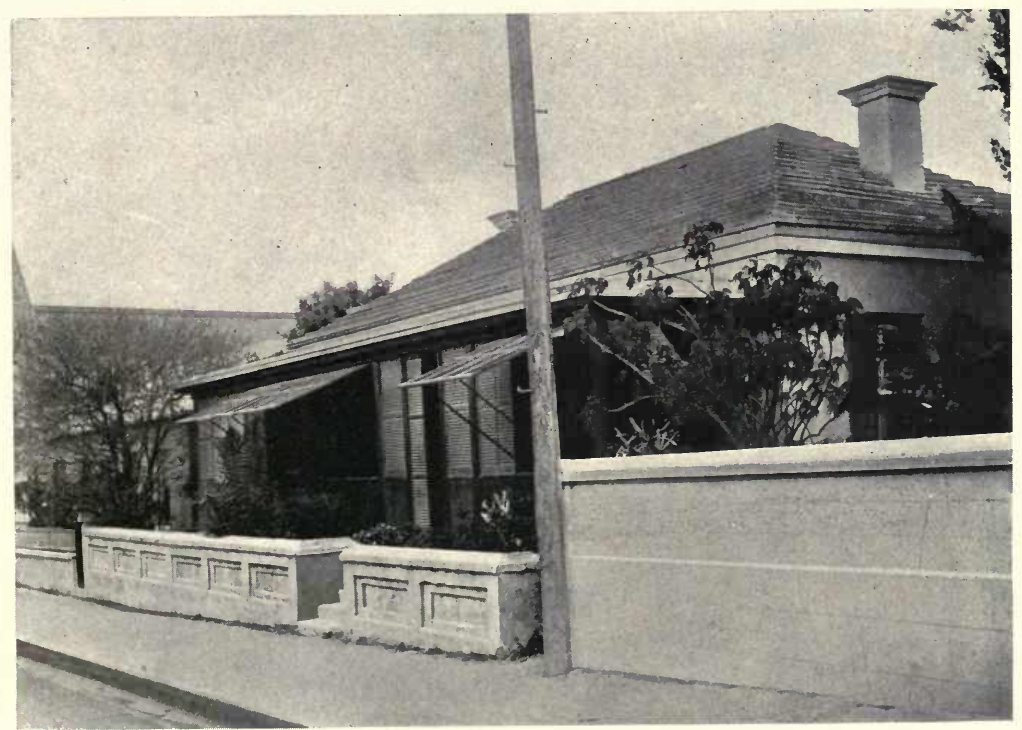

A COMBINATION OF LOW WALL BEFORE THE HOUSE AND A HIGH ONE SCREENING THE GARDEN 


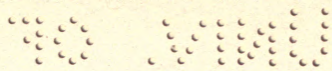

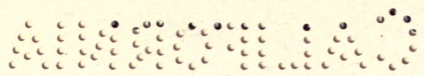




\section{THE WALLED GARDEN}

of brick or stone built in a manner conducive to charming plant growth.

There are many beautiful gardens in Bermuda famous for the wonderful walls that enclose them and the luxuriant growth of tropical vegetation. The wealth of trailing plants and brilliant flowers that crown the high copings, flourish in earth pockets and on rocky projections, makes the entire garden enclosure a bower of bloom throughout the year. There are other gardens in the same tropical islands which serve as examples of what to avoid in wall enclosures. There are high, straight, forbidding gray walls, built along the street front of otherwise beautiful thoroughfares; walls that shut out every possible glimpse of garden beauty, that make the winter visitor to this balmy land of perpetual summer feel that he has been cheated of his right to enjoy a portion of its beauty. A single high wall, with prison-like enclosures, along the front of the garden, can readily ruin the charm of many adjoining properties. In the Bermuda gardens observing the correct principles of walled enclosures a pleasing type is found in which the high walls of side and back gardens have the street side as well as the livingroom side of the barrier clothed in floral beauty. The majority of these walls are built of concrete or of the coral rock in irregular stone-work. White is the 


\section{PRACTICAL BOOK OF GARDEN ARCHITECTURE}

prevailing color for all garden walls among the beautiful estates perched on the green hillsides overlooking the ocean, even the plaster and concrete walls having powdered white coral rock used in place of sand.

The treatment of the higher enclosures of concrete construction is as admirably carried out as that of the stone walls built of the white rock. Instead of a wall with delightful small plants flourishing in cracks and crannies between the stones, the high concrete wall has a luxuriant growth of the enduring "life plant" along its upper coping, seemingly living on air and moisture alone, with its numerous green feet clinging to the wall and nourished by its moisture. At the base of the smooth-surface walls all sorts of thrifty climbers are planted-preferably those which bloom throughout the long tropical seasons, and these are carefully trained to cover the wall on both sides. Lattice is seldom used to support the trailers and climbers along the Bermuda walls, the moisture-loving plants prefer to cling directly to the cool surface, and the high barriers with their green draperies remain from year to year with little change in their beauty.

Where there is a choice of materials for wall building, there is no necessity for sameness in our garden closures. And there is no longer any con- 


\section{THE WALLED GARDEN}

troversy as to the suitability of using the high enclosures for garden privacy. Not only do we shut out noise and dust and prying eyes from our openair living rooms by means of the high wall, but we also shut out stray dogs and thieving boys where fruits abound; and shut in peace, and repose, and a sane, healthy mode of living in the air and sunshine. The abounding good health and clear complexions of our English cousins are claimed to be due to the hundreds of miles of high wall which encourage their women to spend much of the time outdoors.

There is still another advantage in enclosing the greater part of our gardens: acting as windbreaks the high walls cause the fruits to mature earlier and in greater abundance than in exposed spaces. Vegetation develops fully a month earlier in the spring and lasts a month later in the autumn when it flourishes close to the protecting walls.

Once convinced that it is the duty as well as the pleasure of every owner of a garden to build walls of greater or less extent and having realized their manifold advantages, it will prove a delightful study to develop the greatest beauty and convenience which these walls are capable of producing. For the garden enclosures of the small suburban place there is little choice in the situation of the wall. . For the large estate it will be desirable to study carefully the 


\section{PRACTICAL BOOK OF GARDEN ARCHITECTURE}

subjects of exposure and the contour of the land in deciding upon site. The big outdoor living room that faces the south and southwest will have the benefit of the cooling breezes in summer, and full exposure of the early spring sun to hasten luxuriant bloom. The garden shelters may be so arranged that shade may be found, when desired, at all times of the day. When there is a bit of woodland at one side of the house, it will form an additional barrier against winter winds if the wall is built in its shelter. When the house and garden buildings shelter the walled garden from the northern exposure a similar effect is produced in securing an inclosure that can be enjoyed early in the spring and late in the autumn. Practical garden architects are now giving special study to this problem of situation and a walled enclosure is sometimes noticed where the northern wall is built considerably higher than the others, and a decorative planting of tall evergreens helps to serve as a windbreak while increasing the decorative value.

When stone is to be used dry-wall construction is preferable for plant growth in the crevices. When it is desirable, because of the nature of the stone, to have the wall regularly laid with mortar, there should be occasional crevices left for rich loam to support blooming plants. For any form of stonework there are various mosses that nature will sup- 


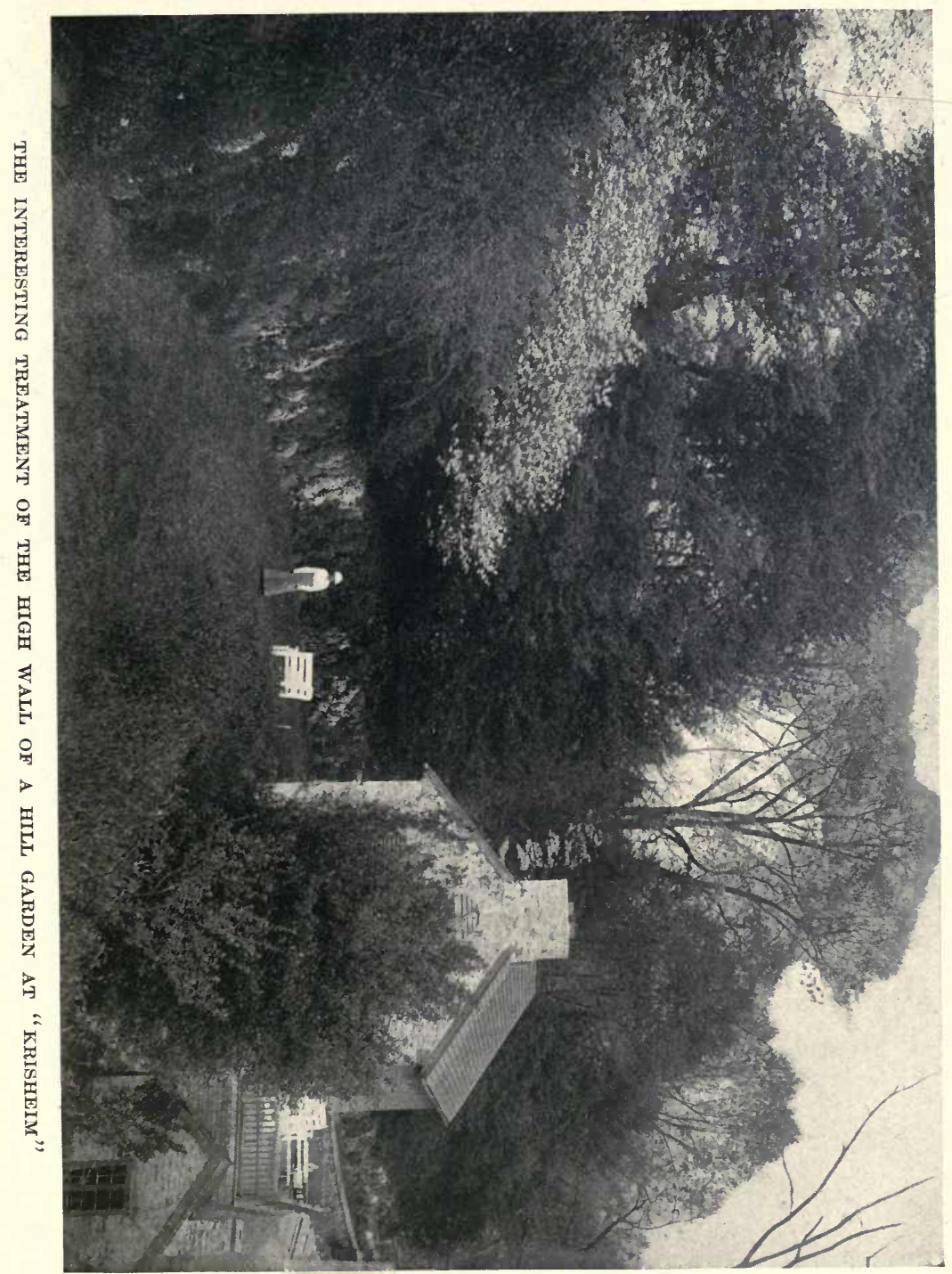





\section{THE WALLED GARDEN}

ply to soften its outlines, and with a little aid on the part of the owner to start the little succulentsthe sedums and stonecrops and a host of dainty creeping things-the wall will soon lose its staring newness and assume the softening grace of age and beauty.

The stone wall is the one most frequently decided upon, without regard to its environments. In order to give the greatest satisfaction, the material should be selected from the source most readily available. Not only will this result in producing the greatest harmony in the wall and its surroundings, but it will have its advantages from an economical point of view.

The treatment of stone walls may be widely diversified, and there are many arrangements that will provide winter beauty. The evergreen trailers in rock crevices will retain their beauty when on the order of the periwinkles and creeping enonymus. The planting of decorative evergreens and various architectural features in the treatment of the walls will make our American walled gardens as attractive as those of England during the winter months.

When brick is used for the garden wall, it need not present the cold formal surface of the brick house which it adjoins. New bricks, all alike in size and 


\section{PRACTICAL BOOK OF GARDEN ARCHITECTURE}

color, and laid precisely in regard to lines and mortar, never give the same charm to the garden enclosure as the cheaper material that might readily be called "waste brick." The old brick of uneven surface and texture, shading from bright to dull reds and browns and nearly to black, when laid with wide joints and in uneven lines, will produce a quaint, subdued effect that will be well worth exposure here and there among the green draperies of the wall. Such a wall can often be cheaply built when the so-called "waste brick" and nicked and broken pieces can be obtained at little above the cost of hauling from a nearby brick-yard. It will be found that the economical principle is only one object, for not only will the general finish be more subdued and pleasing, but the rough texture will give better support for vines than the "finished" surface; and, while reflecting the sun's rays less fiercely, it will produce the effect of greater coolness for the enclosed garden.

When cobbles and other quaint forms of field stones may be secured, picturesque walls may be built that will be decorative in themselves without vine draperies. A combination of cobbles and concrete forms an attractive wall, and evergreen shrubbery planted along the base will give sufficient drapery. For any sort of novel wall arrangement it is important to have a solid stone foundation two 


\section{THE WALLED GARDEN}

feet or more below the surface of the ground. Not only must it be below the frost line, but deep enough and broad enough to support firmly any wall of extra height; and all buttresses and pilasters between panels of concrete or cobble formation should have special attention given to firm foundations.

It is frequently argued that our American estates will never possess the many miles of walled enclosures found in all parts of England, for the reason that even when we are convinced of their desirability we will find their expense too great because of the excessive charges of skilled masons. The fact is too often overlooked that skilled laborers are not required for this work and may indeed be undesirable. In their wish to do a "good job," they will insist upon dressing the stone according to their rules of expert labor, in spite of all directions on the part of the owner to leave the wall in the rough. When our forefathers struggled to secure fertile acres from the rocky soil of New England they built the finest sort of garden and field enclosures by throwing up walls of the rough stone accumulated in clearing their fields. These cheapest of old time walls are to-day examples of durability and picturesque attraction. An amateur in wall building may spend his odd moments in building an inexpensive wall from materials at hand that will prove more de- 


\section{PRACTICAL BOOK OF GARDEN ARCHITECTURE}

sirable than the costly structure built for show by an expert. The important thing is to have the foundations staunch and dependable, and the wall so intelligently laid that it can be depended upon to last for years. Let the painstaking care lie in these directions rather than in smooth, precise surface finish.

There is a famous old garden wall in Haddonfield, New Jersey, enclosing a great space of bloom and beauty and romance. The whole composition closely resembles some wonderful castle garden. There are rare old yew trees, and tall box bushes and fine old specimens of other trees and shrubbery brought over from England in the long ago. Hundreds of yards of time-softened, picturesque brick wall enclose this garden of the historic Haddon estate, the place that gave the town its name, and portions of it have stood for nearly two hundred years. It was about the year 1719 that the English gentleman, John Haddon, purchased four hundred acres of land in this section of New Jersey, where many English Quakers were making investment. When it became important to look after his possessions in the new world, John Haddon was finally persuaded by his ambitious little daughter Elizabeth to allow her to take the perilous journey across the ocean. As he had no sons able to make the voyage 


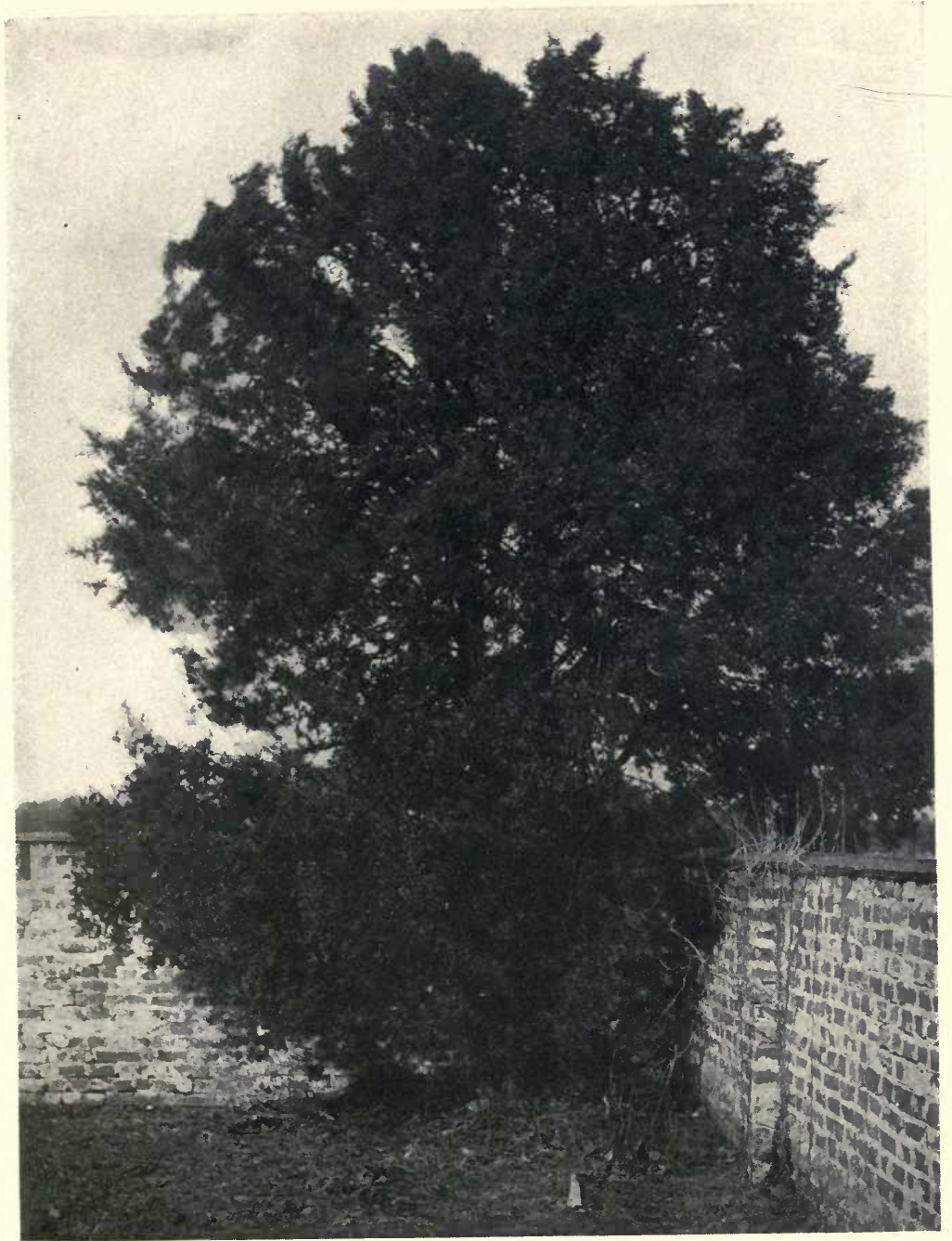

GIANT BOX BUSHES OVERTOPPING THE HIGH WALL IN THE GARDEN OF HADDON HOUSE, HADDONFIELD, NEW JERSEY 


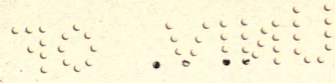

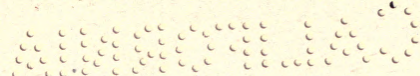




\section{THE WALLED GARDEN}

there seemed to be no other choice; he sent Elizabeth, then about twenty years old, to make a settlement on his land, and get matters in readiness for him to make his home in the new country.

This modest little Quakeress not only displayed wonderful pluck and perseverance (when she unconsciously developed the qualifications of the twentieth century "new woman" very early in the eighteenth century), but showed unusual foresight in her practical methods of establishing the new home in the wilds of New Jersey. The young trees, plants and shrubbery which she brought over from her English home were carefully planted by the spot chosen for the rude cabin, which was later followed by a mansion built of brick brought over from England. Of the same English brick the high wall was built to surround the big garden at the back of the mansion. Over six feet in height it is, and roofed with the quaint shingle coping typical of brick walls in England. The old clumps of box have outgrown the high enclosure and overtop the wall. Of the ancient yew trees, one of the original veterans still survives, with its splendid branches chained together to keep them from breaking in times of storm. The other fine specimens of English yew that surround the aged parent tree, and various plants and shrubbery propagated from those estab- 


\section{PRACTICAL BOOK OF GARDEN ARCHITECTURE}

lished here nearly two centuries ago, are carefully treasured by the present owners of the Haddion estate, but no other object is so tenderly cared for and preserved as the famous wall. It was in this typical English garden that much of the romance of Elizabeth Haddon's courtship occurred. The story is well known of how the demure littleQuakeress gave very decided assistance to her bashful lover, the Quaker boy preacher, John Estaugh, during his lovemaking. When she finally encouraged him to end his uncertainty, and they were married, John Estaugh became the attorney of John Haddon, and took charge of his large landed interests in New Jersey. When many homes and gardens were afterwards established on the Haddon holdings, the numerous walls dividing and enclosing the garden spaces were strictly English in character. For this reason there are many inspirations for wall building in Haddonfield to-day, examples of quaint mortar-joining, moss-covered interstices, shingle roofing, and plaster coping.

There seems to be a very general impression that only walls built against terraces (retaining walls with banks of earth on one side) can be made really beautiful. A study of these ancient walls standing straight and firm and high, with picturesque supporting buttresses and pilasters, will convince one who 


\section{THE WALLED GARDEN}

has not travelled that there is a wonderful charm and beauty to the hundreds of miles of high walls enclosing old English gardens. The vines that may be trained up on both sides of these high walls should never be allowed entirely to cover the stone or brickwork; a glimpse of quaint wall spaces should appear here and there among the greenery. Allow the heavy buttresses of the high sections to display their sturdy beauty. Encourage dainty succulent plants and glossy-leafed trailers to cling to quaint roofing and coping; then, aside from its many useful purposes, the enclosure of the big walled garden will grow in interest and charm and beauty with the passing years. 


\section{V \\ TERRACE WALLS AND THEIR TREATMENT}

\section{THE FUNCTION OF THE RETAINING WALL IN RELATION TO GARDEN DEVELOPMENT}

STEEP garden terraces are deserving of more attention and careful study than they usually receive. There are many types of retaining wall that may be built not only for the utilitarian purpose of keeping the bank of earth in trim, firm condition, unharmed by dashing rains and rushing freshets, but also for making the terraced garden a place of beauty and enchantment. The manner of laying the retaining wall, the material to use, the trailing plants and flowers most suitable for clothing wall surfaces, and how to plant and maintain them, must receive due consideration. In the ever-increasing interest in developing this form of beauty will lie the chief charm of terraces. It is a work of development that will not be accomplished in a few days or weeks ; it will present fascinating suggestions and wonder-working problems with every change of the seasons.

The garden builder and architect who refuses to acknowledge the desirability of retaining walls in solving the problems of terrace finish will find that 


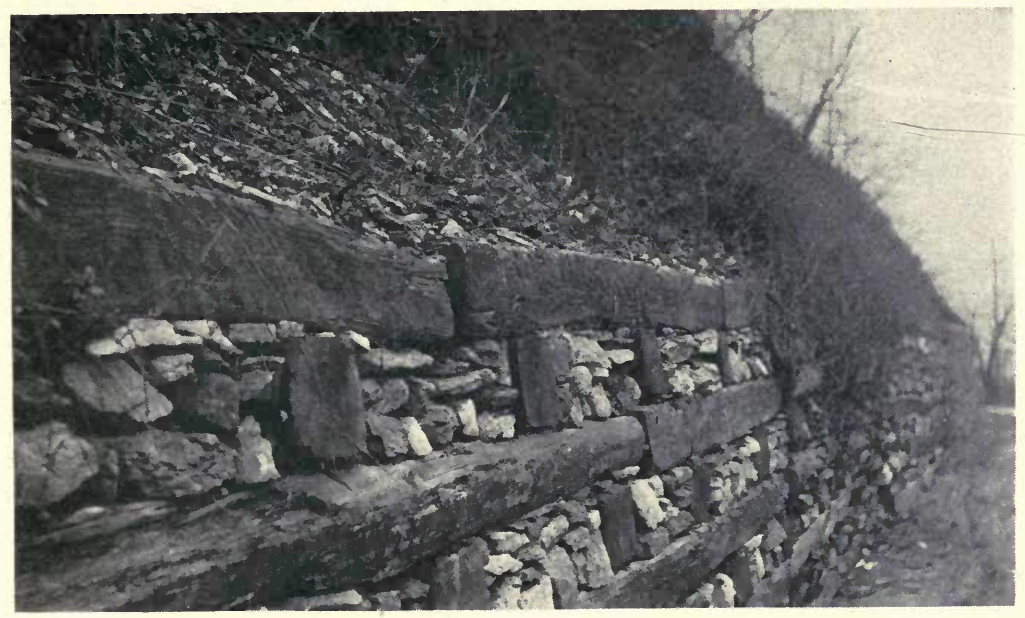

A RETAINING WALL OF LOGS AND STONE

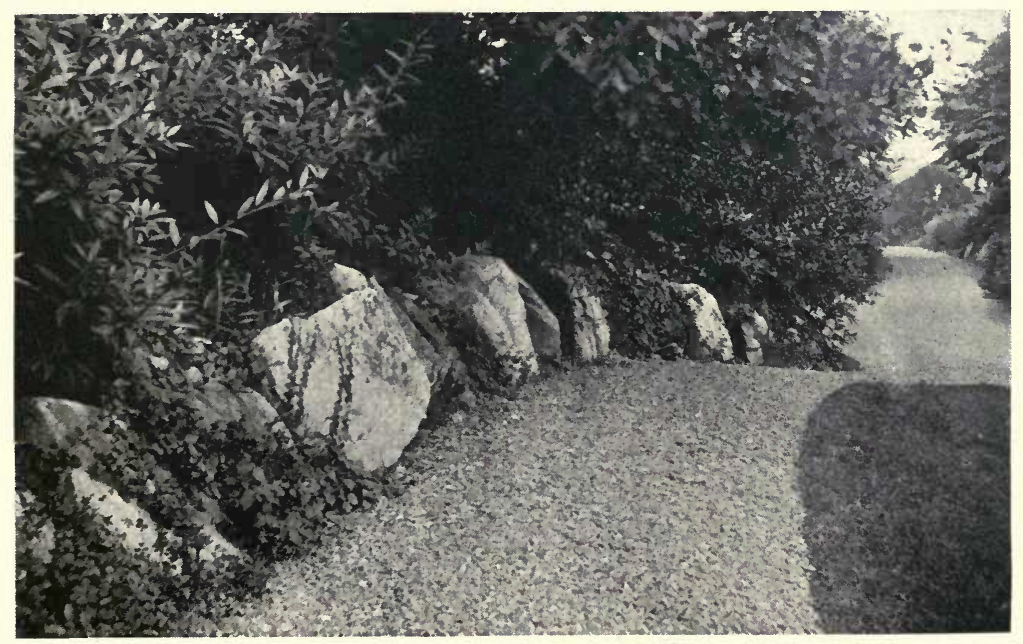

TERRACE BOWLDERS DRAPED WITH TRAILING PLANTS AT "LYNNWOOD HALL," THF WIDENER ESTATE AT ELKINS PARK 


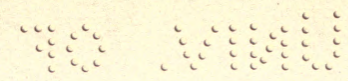

and 


\section{TERRACE WALLS}

he is piling up much hard work and many perplexities in the care of steeply sloping ground. When he foolishly forms steep banks of grass, with sharp formal edges, he will be certain to find them difficult to mow and costly to maintain in perfect condition. When he encourages a tangled growth of trailers and creeping plants to clothe the banks of earth, the annual trimming of stragglers and frequent adjusting of crumbling surfaces will prove an aggravating feature. Shrubbery and long lines of blooms arranged in steps to outline the terraces will be subjected to washouts and other annoyances. It is only the long bank of earth tucked snugly behind a retaining wall that can be depended upon for durability in outward surface and for decorative possibilities.

Unique combinations are sometimes resorted to in order to construct a retainer for a very high, steep bank of earth. The straight, high wall is liable to be pushed out of shape by the action of the frost unless there is considerable expense involved in preparing a special lining between the wall and the earth. When but one kind of wall material is usedall stone, all brick or all concrete-frost heavings are difficult to prevent. When huge logs lend their assistance in supporting the masonry there will be little need of first-aid-to-the-injured. Log retaining walls also may be built without the brick or stone 


\section{PRACTICAL BOOK OF GARDEN ARCHITECTURE}

combinations. Alternate layers of long logs lying face out, parallel with the terrace, and logs driven well back into the bank of earth with butt ends resting evenly on the ones below them will form a quaint and durable wall that will prevent washouts and frost injuries and will furnish many earth crevices for the growth of plants all along its surface.

Where steep roadway terraces and abrupt divisions in garden planning can be avoided, a series of low, sloping terraces will always prove more satisfactory than high embankments. When it can be satisfactorily arranged the lawn slope reaching out to a high bank above the garden driveway or public thoroughfare should be well rounded with the green turf, sloping gradually to meet a simple, low wall securely built of stone or brick. The turf that rounds over the top of the wall-with trailers dropping down to hide the line of connection-will prove more durable than the grassy outline ending just within the wall surface and encouraging rain water and melting snow to run down back of the wall.

The popular type of dry wall, with stones irregularly laid without the use of mortar, will prove both satisfactory and picturesque for the high terrace. The low one may be suitably walled with mortar-laid stone and prim formal coping for the formal garden, but a certain amount of green 


\section{TERRACE WALIS}

drapery will always be desirable for softening and beautifying even the most elaborate stone-work.

There is a happy medium between the rough, irregular dry wall and the formal mortar-laid stonework; and it is in this sort of wall that the numerous blooming plants find their best foothold, and flourish with greatest luxuriance. It is possible in this form of wall to leave spaces where pockets of soil run back to the natural soil behind the stone-work. These are for the retaining walls which follow a gradual terrace slope, and the earth pockets should be carefully laid to avoid flooding. The largest of the moistureloving plants may be used in these spaces, as they will not dry out so readily as when planted in shallow crevices and wall crannies. The roots will reach down into the bottomless pocket and secure moisture and nourishment from the soil back of the stonework. Brick walls may be provided with earth spaces, in the same manner, if good judgment is used in leaving out a brick or two here and there, and laying the adjoining bricks with good support, and to throw off surplus water without loosening the earth.

The mistake most frequently made in building irregular dry walls that are to depend upon numerous little succulent plants and mosses for their softening grace and beauty is the building of the wall first and then introducing the plant growth. It will 


\section{PRACTICAL BOOK OF GARDEN ARCHITECTURE}

be far better to "lay" the plants while laying the wall. Have a good collection of alpines or rockloving plants on hand, such as the saxifrage, edelweiss, and gentian. For the little succulent plants like the sedums or stone-crops, choose according to color, including the golden moss sedum with a mass of small bright yellow flowers; the album, bearing quantities of pure white flowers among its green foliage; the sieboldi, with its quaint beauty of round succulent foliage and masses of bright pink flowers, and the showy crimson-flowered coccineum. Then there are various stone-crops with glaucous foliage, and tall-growing varieties which hold their foliage and flowers quite erect after emerging from the rock crevices. These are among the quaintly decorative features in wall building, and they are permanent, clinging to the stone- or brick-work indefinitely, and renewing their beauty from year to year.

The wall plants with decorative foliage will prove quite as desirable as flowering ones. When the florists advise maximum atropurpureum, never mind its spelling or pronunciation, just remember that it will send up quantities of rich, bronzy purple foliage from the crevices of the rock, and form an erect compact mass of unusual beauty. When spectabilis atropurpurea is suggested, remember that it is strictly one of the desirables, as its broad foliage is of a 


\section{TERRACE WALLS}

delicate light green tint, held well erect; and that it also bears showy crimson flowers. The variegated periwinkles will give perpetual beauty to the rock or brick surfaces, and the creeping euonymus will display its glossy leaves, with green and white variegations, all the year round. There are numerous other desirables and dependables, but these will guide in the choice, and give pleasing variety. They will flourish with the usual methods of wall laying, being tucked in crevices after the wall is finished; but, as has been said, it is better to provide for them in the building of the wall.

As the stones are laid in place, set the roots of the little plants at the desired intervals well back in the crevices, with a good sprinkling of soil over them. They should be set in the right direction to reach back into the moist earth behind the wall for sustenance. Rich earth and gritty sand, well packed back of the wall, will be of lasting benefit to these plants, and with such provision for their development they will be sure of good drainage and moisture among the rocks. When both large and small stones are used in dry walls the irregular spaces give opportunity for a great variety of plants that will keep the wall rarely beautiful from early spring to late autumn, with evergreen trailers clothing the rocks during the winter. 


\section{PRACTICAL BOOK OF GARDEN ARCHITECTURE}

"Krisheim," the beautiful estate of Dr. George Woodward, overlooking the Wissahickon Creek, at Chestnut Hill, Pennsylvania, has one of the finest retaining walls of this order to be found in the country, winding for hundreds of feet in and out along the broad curved walk, following the line of the creek. Perched high on the hill slope above the historic stream, this wonderful wall is "beautiful for situation" as well as most wisely and cleverly managed; and when the estate is thrown open for public inspection it attracts visitors from all sections of the country. There is an ingenious device for watering the plants during the droughts of midsummer-a long line of sprinkling-pipe along the upper part of the wall, concealed among the foliage plants, and easily operated in times of need.

There are various arrangements for supplying moisture along high retaining walls when water can be provided from a natural spring or by hose connection from the house supply, but with a wise choice of plants, and carefully laid stone-work, they are seldom needed.

Another splendid Pennsylvania type of retaining wall for high terraces is found on the Widener estate, "Lynnewood Hall," at Elkins Park; and among the hilly New England gardens there are many similar 


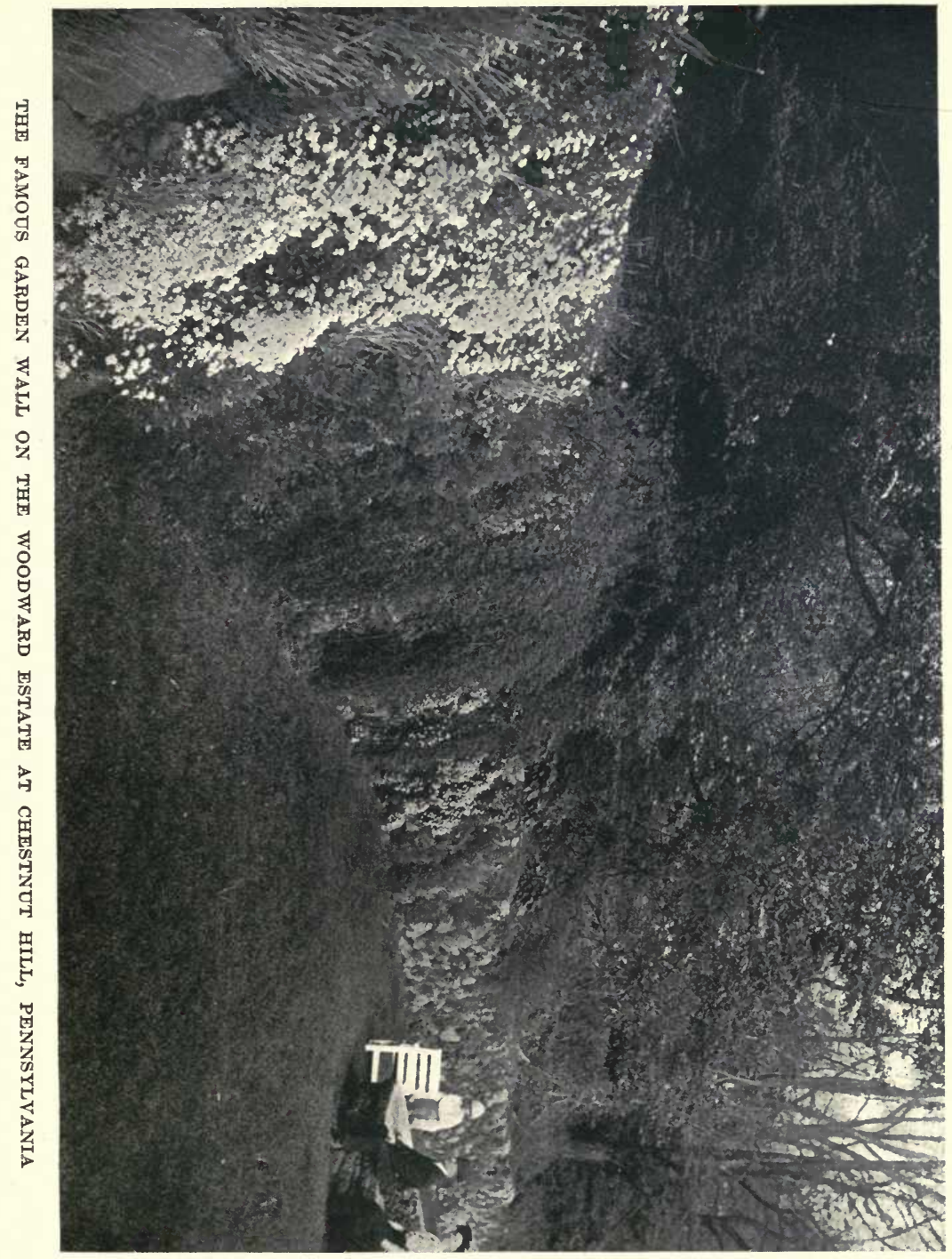





\section{TERRACE WALLS}

flower-clothed walls, such as those in the old Salem and Marblehead gardens of country-wide renown.

There is an unusual type-seldom seen in this country but which has long flourished in Englandknown as the ha-ha wall. It is in reality two walled terraces (one slightly sloping and one almost perpendicular) outlining and retaining the earth in a deep moat. When next you visit England do not fail to travel down into Kent, to the home of Frances Hodgson Burnett, and see her famous wall of this character. In humorously describing the place, the author of "Little Lord Fauntleroy"'admits that when she decided to purchase this beautiful home in England, with its historic legends and traditions, and its splendid old garden, she was largely influenced by the fact that it possessed a ha-ha. "Concerning the ha-ha," she explained, "I burned with curiosity. I had never had a ha-ha. I had never even seen one. I had, however, read several English novels in which it was-most casually-stated that the hero 'leapt lightly across the ha-ha,' to join the heroine on the other side. Upon the whole I went down into Kent looking forward to making clear to myself at last how it was done, why, and at what personal risk."

After describing the charm of the old house and garden, with its beautifully timbered and undulating park and the ancient stone terrace from which one 


\section{PRACTICAL BOOK OF GARDEN ARCHITECTURE}

could obtain a view of half the Weald of Kent, she described her discovery of the ha-ha: "When I walked out upon the great tufted spaces and approached the point where they joined the park, I found that I had not been misled. The ha-ha was there; and when I saw it I realized (I must confess with some assistance from the head gardener) its utilitarian purpose and meaning. Literally it is an extremely clever arrangement of the landscape gardener of long ago (or one may suppose he was of long ago, as the ha-ha is found oftenest in old places), and it is the device of one who dealt with English gardens attached to broad English private parks. Its raison d'etre is the following:

"In most private parks, deer, cattle, or sheep are usually pastured, partly for the utilitarian purpose of fertilization and close cropping of the turf, and partly because of their forming a picturesque detail. Deer are obviously ornamental, so are fine cattle, and nothing produces a more softly completing effect than a scattered flock of snow-white sheep, straying and nibbling, or resting in groups under spreading boughs of oaks and beeches. From these, of course, the garden must be protected by some sufficient barrier, and for this purpose the ha-ha was invented. A feature of most park-surrounded pleasure grounds is that it has been a part of the de- 


\section{TERRACE WALLS}

signer's plan that they shall not appear to be limited by any stretch of fence or hedge, which would break the line of sight, but that the garden shall produce the effect of melting into the sward of the park and seem to be a part of its broad sweeps and spaces. A hedge or fence would form an obvious boundary, and the ha-ha was the ingenious alternative."

This is how it is made, according to Mrs. Burnett's description. A dry moat is dug where lawns join park lands. One side, that toward the lawns, is perpendicular; the other gently slopes; the tops are carefully levelled with each other and the whole neatly turfed. The perpendicular side is securely walled, and also is fitted with a short horizontal fence or wire netting, to prevent the incursions of rabbits. No animal can cross this, and when it is carefully levelled the result achieved is that when one stands at a distance of only a few yards from it, the eye notes no break in the sweep of turf and sees nothing of the barrier, the moat being below the line of view instead of forming a limiting obstruction to it. "Since I have possessed a ha-ha of my own," says Mrs. Burnett, "I have met many people who are as interested and as vague on the subject as I myself once was, and when asked to explain the matter I have felt-judging from my own past emotions-that to do so would perhaps be to allay a 


\section{PRACTICAL BOOK OF GARDEN ARCHITECTURE}

desire for elucidation as keen as was my own. Concerning the original meaning of the word ha-ha I do not feel that I have yet been satisfactorily enlightened. Dean Reynolds Hole, in one of his famous garden books, gives this story as the solution of the mystery: 'An individual being brought without warning to the edge of the first specimen of the barrier, on suddenly finding it yawning at his feet, cried out in delighted amazement, Ha-ha!' But this to the romantic mind seems banale. For myself, I should prefer an explanation more picturesque and early English. But so far one only knows that the thing is called a ha-ha."

On many of our American estates the ha-ha would prove an ideal manner of dividing parks and pasture lands from lawns and gardens. It has been tried on a small scale, but not with the splendid results achieved in England. With well-formed terraces on opposite sides of the deep moat, big bowlders in the bottom, where drainage water will supply dampness for bog and rock plants, and large flat stones outlining and protecting the terraces, this can be made an unusually attractive feature.

The big, flat stone and bowlder walling is also applied with good results to terraces along the garden driveway. When the grade of the lawn makes it necessary to have the drive cut through a hilly por- 


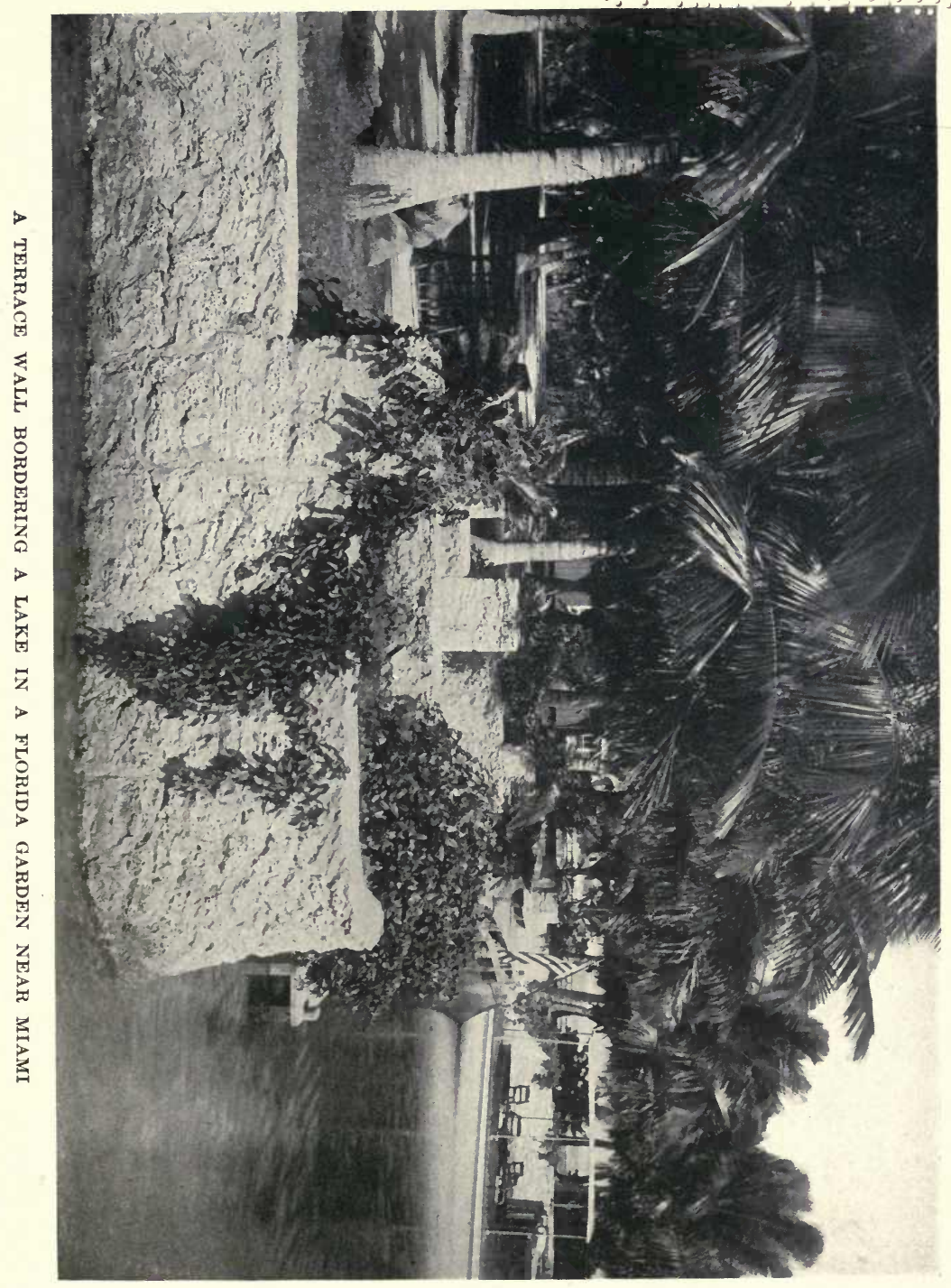


$\because \because y \quad \quad \because z i z i z$

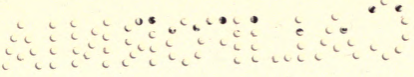




\section{TERRACE WALIS}

tion, a regularly laid wall of brick or stone will be out of harmony with its surroundings. In order to produce the effect of a natural outcropping of rock, have the stretch of terrace packed down firmly at the top, with a tangle of trailers and creeping roses like the wichuraiana, to keep the soil from washing, and an irregular line of big rocks along the base of the embankment. This rugged retaining wall will not require any foundation. The bowlders are simply set in a slanting position against the bank of earth, and will be kept securely in place by their weight and their incline. When the nature of the garden is hilly and rocky, picturesque retaining walls can be built on this order at little cost beyond the expense of hauling from the garden quarry or the rockcleared lawns to the wall and driveway terraces.

The form of garden construction and decoration that expresses personality is the only type that is really successful. The land flattened and levelled by expensive grading until all its beautiful natural contour is obliterated presents one of the most serious mistakes in home surroundings. Rolling lawns and picturesque terraces, intelligently treated, are always more beautiful than flat sameness. 


\section{NATURAL AND ARTIFICIAL LAKES}

HOW TO CONVERT UNSIGHTLY SWAMP AND MARSH LAND INTO BEAUTY SPOTS AND CONTROL OBJECTIONABLE FEATURES

THE location and the treatment of the garden lake will depend largely upon the natural advantages afforded for its installation. The little stream or brook fed by a hillside spring will afford the best means of establishing a body of water of spacious dimensions by simply damming up the stream after providing the big water-tight basin in the lower section of the garden, to which the water course leads. When there is no stream of appreciable size, but a low, wet, boggy spot or a bit of marshy land included in the home grounds, the lake will naturally be located at the place where this objectionable spot can be dredged into a thing of beauty and charm. Where there is neither stream nor low land, and the water for the big basin must be piped from the nearest source of supply, the location of the lake is merely a matter of choice, and its treatment will be of a more formal nature.

The possibilities of water gardening in effective landscape work are endless; but in no other form can practical beauty be so quickly installed as in con- 
verting a bit of unsightly swamp land into a lake. When the swampy land leads down to ocean or channel, as in seaside gardening, the area for the lake may be dyked, in order to keep the water at a constant level. Then no matter how the tide rises and falls outside, the lake, with its decorative planting of lilies and lotus and its ornamental margins, will remain under the control of the gardener, with little to fear from flooding.

Dredging is even better than dyking. This is practical for any sort of inland lake when the home grounds are situated far from tide level of channels or bays. The dredging consists of pumping out the water and mud of the swamp by scooping or by sucking it up with a suction dredge. After deciding upon the size and the outlines of the lake, the space is dredged out; and the sand and mud scooped out are deposited to fill in the remainder of the low spot, so as to provide a high, even embankment all around. The bank should be of the right height to give a good retaining wall and merge into the higher ground surrounding. The lake will then present the appearance of being a part of the broad sweep of lawn, without any suggestion of the original pest-hole of mosquito-breeding swamp.

When it is not practical to dam up some natural depression through which a stream flows, and there is no opportunity for dyking to keep the water at 


\section{PRACTICAL BOOK OF GARDEN ARCHITECTURE}

the desired level, and no swamp or marsh land to be dredged, the only alternative is to excavate the ground, and thus create a depression sufficient to hold the required amount of water.

The artificial lake should be from two to three feet in depth, at least, to allow for the growth of water plants; to avoid injury by freezing, when cement is used in constructing the basin; and to keep the water from becoming stagnant because of shallowness. Any sort of still water will have a tendency to breed mosquitoes unless precautions are taken to guard against the pests. The precautions are so simple, however, that no one should forego the pleasure of a garden lake on this account. For the small lake, a few gold fish will be all that is required to keep the water free from larvæ and wrigglers. For the large lake, covering a wide area, and of considerable depth, it may be necessary to have fish that are both surface and bottom feeders. Top minnows and stickle-backs have been suggested for this purpose; but any lake fish that will flourish in the artificial water supply will be useful for keeping the place free from mosquitoes. Trout and fish of a similar nature will not live in the still water lakes, as they flourish only in the clear cold water of spring. fed streams.

The formation of green scum on the water is a 


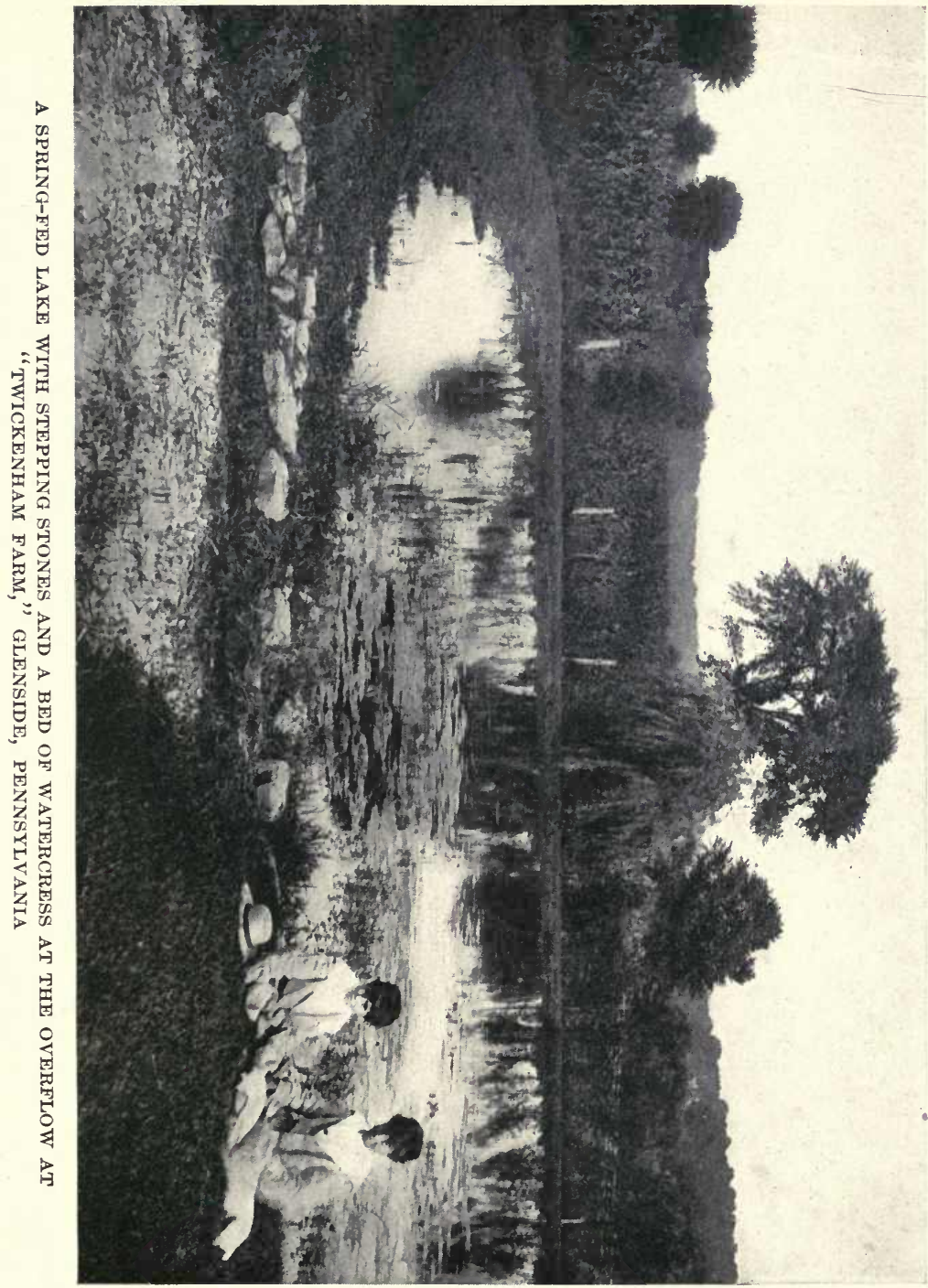




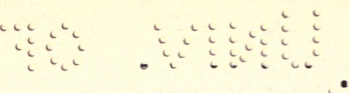

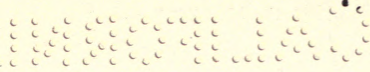




\section{NATURAL AND ARTIFICIAL LAKES}

serious objection to many garden lakes. This is supposed to be simply a sign of stagnation, and a plague difficult to overcome. In reality, it may be as easily managed as the mosquito troubles. Thanks are due to the Government Department of Agriculture for the remedy that is certain to obliterate this yellowishgreen scum, and to keep it from forming in the future. For many years this nuisance, which is sometimes called "purging," has made thousands of fresh-water lakes and mill ponds throughout the United States unsightly and unhealthy. The sucsessful experiments of the Department of Agriculture in treating these bodies of water are of equal advantage in treating the garden lakes.

According to the expert authority of the Department, this green scum is the formation of algæ in the water. It becomes an important matter to remedy the formation, and to keep pure and fit for use the public water supplies, that in the past were practically useless for months at a time because of that troublesome algæ. It has been found that it can be thoroughly controlled by the use of copper sulphate, which is the "blue vitriol" of our well-known Bordeaux mixture.

The trouble with the average home gardener, in experimenting with this cure, is his tendency to use too much of it. It is better to follow closely the given 


\section{PRACTICAL BOOK OF GARDEN ARCHITECTURE}

directions. This is what the experimenters say who speak from actual experience:

"It is hard for people to believe that the reason for this scum is not frog or fish spawn, nor even the decomposition of the vegetation that grew the year before, and which the winter has killed and the warmth of spring decayed. These misconceptions have existed so long that they have become traditions. This 'purging,' or 'scum,' is alive-a microorganism-and exists in hundreds of distinct varieties, differentiated and classified by scientists under the general name of algæ. The trouble makes its appearance as soon as the weather becomes warm, and often lasts through the entire season.

"When it is at its height, the fish absolutely refuse to take bait, and horses and cattle frequently refuse to drink the water. The method of getting rid of the nuisance is very simple, and consists of applying the copper sulphate in extremely dilute solutions: one part to a million of water. Roughly speaking, this means five or ten pounds of the sul. phate to each acre of a pond averaging four feet in depth. There is no advantage in using a stronger solution. The exact amount can be computed by ascertaining the number of cubic feet of water in the pond (area multiplied by depth), then by multiplying this by $62 \mathrm{r} / 2$ (the weight of a cubic foot of water), and divide by a million. 


\section{NATURAL AND ARTIFICIAL LAKES}

"Put the required amount of sulphate of copper in a coarse gunny-sack or feed bag, and draw it around in the water behind a boat; or, in the case of a very small pool, on the end of a pole. It will dissolve slowly, and must be distributed as evenly as possible over the entire surface. Nothing will happen at first; but the day after the treatment, the algæ will be seen to have changed from yellowish green to brown, and will break up and precipitate to the bottom. The effect of the sulphate apparently has been to wither it up; and a mass formerly the size of a barrel will be like a handful of wet hay. There will be an unpleasant odor for a day or two; but getting rid of the nuisance will more than compensate for any annoyance from this cause. While blue vitriol is a poison, the very dilute solution that is used renders this quality negligible."

The objection is sometimes raised that the presence of blue vitriol, or sulphate of copper, will kill the fish in the lake. But as this proportion is merely "a drop in a bucket," there is little to be feared from this cause. When one possesses a sure cure for the algæ, and also for the malarial tendencies through the extermination of the mosquito-distributors, it will be a pleasure to establish garden lakes of goodly dimensions, in whatever location they may be found desirable. 
As a help to aerate the water, and keep it sweet and free from objectionable features after the algæ and mosquitoes have been destroyed, it will be important to plant intelligently within the pond. The plants that best supply the required oxygen and keep the water pure are the sub-aquatics, like the eel grass and the giant water weed, and others of this nature that are natives and certain to flourish. Then, for plants to beautify the lake, if it is undesirable to establish water lilies, except along the border, try some of the floating plants that are easily controlled.

The water hyacinth is one of the best, as it develops rapidly, bears quantities of the blue, hyacinthlike blossoms, and makes a fine display without requiring a place for rooting in the bottom of the lake. This general favorite for northern lakes, botanically known as Eichornia crassipes, and also as Eichornia speciosa, is the famous "million-dollar weed" which became such a nuisance on the St. John's River, in Florida, that it caused over a million dollars' worth of damage in obstructing navigation. But there is no danger of destructive development outside of the mild southern climes. It is a tender annual farther north, and unless care is taken to keep some of it in the houses during the winter, it will be destroyed by freezing.

Another good floating plant for the garden lake is the water chestnut, or water caltrops (botanically 


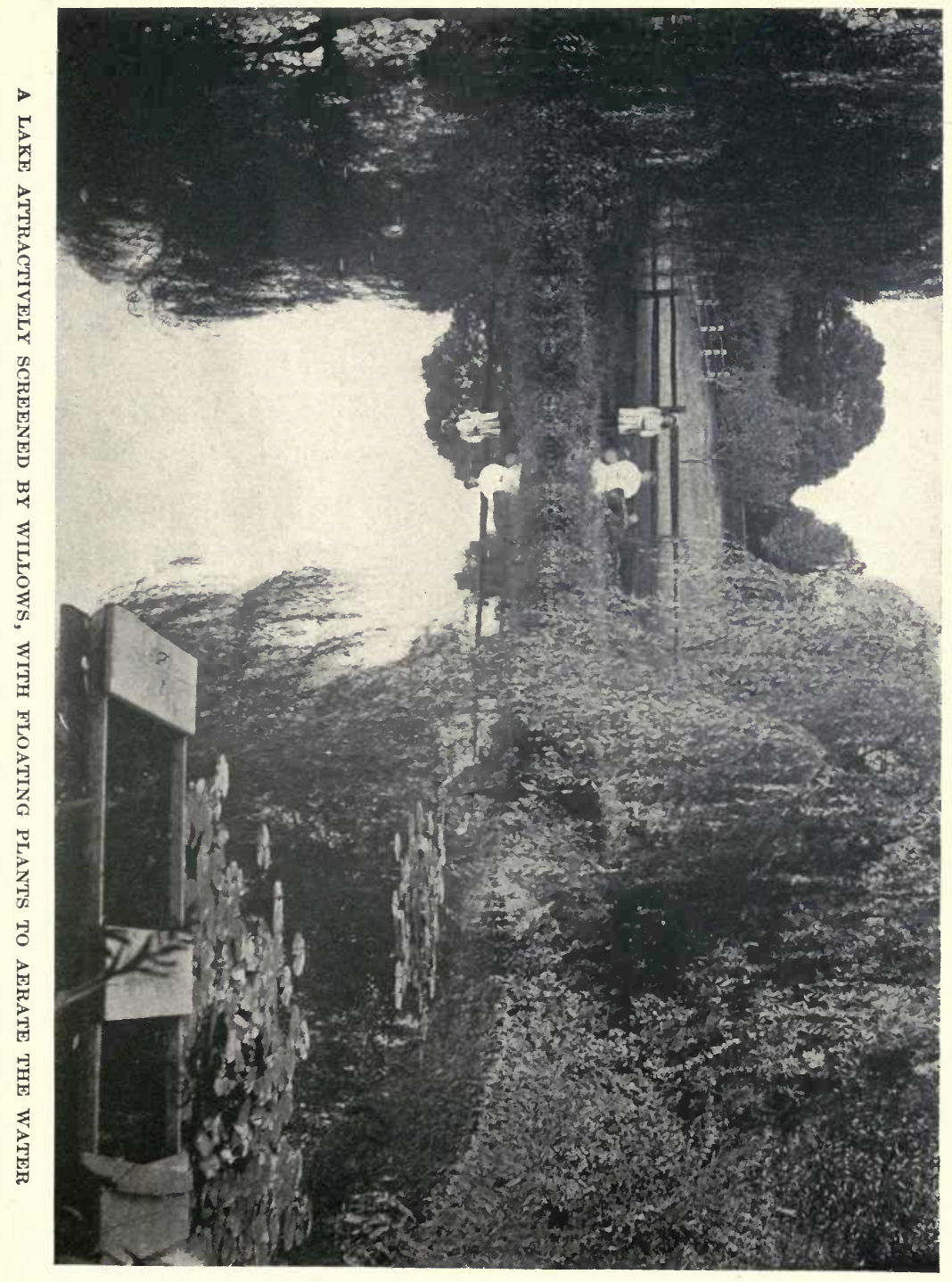


$\because \vdots \because \quad \because \because \vdots i \vdots \vdots \vdots$

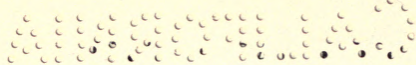




\section{NATURAL AND ARTIFICIAL LAKES}

known as Trapa natans), which bears white flowers; and the floater with attractive foliage, Salvinia Braziliensis. In order to keep these annuals from year to year, it is necessary to take a little clump of each into the house, and keep them floating on the water in a deep bowl or jardiniere. On placing them in the lake again in the spring, they will quickly flourish into fresh luxuriance.

Native rushes, sweet pepper bush, papyrus, sweet flag, irises, and plants of a similar nature will flourish along the outer margin of the lake in the damp soil caused by the overflow. It is important to give both classes of water plants careful studythose used merely to decorate, and those used to aerate the garden lake-if we would have it continue a success.

The lake of ample dimensions offers other delights besides those of water gardening. One of the most fascinating features is to follow the old Roman custom of collecting and raising decorative water fowl. There are few forms of garden "ornamentation" that will equal the beauty and interest in showy swans, ducks, and geese collected from various countries. It is claimed that the average garden lake owned by one whose hobby runs to collecting water fowl can become the possessor of many treasures unknown to Roman gardens. In these days of frequent travel and cheap transportation, we are gradu- 


\section{PRACTICAL BOOK OF GARDEN ARCHITECTURE}

ally attaining a very wide knowledge of unusual sorts from European lakes and ponds, that will readily flourish on our American lakes and ponds. There are said to be at least three naturalists within a few hours of New York City who have world-famous collections of these beautiful water birds; and many others can display wonderful collections, although they may not be so widely known.

Quaint houses built on the margins of the lake to accommodate these water fowl present a decorative feature but little known to the average garden until within recent years. Little, low, thatched shelters on the lake border are picturesquely designed for the accommodation of the smaller ducks. The big shy ducks, which are not so readily acclimated when brought from European lake gardens, prefer more secluded houses, back in the shelter of trees and shrubbery. The swans and geese require larger quarters; and with thatch and bamboo and cedar saplings, they may be made to resemble picturesque Japanese houses on the lake shore. Little stationary houses are also built out in the centre of the lake, with low roofs and wide spreading eaves. Here the water fowl find rest and shelter without retiring to the secluded houses on the banks. Many varieties prefer the houses built out in the lake, with the floors raised only an inch or two above the highest level of the water. 


\section{NATURAL AND ARTIFICIAL LAKES}

- A lake that is fed by a brook may form a special decorative feature by means of pictorial rock work. Avoid sameness in the arrangement of the rocks along the edge of the stream and in the bed of the brook. Let them range from big bowlders to little stepping stones across shallow fording places. Have their bare, rough surfaces partially screened with dainty bog plants; and in the bed of the shallow stream have luxuriant growths of water plants reaching up over the bowlders, protecting the bank, and the source of supply will be as attractive as the lake itself.

For those who admire garden statuary, this may be made an acceptable feature in ornamenting sections of the big water garden; but it must be used in moderation. The Greeks used to group choice bits of classical statuary beside their sacred springs; these were not only treasured for their decorative value, but because they were supposed to personify the nymphs that haunted these mystic shrines of beauty. In order to have types of lake statuary harmonious and pleasing, it must be carefully chosen to follow the Grecian idea. It is very easy to overdo this form of decoration. Large trees for lake margins must be handled with equal care. It is best to err on the side of simplicity rather than on that of ostentation. 


\section{VII}

\section{LAKE PAVILIONS AND TEA ROOMS}

NOVEL WATER FEATURES DEVISED FOR DISPENSING HOSPITALITY

MANY fascinating forms of aquatic amusements have had their origin in American gardens. Nor are the best of these water features necessarily to be found on great estates. Frequently the little pond or lake of the unassuming suburban home will display a delightful arrangement on an island of very limited dimensions; or an ingenious arrangement of piling supporting a charming pavilion, summer-house, or tea room. We frequently hear of the wonders wrought in old-world gardens in the treatment of water. "You can't possibly find anything new in that line," declared a traveller on his return to America, after studying the architectural achievements of famous Europen gardens. He went on to explain that the Romans knew it all, when it came to the introduction of water into the garden. He claims that concrete water basins are not new. The old Romans did wonders with concrete-witness their roads which have survived for nearly two thousand years. According to his verdict, "our modern millionaires have not originality enough to beat 


\section{LAKE PAVILIONS AND TEA ROOMS}

Lucullus and his live lampreys. Our architects only imitate. They all go to Rome and Pompeii for inspiration. We flatter ourselves that we do things on a big scale, but for colossal things you must go to Rome."

We may find many convincing arguments against this declaration; for we have learned how to handle water features that the Romans never dreamed of. Without travelling very far among famous American estates, we find marvels accomplished in dyking and dredging to form wonderful water parks; we find artificial lakes entirely free from the disfiguring green scum known as algæ; we find poisonous malarial swamps converted into beautiful garden ponds and canals; we find damp, boggy pest-holes in little gardens transformed into fascinating water features, rivalling those of big estates, and accomplished at little expense.

Best of all, we have discovered that the danger arising from what the Romans thought was bad air that proved so destructive in the Campagna-and what was in reality malarial fever germs carried by mosquitoes of the genus Anopheles-can be obliterated from our ponds by the introduction of the right kind of fish to eat the wrigglers. Then by keeping the margins of our lakes and ponds free from the grass and weeds that provide a hiding place for 


\section{PRACTICAL BOOK OF GARDEN ARCHITECTURE}

larvæ, and by growing sub-aquatic plants in the lake, the giant water weed, Anacharis Canadensia, and the eel grass, Vallisneria spiralis, we can aerate the water and keep it free from impurities. After attending to these practical details, we can show the ancient garden architects how to accomplish wonders in introducing water just where it is wanted by means of hydraulic rams, numerous inventions that enable us to pump and store water, and quaint contrivances that make it possible to have the spouting waters of our lakes colored by electricity. In no other country in the world are splendid water features brought within the reach of the modest home, at slight expense, as in the United States.

Take, for instance, the introduction of the lake pavilion, where it is possible to find rest and amusement in the midst of rippling water, with overhanging roof for shade, and the fragrance and beauty of flowers and vines trailing up the lattice enclosure. The water summer-house, fitted up with rain-proof closets and cabinets for books and fancy work material, or for following one's talent in art, literature, or music, need not be a costly affair, even when stationed far out in the garden lake. The little screened summer-house in the form of a tea room-either stationary or floating on the water-is another of the newer conceptions that are finding favor in 


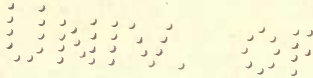

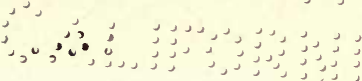

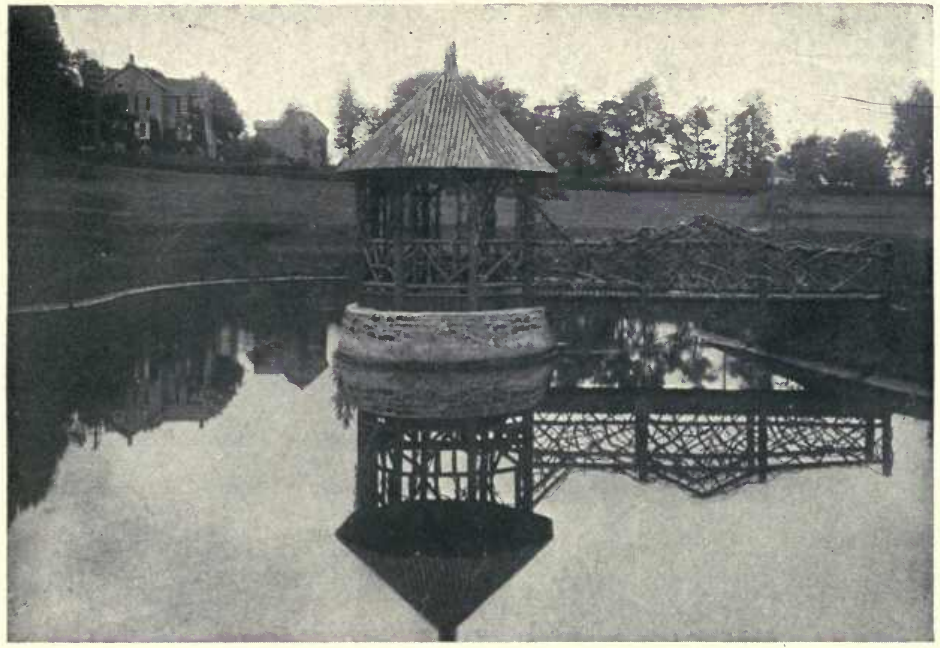

A LAKE TEA ROOM GIVING BEAUTIFUL REFLECTIONS

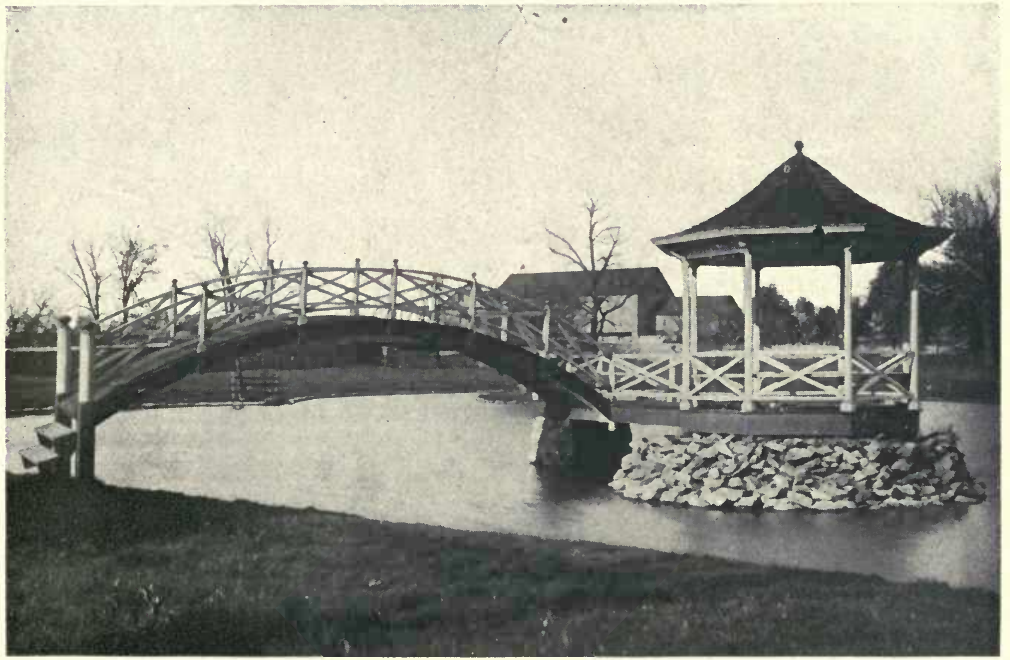

A LAKE HOUSE AT "ERDENHEIM" IN THE WHITEMARSH VALLEY 


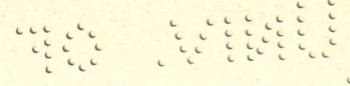

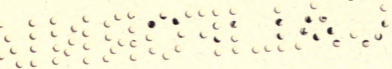




\section{LAKE PAVILIONS AND TEA ROOMS}

wonderful water gardens. The ingenuity that plans the novel tea room will be certain to devise equally delightful methods of dispensing hospitality.

The tea-room idea for water pavilions and summer-houses has been developed to a remarkable extent among California water gardens. There is one on Mr. Charles Frederick Eaton's place, at Montecito, that has attracted considerable attention among architects and craftsmen. It is a pavilion boat built in the form of a floating tea room-a square structure, with a picturesque roof of yellow thatch, and broad, overhanging eaves. There are long flower boxes-wide and deep-built at the base of the pavilion. From the rich soil in these, vines grow luxuriantly, and after climbing up the sides of the tea room they hang their blossoms from the eaves thatch.

The chief fascination of this tea room lies in the fact that it is built to glide mysteriously over the waters of the lake, without any apparent propelling power. There is a secret cable under the water, by means of which the pavilion is sent gliding here and there among the water lilies. A high railing surrounds the structure, supporting vines and flowers on the outside; while within there are broad cushioned seats for the accommodation of guests, when the hostess sits enthroned at her tea-table. The 


\section{PRACTICAL BOOK OF GARDEN ARCHITECTURE}

situation makes this pavilion tea room especially fascinating. The little lake occupies a prominent position on a hill top overlooking the ocean, with the Santa Barbara Isles in the foreground. Enormous trees of live-oak, and various other trees of semitropical growth, like the palm and the olive, break the distant view, and afford glimpses of the blue Pacific glinting in the sunlight. Numerous water plants, from the varied water lilies and the bigleafed lotus to the Egyptian water grasses, flourish in the lake at "Riso Rivo," as the place is namedmeaning "Laughing Rivulet." In the midst of the tea ceremony, the pavilion is mysteriously guided among the various water attractions of bloom and fragrance. With the flowering vines trained over the pavilion from its floor boxes, it forms a veritable place of enchantment.

There are many attractive tea-room pavilions on the pleasure lakes of New England. The little garden lakes along the Connecticut River, and the homes of summer residents in the resort sections of old Marblehead, show many quaint designs, with foot-paths, on pilings, leading out from the shore of the lake or pond. In the park sections of Boston, and in the Roger Williams Park at Providence, there are music pavilions and restaurant pavilions that have been built out in the water, and that have served as 


\section{LAKE PAVILIONS AND TEA ROOMS}

inspiration for garden buildings constructed on a smaller scale. With a close background of shade trees, these water rooms are sometimes left without roofing over the larger space, and only a canopy shelter at the entrance. But the summer-house plan with roof covering the entire structure is the most popular type.

Among the handsome estates of suburban Philadelphia, including Germantown, Wyncote, Chestnut Hill, and the Whitemarsh Valley, there are probably more picturesque lake pavilions than in any other part of the country. Where the branches of the historic Wissahickon leave the upper section of Fairmount Park and flow through the estates, no expense has been spared to take advantage of the abundant water supply by establishing spacious garden lakes. For the less favored country seats, where the natural water supply is limited, artificial lakes have been formed that rival the natural waterways in beauty. In forming the artificial lakes, provision is usually made for an island of good size. On this the tea-room pavilion is constructed. In some instances the building stands far out from shore, in the centre of the lake, the only means of reaching it being a floating garden in the form of a flower-boxed barge, to be poled out to it.

A picturesque device for reaching one of these water tea rooms is a rope ferry, with the ropes 


\section{PRACTICAL BOOK OF GARDEN ARCHITECTURE}

strung tight from a big tree on the bank of the lake to the building in its centre; and the ferryman who is usually the host or hostess taking out the guests, stands in the centre of the shallow ferry boat, which is pulled back and forth by means of the rope, while the guests are seated. The little tea rooms built on smaller lakes, and necessarily near the shore, have arched bridges and rustic walks leading to them. The foundations of concrete or stone-work are of limited dimensions, usually sufficient to support only the little building and the bridge abutments.

Another plan for providing access to the lake building is to throw out a rock walk or to extend a walk of bowlders joining a big rock on shore. This is suitable only for the garden lake with a rocky bank on one side. For the summer-house built out in the centre of the pond, with grassy borders, the rustic bridge or pile-supported walk gives greater harmony between the lake house and its surroundings. When the bowlder walk is arranged on a rocky shore, the building should be built close to the shore; with the effect of being constructed on a natural rock foundation, even though it may be supported by piles, or concrete, where it extends into the water. Thatch roofing is always attractive for these lake houses, when the surroundings are rustic. Roofing, railing, and foundation trimmings of slender cedar limbs produce the effect of bamboo, 


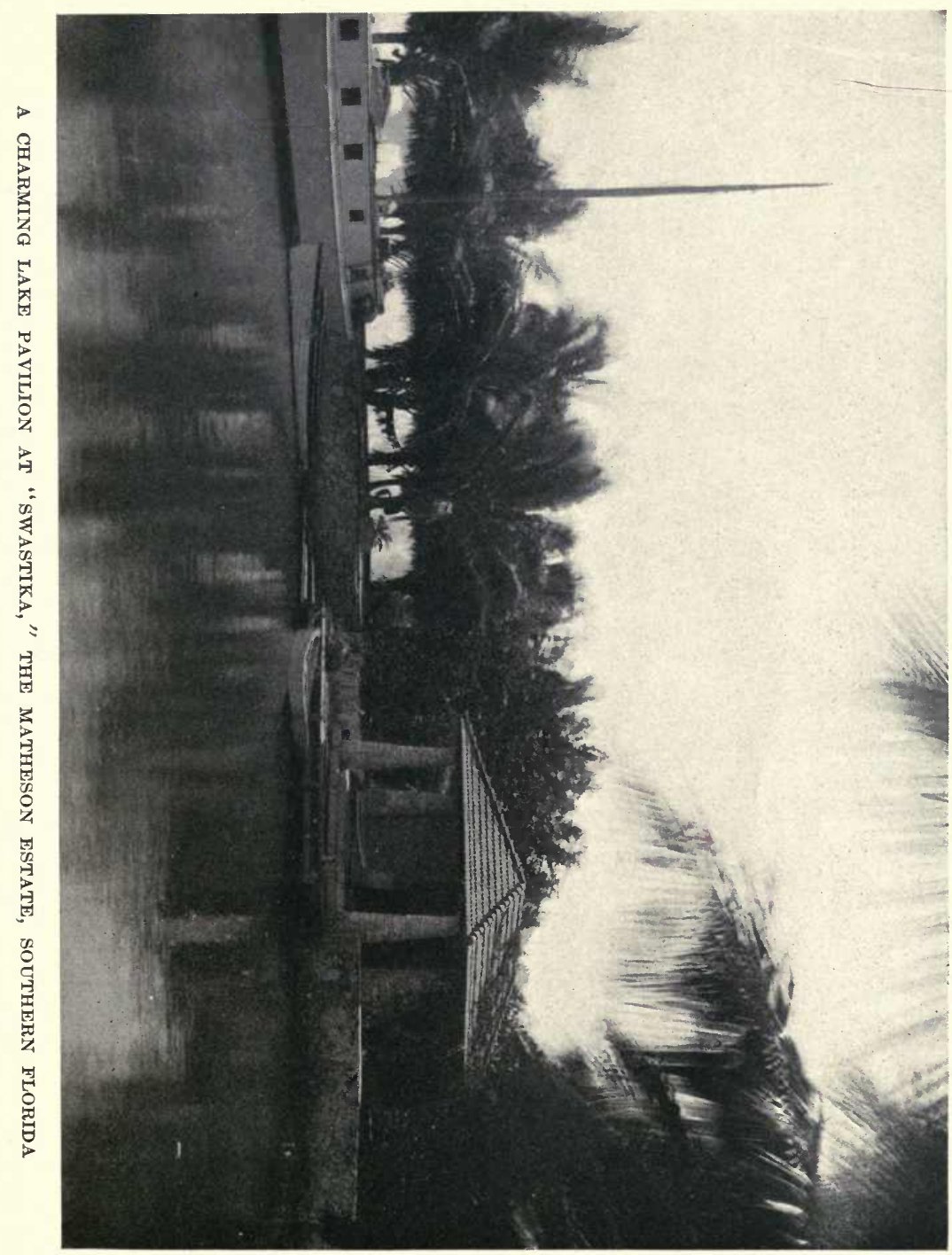




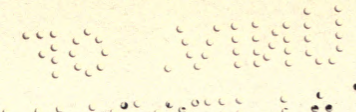

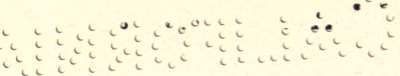




\section{LAKE PAVILIONS AND TEA ROOMS}

and may be carried out in quaint Japanese designs. For the stately lake house with round, white columns and foundations of stone-work, a shingle roof in conical or octagon form gives appropriate finish.

For the small lakes and ponds, the little pavilions and summer-houses should be built stationary, like those of the illustrations. For the large lakes and natural waterways, floating pavilions always provide additional charm and novelty. It is not necessary to provide costly contrivances in cables, etc., under the water for automatic guiding, nor is the flower-barge idea necessarily a part of the floating pavilion. There is a decidedly attractive type found at the southern home of Mr. Wade, at Thomasville, Georgia, built to float about or to be propelled in a large lake. This big summer-house on the water is finished with thatched roof and flower boxes on its broad platform, like the lake tea room at Santa Barbara; but instead of gliding over the lake by means of a hidden cable, it is poled from place to place, when one desires to gather water lilies or to reach the opposite shore of the lake. But for the greater part of the time, it stands anchored at the garden shore of the lake.

There is an attractive water pavilion on the estate of Mr. W. J. Matheson, at Cocoanut Grove, Florida. It is anchored firmly on the white coral rock foundation-the same white rock that walls up the 


\section{PRACTICAL BOOK OF GARDEN ARCHITECTURE}

bank of the big lake or basin, which has been dredged to splendid dimensions. A wide expanse of marsh land leading down to the bay-this low, wet land is known as the "savannah" in southern Florida-has had the sand and soft white rock scooped from Biscayne Bay, by means of a powerful dredge. After dumping the dredging about the rim of the great basin, or garden lake, the dredge was put to work within the enclosure; and the wet swampy land was removed, to increase the height of the walls, and to leave a big basin to be filled with water from the bay. A sea wall of the coral rock, which hardens on exposure to the air until it is as firm and durable as granite, was then built all around the big lake. A stately grove of cocoanut palms was planted along the broad margin, where the rich soil and sand were filled in. Finally a little canal was cut between the new lake and beautiful old Biscayne Bay, and the lake filled with water to tide level. The rich tropical vegetation, peculiar to southern Florida, clusters closely about the banks of the water, and overhangs the picturesque pavilion tea house, anchored securely on the white rock. The tall palm trees, with their immense clusters of cocoanuts, reflected in the water; the great screening tangle of palmetto, the overpowering fragrance of myriads of blooming plants, and all the fascinating mystery peculiar to the tropical garden, require this one little touch of home 


\section{LAKE PAVILIONS AND TEA ROOMS}

life, this suggestion of gracious hospitality, personified in the lake pavilion, to make the spot complete.

In building a lake pavilion, it is made the keynote of the decorative accessories. When it is situated near the margin of the lake, the tallest planting that surrounds the borders of the water should stand just behind the building. This tall planting will serve as the background of the pavilion, from the water view, and from the land view it will serve as a screen and a shelter. When situated in the centre of the body of water, the stationary pavilion may have considerable advantage in the decorative treatment of the little island or the rocky base supporting it, and in the establishing of plants in flower boxes and in pockets of rich earth in the rocks. The rustic walk or bridge leading out to the pavilion is capable of many attractive forms of decoration, and the concrete arrangements for intake and overflow also contribute to the ornamental features. For the floating pavilion tea room, special attention is given to the treatment of plants and blooming vines growing in boxes on the barge-like extension at its base, and to the display along the banks of the lake. There should not be any suggestion of a sharply defined margin in the border. Groups, gaps, and breaks in planting should give access to paths leading to landing places. 


\section{VIII}

\section{OUTDOOR SWIMMING POOLS}

NATURAL AND ARTIFICIAL WATER SUPPLIES FORM AN ARCHITECTURAL FEATURE CAPABLE OF WIDE ADAPTATION

From the old swimming hole of the farm home, made by damming up a brook or other natural watercourse, to the elaborate swimming pool of marble and Carrara glass and various costly accessories, with water supplied by artificial means on the millionaire estate, widely different plans are presented for providing a delightful feature for the home grounds. Between the two extremes there are numerous types of swimming pools that may be built in harmony with any sort of house and garden, and to accommodate any purse. It is not unusual, in these days of over-elaborate architectural devices in home surroundings, to find wonderful swimming pools built in conservatories and spacious greenhouses, where the water can be kept at an even temperature during the winter, so that the pool may be enjoyed for swimming and bathing the whole year round.

The most practical pool, however, and the one that will appeal to the average home builder, is the 


\section{OUTDOOR SWIMMING POOLS}

one that is made an attractive feature of the garden - a pool that can be constructed at little cost, and with a certainty of proving durable for practical use and constant enjoyment; a pool so carefully constructed in regard to depth and finish that it will accommodate the baby of the home taking his first lessons in the natural art of swimming, and the father of the household, who will want a deep space for diving and practising various water sports.

The swimming pool will require very different construction and treatment from the lake. The latter is intended mainly for garden decoration, for the enjoyment of water features in aquatic gardening, and for rest, meditation and hospitality in the ornamental accessories of shelters and pavilions along its banks and in mid-stream; it seldom requires to be more than two and a half feet in depth -a depth that will accommodate the owner or gardener, in hip boots, wading among the plants and attending to its various requirements throughout its entire extent.

The swimming pool, on the other hand, should have a varying depth, according to the family it is to accommodate. For the long, rectangular pool it need not be more than three or four feet at the end where the children will bathe and learn to swim; while at the deepest portion at the opposite end, seven or 


\section{PRACTICAL BOOK OF GARDEN ARCHITECTURE}

eight feet may be required for diving and swimming.

Payne Martyn voiced the expression of the universal desire when he said of the swimming pool: "It is a walling in of a portion of an elemental thing, and owning the tenth of an acre of the deep sea and all rights and privileges thereto. When swimming pools become as widely popular as they deserve to be, the swim will be as much a daily necessity as the breakfast. Bathing and swimming were never intended to be divorced. Swimming was meant to be one expression of a man's activity, and by means of it unconsciously he was to achieve cleanliness. Every piece of constructive work has its model in nature; just as the Gothic vault was an indoor imitation of the forest isles, so the marble pool is just a highborn adaptation of the old 'swimming hole.' It is giving width and geometrical shape to the flow of water."

It will not be possible for all who are planning garden swimming pools to provide the luxurious surroundings that will make them a daily pleasure throughout the year. But it will be feasible to build inexpensive pools to fit the requirements of the majority of homes, that will be perfectly practical in regard to safety devices for keeping them unharmed through the freezing weather and have them 


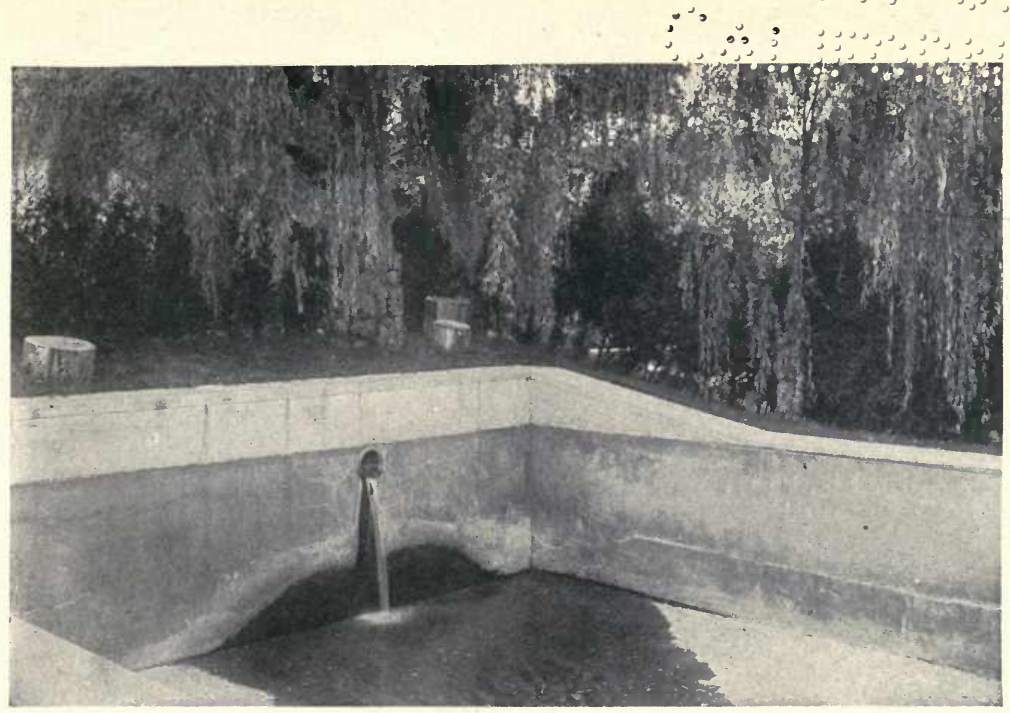

A POOL WITH THE INTAKE END BORDERED WITH A HIGH RIM OF CONCRETE

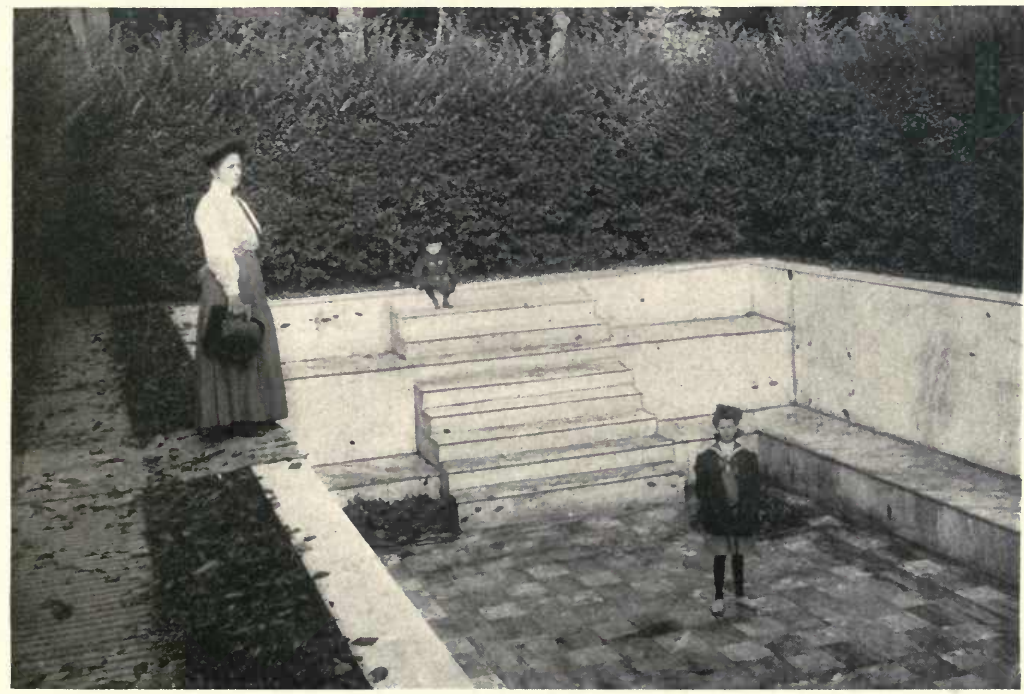

A POOL SCREENED BY A TALL PRIVET HEDGE 
$\because \because y \quad \because \vdots \vdots z \vdots \vdots$

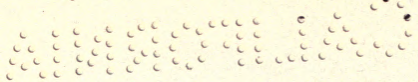




\section{OUTDOOR SWIMMING POOLS}

ready for enjoyment from early spring until late autumn.

When lined with brick, stone, or concrete, precautions must be taken to provide for the comfort of the swimmers. No jutting pieces should be allowed in the pool-no rough projections that can hit or catch the bather. A pool that is bull-nosed at the cormers and has the angles coved will be ideal in its make-up, and these precautions need not add materially to the cost. A bit of inventive ingenuity, and a fund of practical good sense, will provide many little comfort-dispensing details during the process of construction that would be overlooked by the careless builder.

Pools of oval and rounded form, are seldom advisable, whether of elaborate or inexpensive construction. The ones built straight, or of rectangular form-especially when of good size-are best for jolly races and straight-away swimming. But the main advantage of having them of the latter form is the management of the material used for lining. When hexagon ceramic tile is employed (for the pool that is to be made quite decorative as well as useful) an oval pool would prove unwise, as the curved form needed to achieve the rounded corners would make the tiles sensitive and liable to crack; for the outside would thus sweep a fuller circle than the inside. Also 


\section{PRACTICAL BOOK OF GARDEN ARCHITECTURE}

in the use of enamelled brick and similar material for inside facing, the straight retaining walls will never be quite so difficult to construct, to insure watertightness, as the walls of the curving surface. Fiveply water-proofing paper is sometimes recommended for use in connection with hot asphalt and concrete to prevent the gentle leakage that sometimes makes the swimming pool a care. Ordinary brick laid in mortar and grouted is also used for the small pools.

Tiles naturally have been the favorite facing for the inside of the pools of the more expensive type, but during recent years Carrara glass-because it is homogeneous-has become still more popular for facing the inside of the retaining walls and for the flooring.

Tile flooring, marble basins, and Carrara glass do not represent the ideal accessories for the average swimming pool, however. Neither will the little natural brook supply, with its inexpensive dam, be within reach of the average home. Concrete is the happy medium that will meet the demand of the multitude. Returning to the "Martyn theory" we are convinced that a moderate-priced swimming poolor at least a pool in keeping with its surroundingsshould be considered as essential to the country home as the barn or the ice-house, for it answers a fundamental need. Pools need not be one-priced any more 


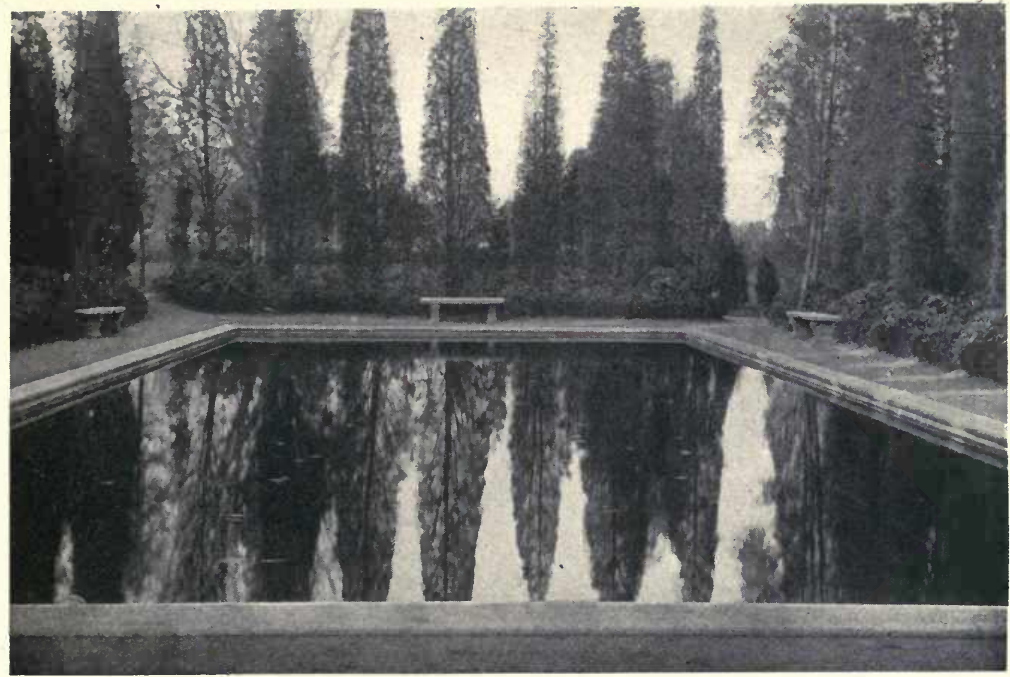

A POOL WITH GOOD PLANTING AT GARDEN CITY, NEW YORK

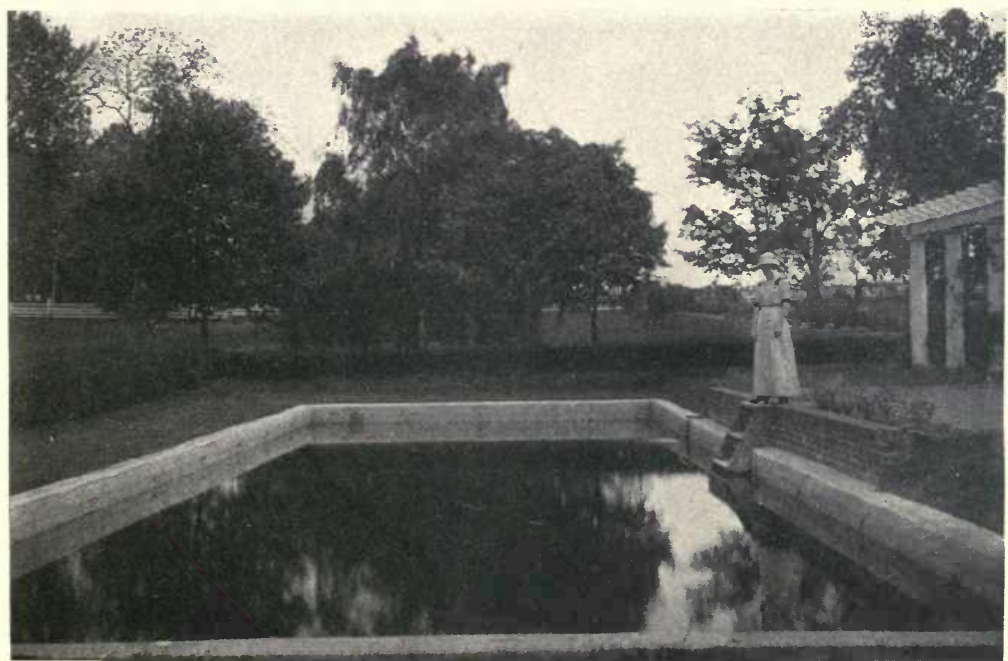

A POOL WITH HIGH COPING KEEPING THE SURROUNDING SOIL FREE FROM DAMPNESS 
$\because y_{i} \quad y_{i} i_{i} i_{i} i_{i}{ }_{i}$

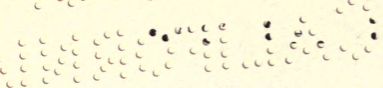




\section{OUTDOOR SWIMMING POOLS}

than barns are one-priced. The modest landholder of one horse and half an acre can have his pool by damming up his brook. With the dam constructed of field stones mortared together, a six to ten-foot brook of medium depth may provide a practical and convenient pool for about fifty dollars. The man of considerable but not six-figured fortune will have his cement pool of spacious dimensions and attractive accessories, at a price of two thousand dollars. The owners of great estates will continue to have their superb marble-lined ponds at ten thousand dollars and upward.

William Walter Smith, who has become famous throughout the country as "the concrete man"- because of his extensive experiments, and the splendid results he has achieved in promoting every sort of building with this adaptable material-has given, in "Suburban Life," directions for building two moderate-priced swimming pools. Fifteen by fifty feet is the size given as filling the requirements of the average home garden. The price of about two hundred and seventy-five dollars covered the entire cost of one pool, built largely by home labor and of inexpensive materials. For a pool of about the same dimensions, where the cost of labor and material is greater, the whole expense will figure up to about four hundred and fifty or seventy-five dollars. Mr. 


\section{PRACTICAL BOOK OF GARDEN ARCHITECTURE}

Smith was not only able to give me facts and figures concerning these good-sized, convenient, durable, and low-priced pools, when I consulted him in regard to establishing one in a secluded corner of the garden, but he was able to show me the most practical and decorative forms of concrete pools that have actually been constructed at these low figures. According to this good authority, concrete usually consists of Portland cement, sand and crushed rock. When more convenient to obtain it, clean gravel (sand and pebbles) can be used instead of the sand and crushed rock. Frequently the gravel can be had for the hauling. In such case the construction is exceedingly cheap, as only Portland cement need be bought.

The swimming pool may be located anywhere except on recently made ground. The tank need not be its entire depth in the ground, but must be sunk deep enough to secure a firm foundation, and it is also important to have the bottom below the frost line. The side walls should extend at least one foot above the ground level, in order to keep out flood water. A height of three feet is better, as the side walls will then serve as a railing or fence, as well as affording a good height for a dive for youngsters who have not mastered the spring-board.

For a rectangular-shaped pool fifteen by fifty feet in the clear, the bottom is made sloping in order 


\section{OUTDOOR SWIMMING POOLS}

to provide a shallow end for the children and a greater depth at the spring-board end for those who care to dive. At opposite ends, the depth of this pool is five and nine feet; but the water is usually kept at the four and eight foot mark. The walls are twelve inches thick, and extend three feet above ground. They are strengthened at the corners, and at equally spaced points along the sides, by concrete buttresses six by twelve inches at the top, built as a part of the walls with flat side to them. The outside face of each buttress is sloped outward for the distance of one inch for each foot; the buttress extends into the ground. At the near end of the pool is the concrete support for the spring-board. It is two feet wide, five feet long (including the thickness of the side wall) and extends three feet above and the same distance below the ground level.

The spring-board is held in position by iron straps fastened to bolts set in the concrete. Eyebolts are imbedded in the four walls, six inches above the normal water mark, through which is passed a one-inch rope, which provides a resting place, and an easy means for the swimmers to leave the tank at any point around the edge. In one corner, at both the deep and shallow ends, is a narrow flight of concrete steps extending to the bottom of the pool. The concrete bottom is eight inches thick. 


\section{PRACTICAL BOOK OF GARDEN ARCHITECTURE}

Since the owner of this pool used a low-priced gravel, and lumber which he could utilize later for building purposes, and the laborers were in his regular employ, he was able to build the pool of good size, and of a quality to last unchanged for years, for the small amount of two hundred and seventy-five dollars.

The best method for constructing a pool of this size is to lay out the excavation seventeen by fiftytwo feet. With a plow, scraper, and team remove the dirt to the depth of six feet eight inches at the deeper end, and two feet eight inches at the shallow end. Drag the dirt out at the shallow end. Trim the ends and sides vertical with a spade. In one of the deep corners lay an outlet drain of sewer pipe, ending with the bell of the elbow bend at floor level, eight inches above the earth bottom. The plug for this pipe should be fitted with a stiff ring, so that it may be raised by means of a long hook or other device. Lay the inflow pipe from the gasoline engine or hydraulic ram at the point desired. If necessary lay an overflow drain. All the materials should be on hand and placed in convenient location before the hole is dug.

- Build the forms of one-inch lumber on two-byfour-inch uprights, spaced two feet. Set the forms on eight-inch bricks so that the concrete floor can 


\section{OUTDOOR SWIMMING POOLS}

be built under them. If the earth walls stand firm up to the ground level, only inside forms will be needed. In cutting the two-by-fours remember that the walls are carried three feet above the ground. Formerly it was thought necessary to put a fill of rock or gravel as a foundation for the concrete floor. Experience has shown that better results are obtained without a fill, provided the bottom of the hole is clay or firm sand and gravel.

With the forms in place, mix the concrete for the floor of the pool-one part Portland cement to two parts sand, to four parts crushed rock. In measuring the quantities for each batch, consider one sack of cement equal to one cubit foot. Four parts of clean gravel (sand and pebbles) may be used instead of the sand and rock. Have the concrete just wet enough to form a little liquid cement on the surface when it is tamped into place. Begin laying the floor in sections, crosswise, at one end of the pool, in the same way as sidewalks are made. Reinforce the concrete two inches from the bottom with onehalf inch iron rods, spaced two feet in both directions. Use a wooden float to bring the mortar to the surface, and finish with a steel trowel.

Immediately thereafter begin on the side walls. For these walls have concrete mushy wet. Fill the one-foot wall space by depositing the concrete around 


\section{PRACTICAL BOOK OF GARDEN ARCHITECTURE}

the entire pool in layers of eight to twelve inches. If the top edge of the excavation shows a tendency to crumble, hold it back by means of a one-foot board braced against the wooden form. To prevent cracks due to changes in temperature, reinforce the concrete walls with two half-inch rods for every foot of height; one rod three inches from the inside, and the other the same distance from the outside of the wall.

As soon as the concrete has been brought to the ground level, set in place the outside forms necessary to give the walls a three-foot height above ground. See that these forms are plumb and perfectly level. In placing this part of the concrete run a flat spade or a thin wooden paddle between the concrete and the forms. This action will force back the stones, bring the mortar to the outside, and give the exposed surface a neater finish. When the forms have been filled to within six inches of the top, insert (through holes in the inside form) the five eightinch eyebolts which hold the "climb-out rope," encircling the tank. These bolts, fitted with nuts and washers, are eight inches long; so that they may be imbedded four inches in the concrete. Fill the forms, round the edges with a trowel, or with a sidewalk edger, and bring the top to a smooth finish by means of the wooden float and steel trowel. 


\section{OUTDOOR SWIMMING POOLS}

During the construction of the pool build the base for the spring-board at the deep end of the tank, and as a part of the wall. Dig the hole two feet wide by three feet deep by four feet long. With the onefoot thickness of end wall this will provide a base five feet long. As a means of holding a two-bytwelve-inch spring-board, set in the concrete (six inches from and parallel to each end of this base) two three-fourths-inch bolts, nine inches long and spaced thirteen inches, heads down and washered to a depth of seven and one-half inches. Iron cleats firmly bolted are used to hold the board down. For the protection of bare feet do not allow the bolt ends to project above the spring-board.

For at least five days protect the fresh concrete in the bottom by covering it with wet straw. Likewise cover the finished top of the side walls with wet canvas or old carpet. Carefully remove the forms after one week. Dress down the rough places in the concrete by rubbing them down with a soft brick, then after wetting, point up the corners and irregularities in the surface with a mortar mixed one part cement to one and one-half parts sand. Water may be turned into the tank immediately thereafter, but the spring-board should not be put in place nor used until the tank is one month old.

If steps are desired in the tank one flight in a 
corner of each end is sufficient. Make the steps of a width of two feet with riser and tread each ten inches. As a means of precaution for beginners in swimming, provide a "life-line" for the pool. For this purpose fasten a rope in the centre of one end of the pool and have it sufficiently long to extend outside the tank at the opposite end.

The following estimate of the quantities of materials needed, together with the cost, is based on the building of the pool by the owner, who buys all the material and employs the laborers without putting it in hands of a contractor-who would doubtless charge an extra fifty dollars:

Crushed rock, 54 cubic yards, at $\$ 1.10 \ldots \ldots \ldots \ldots \ldots \ldots \$ \ldots 9.40$

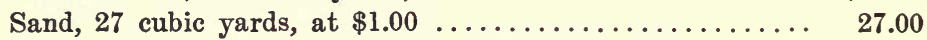

Portland cement, 90 barrels, at $\$ 2.00 \ldots \ldots \ldots \ldots \ldots \ldots .180 .00$

Reinforcement, 2,040 pounds (3,060 feet) of $1 / 2$ inch rods at

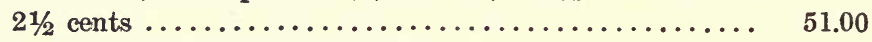

Labor, 1 foreman, 5 days, at $\$ 4.00 \ldots \ldots \ldots \ldots \ldots \ldots . \quad 20.00$

Labor, 5 men, 5 days at $\$ 2.25 \ldots \ldots \ldots \ldots \ldots \ldots \ldots \ldots .6 \ldots \ldots . . .6$

Labor, 3 teams with drivers, 3 days at $\$ 4.25 \ldots \ldots \ldots \ldots \ldots .38 .25$

Mechanical mixer, 3 days' rent at $\$ 5.00 \ldots \ldots \ldots \ldots \ldots \ldots . \quad 15.00$

Lumber waste, nails, bolts, etc., ............. 18.10

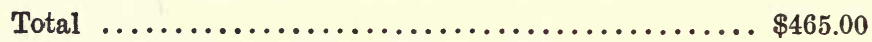

With these directions for guidance, it will not be difficult to estimate the cost of swimming pools of different sizes, when the water supply is already installed for other purposes. The same directions in regard to mixing, placing and reinforcing the con- 


\section{OUTDOOR SWIMMING POOLS}

crete will apply to the building of big fountain basins and lily ponds.

It is advisable to build only the swimming pool walls above the surface of the ground-to save expense in digging to the greater depth, and to protect from surface water. For the average garden pond the rim should merge into the sod or an ornamental border. Judicious planting of low climbers and trailing plants, close about the pool, will soon screen and beautify the high walls. 


\section{IX}

\section{GARDEN BATH HOUSES}

QUAINT RUSTIC SHELTERS AND HIGHLY ORNATE STRUCTURES ARE BEING BUILT IN HARMONY WITH THE ADJOINING SWIMMING POOL

ON landing at Hamilton, Bermuda, the visitor, who has been enjoying fascinating glimpses of fairyland in the blending of colorful sky and water, and green hills dotted with pure white houses, finds that the first view of the famous harbor includes many picturesque structures along the shore-among them the quaintest imaginable of bath houses. The private bath houses of beautiful old homes that have stood for a century or more, where the gardens reach out into the coves of Hamilton Harbor, prove a special attraction. They are usually built in circular or octagonal form, of the white coral rock dug from beneath the top soil of the garden. The sturdy platform, the side walls, and the roof are all of the white rock and white tiling that is seemingly indestructible, as it is encountered everywhere in the Bermuda Islands, in the old, old buildings as well as in the more modern types.

Among the beautiful estates in this English country of perpetual summer, set in mid-ocean, there 


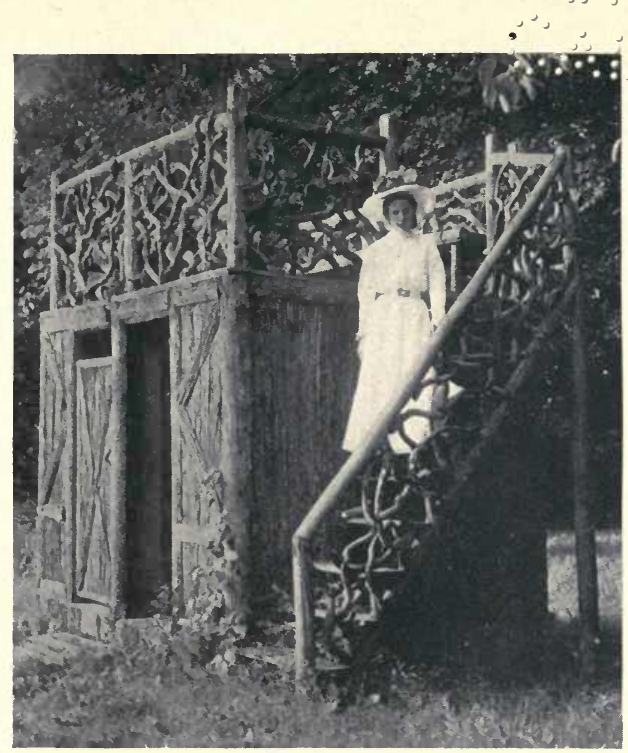

A RUSTIC BATH HOUSE WITH RAILED ROOF

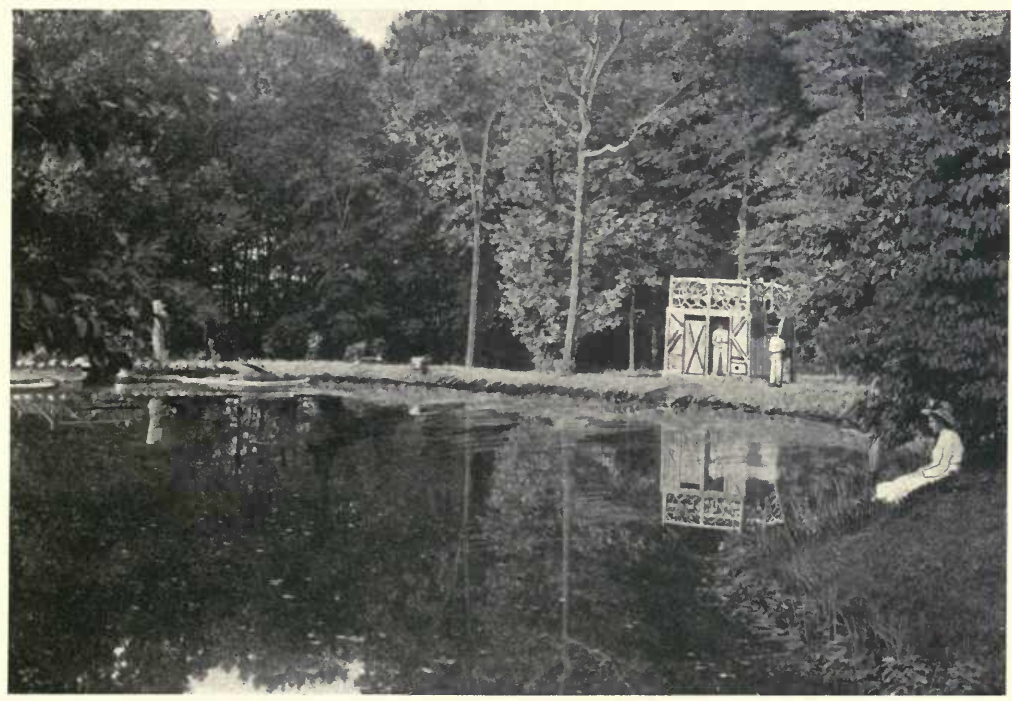

AN ATTRACTIVE BATH HOUSE SET AMONG LARGE TREES AT THE POOL'S EDGE 
$\because \vdots \quad \vdots \vdots \vdots \vdots \vdots \vdots \vdots \vdots \vdots$

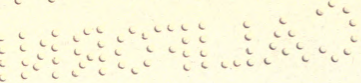




\section{GARDEN BATH HOUSES}

are elaborate bath houses flanking the private swimming pools where sea water has been piped into gardens gay with tropical bloom. Whether one studies the new types of elaborate bath-house architecture or the little old circular structures with conical roofs, the impression is the same-intense admiration for the people who know how to make the most of life by interspersing the daily duties with ample time for leisure; and who spend the greater part of their playtime in the most healthful form of relaxation - the enjoyment of swimming and water sports.

There are costly marble structures built on the edge of marble-lined pools that afforded sumptuous bathing places in the old Roman villas of Italy; and the visitor of to-day who finds that many of the beauties of the old gardens have been destroyed rejoices in the fact that the wonderful swimming pools and their architectural bath houses remain in a good state of preservation.

Along the Atlantic coast, in our own country, there are private bath houses of various forms where the sea dip can be made practical without patronizing the baths of crowded resorts, and without the inconvenience of journeying for a considerable distance from the surf to the privacy of the home for the change of clothing. Near the newer shore resorts 
it is not unusual to find these little private bath houses made a very decorative feature of oceanfront homes; though the swimming pool, in this instance, is the great sea. Where strips of woodland reach down to the water's edge, quaint little structures of logs provide the needed privacy for the bathers and fill every requirement, though the dressing rooms may be crude affairs, built at little cost.

Whether we study the fascinations of the Bermudian bath houses, the ornate structures of famous Italian gardens, or the types of recent construction along our coast lines, we find them, when appropriately built, teaching the same lesson of harmony with their surroundings, and making the most of the material at hand for their construction.

Until recent years the bath house as a garden feature has been unknown in this country. It is only among the coast resorts and seaside homes that we find them in general use. Even the swimming pool has not been so generally introduced among the water features of the garden and enjoyed as it should have been. We have not been slow in installing methods of enlivening and beautifying the home grounds with water; our efforts have been directed most frequently towards shallow lakes and ponds for growing water plants, rather than towards the deep pool intended for swimming. When finally 


\section{GARDEN BATH HOUSES}

the swimming pool began to grow in popularity, it was seldom accompanied by a garden bath house. It was thought to be sufficient to provide the pool, and surround it with decorative planting and sheltering arbors and pergolas. When situated far from the house, it could not be enjoyed by the household and their guests without the inconvenience of retiring to the privacy of the home in wet garments.

The garden bath house has changed all this, and now the really practical swimming pool is accompanied by commodious dressing rooms where the members of the family and all their friends can disrobe on reaching the sporting place, and where they can remove their wet garments after leaving the pool. For the garden planned for the enjoyment of children, rather than for mere display, the big bath house adjoining the swimming pool makes it possible for them to entertain jolly parties of neighboring children without "cluttering" the well-kept home with wet bathing togs.

A Wyncote lawyer was one of the first to recognize this necessity for suburban youngsters. One would not have supposed that a busy lawyer, with his time well filled during office hours, and a splendid country seat to occupy his leisure moments, could find time for this form of philanthropy-pro- 


\section{PRACTICAL BOOK OF GARDEN ARCHITECTURE}

viding a swimming pool and bath house for children who could not otherwise enjoy this luxury.

The visitor to his home, on one of the beautiful hill tops of Wyncote, Pennsylvania, is soon convinced that a master-mind has found expression in the development of every part of the estate. Especially is this evidenced when one reaches the broad lake on the sunny slope of the hill, at the back of the mansion. Here the fascinating stone-walled grotto, with its cold spring water and picturesque overflow, the rustic bridge with its stone abutments, the cement-capped walls, and the winding walks amid overhanging trees, display the many allurements of the modern garden with a natural water supply. There are other suggestions of delightful water sports in the plan of the lake, with its bath house and dressing rooms. There is a row boat at the water's edge, a raft and a life line for timid swimmers and beginners, and a well-planned flexible diving board for the experts. The depression which originally collected the overflow from the spring and drainage stream, to form a shallow lake, has been dug out to form a deep swimming pool with gradually sloping bottom, and walled up to retain a satisfactory depth.

"One would suppose that your beautiful estate would be overrun with boys, with such inducements 


\section{GARDEN BATH HOUSES}

offered for their enjoyment," was suggested by a visitor who had been informed that the neighborhood children were allowed the privilege of swimming there.

"Not at all! Not at all!" declared the philanthropic owner. "The great majority of good swimmers among the Wyncote boys had their early lessons in this pool. I have provided a convenient walk through the woodland sloping down from the lake. Here they may come and go at will, and although the bathing place is in view of the house, and amid the choicest of garden plants and shrubbery, they have never been known to abuse the privileges granted them, by appearing in the pool in objectionable garments, or by injuring the plants. No matter how noisy the crowd of joyous bathers, I never hesitate about taking my guests down to the swimming lake, for I know that I can depend upon the swimmers to observe the proprieties.

"I was deprived of such pleasure when I was a boy," he continued. "My great desire for a convenient swimming pool lasted throughout my boyhood days. There was no home pond at my command, and we boys were continually requested to move on when we attempted to enjoy a swim in public streams in our suburban section, no matter how carefully we selected secluded spots. Swim- 
ming with a crowd of boys-probably the greatest delight of childhood-was the stolen and forbidden pleasure of my youth; and I resolved that one of the features of an estate of my own should be a big, roomy swimming pool, with a convenient bath house and dressing rooms, where boys could enjoy to the full the sport which I was not enabled to enjoy during my own boyhood."'

With the garden bath house, girls as well as boys may become proficient in water sports; and every member of the family will be benefited by the openair bathing. The structure need not be an elaborate affair to have it extremely decorative. Rough cedar posts and bark-covered walls, with rustic stairs, will be most appropriate for the garden lake near a woodland or garden grove. With a roof only slightly sloping and covered with one of the rubberoids or tar paper, and with a high railing of rustic work, a dainty roof garden may be established where onlookers may watch the sports of the swimmers. Rustic seats should be built around the roof inside of the railing, and a level floor of slats, an inch or two above the roof, will provide a dry floor and keep the roof from being injured.

A combination of bath house, tea room, and pergola forms a decorative feature on many beautiful estates. The cost need not be excessive. The genius 


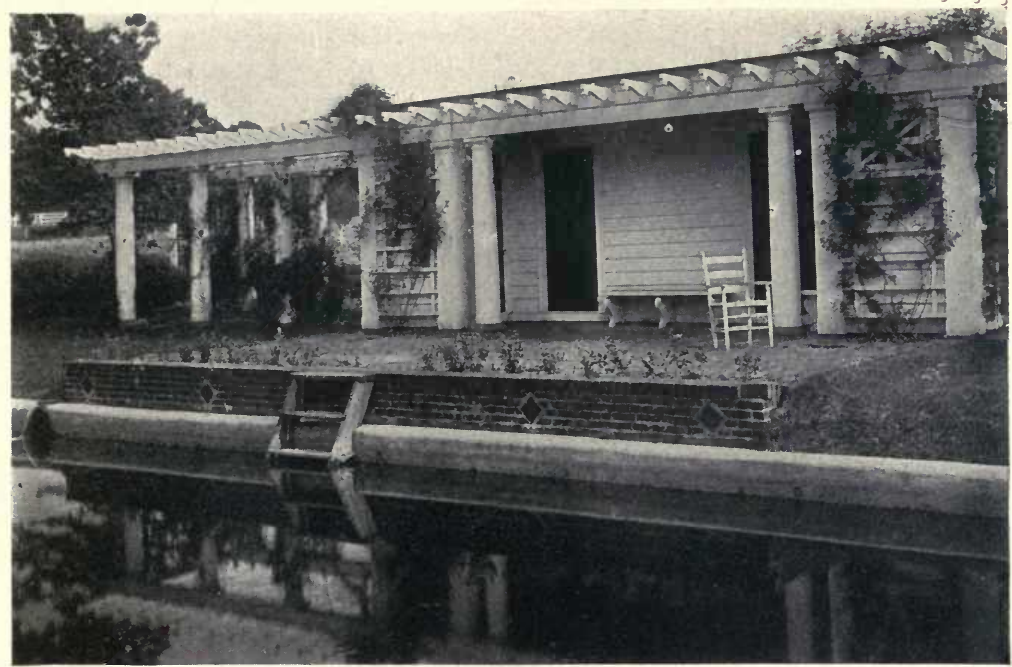

A BATH hOUSE WELl SITUATED AND REFLECTED IN THE POOL

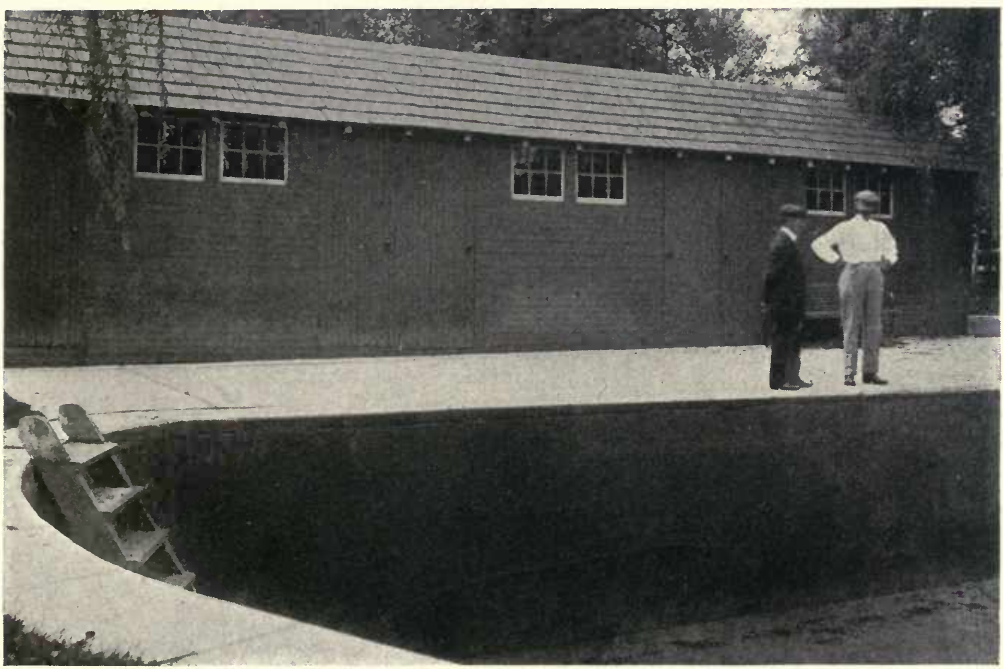

A LONG BATH HOUSE WITH SIX DRESSING ROOMS AT "SPRING DELL FARM" IN THE WHITEMARSH VALLEY 


\section{GARDEN BATH HOUSES}

of the architect is the secret of the charming conception. On the Bethlehem Pike, the Kolb estate, known as "Kathaleen Farm," displays an interesting bath house of this type. A rectangular concrete pool of spacious dimensions has an ideal situation on a slight elevation of the beautiful grounds, at some distance from the old mansion. A cluster of decorative planting and fine old trees provides an appropriate background for the picturesque structure extending the entire length of the pool. For a hundred feet or more the white pergola, with its stately columns and ornamental roof beams, supports a luxuriant growth of climbing roses, climbing up decorative strips of square lattice, and twining around the columns. In the centre of the pergola stands a bath house of good dimensions, divided into several rooms, and possessing every convenience of a modern dressing room. Between the bath house and the swimming pool, under the shelter of the pergola, is a broad expanse of brick-tiled floor, where tea is served to the guests, beneath the overhanging roof of the vine-shaded pergola.

From the elevated floor of the tea room, steps lead down to the pool and out into the water. Because of its prominent position, it has been necessary to have this bit of garden architecture as attractive at the back as in front. Four quaintly decorative windows 


\section{PRACTICAL BOOK OF GARDEN ARCHITECTURE}

admit air and sunlight to the four dressing rooms on this side, and the ventilating openings in the doors at the ends of the house are of the same pattern. The entire back of the building is attractively trellised, the luxuriant growth of green climbers contrasting well with the white lattice work. The long pergola extensions at each end are so closely screened with ornamental planting that these also make ideal tea rooms. The suggestion of gracious hospitality, the delight of water sports, and the conveniences of modern equipment in dressing rooms, make this entire conception an ideal feature for garden ornamentation.

There is a similar combination, including pergolas, tea room, bath house, and well-furnished dressing rooms, at "Rippowan," the country place of Mr. Jonathan Bulkley, at Ridgefield, Connecticut. The arrangement presents another idea, however, and one that readily can be carried out in many gardens. The pool, which is of spacious dimensions, with a slope of three feet deep at one end to ten at the other, is placed in a splendid garden court, screened on each side with tall trees and its architectural embellishments. At one end is the combination bath house and tea room, and extending along both sides of the pool are the long pergolas, similar in design, and forming an ornamental wall for 


\section{GARDEN BATH HOUSES}

the pool, with broad shelter and convenient seats beneath the latticed and vine-draped roofs.

In Ghent, the quaint old Flemish city of Belgium, there are bath houses and accessories of famous swimming pools that have been eagerly reproduced in this country. The designs are the work of Mr. William De Vos, of Ghent, and they are typically continental in their general layout and arrangement. In these designs the large open space is surrounded by a gallery or promenade. And the gallery, which is supported by Ionic columns, is attractively roofed or covered with vines. The dressing rooms on each side of the pool are within these galleries, and decorative seats complete this ornamental adjunct of the swimming pool. The general plan of these more elaborate types may readily serve as suggestions for building inexpensive bath houses, with pergola screening instead of galleries. 


\section{$\mathrm{X}$}

\section{WATER TOWERS AND GARDEN DENS}

THE WATER SUPPLY OF THE COUNTRY HOME MAY PROVE AN INSPIRATION AS WELL AS AN ESSENTIAL

The storage reservoir, and the gasoline engine or hydraulic ram, or other practical means of supplying plentiful water for kitchen and bath and grounds of the big estate or the modest country home, may all be made to contribute to the decorative and architectural effect of the place by means of attractive water towers. Occasionally one finds a fac-simile of the poetic old oaken bucket on modern estates. The ancient appearing well-curb, the genuine old oaken bucket, worked by the typical old-time rope and weighted pole, may preserve all the romance of the original farm home of long ago. It may even form a useful purpose; and the quaint "well-sweep" may include a well of good clear spring water; but it will naturally be constructed in this form for romantic beauty, for calling up delightful memories, or for mere show. In these practical days of inexpensive engineering it will not be expected to contribute greatly to the water supply of the home, the gardens and the live stock.

The services of a garden architect and an expert 


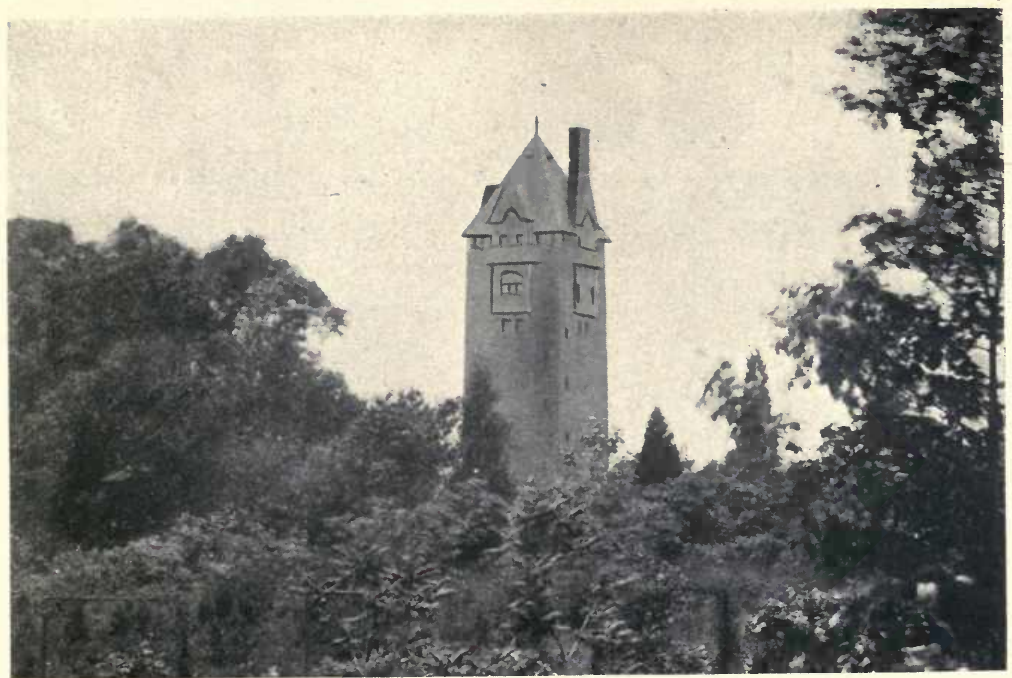

THE FAMOUS WATER TOWER ON THE ALDRICH ESTATE, ROCKY POINT, RHODE ISLAND

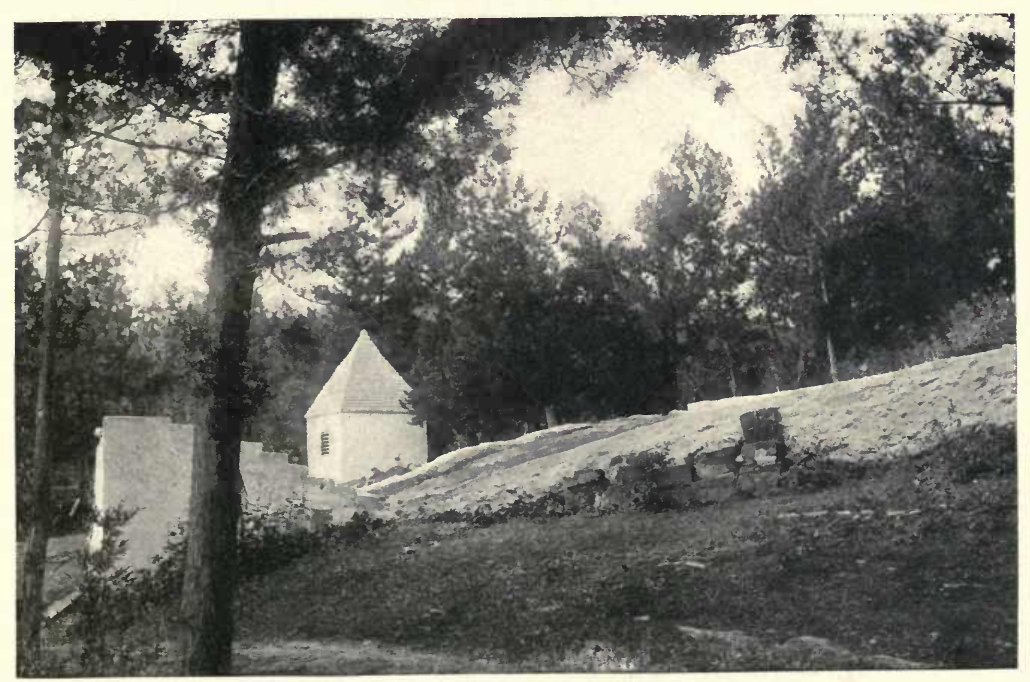

A BERMUdA WATERSHED, CISTERN, AND TOWER 
$40 \quad$ and

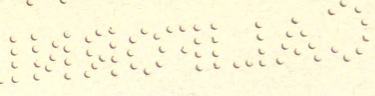




\section{WATER TOWERS AND GARDEN DENS}

engineer may be required to make the water supply satisfactory for some big estates where the architectural features are arranged on an extensive scale, and where there are certain difficulties to encounter in making the water supply adequate for all purposes. Many attractive suburban homes, on the other hand, show quaint and beautiful water towers that are architectural achievements, at the price of a bit of ingenuity on the part of an amateur craftsman, assisted by a local carpenter and stone mason. And the abundant water forced into the tank of the receiving tower will also be supplied at little cost by the practical ingenuity of the same handy man, who has made a study of the simplest form of pumping engines.

A few years ago it was customary to find the water supply tank of the country or suburban home (out of the reach of the city supply) placed in the garret, or an upper room of the dwelling house. There is always more or less danger of leakage and overflow, and other injury to the house. Some housewives also object to this arrangement because of possible dampness. In any case it is not advisable to have the storage tank in the upper room of the house if it can be avoided. Its place is in the garden, out of the reach of possible harm from dampness or leaking. The necessity of having it elevated to 


\section{PRACTICAL BOOK OF GARDEN ARCHITECTURE}

tower-height, to have the tank in position to supply the upper rooms of the home, will immediately suggest a building that will prove an attraction to the house surroundings. It need not necessarily be expensive, but at least it should be picturesque, and many unusual structures are encountered in the study of water towers.

Before deciding on the architectural scheme of the tower or supply house (whether it shall be quaint and rustic or of stately, costly masonry) it will be important to study the means of securing the necessary force and supply of water to meet all the demands of the home and the grounds. In hilly sections, where springs abound, there is little difficulty in solving the problem. Location and environment combine to make it possible to install the simplest form of "power" - that of pressure supplied by gravitation. In this case the spring selected to afford the house and grounds an adequate supply of pure water must be on a hill as high as the house. Or, on the other hand, the house must be built on a lower slope of the hill when the question of water supply is being considered during the process of building. After being assured of the purity of the water, supplied by the spring with a copious flow, it is simply necessary to build a reservoir between the 


\section{WATER TOWERS AND GARDEN DENS}

spring and the house, lay the pipes and allow gravitation to do the rest in the process of distribution.

When the house and the spring or brook are not so satisfactorily situated, it will be necessary to supply means of pumping the water to the right height to effect proper distribution. The windmill has long been depended upon for country and suburban homes for the watering of stock and supplying the house where the demands are not great; but, as the wind cannot always be depended upon to afford sufficient power at the time when it is most needed, other forms of pumping are carefully considered.

The various engines run respectively by gas, gasoline, hot air, steam, and electric motor all have their good points, according to the environments of the home and the source of the water supply. The hydraulic ram is one of the simplest methods of solving the problem; but, like the pressure by gravitation, it demands special conditions, in this instance it being required to have a stream of running water near the house, or some means of damming up spring water to supply the power, as the ram is entirely automatic in its action. When it is possible to obtain from the water of the stream the energy necessary for its operation, the hydraulic ram will prove to be the most economical means of obtaining 


\section{PRACTICAI BOOK OF GARDEN ARCHITECTURE}

a dependable water supply, as it will require no fuel for its power.

When one of the various engines must be employed one has the advantage of pumping the water direct from a good well. An artesian well, driven through earth and rocks to a deep source of supply, until water is procured that is pronounced chemically pure, will give the best results; and the type of engine best for pumping it up to the supply tank will depend on the situation of the home. When one resides in a district covered by a company distributing the electric current, or near a trolley line where arrangements can be made with the management for the necessary power, an electric motor will probably prove to be the simplest apparatus to operate. The best plan in this case is to install a water pump of centrifugal form. When directly connected to a small electric motor this pump can be operated at a comparatively high efficiency, and it can be depended upon for instant service, at the same time being clean and compact. Its cost and maintenance will not be prohibitive if good judgment is used in making arrangements at the source of supply. The wise householder will secure low rates by arranging to do his pumping at an advantageous time, when special demands are not required of the electric current for lighting and other purposes. When modern 


\section{WATER TOWERS AND GARDEN DENS}

safeguards are taken advantage of to avoid all possible danger in dealing with the powerful electric current, and the home is in the right section to maintain the motor to the best advantage and the least expense, this will be decidedly the best form of power for the house and grounds requiring a big storage tank.

The requirements of installing a gas engine, like that of electric power, will depend greatly upon location. In country places, out of the reach of city gas, it may prove too costly to manufacture it for private use, and a more simple arrangement for supplying power will be resorted to. When within reach of the city supply the cost of one dollar per thousand feet will make the gas engine too expensive. Where natural gas is available, for thirty cents or less per thousand cubic feet, economic conditions will be at their best, and the gas engine will doubtless be very readily decided upon in these districts.

The gasoline engine is the good old standby where gas engines and electric motors are out of the ques. tion, and lack of pure springs and forceful running streams make gravitation and the hydraulic ram practically unavailable. Now that the very general use of gasoline for automobiles in all parts of the country has demonstrated its dependableness, and taken away the old fear of possible explosion, its 


\section{PRACTICAL BOOK OF GARDEN ARCHITECTURE}

economical use under proper care is widely known and appreciated. The pumping of water to the height of the largest tank or reservoir is very simply accomplished by use of one of these small engines. It has an additional advantage in being so simple in operation that it can be started and stopped in a few seconds' time. This not only effects a saving in the cost of the fuel but also in doing away with the necessity of employing skilled attendants-the small boy of the home being able to stop or start it at will-and there is a decided point in its favor in the fact that this form of engine costs nothing when it is not working; and the working time is short for pumping enough water to fill a large reservoir. The first cost is also slight compared with some forms of power; as an engine can be installed for from eighty-five to one hundred and fifty dollars which will give good service for many years. Engines at the low cost of eighty-five dollars under proper management will pump one thousand gallons an hour from a well twenty-four feet or more in depth, to a tank situated at least eighty feet above the well. Another advantage lies in the fact that the gasoline engine used for pumping water may also serve other home requirements as a source of power.

The hot-air engine is another of the dependables which will not require special conditions of location 


\section{WATER TOWERS AND GARDEN DENS}

for working it to advantage. It is an old and welltried device, and a point in its favor not applicable to other forms of supplying power, is that it can be operated with any kind of fuel that is most convenient, from wood and inflammable refuse to gasoline and alcohol. This form of engine is especially economical for small installations, for it not only gives a choice of the cheapest fuel, but it has the advantage of not requiring expert and expensive attendance.

Mr. John F. Springer, in "Country Life in America," says, concerning hot-air engines, "there are, in one of the most prominent types, two vertical cylinders in which pistons move up and down. In the one, air is compressed; in the other, compressed air is heated. The compressed air finds its way from the compression cylinder into the heating cylinder through a device known as a regenerator. The effect of heat on the compressed air is to give it great expansive power. This expansion is what drives the engine. The heating is done by means of a stove enveloping the heating cylinder. The stove may be run by kerosene, gas or anthracite coal. An idea of its expense can be gained from the following estimates of the makers: An engine able to lift three hundred and fifty gallons per hour to a height of fifty feet will consume twenty cubic feet of gas, two 


\section{PRACTICAL BOOK OF GARDEN ARCHITECTURE}

quarts of kerosene, or three pounds of anthracite coal per hour. An engine able to lift ten times as much water to the same height, in the same time, will consume one hundred cubic feet of gas, five quarts of kerosene, or seven to eight pounds of anthracite coal per hour."

This gives a fair estimate of cost, which varies but little with other forms of fuel. In some of the old forms of hot-air engines there was difficulty in obtaining the necessary vacuum for raising the water to the required height, when pumping from an artesian well to a tank from forty to fifty feet above the source of supply. To overcome this difficulty, one model is so arranged that the pump itself is placed on a long rod, thus making it possible to operate it much nearer the surface of the water than the usual location of the engine would permit. The usual location, by the way, for the hot-air engine is in the cellar, the barn, or some outbuilding or a small power house. An engine of this sort need not require any attention beyond the supplying of fuel at proper intervals during pumping, it will practically last a life-time with little cost for repairs and is suitable for keeping the water tanks well filled in the most remote country districts.

When the steam engine is used, as another solution of the water power problem, the working of the 


\section{WATER TOWERS AND GARDEN DENS}

pump, the filling of the water reservoir and other demands are done in the same manner as with the other engines. The pneumatic tank system need not be considered where the means of supply relate to the filling of the tower tanks elevated at some distance from the ground and serving as a decidedly ornamental garden feature in connection with their usefulness. In the pneumatic system no elevated tank is required, as it can be situated in connection with the pump and engine in the cellar or barn or in any out-of-the-way place where there is little danger of freezing. This is the system as it was explained to me when I gave it thorough investigation: "The pressure is obtained by forcing the water to be used into a heavy steel tank having no air outlet. As the water is pumped into this tank the air is compressed in proportion to the increase in the volume of water. The service water outlet is at the bottom, and the tank is so designed that the pressure is sufficient to raise the required amount of water to the desired height as needed." There have been some complaints of this system because of possible leakage; unless an expensive tank is used that has been very carefully manufactured by skilled workmen, it will prove a difficult matter to construct an air-tight tank that will not leak when the contained air is crowded into a continually decreasing 


\section{PRACTICAL BOOK OF GARDEN ARCHITECTURE}

space as the amount of incoming water grows greater. For supplying the high tank or reservoir, however, which in turn is to be situated in the high tower, serving as an architectural achievement in beautifying the home grounds, any one of the many inexpensive forms of supplying power will give satisfaction at comparatively small expense. Just how small the cost may prove a surprise to many who have not given the subject careful consideration, and who have accordingly refrained from establishing this very essential source of comfort in the home. The expert who has given me the following figures knows what he is talking about, even though the few cents per day for fuel and oil will prove a surprise. "One horsepower expended for one hour will easily raise one hundred gallons of water to a height of one hundred feet; and as half that distance furnishes enough pressure for the ordinary country house, two hundred gallons would be available at the end of an hour's pumping. This is a sufficient amount for the daily domestic use of an ordinary household; and in this manner an ample water supply could be obtained for a small family at a cost not exceeding three or four cents a day for fuel and oil, plus the proportionate cost of installation, attention, housing, and wear and tear. The height to which the power would be raised is taken as the distance 


\section{WATER TOWERS AND GARDEN DENS}

from the surface of the main supply to the top of the tank." With such facts and figures there need be no hesitancy in seriously considering the supplying of any home with water for the entire house and grounds and live stock, no matter how remote from "city conveniences" is the farm home, the suburban estate, or the summer cottage.

When once assured of the most practical means of keeping the big tank in the water tower well supplied with water, there may be a wide range of fancy in deciding upon the best architectural plan for making the erection of the tower-house contribute to the beauty of the home surroundings. A study of illustrations of typical designs will convince one that they may be even more varied than the practical sources of supply. There is a special advantage in the construction of a building of good height and beauty. Not only will the height be required to supply water to the upper rooms of the house, but as only the highest or third-story section of the tower: will be required for the tank or reservoir, the second floor is available for an ideal work room, or "den," or an artistic or literary workshop. The first floor of the tower building may serve the same purpose of supplying a place of retirement for brain work, away from the confusion and social distractions of the home; or it may serve a decorative purpose, as a 


\section{PRACTICAL BOOK OF GARDEN ARCHITECTURE}

pergola extension, or open-air retreat, when it is not desirable to have it enclosed.

In Bermuda, where rain water must be depended upon for drinking, the pure white tank houses and the spacious expanse of white surfaces spread over the hill sides form one of the most interesting "sights" of this fascinating group of islands. Not only are these charming houses and their roofs built of the white coral rock of which the islands are formed, but they are also whitewashed at very frequent periods, to keep them free from dust and impurities, as the rain water collected from the roofs of the houses furnishes a portion of the supply. In addition to this any home or estate of good size has its water-plant. Over a broad expanse of hilly garden will be constructed a rocky or concrete surface, kept immaculately white and clean, from which the dashing rains of these tropical islands are collected in great quantity. The white surface for collecting the water, as well as the pipes from the house roofs, all lead to big cisterns and water tanks. The rain water, after undergoing a special system of additional purification in the cistern, is pumped up into the tank or reservoir, from which it is piped to the houses and farm buildings. Many of these high tanks are built in tower and pyramid form, and from balconies reached by outside stairs the tourists 


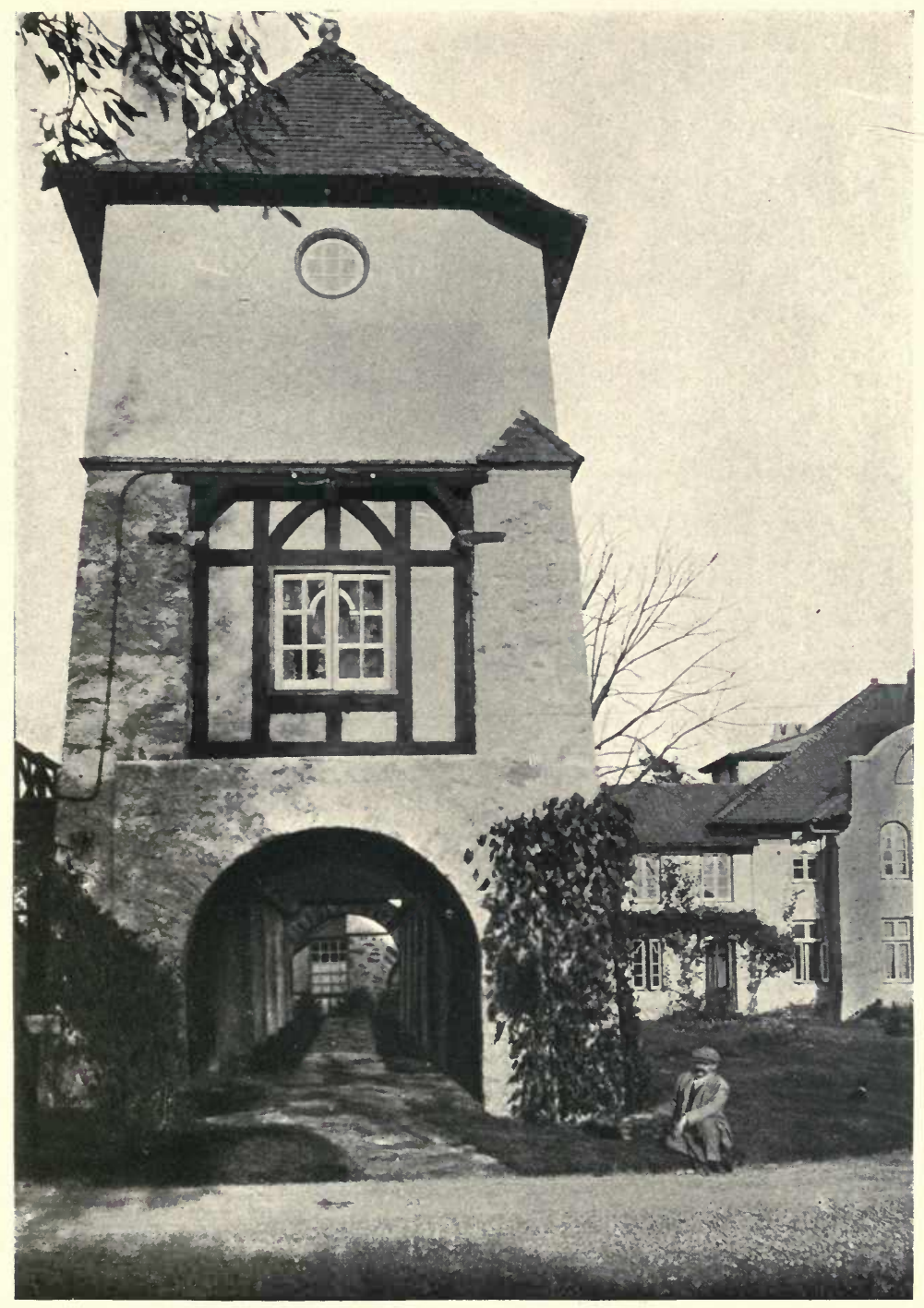

WATER TOWER AT “ROSE VALLEY FARM," THE HOME OF MR. CHARles T. SCHOEN, MOYLAN, PENNSYlVANIA 


\section{WATER TOWERS AND GARDEN DENS}

can obtain entrancing views of the islands and secure many excellent ideas for the treatment of water towers at home.

A well-planned tower with good types of interior rooms on the first and second floors, and a broad balcony extending around the tank room of the third floor, is found at the charming home of Mrs. B. H. Gilbert, at Great Neck, Long Island. This structure presents a massive appearance, as it is finished in stucco; and this is especially fitting as it supports a great tank having a capacity of from fifteen to twenty thousand gallons at an elevation of about seventy feet. The height and massiveness of this tower have appropriate surroundings among fine old trees and being well elevated it supplies a good flow to the upper rooms of the mansion. A picturesque stairway built of stucco leads to the balcony outside one of the second story window-doorways, making the look-out tower private and secluded without an entrance from the ground. This is an ideal plan for the literary den or studio, for which tall decorative towers of this type are especially fitted.

Another excellent example of a beautifully constructed water tower has been designed by a capable architect for the Rose Valley Farm of Mr. Charles T. Schoen, at Moylan, Pennsylvania. Under the wise guidance of the expert this has been made a part of 


\section{PRACTICAL BOOK OF GARDEN ARCHITECTURE}

the general architectural scheme, and in harmony with the mansion and outbuildings of the estate. The first floor of this structure is an open-air rest room, with four great arches admitting light and air. The second floor provides the ideal tower room; and in the great third-floor space the water tank is enclosed by massive stone and stucco walls, and finished with a conical roof. The stone-arched rest room gives entrance to a shady pergola with heavy concrete columns leading to the side entrance of the mansion.

Built in harmony with modest little suburban homes there are many rustic forms in which the tank is securely supported at the right height to provide water to the upper rooms, with designs in lattice or trellis walls forming open-air rooms at little cost. Towers built inexpensively of the field stone found on the place, or of rough brick, are well covered with ivy, which provides perpetual beauty of green drapery without further care, when once started.

In the tropical sections of southern Florida there are many charming types of garden towers in which big tanks hold the ample supply of water demanded in this section, and the space beneath is utilized by building cool, airy, open rooms, in the midst of the orange and grape-fruit trees. One of the massive 


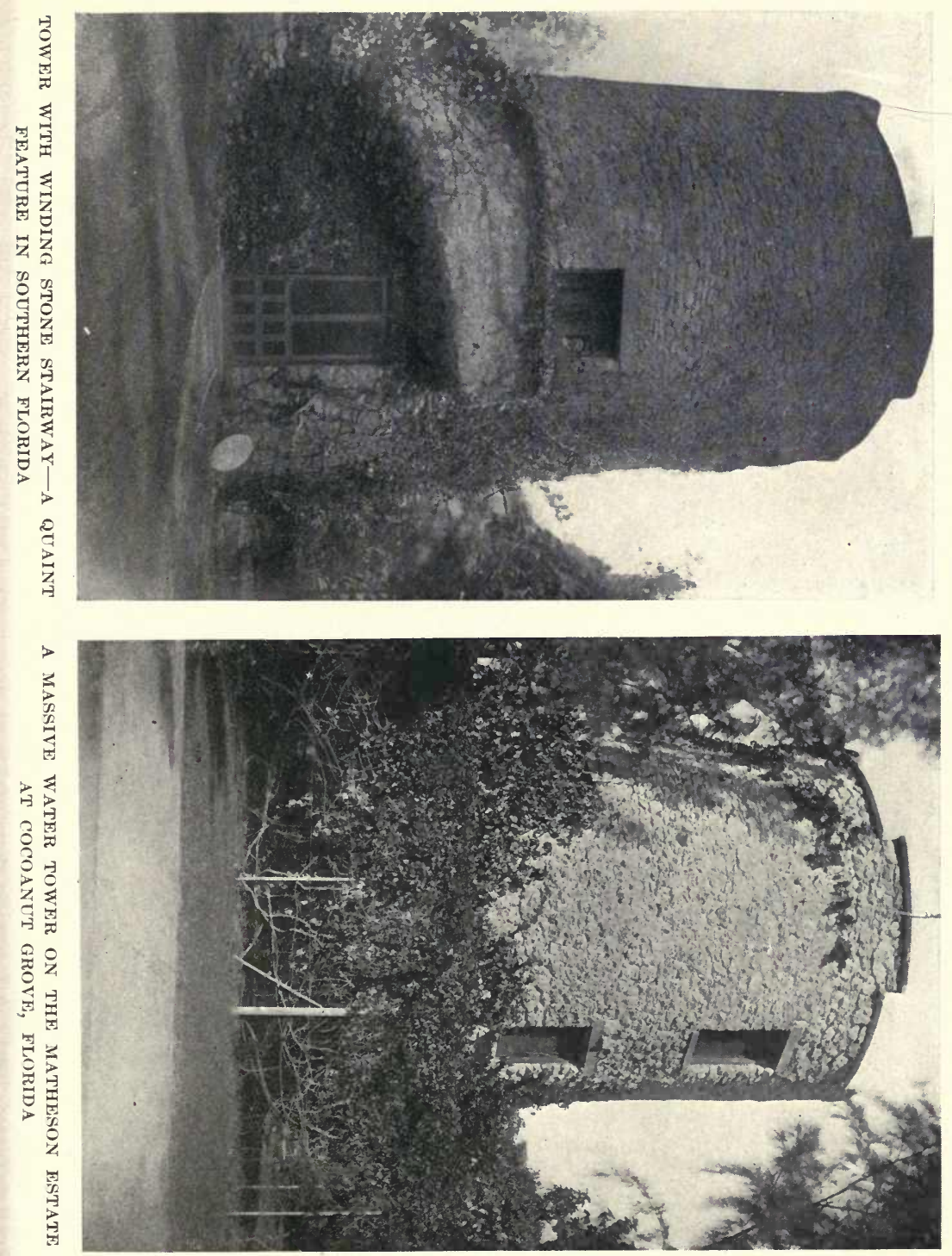




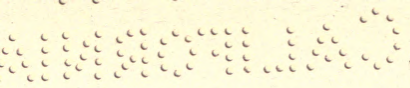




\section{WATER TOWERS AND GARDEN DENS}

castle-like designs is found on the Matheson estate, "Swastika," at Cocoanut Grove. Here the entire structure is built of stone, in cylindrical form, with quaint castle-like windows piercing the thick stonework, making the interior cool and secluded on the hottest days, the heavy masonry excluding the heat of the tropical sun. An outside stairway leads from the ground to the upper rooms. It is picturesquely built, with steps and balustrade-wall of stone and concrete, and winds in spiral fashion around the tower. 


\section{XI}

\section{DECORATIVE WINDMILLS}

\section{HOW THEY MAY BE MADE TO GIVE DISTINC- TIVE CHARACTER TO SUBURBAN PLACES, AND HOW SATISFACTORY TANKS MAY BE BUILT}

A PRACTICAL knowledge of tank requirements, and a good fund of ingenuity in changing the usual tall and unsightly windmill into a picturesque structure, are important adjuncts in the decoration of the home grounds. It is true that the windmill has fallen into disfavor in many sections where other forms of supplying water have been installed; but it sometimes happens that the windmill erected for the purpose of pumping water from an artesian well is found to be the best possible means of insuring a dependable supply of fresh, pure water to all parts of the house and outbuildings.

Where the windmill is a necessity, it is wise to turn it into an object of decorative value instead of deploring its ungainly appearance. Quaint devices for utilizing the different portions of the structure offer some interesting studies, and convince us that utility alone does not suffice in the planning of the "garden beautiful."

The roomy enclosure at the base of the tall sup- 


\section{DECORATIVE WINDMILLS}

ports may be fitted up as a playhouse for children, or as a spacious tool-house or garden storehouse. Then the decorative possibilities of the exterior call for special ingenuity. It sometimes requires a touch of genius to give character to the entire home surroundings. Experienced architects claim that a suburban home with a distinctive character of its own is difficult to find. Among the hundreds of houses that one sees in a day's travel through the country, the great majority make but slight impression-they are seen and forgotten. Perhaps out of a hundred homes, ten will catch the eye and impress one with their unusual features, while only one or two will appeal to us as homes of real distinction-homes in which the dwelling house and all its grounds and accessories are the result of a gradual, beautiful growth rather than mere piles of brick and mortar, with the regulation walks, shrubbery, trees, and garden buildings. The majority of the windmills shown in the illustrations are typical of distinctive thought in producing an attractive whole, while utilizing all available space required in their construction.

Special flower planting about the base is a decorative feature where the iron supports are not enclosed. An attractive design shows the entire ground floor planted with different varieties of Japanese 


\section{PRACTICAL BOOK OF GARDEN ARCHITECTURE}

iris, with the great rectangular bed outlined with a thick, showy edge of blooming nasturtiums. Ivies and climbing euonymus provide perpetual greenery for the supports. The base of another mill provides an ample playhouse enclosure, with a garden reading room and studio above; and, being well set up from the sloping ground on one side, it is supported by picturesque rough stone foundations. This stonework forms a floral rockery and drainage canal for draining the sharp incline of the garden terrace.

The mill of the "rustic" type has a roomy double house at its base. One part is fitted up as a charming playhouse for the children, while on the opposite side of the structure is a place for storing garden tools. The convenience and attractiveness of the interior finish of this triple-duty windmill are apparent as soon as one sees the well-arranged rooms. But the exterior finish is even more appealing, from a decorative point of view; for it is arranged on the slab-bungalow plan, so popular for little summer cottages in wooded sections. The fact that this particular finish was adopted here is typical of the keynote of the entire estate-harmoniousness. Back of the windmill, which is set in a secluded part of the garden, there is a fine old wood, reaching far down the hill slope to the lower section of the estate. The bark-covered, slab-decorated windmill rooms seem 


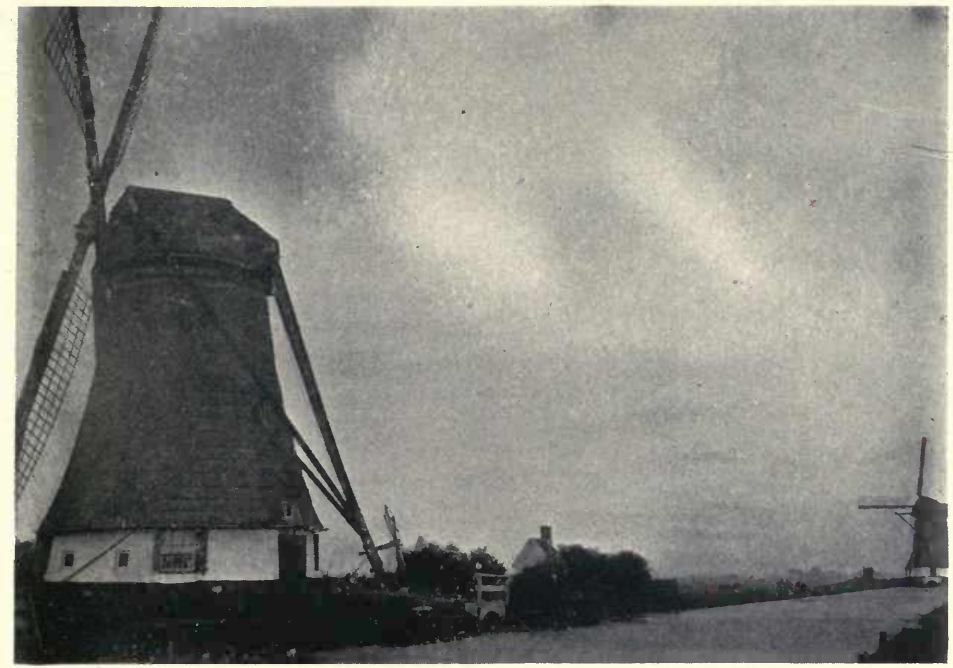

A QUAINT HOLLAND WINDMILL ON A ROTTERDAM DYKE

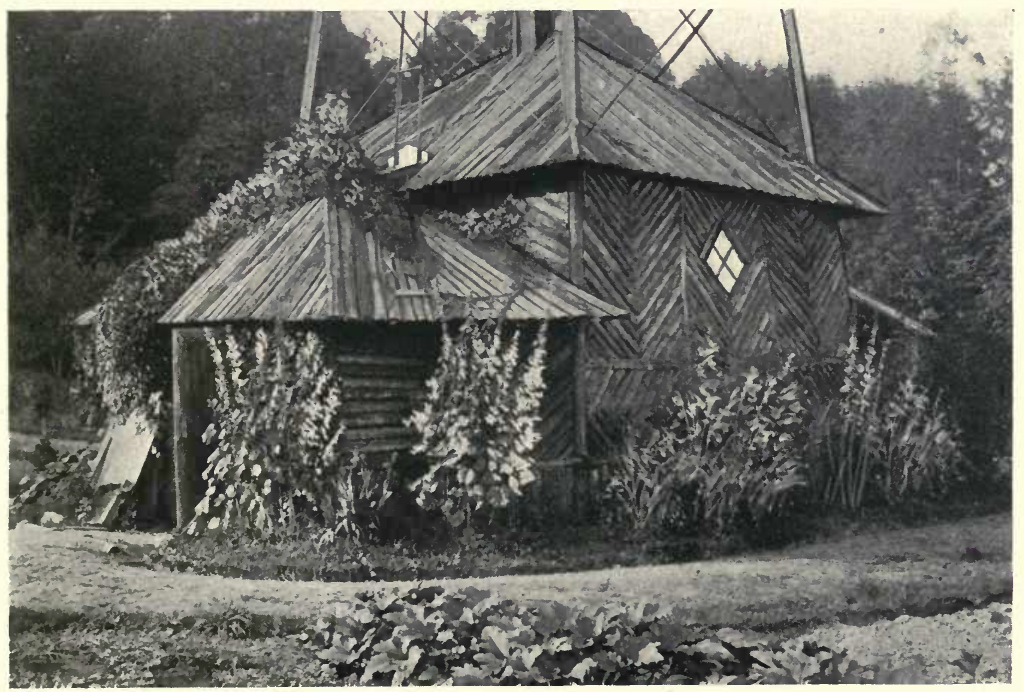

A Charming Playhouse fOR the CHILdREN bUILT at THE BASE OF A WINDMILL 
$\because i y \quad \because i_{i} i_{i} i_{i}$

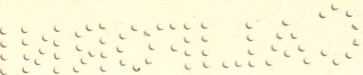




\section{DECORATIVE WINDMILLS}

an alluring part of the woodland; whereas a more conventional type would have lost its charm by being out of harmony with its surroundings.

This slab-finish for garden buildings has become exceedingly popular where the surroundings make it effective. Slabs with the bark left on are the most desirable, as they produce the rustic effect of a log house, at much less expense than logs. When used for cabin or playhouse construction, the walls are usually double, the slabs being nailed to both sides of the studding, and the cracks filled with a mortar made of lime and cement. For constructing the windmill room only the outside wall is slab-bound, with the roof showing the same rustic finish.

When the slabs are cut from chestnut logs, they are of permanent value, and the bark is retained without difficulty. If the bark edges have become roughened, a slight tacking in place may be necessary during the construction. After the slabs are prepared at the sawmill-being trued on one face and both edges, leaving the other face with the bark on-they are nailed to the sheathed wall of the building in quaint Japanese style, forming designs in triangular fashion. The roof slabs are laid on plain and straight, without any attempt to form patterns, the main feature here being the prompt shedding 


\section{PRACTICAL BOOK OF GARDEN ARCHITECTURE}

of water. An under roof, or special chinking, is required for the water-tight finish.

Objections are sometimes made to this popular rustic slab finish, the most common fault found being that the bark will eventually crack and dry on the slabs and become unsightly. But it must be kept in mind that the slabs will continue decorative even after this occurs. So long as the bark remains intact, the log-cabin effect will be charming. After it begins to crack and peel to such an extent that it becomes objectionable it can readily be stripped off, and the slabs beneath will be found to produce the same rustic effect and will become "weathered", to a soft gray. In order further to preserve them, the slabs may be painted in dull green or brown, without destroying the rustic effect.

The spring-house design is another device for utilizing the base of the windmill. With a great square room of rough stone-work, the thick walls pierced with a doorway on one side, and a window in the opposite wall, the enclosure presents a staunch, old-time, spring-house suggestion that is not only pleasing but useful. A flight of stairs on the outside leads to an upper floor of roomy construction, well lighted by windows. Above this second-story room, the tall windmill has its heavy supports enclosed with neat weather-boarding throughout its 

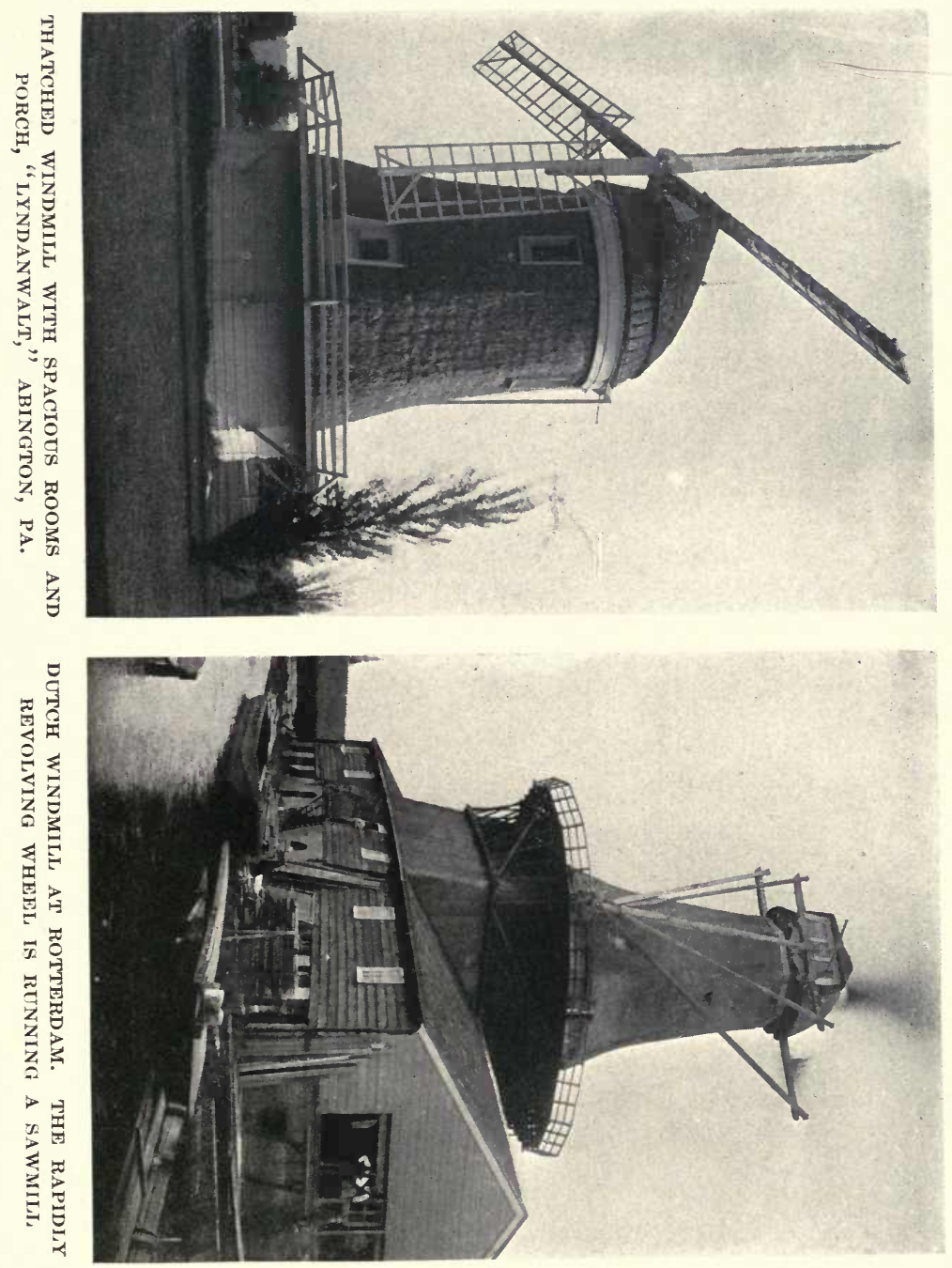


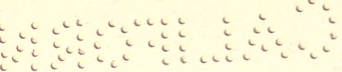

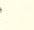

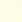




\section{DECORATIVE WINDMILLS}

entire height, surrounding an inner stairway for climbing to the wheel.

Quaint and beautiful types of Holland windmills are frequently found on American estates in these days of extensive travel and the desire for introducing old-world garden accessories. The Holland windmills invariably have a great, circular outside platform about half-way up the roomy enclosure, and the window-pierced walls reach to the top of the mill, which is surmounted by a great dome and lookout tower.

Thatched windmills of great decorative value are distinctive features of various suburban sections. Dutch, Scottish, and English types of thatching are carried out in unique designs, some of them covering sides as well as roofs, like that of the "Lyndanwalt" estate at Abington, Pennsylvania. The attractive exterior of these thatched structures suggests an equally artistic interior, and one is not disappointed on viewing the spacious rooms, well lighted from the long windows set deeply in the thatched walls. The immense circular platform surrounding the mill near its base serves as a roomy porch. It is securely railed, of course.

In order to have the windmill practical as well as decorative, it requires special study of tank construction and piping. As the wind power cannot al- 


\section{PRACTICAL BOOK OF GARDEN ARCHITECTURE}

ways be depended upon to afford a satisfactory water supply, it will be necessary to have a tank large enough to store a quantity for use in emergency. The big water tank may be at the top of the windmill, or in the house or barn. No matter where it is, it must be so arranged that the bottom will be sufficiently elevated to distribute the water freely to all parts of the house. To have the tank sufficiently elevated, and of satisfactory size and strength, to supply water for a large country estate may prove a difficult problem. In order to realize just how serious this problem may be, I will state the facts and figures given to me when I consulted an expert authority.

The water which fills a ten-thousand-gallon tank weighs eighty-three thousand pounds. Ten thousand gallons for a family (and stock), using five hundred gallons a day, will last only twenty days. The support for eighty-three thousand pounds must, of course, be an adequate one. In every case the total weight of water and tank must be provided for. As to the strength of the tank, we have to remember that water exerts a bursting pressure tending to disrupt the side walls. This pressure ranges from nothing at the water level to a maximum at the bottom. If the bottom is ten feet below the level of the water, there will be a bursting pressure outward 


\section{DECORATIVE WINDMILLS}

at that point of four and one-third pounds a square inch. A consideration of such facts will show that the tank must be strengthened to resist the outward impulse, and that the strength must increase toward the bottom.

The tank may be of wood, steel, or reinforced concrete. When it is of wooden staves, the metal hoops may be provided with turnbuckles, so that they may be tightened at will. The hoops may be placed closer and closer together toward the bottom, to give additional strength. The concrete tank is the favorite, where it can be placed out of danger of freezing. A thin coating of ice will not matter for any sort of tank; but in cold northern climates, where it is desirable to keep up a satisfactory supply of water for the house throughout the winter, special care must be given to the location of the tank. If it is within the house, there are easy and practical methods of insuring its safety from freezing; and even in cooler locations it may be rendered "safe" by surrounding it with sawdust, or tan bark, or the material most recommended by the experts who have given the subject special study in the locality in question.

When the tank is placed at the top of the windmill and surrounded by a tight, warm enclosure in tower design, its elevation in regard to giving an 


\section{PRACTICAL BOOK OF GARDEN ARCHITECTURE}

adequate supply of water to the highest rooms of the house will be readily solved. It is especially advantageous when the artesian well from which the windmill pumps the water is situated on an elevated point, and the well is driven through the rocky soil to a good depth. With this assurance of good pure water, out of reach of contamination from surface drainage, and with the elevated position of windmill and tank, there will be little danger of an insufficient supply. The use of large round pipes, of short length, and of as few bends as possible, will insure a generous flow to the highest points to be supplied.

Close attention to seemingly insignificant details, during the process of tank construction and piping, will provide for many years of solid comfort in the enjoyment of an adequate water supply, when wind power is to be depended upon. The decorative form of the structure, and the use of its different enclosures, may be varied according to its locality and the artistic ingenuity of the owner. 


\section{XII}

\section{CROWS'-NESTS AND TREE HOUSES}

\section{SECLUDED RETREATS IDEAL FOR SECURING REST AND INSPIRATION}

ONE of the chief attractions of quaint houses, furnished rooms, and open rustic retreats built in tree tops lies in utilizing bark-covered building material. The retreat then has the appearance of being a part of the tree in which it is built. The harmony of the structure with its surroundings will be a source of unending satisfaction. Stout, durable cedar posts and branches are best for this form of building. To avoid the peeling of the bark, which is often an aggravation in working with bark-covered cedar, the building material should be gathered in the autumn; for at this season the sap is going down, and the bark is more tenacious. This and a little care in nailing and wiring the ends of the timbers will insure durability.

Rustic open shelters are inexpensive. They are not intended to serve as an ornamental feature of the home surroundings, but are meant to provide delightful seclusion up among the breezes in the shelter of tree branches. As work rooms for an author, an artist, or a musical composer, they are ideal. Amid 
such surroundings one's inspiration should come as spontaneously as the bird songs caroled in the upper branches.

These open crows'-nests may be situated closer to the ground than the tree house that is enclosed with roof, walls, and windows. The real crow's-nest is never roofed over, the shade and shelter of the green foliage being sufficient. Board tables and benches or rustic chairs are the only furnishing. Nothing should be used in any part of the building, or its furnishing, that will be injured by the weather. It is important that the floor should be evenly and firmly laid, either on large tree limbs or on strong posts imbedded in the ground. Winding rustic stairs can be built about the posts, with tall growing vines, such as wistaria, draped about the railings, thus converting the utilitarian posts into objects of beauty. The upper railing, built to enclose the floor space of the crow's-nest, will require special attention as to its strength and durability. When a rustic finish is desired to correspond with the decorative stair railing, the frail decorative portions must be confined to the spaces between the rails. The stout corner posts and connecting rails must be strictly "fall-proof" - that is, so well secured and of such heavy material that there is no possibility of a careless visitor pushing over or breaking through 


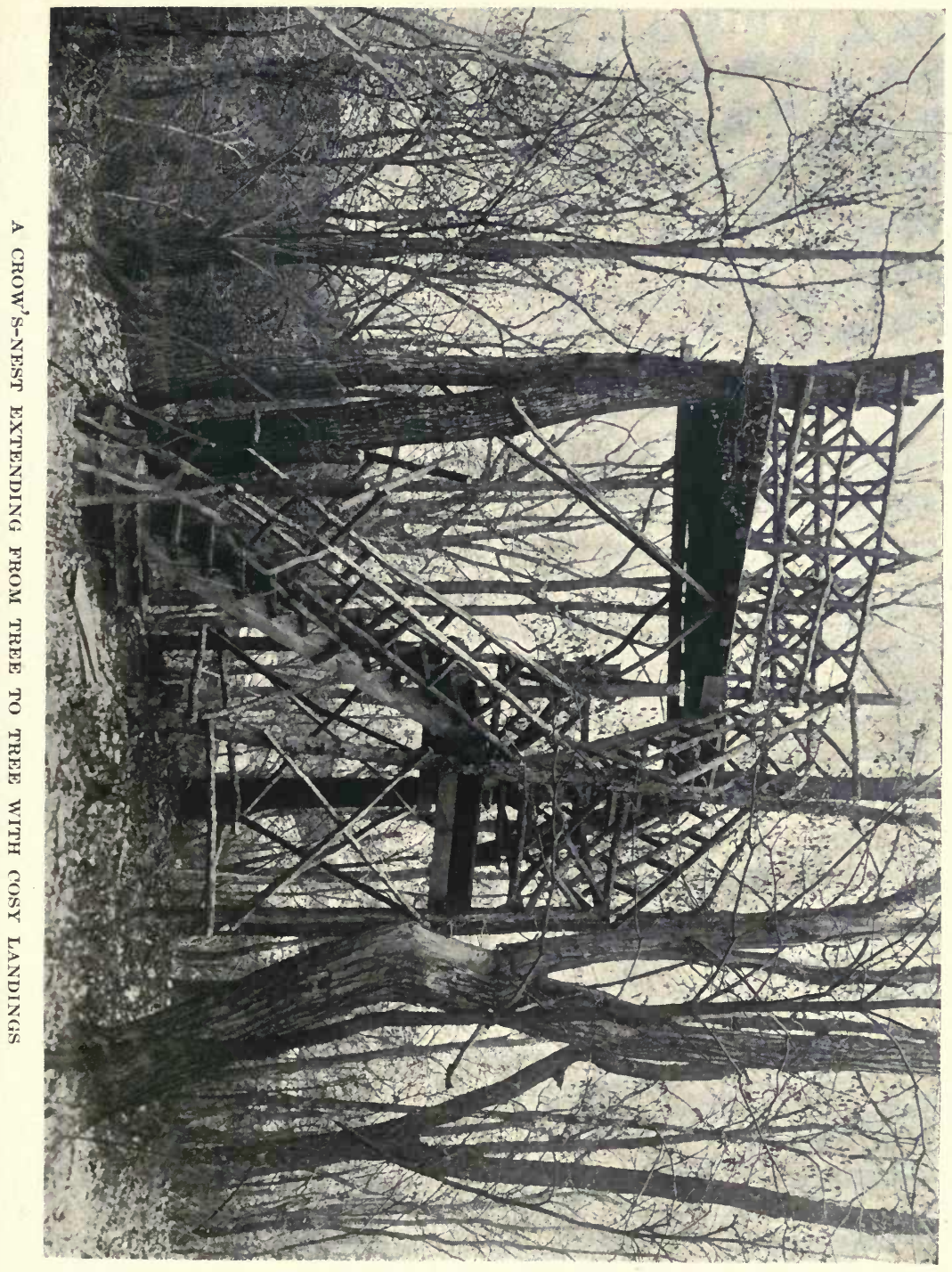




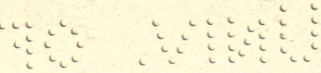

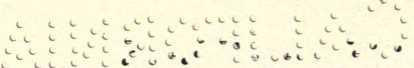




\section{CROWS'-NESTS AND TREE HOUSES}

any part of the enclosure and falling from the retreat.

For a rustic house up among the tree branches, the services of an architect may be necessary. Yet with care in certain important details, almost any handy man should be able to design and build a satisfactory structure.

A few years ago, while in quest of inspirations for building a writing room out in the branches of a fine old tree adjoining my "den," I chanced upon a description of a tree-house studio in a section of the Catskill Mountains, where authors and artists congregate during the summer months. A visit to this novel tree house (which the resourceful owner generously described for the benefit of any one who might desire to copy his design) afforded suggestions for building many forms of quaint structures, by slightly altering the plans to meet individual requirements. Any one of these designs may serve as a fascinating little retreat in the home garden, if there is a tree of sufficient breadth and dignity to support it.

When there are a number of well-developed trees from which to choose a site for the rustic house, do not make the mistake of selecting one near the street or public roadway. The quaint decorative house built up in the branches may seem worthy of a promi- 


\section{PRACTICAL BOOK OF GARDEN ARCHITECTURE}

nent place because of its ornamental features; but in this position its chief charm will be lost. It is intended as a secluded retreat, not as a show house. A shady garden at the back of the house, out of sight of all passers-by, will provide the proper seclusion. When there is limited yard space, or there are few trees suitable, care must be taken to have the house so placed that it will be well hidden by encircling branches and thick foliage on its most public side, and open to light, air and passing breezes on the secluded ones.

The description of the tree house in the Catskill Mountains, which I have mentioned, is one that may be readily followed in building a structure of this nature about the trunk of any well-grown garden tree with low drooping and wide spreading branches. The attractive model was discovered far up in the mountains, about two thousand feet above sea level. This quaint tree house proved to be of good dimensions, built among the trees, rather than in a tree. As the floor space is sufficiently large to accommodate two verandas reaching out among the branches, and a large room to serve as studio, or work-shop, with ample chair, table, and desk furnishings, and curtained corners for a sleeping couch and dining accessories, it proved too heavy to be built directly on the trees for support. 


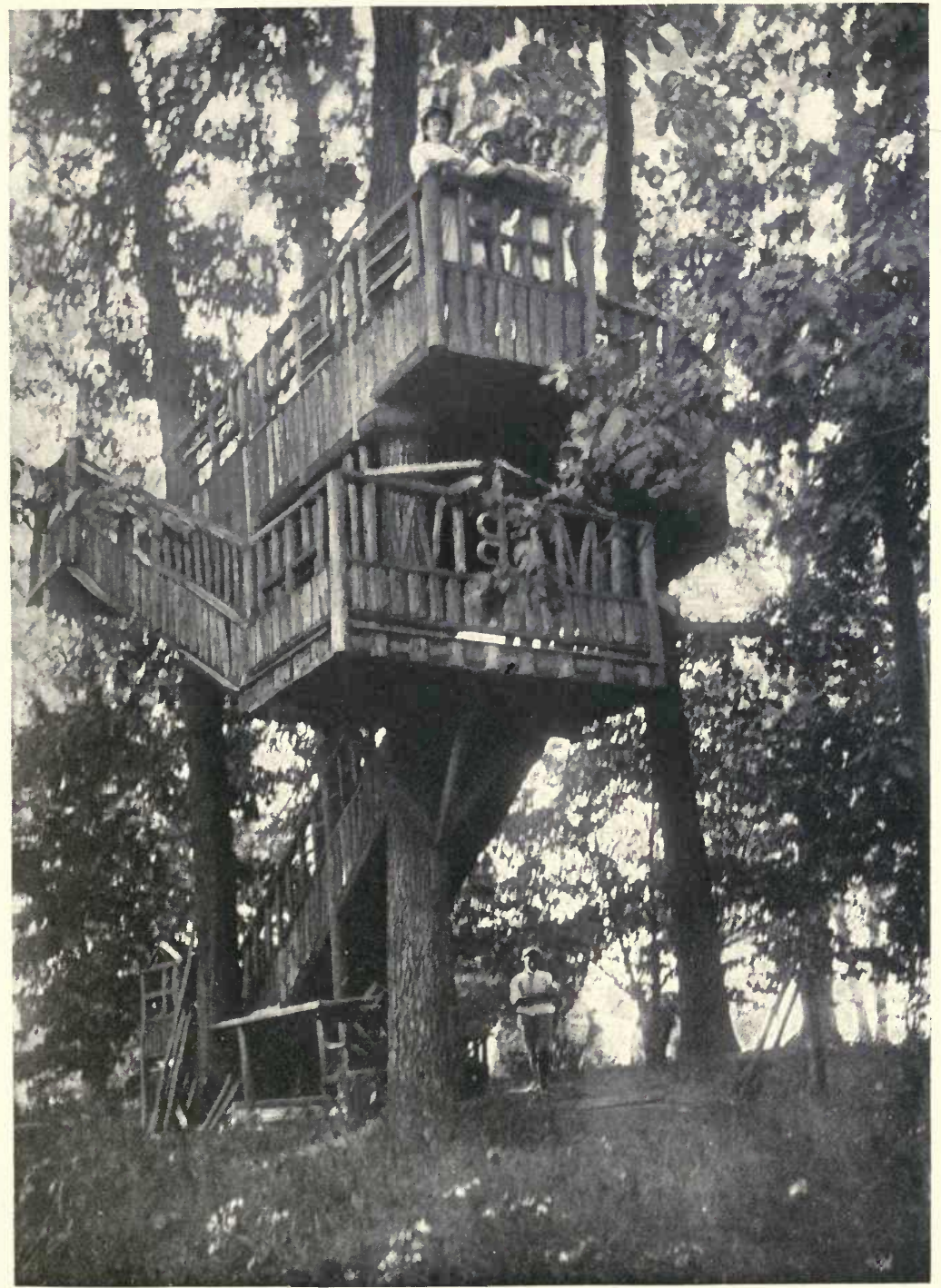

A TWO-STORY TREE HOUSE SERVING AS A COMMODIOUS PLAY HOUSE 
$\because \vdots \vdots \quad \because \because 3 \vdots \vdots \vdots \vdots \vdots \vdots$

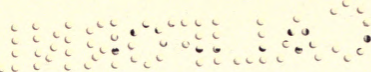




\section{CROWS'-NESTS AND TREE HOUSES}

Four closely-grouped trees were chosen for the site of the novel house. As their natural position was in the form of a square, the house readily could be arranged to have the appearance of resting directly on the tree branches. In reality, the house is supported by stout hemlock posts, about six inches thick and ten feet long, holding the house up at a good stair-climbing distance from the ground, and sufficiently high to be well hidden by foliage, as the four big trees spread their branches wide on every side. These supporting posts rest on flat stone foundations, set below the frost line, and are kept in position by the weight of the house. Four heavy sills are firmly braced to the posts, between which the floor beams are laid. These floor beams were suffciently long to extend beyond the room of the house, and provide spaces for the front and side veranda. The flooring for exterior and interior is of Georgia pine. When built upon this firm though elevated foundation, there is little danger of it being injured by heavy wind storms. The four corner posts of the house walls are also about six inches thick; and the precaution was taken, in working up the rough lumber, to have the two front corner posts from eighteen to twenty inches higher than those at the back. This provides sufficient pitch of the roof readily to shed the rain, when simply covered with roofing paper, 


\section{PRACTICAL BOOK OF GARDEN ARCHITECTURE}

renewed with an occasional coating of black roofing paint. In placing the studs between the posts, spaces were left for the door and for windows on all sides, to catch the breezes from every direction.

This dainty tree house is quite elaborately finished in many details. Shingles painted moss green are used for the roof, where a considerable saving may be made by the use of heavy tar-paper or some form of rubberoid roofing; and the house has been sheathed with white pine, and covered on the outside with hemlock slabs. A heavy Dutch door, slabbed on the outside in harmony with the rest of the exterior finish, gives entrance to the home.

The wall surface of small tree rooms built somewhat after this plan may be cheapened and turned into convenient closet spaces by omitting the sheathing, and covering the studs and supports with smooth, upright wainscoting. Between the outside finish of hemlock slabs, or weather boarding, which should be made water-tight, ten or twelve inches of space should be left, and fitted with shelves. These give the firmness of sheathing to the structure. Instead of stationary wainscoting for the interior, it is panelled and hinged in convenient sections, reaching from floor to roof rafters. When the wainscot doors are thrown open, they disclose closet space in the bedroom or couch corner, for bed linen and 

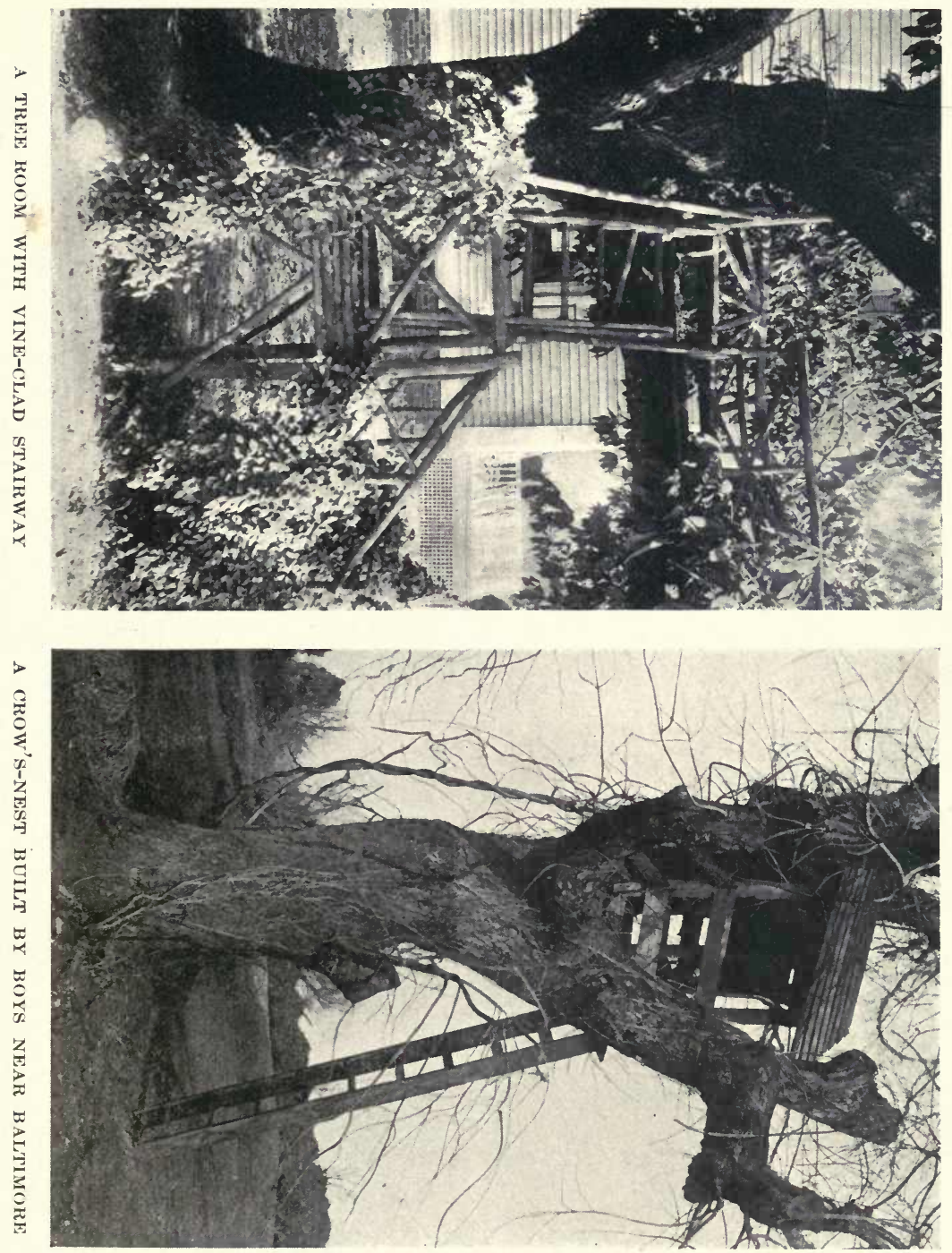


\section{CROWS'-NESTS AND TREE HOUSES}

every form of sleeping comfort. In the tea serving corner, on opening one of the wainscot doors, dishes are disclosed, with a tiny, wickless, blue-flame oil stove, and all the delightful paraphernalia for tea making and refreshment serving. The other sections of shelf-lined walls provide ample space for various housekeeping requirements, and for books of reference and all the helpful accessories that should be at hand for assisting one's muse. It is probably unnecessary to state that the plainly sheathed and slabcovered tree-house in the Catskill Mountains is a man's studio; while that of closet conveniences built throughout the entire wall space was designed by a woman.

When these tree houses are built merely as secluded retreats, rather than as studios or workshops, the wainscot cupboards will prove equaliy satisfactory for containing reading material, fancy work, and dishes, and dainties for serving afternoon tea to chance guests. When built as a necessary part of the wall supports and interior finish, these cupboards will not add materially to the cost of the structure.

Expensive window frames and casings will not be required for these tree houses. The plain finish of window framing, and outward sloping sill, will be satisfactory; and in order to admit the air through 


\section{PRACTICAL BOOK OF GARDEN ARCHITECTURE}

the entire window space, and to shelter the interior from showers even when they remain open, the windows are hinged at the top, and swing out from the bottom, being adjusted and held open and braced by an iron bar which fits into a socket in the sill. Stout hooks and staples fasten the windows against intruders when the tree house is not in use.

Vine-draped stairs leading from the ground up to the tree house provide the best entrance when the tree stands at some distance from the house. For the tree room or crow's-nest built in a tree near the home, have the tree room extend out from an open balcony, or sleeping porch, if possible, with the only entrance into the tree apartment leading from one of the upper rooms of the house.

A tree growing from a garden ravine provides a charming place for the crow's-nest or rustic retreat. The bridged entrance should have firm support from the upper level of the home grounds, and reach out over the ravine into the tree top. For winding stairs leading up to the simpler forms of tree houses and nests, and for the rustic finish and furniture, one should avoid any suggestion of freakishness. The beautiful simplicity and dignity of the tree growth will give the best lines to follow. 


\section{XIII}

\section{ARCHES AND PLEACHING}

\section{ENGLISH AND CONTINENTAL TYPES SUITABLE FOR AMERICAN GARDENS}

Two distinct forms of garden arches distinguish modern landscape architecture. They give dignity to the perspective of public gardens and attractive cosiness to shady nooks and retreats in home gardens. The most common is the arch constructed of wood or iron, with lattice and trellis combinations for supporting vines and climbing roses to cover the arch with greenery. Another type, not so frequently seen in this country as it should be, is the pleached arch or "pleached alley," as it is known in England and in Italy. In the latter form not only the support for the greenery but the entire arch is composed of living trees.

The pleached alley is the type belonging to the Elizabethan period of old English gardens and to the early villas of Italy. It is much more extensive than the pleached arch, which usually consists of one or two trees on opposite sides of an entrance gate, with the tops closely interwoven to form a continuous arch of green. The pleached alley is formed of a succession of these closely planted and interwoven trees, with their tops forming an unbroken mass of 


\section{PRACTICAL BOOK OF GARDEN ARCHITECTURE}

green, arched over a walk, extending for a considerable distance across the garden.

Pleached alleys of ilex, and various other evergreen trees, are to-day considered one of the "sights" of special charm for travellers visiting the gardens of famous Italian villas. In England closely planted elm trees and cornel, and pliable willow branches, are the favorite trees for interweaving into living arches. The finest type of pleached alley to be found in this country is composed of American hornbeam-Carpinus Caroliniana. It is the distinguishing feature of Mrs. Henry Lee's garden at Brookline, Massachusetts, and is known throughout the country for its great length and the beauty and uniformity of its splendid arches. It is over two hundred feet long, and about twelve feet wide beneath the arch.

Cedar trees and various evergreens with tough, pliable wood are the favorites for the gateway arches. At the Mercer estate at Doylestown, Pennsylvania, there are excellent specimens not only serving as decorative arches over the entrances to the garden, but also as a green background for garden statuary. The choice of the trees to form these living arches will be of great importance when the series is to be of special length. The long evergreen arches with closely interwoven branches will often 


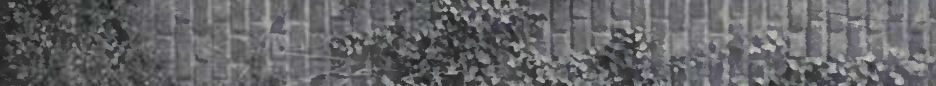

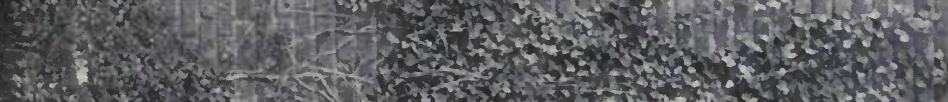

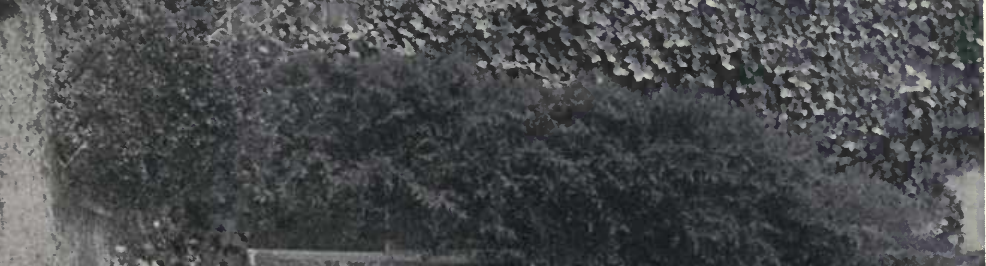

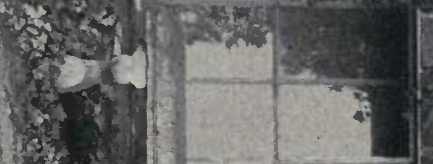

$1+x-2$

$13 x$

ats

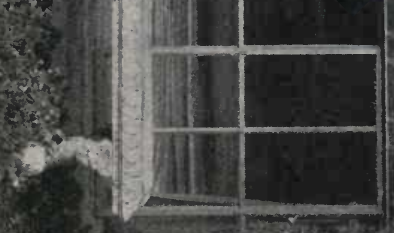





\section{ARCHES AND PLEACHING}

be required to carry a heavy burden of snow during the winter, and it is important that they shall be strong enough to support it. Any sturdy growth of springy, long-fibred wood will be suitable to form the living arch that is to endure unchanged for many years, but the various evergreen growths have the preference, because of their winter attractions.

The usual definition given for pleaching is to fold, lay or wind together. To unite by interweaving, as branches of trees. There is more tedious work than the mere braiding and interweaving, however, to form a permanent pleached alley or arch. The usual process of building this live arch with its broad, shaded walk beneath, is first to form a strong trellis of wood or heavy iron along the two rows of closely planted trees which are to be intertwined over the walk. This supporting trellis is carefully built in the form desired for the finished arch. For the arches formed of some of the closefoliaged evergreen trees, the supporting trellis of iron, forming the uniform arch overhead, is of permanent construction, intended to remain after the arch of trees has become well formed and tied in place. The closely pruned foliage above and below the arch completely hides the support, and it gives extra durability without spoiling the effect of the living arch. For the trees with swaying foli- 


\section{PRACTICAL BOOK OF GARDEN ARCHITECTURE}

age, or the pleached arches that partially shed their leaves in winter, the supports are only temporary. The trees when planted are about four feet high, and are set quite close together. As the new growth starts from the pruned tops, it is well branched, and ready to begin tying to the support, which begins to arch slightly at a height of four or five feet, at the edge of the path, with the top of the broad arch at least eight feet high over the centre of the walk. The branching growths (which continue to be pruned to give many branches for intertwining) are interwoven and braided above the supporting trellis, and are kept well rounded over the support, but are seldom tied to it. When the heavy upper branches become sufficiently thick, and compactly joined, to retain the arch, the trellis is removed. Then annually pruning and tying will be sufficient to keep them in position.

Evergreen gateway arches are typical of many beautiful New England gardens, as well as of many old Colonial gardens of the South. They possess a subtle charm that invariably causes the visitor to pause at the threshold of the old-fashioned dooryards, while eager to explore the farthest recesses of the flower and herb-bordered walks beyond.

The arches of these old-time gardens are most frequently built of wood, with the sides quaintly 

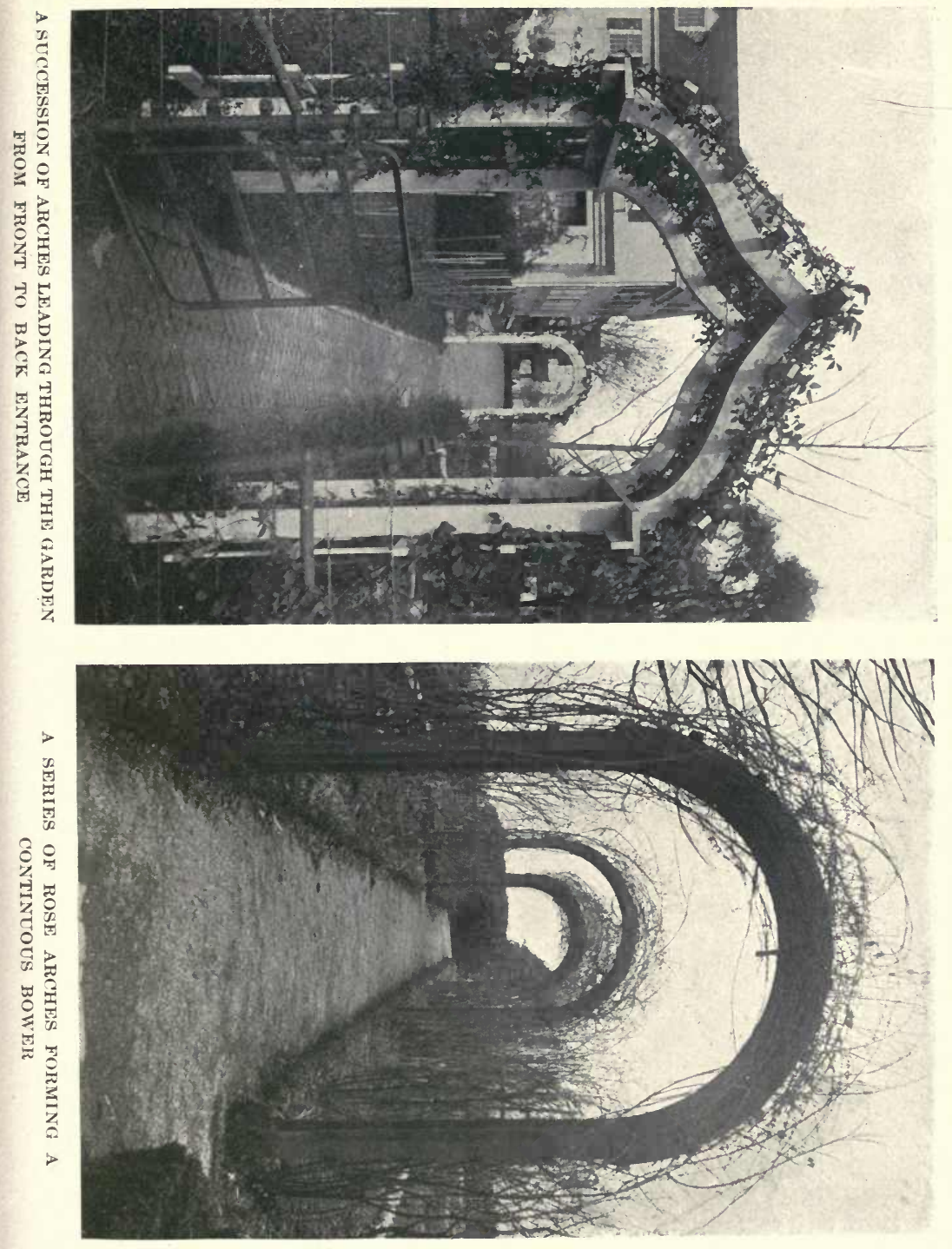
$\because \because \quad \because \vdots \vdots \vdots \vdots \vdots$

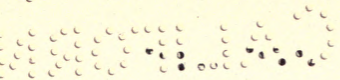




\section{ARCHES AND PLEACHING}

latticed in diamond or square patterns, and the woodwork painted entirely white, giving a pleasing contrast to the green of clinging vines. Gateway arches are frequently a continuation of the woodwork of white fences of palings, with the same pattern carried out in the high arch extending over the gate. A pleasing type, popular to-day, is of rustic work with bark-covered cedar posts, set at intervals of two or three feet apart with heavy rustic branches forming the cross supports for the vines.

A succession of arches leading from the gateway to some distant point in the garden is most attractive following the line of a curved walk, and when draped with climbing roses with the blooming branches meeting and intertwined over the top of the arch, they possess all the charm of the pleached evergreens, with the additional fascination of flowering beauty and fragrance.

No matter how beautiful is the foliage and bloomcovered arch, in itself, it will lose its attractiveness when unwisely placed. Standing out prominently in the centre of the lawn it has very little excuse for its existence. The fact that it shelters a garden seat does not help to give it dignity; for the seat, as well as the arch, is entirely out of place. The same structure placed in a cosy sheltered retreat, or standing before a garden vista of special 


\section{PRACTICAL BOOK OF GARDEN ARCHITECTURE}

loveliness, calling for studied, restful enjoyment, would have made it purposeful and pleasing; whereas it is without use or meaning in its present position.

For sheltering and partially obscuring a garden seat an arch of greenery and bloom has a special charm and may be constructed in various designs. When built of iron supports with wire between the irons to carry the thick growth of foliage good results are achieved by carrying the wire down back of the seat; continuing the background of greenery and bloom from the arched canopy, over the seat, to form a screen at the back. This is especially appropriate when the garden seat is in a sheltered nook, with a kitchen garden at the back, or some object that it is desirable to screen from the lawn view. The screen dropping down from the arch at the proper place, the one who is seated naturally faces the direction where the beauties of lawn and garden are most alluring.

It is quite as important to have an imposing series of arches provided with a good approach as it is to give the isolated structural arch an appropriate position. When the series bordering a curved or winding walk stands well within the confines of the garden (without an entrance gate to serve as an approach) a bit of statuary, flower tubs or vases, or 


\section{ARCHES AND PLEACHING}

an ornamental planting of evergreen shrubbery will provide additional dignity and beauty. Whenever possible, this approach to the arched or pleached walk should be so arranged that it may contribute to the winter attractions of the property.

When a long arch, or a series of small arches, have seats provided for tempting the visitor to pause and admire the fascinations of the garden retreat, special care must be given to have the seat face in the right direction and to have both approaches to the arched walk leading to partially hidden beauties of varied characteristics. When studied from the resting place in the centre of the arch, there must be a suggestion of hidden beauties just beyond; this will give a satisfying completeness to the arch and its surroundings.

The garden architect who appreciates the value of expectancy has solved an important problem in making home surroundings a success. With the entire expanse of garden beauty laid out before one's admiring gaze, one quickly tires of its unchanging sameness. With hidden beauties and screened attractions at the end of a garden arch, there is an expectation of varied charms awaiting inspection, and the thrill of anticipation one feels on approaching the secluded spot shows the wisdom of this bit of architectural strategy. 


\section{XIV}

\section{DEPENDABLE BIRD HOUSES}

WHERE THE FEATHERED SONGSTERS FIND PRACTICAL NESTING PLACES AND PROTECTION FROM THEIR ENEMIES

In the West Indies there flourishes a stately tree that can give the whole world a lesson in providing dependable homes for the birds. It is commonly known by the curious name of "Monkey Puzzle Tree." Occasionally it is called "Snake Puzzle Tree." At first glance it does not seem to offer any special characteristic to account for its fame or its odd name, as it is simply a well-proportioned tree, with its symmetrical growth held well up above the ground, the big trunk being bare of branches for about fifteen or twenty feet. But whether the tree is found over-towering the low growths in the hot, moist tropical jungles or in the dooryards, near the homes of the natives, it is invariably well filled with many varieties of birds. The chattering monkeys and the big snakes that flourish in the jungles never climb this tree, nor attempt to molest the nesting places to search for eggs and young birds among its branches. Close inspection of the bark of the trunk discloses the secret. What appears at a little 


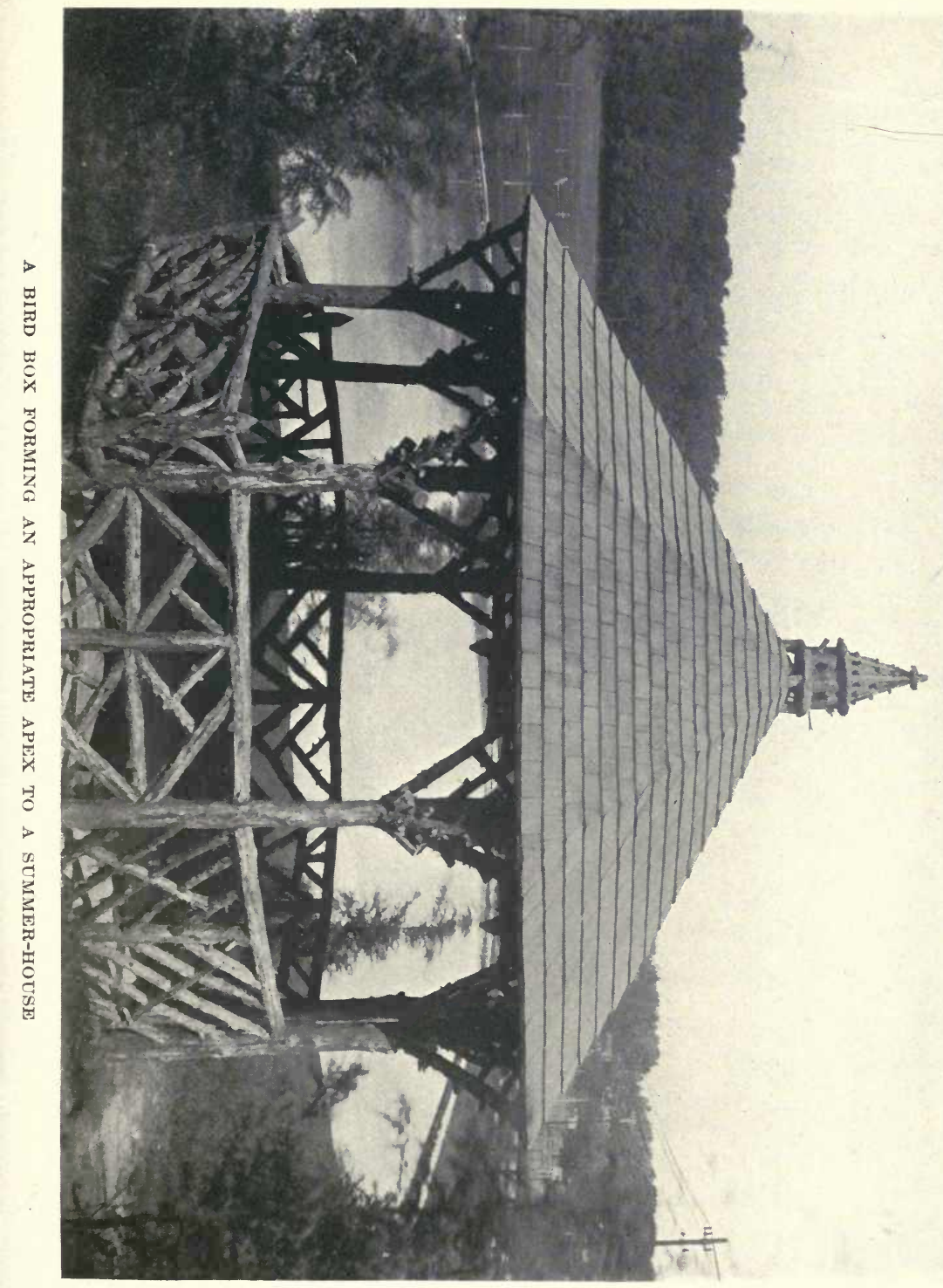


$\because \because \vdots \vdots \because \vdots \vdots \vdots$

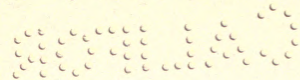




\section{DEPENDABLE BIRD HOUSES}

distance to be but a mottled whitish bark is in reality a mass of short and extremely sharp thorns, entirely covering the trunk and limbs. No monkey or snake could climb many inches up this thorn-covered surface to secure his prey. He is satisfied to give up the puzzle and his discomfiture and seek the toothsome eggs and birdlings in other places. Birds of every variety native to these tropical islands soon realize that nature has provided them a well-protected stronghold, and they are quick to take advantage of it.

We may not be able to provide thorn-covered trunks for the trees of our lawns and gardens, but we can profit by nature's lesson, and carry out many practical devices for protecting our native birds from cats, squirrels, and other enemies quite as effectively as they are defended from the snakes and monkeys in tropical jungles. The birds are quick to appreciate the protected houses, whether they are boxes set upon poles in the garden, or odd contrivances for nest building, situated in the branches of trees or under the eaves of garden buildings.

To guard the nesting places among the tree branches, it is not always possible to give safety from cats by encircling the tree trunk with zinc, or with a broad board to act as a head bumper when 


\section{PRACTICAL BOOK OF GARDEN ARCHITECTURE}

cats attempt to climb the tree. Other contrivances, which may be entirely practical when applied to bird homes erected on poles, will fail to be effective when applied to trees.

The best plan is to swing the bird box several inches below the limb of the tree instead of in the convenient crotch. It is sometimes placed far out on the end of a limb, where cats do not like to venture, but the birds will probably be annoyed by having their enemies make repeated attempts to steal their babies, and the box may become dislodged. When swung several inches below the limb, and out of reach from the one below it, the box will be out of danger from cats, and will produce safety that the birds will readily appreciate. To keep it from swaying uncomfortably the box hanging midway between two limbs may be firmly wired to each. The sturdy perch in front of the opening will be all that the birds will require for entering or leaving their home.

For the bird boxes mounted on poles, or forming the ornamental apex of summer-houses and other garden retreats, there are devices in zinc and wooden platforms that will serve as feeding-tables for the birds. When built just below the entrance to the box, and encircling the support by a platform extending 


\section{DEPENDABLE BIRD HOUSES}

out on all sides, these will prevent prowling enemies from reaching over or climbing up to the box.

When perfect safety from prowlers has been assured the homes provided for the birds should be made capable of withstanding all weather conditions. Frail boxes with glued ends may be secured, of attractive form, in which merchandise has been packed -boxes that seem too attractive to burn, and "just the thing" for furnishing homes for songsters when a few decorative features have been added. But it will be necessary to strengthen all glued edges and connections with wire nails, or they may become weather worn, warped and leaky before the first season is over, and in the midst of the most important time of hatching and caring for the birdlings. When assured that the bird homes are dependable in regard to the safety and durability of the structure and the protection of the occupants, one's attention may be turned to such decorative features as will make them an attractive part of the gardening furnishings.

Ornate structures, built after the plan of elaborate houses of many rooms, are not in good taste nor do birds appreciate the apartment-house idea. The position usually selected for such pretentious bits of handicraft-on a pole in the most prominent part of the open lawn-will not satisfy the desire for 


\section{PRACTICAL BOOK OF GARDEN ARCHITECTURE}

seclusion naturally shown by most birds in seeking their places for nest building. Wrens, martins and chickadees may be satisfied with houses of many rooms with a tenant in every room, but the majority of birds will desire greater privacy for the delights of housekeeping and rearing their young. When the bird house is to be designed after the order of an architectural plan for human habitation, it is well to have it small and well built rather than large and showy.

In building houses of this nature-if it be done at all-it is of first importance to have the roof sloped at a good angle, about forty-five degrees, with overhanging eaves, and made rain-proof. The little outside veranda or other decorative approach must be placed in the right position to give the birds a resting place where they can look into the nest before entering. The separate rooms should be at least six by six inches square, or six by eight, according to the size of the nest built by the birds which are expected as tenants. There should be space for the birds to move about while building their nests in the corner, and for the birdlings to be comfortable when they begin to over-crowd the nest. Another point to be kept in mind-if there are four or more apartments to the house, do not have all the entrances on the same side, but give each bird the 


\section{DEPENDABLE BIRD HOUSES}

privacy of a different entrance, one from the front, one from the back, and others from the two ends of the structure. Then with decorative posts forming tiny roofed verandas for each separate entrance perch, with ornamental eaves and gables, with quaint windows on either side of the doorways, and many fanciful devices, the decorative features may be added after sensible construction has had first consideration.

A rain-proof thatch of straw or hay forms a most appropriate roof for a bird house, and it is decidedly decorative when well laid. With a durable structure like a stout nail keg for the house proper, and a thatched roof, the house may be made to last for many years, and it will be interesting to watch for the same birds returning to their beloved home every summer. This kind of roof is especially pleasing to the tenants, as it will provide a portion of the nesting material without injuring the thatch; and in this connection it is well to mention that all wellregulated bird houses should have attractive nesting material hung near by-not within the box (as the birds prefer to search for and select their own materials for building), but sufficiently handy so that the search need not be arduous. Bits of wool, fine hay, ravelings, and similar material hung from tree branches near the bird boxes will create con- 


\section{PRACTICAL BOOK OF GARDEN ARCHITECTURE}

fidence when the birds are contemplating building in the homes provided for them. When a stout nail $\mathrm{keg}$, or a similar receptacle, is chosen because of its durability, the thatched roof is easily applied in conical fashion, being brought to a sharp apex, which is securely wrapped with rope to make it rain-proof. The keg may be divided into two or four distinct rooms before arranging the roof and platform. The end of the keg from which the head has been removed is turned downward on the platform, which mounts the top of the post supporting the house. The other end, with the original "head" still fastened securely in place, will receive the upright stakes that hold the thatch in place. The head which was removed when the nail keg was opened can be enlarged slightly to make this circular partition fit into the centre of the keg, where it is nailed to form the floor of the upper apartment, and the ceiling of the one below. When the keg is sufficiently large to form four apartments, both the upper and the lower rooms are divided in the centre by upright boards. The entrances to these different apartments should be on opposite sides of the keg and should be large to admit plenty of light and air, as the overhanging eaves of thatch will keep the house dry.

For the two-story homes, the roof thatching should be kept up near the top of the keg, with the 

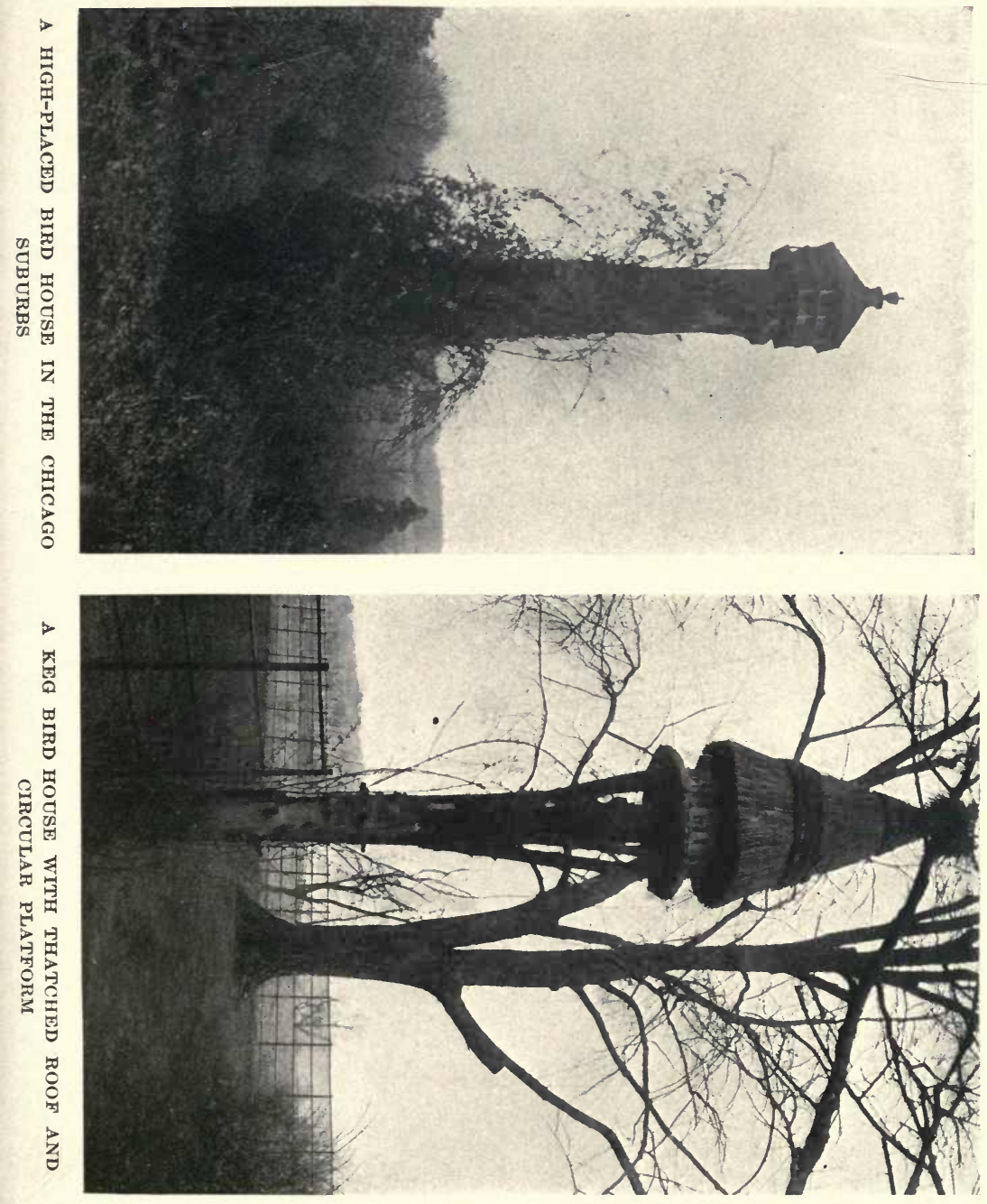


\section{DEPENDABLE BIRD HOUSES}

decorative eaves spread out to protect from beating rains. When using smaller receptacles-on the gallon paint keg order-for the bird homes to be tenanted by but one family the thatch may be brought down over the sides, to nearly cover the small keg. Two rows of roping, one at the apex and one near the eaves, will keep the thatch secure. The birds will cleverly show their delight in the house while sitting on the circular platform beneath the overhanging straw and pouring forth their songs of rapture, and the garden craftsman will realize that the really appropriate and most pleasing bird houses are those which best fit the requirements of the tenants.

In the gardens of suburban Chicago it is the rule rather than the exception to find decorative bird houses set on extremely high poles. They sometimes reach the height of the tree tops both in garden groves and among the country seats near park sections. In one instance a tall tree standing at some distance from others was bared of its branches, instead of being cut down, when it began to decay, and a many-storied bird box was perched high on the tall trunk. The prevalence of squirrels furnishes the reason for placing the nests in these situations, and even then the supports require extra protection, in the way of zinc or wooden barriers, to keep 


\section{PRACTICAL BOOK OF GARDEN ARCHITECTURE}

these animals from darting up to the highest point. Shorter poles can be quite as effectively guarded from trespassing squirrels and cats, but as both red and gray squirrels are dreaded enemies in this section, the birds always choose nesting places situated at a good height from the ground and away from a thick growth of trees.

Naturalists may argue that squirrels, being rodents, are not carnivorous, but it has been proven beyond any controversy that these animals, so abundant in western parks and woodlands, not only delight in sucking the eggs but will also rob the nests of young birds.

Houses perched at a considerable distance from the ground should be constructed on a larger scale than the wren and chickadee houses, built down on a level with the other garden furnishings.

Other contrivances for bird houses are numerous. Long-necked gourds suspended from tree branches are a favorite device. From a hole cut in the upper part of the bowl all the seed and pithy contents can be extracted, leaving the interior smooth and clean. The perch in front of the opening should also be made secure while the gourd is still comparatively green and soft. After it has dried it will become a hard shell which may crack in adding the perch and completing the entrance-way. The gourds 


\section{DEPENDABLE BIRD HOUSES}

will serve as decorative features when they are hung among the thick branches of evergreen trees, or among the vines of a garden arbor. This novel home will be safer from prowling enemies and more durable when suspended from the roof of a porch or summer-house-a situation which the house wren frequently prefers for her nest building.

When hung outside, the opening must be protected from the rains which would soften the interior. With a little ingenuity in the manipulation of long vertical wires, and two or three wire hoops to hold the roofing material out from the neck of the gourd, a thatch of straw may be applied with a raffia-threaded darning needle. Quaint thatched circular projections also may be arranged around the neck of the gourd, close down about the bowl. This collar-like roof will shed the rain from the opening, and leave the upper part of the long neck exposed. This bird house will be found a novel and durable home for wrens and small birds.

Bark-covered logs, carefully hollowed out and suspended from the roof or walls of summer-houses and garden retreats, form attractive bird homes for woodpeckers.

The entrance holes in all these contrivances should be made in proportion to the size of the birds to be attracted. It is well known that the opening to the 


\section{PRACTICAL BOOK OF GARDEN ARCHITECTURE}

wren's house should be exactly the size of a silver quarter. This is the smallest opening used. The martins, bluebirds, nuthatches, and even the chickadees, all require larger openings, with a generous size for the woodpeckers and others that are to be attracted to the hollow logs. In making the plain wooden boxes, it will be well to have the sloping roof hinged, so that the box may easily be cleaned when desired, although, the birds usually attend to their own housecleaning. An overhanging of tar paper will keep the hinged portion water-tight. The sides of the box should be nailed outside of the floor portion, and made to extend slightly below it, to be perfectly rain-proof. The entrance hole should never be placed quite close to the bottom of the box, and should never be left without a perch on the outside, about an inch below it. The bird does not like being compelled to jump or flutter from the platform of the box, or the top of the pole, into the entrance. Neither does the average bird enter its home flying. It wants to perch for a moment outside of the entrance, and look into the house before hopping inside. Room for nest building should be left in the bottom of the box below the entrance; when the hole is too close to the bottom, it is often obstructed when the nest is finished.

Houses in the form of crockery balls and cylin- 


\section{DEPENDABLE BIRD HOUSES}

ders may be purchased; these are indestructible, as they are made of heavy stone-ware with the openings in different sizes. The garden craftsman who dabbles in clay modeling and concrete may invent many attractive contrivances that will defy cats and weather.

In providing homes for the wrens, with the quarter-size entrance, it must be remembered that although the bodies of these birds can take advantage of an opening that will exclude other birds, the box must not be small in proportion; the little wrens require plenty of room within the box, as they build bulky nests and rear large families. The openings to the single houses should face the south and west, to avoid the cold north winds and beating rains. Protected nooks under the eaves of the summer house will provide the nesting places preferred by Phoebe-birds. Generous entrance holes between the rafters of the garage roof will attract the barn swallows. A study of bird habits will give us many inspirations in their home building. 


\section{XV}

\section{BIRD BASINS AND FEEDING TABLES}

AN INTERESTING FORM OF GARDEN DECORATION URGED BY AUDUBON SOCIETIES AND STATE GRANGE COMMITTEES

THe garden that can show numerous robins and other birds bathing in a bird fountain down among the flowers, drinking from basins suspended from low branches, and clamoring for "best places" at feeding tables set securely on high posts out of the reach of cats, will prove a source of inspiration and delight, even though it may be lacking in many architectural features.

During recent years special stress has been laid upon the importance of this form of garden decoration. The Massachusetts State Grange Committee was one of the first to urge property owners to protect the birds that are our most important safeguard against destructive insects. The committee issued considerable literature setting forth the desirability of attracting and protecting wild birds near our homes, not only by supplying them with houses and nesting material, but also by providing bathing fountains, drinking basins, and feeding places. 


\section{BIRD BASINS AND FEEDING TABLES}

Other state granges have taken up the plea for better bird protection. It has been suggested that bird fountains situated on the ground, where many varieties of birds prefer to drink and bathe, shall be protected from cats by an enclosure of chicken wire, open only at the top. Drinking basins and feeding platforms can be protected by outspreading bands of zinc or tin about the poles or tree trunks on which they are set. Chicken wire shaped like a hat brim is another simple contrivance for placing around the pole to keep cats and squirrels from climbing up.

When California established the state bird farm near Hayward, Alameda County, it became an object of interest to travellers from all sections. These efforts to conquer the insect pests that afflicted the state, by the breeding and protecting of birds, attracted a wide-reaching attention.

The League of American Sportsmen and the Audubon societies of various states are not satisfied simply to enlist the aid of all good citizens in creating legal barriers against the useless destruction of bird life. The slaughter of the egret and other birds to satisfy feminine vanity and the killing of song birds for food are responsible for only a part of the strong public sentiment which these societies are arousing. The breeding, protecting, and be- 
friending of birds are assuming as much importance as the abstention from slaughter.

When the first census of birds was taken a few years ago by the Director of the New York Botanical Garden, figures and facts were shown that proved appalling to farmers and market gardeners and fruit growers; facts that should encourage every owner of a garden, interested in turning its practical and ornamental features to good account, in the propagation of birds. In this recent bird census it was shown that during the past fifteen years there has been a decrease of forty-six per cent. in the number of birds, with the prophecy that the percentage loss will grow as our forests are depleted and our ordinary operations of forestry and agriculture fail to augment the numbers of our non-migrating birds.

The protecting of natural nesting places, the building of winter feeding houses and provision for drinking places during freezing winter weather, and for bathing and drinking places during the summer, are the best means for increasing the number of birds about our homes and gardens.

Quaint food bells hung in trees and supported from the eaves of garden houses form an attractive feature of garden decoration. The self-feeders of our poultry houses are utilized in novel ways to 



\section{BIRD BASINS AND FEEDING TABLES}

make these decorative food bells of practical value. The original food bell as tested in Germany, on the bird experiment station of the Baron von Berlepseh estate, consists of an ingenious mechanical device which serves out food automatically and without waste, like our patent poultry feeders. As originally used, the mechnical food bell was an inverted glass jar or bottle, holding the supply of seed, and feeding it as needed through a tube to a bowl or bell below. It was necessary to have the construction of this apparatus carefully adjusted, with the lower end of the tube extending just below the upper end of the food dish, or it would not work properly.

Special food trees are another garden feature. A low-growing tree with wide-spreading, horizontal branches and located in a prominent place in the home garden is selected, and in this little food platforms are arranged where seed and crumbs and bits of meat are left daily. An upright wooden rim surrounding the feeding board or table keeps the food from being scattered by the eager fluttering of the birds. This is much better than having crumbs and seed thrown on the ground, especially when the trees are protected with wire, as previously suggested.

Another interesting feature of the food tree consists of "hangers" which hold securely in place lumps of suet and pieces of meat, suspended in such 


\section{PRACTICAL BOOK OF GARDEN ARCHITECTURE}

manner that the birds can pick off small particles without displacing the whole. When a deciduous tree is chosen for the food table, the antics of the eager birds may be plainly watched during the winter feeding, and the object lesson is clearly taught to passers-by who stop to admire this practical and beneficial form of garden decoration.

The "food house" in its evolution has assumed many interesting forms, all more or less decorative. Its usual position is standing rather high on a bandor wire-protected pole or post. An overhanging roof of thatch or bark or slender ornamental branches, on the rain-proof foundation, may be varied according to the taste of the garden craftsman, or may be in keeping with the roofing of tea rooms and summer-houses. These feeding places sometimes have the appearance of elaborate bird houses, but closer inspection shows that they are simply big, square platforms, arranged one above another, to hold the different varieties of food, with a generous roof to shelter the whole.

For extremely decorative food houses, stately pillars support the different platforms and the roof. The round white columns are in Colonial form, and the platforms are finished with a bit of upright molding surrounding the edge, to keep the food in place. The roofs are also of simple Colonial design. For 


\section{BIRD BASINS AND FEEDING TABLES}

the rustic structure, bark-covered posts are used, with bark-fringed collars around the wire "cat-teasers," and bark-covered limbs to finish the edges of the food shelves or platforms. On the sloping roof gables the covering of tar paper or rubberoid is finished with closely set rustic branches covering the entire surface, on the order of a bamboo roof. Two tables, or floors, or platforms, as they are variously called, are generally used for these food houses. They are set about a foot apart, and, with different varieties of food, they will accommodate many birds. When three or more shelves are desired for the larger houses, they are set closer together. Then from the roof of the house may be hung the suet or meat bones that give zest to the feast. It is not unusual for decorative food houses to be constructed on large dimensions, from three to six feet square. The overhanging eaves of the decorative roof give a curious appearance mounted on a pole high above the ground. When the food houses are large enough to require four corner posts for their support (instead of the one stout post), each must be carefully protected by tin, zinc, or wire, to insure safety for the birds.

When it is possible to attract birds of larger size, such as the quail and the blue-jay, they should have 
a more secluded feeding table. Because of their shy nature, they prefer a spot near the ground.

Probably the most important provision that we can make for the comfort of birds is to supply them with water for drinking and bathing. Quaint and artistic bird basins should occupy a prominent place in our scheme of garden decoration, yet they are more frequently overlooked than any other decorative plan. They need not appear in expensive fountain form. It is true that many birds delight in the rush and sparkle of falling water, as supplied by fountain or hose spray, but the majority will find greater pleasure in a quiet basin with sloping sides, in some sheltered spot in the garden.

Some attractive forms of garden pottery have been constructed especially for birds. Nesting and feeding places will not be sufficient, especially in making provision for winter birds. In times of ice and snow, the birds that stay with us during the winter months may find comfortable shelter and food. Yet they will certainly suffer for want of water if we fail to provide this important need. When our potteries began to turn out unique designs in bird basins, and odd specimens were imported from Florentine villas, where birds are encouraged to gather in great numbers to brighten famous garden terraces with their songs and gay plumage, we 


\section{BIRD BASINS AND FEEDING TABLES}

began to realize that an ornamental lawn feature might be made extremely useful.

A deep stone crock, or an agate pan, like a deep milk pan, will not prove a wise choice, although these are sometimes noticed mounted on poles beneath the shade of a tree, with bark-covered exterior or other rustic decoration for the metal vessel. The deep pan may serve its purpose in providing a drinking place if it is kept filled to the brim with water, and the birds stand on the brim to enjoy it. But the majority of the small birds dread the deep water; they prefer a shallow basin where they can wade in and bathe after drinking. A basin with a flaring edge, of about an inch in depth near the rim and several inches deep in the centre, will give pleasure and comfort to birds of various sizes.

Smooth tin, agateware, and similar vessels with slippery surfaces do not give a satisfactory foothold for the bathers and waders. A coat of rough paint will partly overcome the difficulty, and at the same time preserve the metal. But for real use and enjoyment, as well as for decorative value, rough crockery and concrete will furnish the most acceptable basins.

The old-world type of bird basins, now found on many American country seats, show elaborately carved and ornamented bowls standing on high 
bases. These tall standards of beautiful Florentine pottery serve the same purpose in holding the huge tapering bowl up out of the way of cats, as does the rustic post on which is set the usual form of concrete or stone-ware bowl.

It is well to study the interior of some of the well-equipped pottery basins and bird fountains which travellers have secured from old-world gardens. Many of them show contrivances in little circular shelves to give different depths. Others have semicircular pockets in the stone-ware, to be filled with sand, where the little waders may find pleasure in shallow water and sandy bottom. An edging of rough stones set at intervals along the interior of the fountain is another means of providing a foothold. The costly bird fountains, standing high on elaborately carved pedestals, frequently display the same rich carving on the exterior and the interior of the fountain bowl. When filled with clear water, the carving glints and sparkles, while the rough surface is not only extremely decorative, but serves its utilitarian purpose in giving a secure footing to the birds.

In planning the inexpensive concrete basins and fountains that are to be of home construction, both the pedestals and the bowls of the costly importations in pottery and marble may have their utili- 


\section{BIRD BASINS AND FEEDING TABLES}

tarian devices followed with little difficulty. Beauty of form may also be closely followed, although it may be unwise to attempt to copy in concrete the decorative carvings and inscriptions. Experts in wood carving will find a delightful field of experimental work in contriving beautifully executed pedestals and fountain bowls, with an interior basin of concrete or stone-ware. When kept well painted, the woodwork will last indefinitely. Tall rustic pedestals, of curious forms, supporting rustic and bark-covered basins, are equally desirable.

For the low basins, to stand on the ground in some sheltered garden retreat (with the necessary wire enclosure), concrete may be used in many pleasing forms. One of the most interesting that has come to my notice is a very wide and comparatively flat or shallow basin that was molded in an old wash-tub. A heavy clay mud was first packed in the bottom of the tub, only an inch deep in the centre, and gradually sloping up nearly to reach the top of the tub at the outer edge. When the stiff, firm clay was well packed down, sand was sprinkled over it. Then a concrete mixture was made of equal parts of sand and cement, with about one-fourth the quantity of gravel. This was thoroughly mixed with sufficient water to make a heavy plaster, and poured into the tub. An iron pipe was set in the centre of the cement, push- 


\section{PRACTICAL BOOK OF GARDEN ARCHITECTURE}

ing it through the wet mixture and the clay mold, to the bottom of the tub, in order to have a hole extending entirely through the concrete basin when finished. While it was setting, the soft concrete was pressed and shaped to give it a saucer form, following the outline of the mold beneath, and it was then left to harden, with its inner surface left rough.

When finally hardened and turned from the mold, this big concrete saucer had the desirable inside flare, sloping gradually from less than an inch in depth at the edge to about five inches in the centre. The hole in the centre is very useful for removing the stale water from the big basin that would be too heavy to handle. A cork is kept in while the basin is filled. When it is removed, the stale water runs out into the flower bed which surrounds the basin, keeping the plants well watered. When it is desirable to set a heavy home-made basin on a pedestal, an eighteen-inch sewer crock may be used to good advantage to hold the basin out of the reach of trespassing cats. Shallow basins, with a broad flare, are best for winter use. They are not easily cracked, and hot water soon melts the thin layer of ice. 


\section{XVI}

\section{TRANSFORMING GARDEN BUILDINGS}

\section{AN ARCHITECTURAL STUDY IN UTILIZING HIS- TORIC STRUCTURES}

THe picturesque transformation of garden buildings " too good to tear down," or treasured for their associations, is a subject of exceeding interest today. The owners of ancestral estates that have become beautiful modern country seats, as well as the founders of attractive little homes in suburban and village sections, are eagerly consulting garden architects for suggestions in remodelling quaint and dilapidated landmarks. It is now considered little less than sacrilege to destroy a genuinely historic homestead, no matter how modern and beautiful may be the mansion of the country seat surrounding it. Various uses are being found in these days of homestead veneration, not only for the old-home structure itself, but also for quaint old-time smokehouses, dilapidated spring-houses, and other such buildings which have withstood the elements for a century or two.

In transforming these old houses for modern usefulness and picturesque value, the homestead 
studio or other artistic workshop is the most pleasing "fad." When there is an artist in the family, the little historic building makes an ideal workshop. When music is the delight of the talented member, a decidedly quaint music room (or musical studio) may be designed within the ancient structure. When literature, science, or other "artistic industry" occupies the time, or serves as a hobby of some one living on the country estate, the homestead workshop is still desirable.

The interior "fitting up" of the studio and the exterior transformation of the ancient building will depend largely upon the use to which it is to be put when reconstructed. In some instances the little one-story buildings which formed the original homes of the settlers have been turned into "billiard cabins," when the ancient farm homes were altered into modern country seats. An author's workshop and a studio for artistic book bindery may be found in other remodelled buildings, that are an attractive feature of the estate. But it has remained for Mrs. Walter Hering, of Abington, Pennsylvania, to display the most quaint, beautiful and practical form of utilizing a picturesque homestead landmark.

When the extensive "Lyndanwalt" country seat first attracted the attention of the entire section of Abington township because of the splendid archi- 


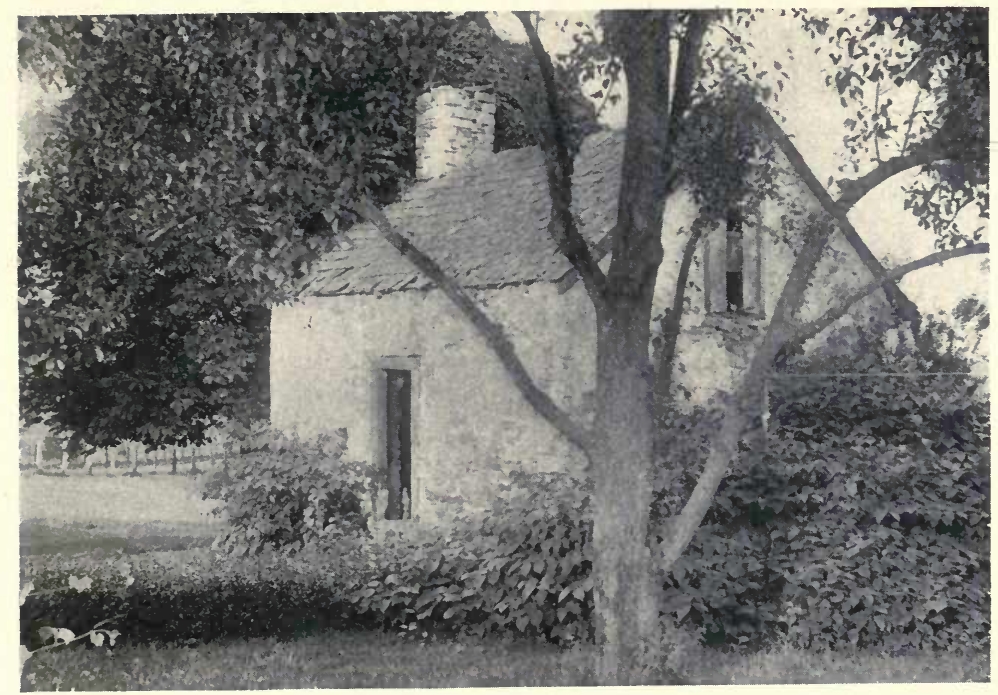

FRONT VIEW OF DILAPIDATED BUILDING AT "LYNDANWALT" BEFORE REMODELLING

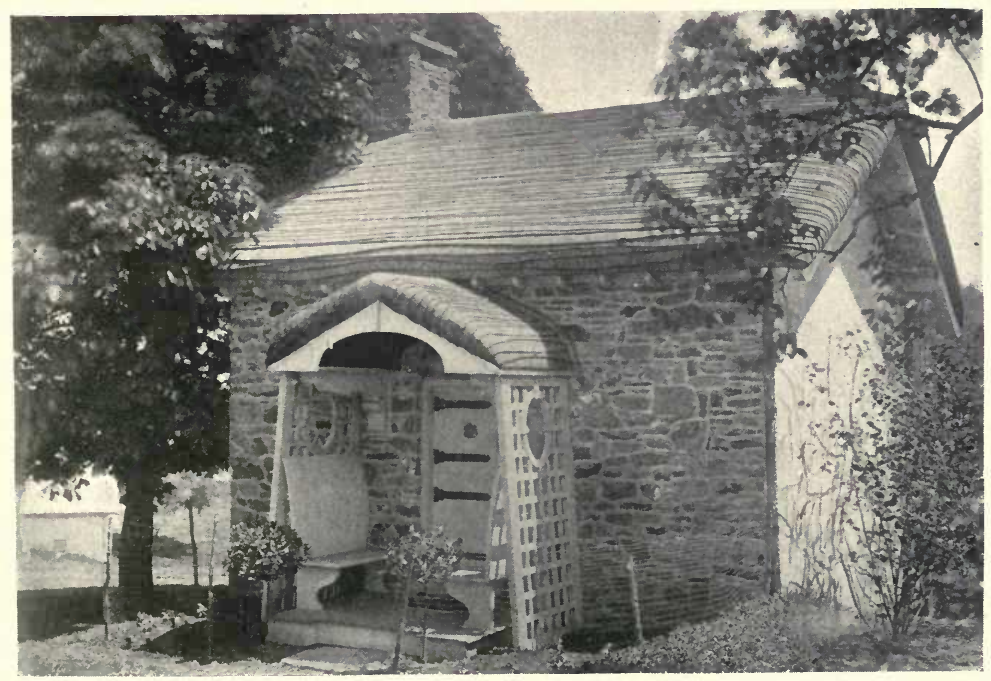

THE GARDEN STUDIO INTO WHICH THE ABOVE WAS TRANSFORMED 


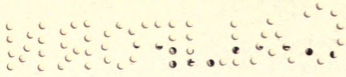




\section{TRANSFORMING GARDEN BUILDINGS}

tecture of its mansion and surrounding buildings, and the elaborate scale on which the grounds were developed, there remained untouched one sacred spot-a little old tumble-down structure, partially hidden in a clump of trees on the lower slope of ground below the mansion. This dilapidated structure was never considered an eyesore, because of its picturesque situation and its quaint surroundings, but wonder was frequently expressed during the gradual development of the fine estate as to the probable use of the old building.

All curiosity was finally satisfied in a most novel manner. At the same time an ideal thought for a studio building was carried out that has set all this section of beautiful country seats longing for artistic talents and an ancient homestead for a studio.

Seemingly ready to tumble into sudden decay, before its transformation, the front of the old structure presented only a doorless entrance-way, a sagging roof full of holes, and a broad expanse of crumbling stone-work. The back of the building likewise presented a doorway, also a dilapidated single window, and an outside cellar door. The upper floor of the old structure was a mere garret loft with a narrow window at each end. The first step in transformation was the removing of the old' roof, it being replaced by the most modern and quaint of 


\section{PRACTICAL BOOK OF GARDEN ARCHITECTURE}

shingle-thatched roofs; thatching made picturesque and durable by the use of soaked shingles laid on by a peculiar modern method. The staunch old stone walls were then pointed, the doorway somewhat enlarged in the front, and entirely closed up at the back to allow room for enlarging the old window into a light and airy bay window. Then the doorway was rendered most artistically "antique" by the use of iron strap hinges and knocker, relics of ancient days. Sheltering the doorway a novel portico has been built, combining old-time high-back settles, latticed sides, and a hooded roof, quaintly thatched.

The windows have been removed from the loft and the stone-work extends from ground to roof; this gives an opportunity of utilizing the loft in most artistic manner within. The ceiling and floor have been removed from between the lower floor and the loft, and a narrow gallery extends quite around the building, lighted from below, thus making the entire studio one big room (with all old partitions removed) reaching from floor to roof. The ancient kitchen fireplace now forms a part of the original living room. Along the entire gallery surrounding the room, historic relics, mementos of foreign travels, and family heirlooms are displayed in most attractive form, tempting visitors to spend hours in this fascinating place. 


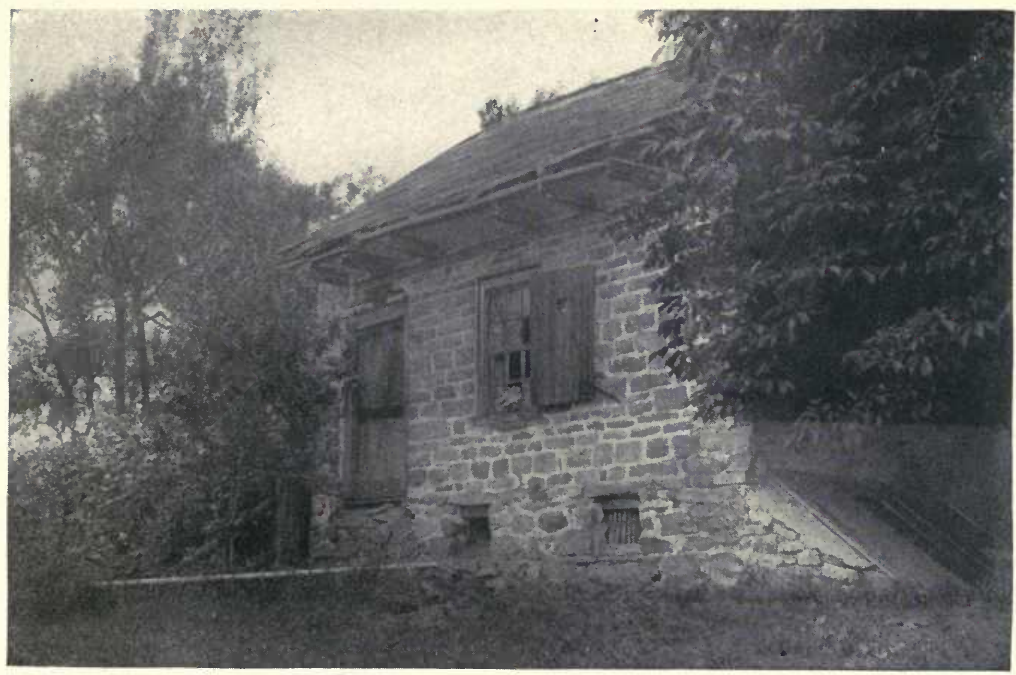

BACK VIEW OF THE ANCIENT STRUCTURE BEFORE REMODELLING

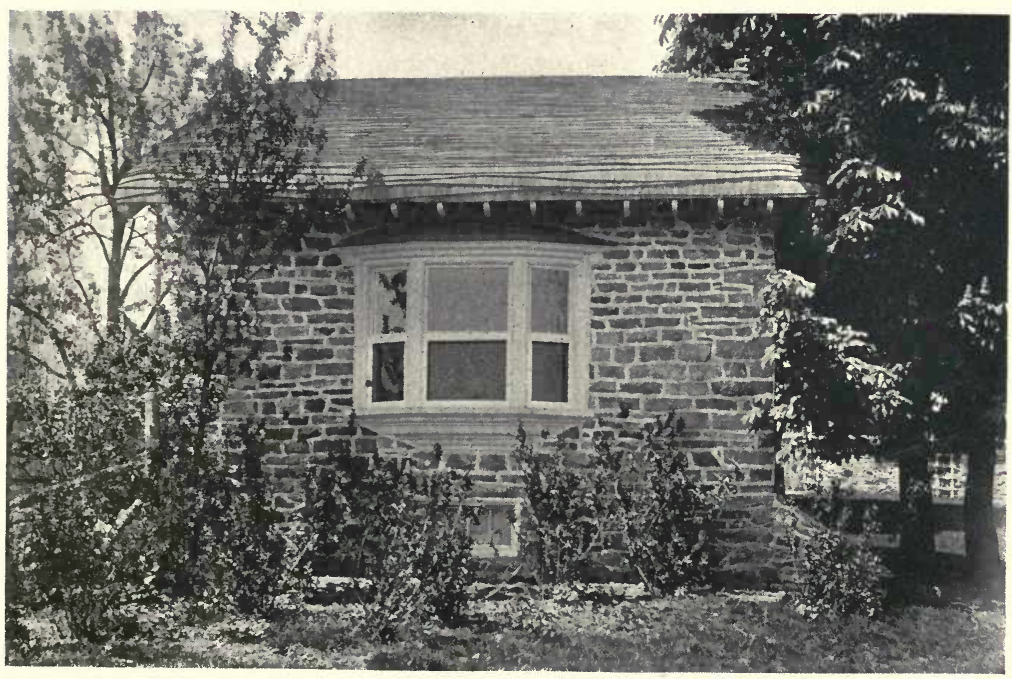

BACK VIEW OF THE WELL-LIGHTED GARDEN STUDIO 


\section{TRANSFORMING GARDEN BUILDINGS}

But the most alluring spot is the main floor of the studio, where the artistic hostess of "Lyndanwalt" spends her leisure hours most delightfully engaged in china painting. While her beautiful work is widely known, only a favored few of her personal friends know of the delightful workshop in which her beautiful painting is executed, or of the effect of her artistic talents on the ancient building and its surroundings.

The old mantel and fireplace have been altered only sufficiently to make them staunch, and presentable for the display of ancient family pewter and other treasured heirlooms. The various details of the interior present a fascinating study for the owners of beautiful country seats who are contemplating the preservation and transformation of ancient homestead buildings. The novel treatment of the exterior presents the most striking characteristics, however. Although the effect is decidedly unique and pleasing, it need not be expensively carried out. Hooded doorways, quaint Colonial seats and screens of lattice panels, are all within the reach of the average craftsman. Wherever it is possible, it is wise to preserve the ancient stone-work of these old buildings, in their transformation. Fresh pointing will make the crumbling walls secure without making them look too new and modernized, if it be care- 


\section{PRACTICAL BOOK OF GARDEN ARCHITECTURE}

fully done. Should there be a side of the building or an end exposed to rough weather that is too crumbled to make fresh mortar advisable, a plain lathing and plaster cast finish will make the wall secure. Ivies may soon be made to cover the "odd" wall, leaving those of stone-work exposed. The roof thatched with straw will prove less costly than the shingle thatch, and will be entirely appropriate for the historic structure. 


\section{XVII}

\section{THE JAPANESE GARDEN IN AMERICA}

\section{QUAINT ACCESSORIES COMBINED WITH UNUSUAL LANDSCAPE FEATURES}

THE ever-increasing demand for novelty in the ornamenting of country seats has of late years led to pleasing results in the reproduction of the best types of oriental gardens. Less than a decade ago an authority on landscape gardening lamented the fact that Americans are slow in appreciating the true art of gardening in regard to the idea of fitness and harmony in details, as evidenced by Japanese landscape artists. The statement was then made that while there have been a few attempts at copying Japanese methods, there is not a genuine Japanese garden constructed upon true oriental principles to be found upon any of our noted American country seats. Now all this has changed. Within the past few years many famous gardens have been constructed by genuine Japanese craftsmen, who have given their entire lives to the study of the religious and symbolic, as well as the picturesque features of landscape gardening; and who have carried out with painstaking care, upon occidental acres, the artistic details that have made oriental gardens of world-wide fame. 


\section{PRACTICAL BOOK OF GARDEN ARCHITECTURE}

The study of Japanese manners and customs, of home decorations and gardening features, first became of prominent interest in this country in connection with the early world's fairs-the Chicago Fair of 1893 presented one of its most charming features, in the form of a complete Japanese village, constructed and ornamented with regard to all the traditional details for which Orientals are famous. Japanese villages then became the fad, not only for later "fairs," but Japanese tea rooms, and Japanese gardens on an elaborate scale were built as side attractions at famous summer resorts; and an increasing interest in the quaint stone lanterns, the curiously dwarfed trees, the winding, rockbound waterways crossed by novel bridges, and all the significant details of garden accessories associated with the traditional and legendary lore of the Japanese, attracted the attention of owners of splendid country seats, who speedily demanded the services of genuine oriental landscape artists thus to decorate a portion of their extensive acres.

In some instances, of late, Japanese gardens have been transplanted bodily from a summer resort (where they have flourished for a time and then become unprofitable) to decorate a home garden of an enthusiastic nature student, as in the case of the quaint and charming bit of old Japan on the Mathias 


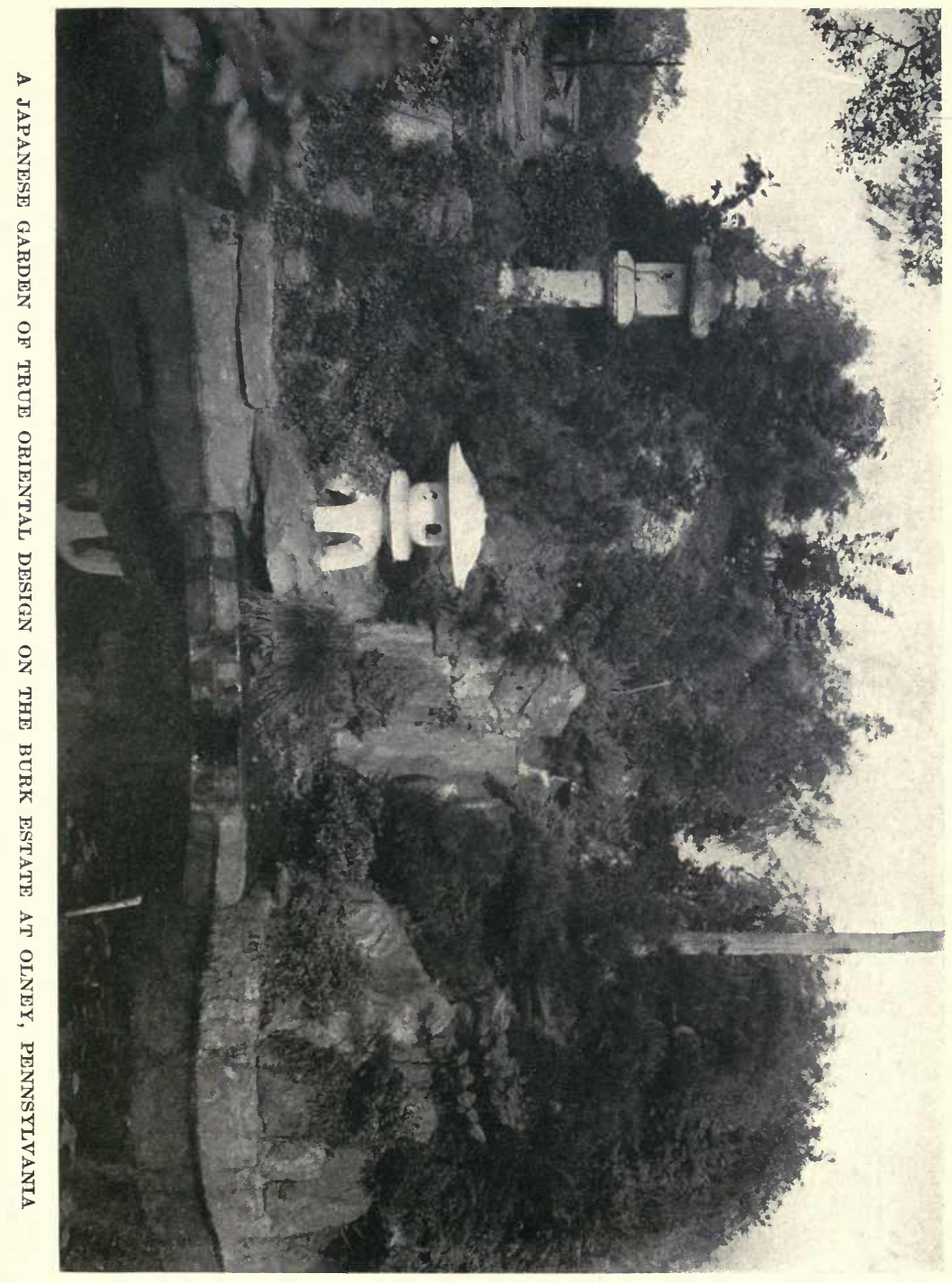


$\because \vdots \vdots \vdots \vdots \vdots \ldots$

$\because \cdots$ 


\section{JAPANESE GARDEN IN AMERICA}

Homer estate at Lansdowne, Pa. In other instances the owners of still more extensive acres have not only employed famous Japanese artists to lay out ideal gardens, but they have themselves become interested in importing the dwarfed and curiously stunted and gnarled old trees direct from the mother country, to decorate their unique gardens. Mr. Charles Pilling was one of the first to follow this fad, and the century-old pines, and many novel plants and trees measuring only a foot or two in height, and numbering their years by centuries, now decorate his Japanese garden nook, imported by himself. Again, the owners of extensive country seats have given all the details of importing the paraphernalia and the construction of their oriental gardens to the care of the Japanese craftsmen who excel in this work, while taking an intense personal interest in the development of their new possessions, growing from year to year-like the garden of Mr. Louis Burk, in which he has watched the tedious process of construction for three or four years with ever-increasing delight (though not taking any direct part in its construction) and who is now planning greatly to increase its area. There is a fourth class who own wonderful Japanese gardens, who look upon them simply as an additional attraction for decorating a portion of their extensive acres, and after being assured that 


\section{PRACTICAL BOOK OF GARDEN ARCHITECTURE}

the garden building is under the supervision of a genuine Japanese artist who will "do the thing up right," they give no further concern to this than they do to the Italian and other formal gardens that are attractively placed on various secluded portions of their grounds. But no matter what may be the object that influenced the owner to include Japanese gardening in decorating his home grounds, the interest thus evidenced has grown until many are becoming familiar with the true art of gardening in Japan.

There is still another class of enthusiasts upon this subject, who have attempted to build their own oriental gardens, fashioned after those that they have studied on their travels in Japan, or by studying the models already established in this country; but in every instance it is noted that such gardens fail to be successful, unless one understands the seemingly endless details that govern true oriental work. It is safer, if one would have it constructed on correct lines, to give the building of the large, attractive Japanese garden into the care of a native craftsman.

The American-Japanese gardens, which present interesting studies in various sections of the country to-day, almost invariably include numerous flowers with their ornamental accessories-the Japanese azaleas, the dwarfed plum trees and many novel 


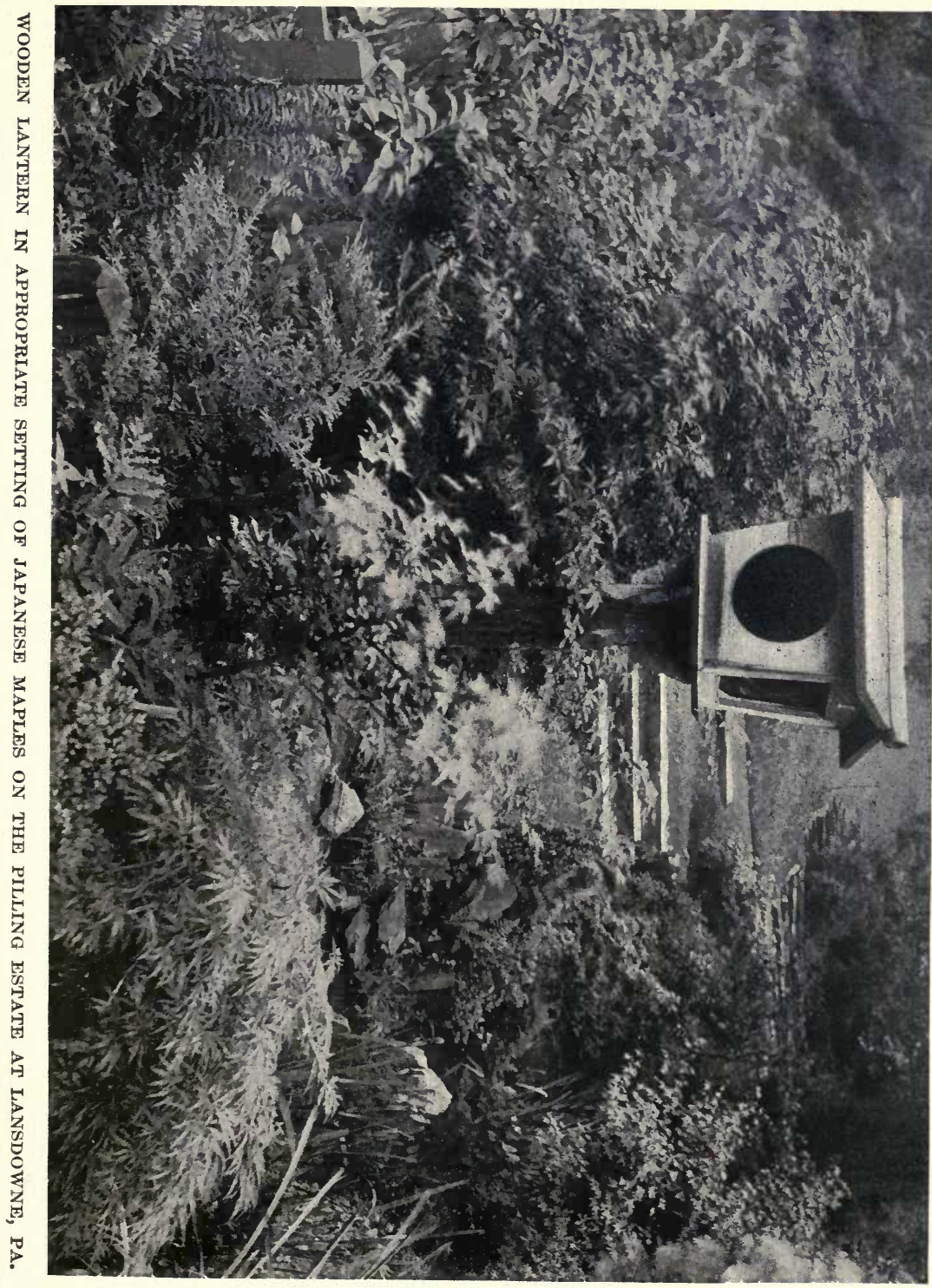




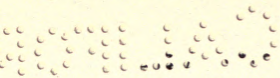


water plants being the prime favorites; but travellers in Japan frequently note the fact that the native gardens are not necessarily flower gardens, neither are they always made for the purpose of cultivating plants. In nine cases out of ten there is nothing in the smaller plots to resemble a flower bed. Some gardens may contain merely a sprig of green; some (although these are exceptional) have nothing green at all, and consist entirely of rocks, water and sand. Neither does the Japanese garden require any fixed allowance of space; it may cover one or many acres; it may be only ten feet square; it may, in extreme cases, be much less, and be contained in a curiously shaped, shallow, carved box set on a veranda, in which are created tiny hills, microscopic ponds and rivulets spanned by tiny humped bridges; while small, strange plants represent trees, and curiously formed pebbles stand for rocks. But on whatever scale, all true Japanese gardening is landscape gardening; that is, it is a living model of an actual Japanese landscape.

It is an exceptional privilege to study at first hand the significance of all the details that go to make up the true Japanese gardens which have now become the fad in this country. I have been informed by an excellent authority on the subject that "through long accumulation of traditional methods, 


\section{PRACTICAL BOOK OF GARDEN ARCHITECTURE}

the representation of natural features in a garden model has come to be a highly conventional expression, like all Japanese art; and the Japanese garden bears somewhat the same relation to an actual landscape that a painting of a view of Fuji-yama by the wonderful Hokusai does to the actual scene-it is a representation based upon actual and natural forms, but so modified to accord with accepted canons of Japanese art, so full of mysterious symbolism only to be understood by the initiated, so expressed, in a word, in terms of the national artistic convention, that it costs the western mind long study to learn to appreciate its full beauty and significance. Suppose, to take a specific example, that in the actual landscape upon which the Japanese gardener chose to model his design a pine tree grew upon the side of a hill. Upon the side of a corresponding artificial hill in his garden he would therefore plant a pine, but he would not clip and trim its branches to imitate the shape of the original, but rather, satisfied that by so placing it he had gone far enough toward the imitation of nature, he would clip his garden pine to make it correspond as closely as circumstances might permit to a conventional ideal pine-tree shape, as though buffeted and gnarled by the fierce winds of centuries.

These native craftsmen also will assure the 


\section{JAPANESE GARDEN IN AMERICA}

owners of the gardens they are constructing, that there are ideal shapes not only for the trees, but also for the mountains, lakes, water-falls, stones, and numerous other accessories; and that it is of the utmost importance that the gardener should take cognizance of a multitude of religious and ethical conventions in working out his design. They call attention to the fact that the streams must follow certain cardinal directions; that the nine spirits of the Buddhist pantheon must be symbolized in the number and disposition of the principal rocks; that the trees and stones must be carefully studied as to their relations to each other, and to the general garden scheme, and only such combinations made as are regarded as "fortunate." And woe to the unhappy gardener who does not study, very carefully, their symbolic relations, and who heedlessly introduces what is considered an unlucky combination.

So conscientious are the oriental garden builders that they give the same care in regard to symbolic details to their "foreign" landscape construction, on American country seats, as in their native country. No matter what the size, form or finishwhether it is large or small, mountainous or flat, rough or elaborate-the true landscape garden must be made to contain, in some form, rocks and water 


\section{PRACTICAL BOOK OF GARDEN ARCHITECTURE}

and vegetation, in connection with various architectural accessories in the form of indispensable lanterns, bridges, and stepping stones; while in the more elaborate gardens are introduced pagodas, water basins, tea houses, boundary fences, or hedges of bamboo, and fancifully roofed gateways.

The careful distribution of garden vegetation is considered quite as important as the arrangement of the principal rocks and stones and the contours of land and water. The eastern travellers who have taken cognizance only of the grounds of the larger temples of Japan will probably fail to realize the significance of tree grouping in regulation landscape gardening. In the temple gardens, groves and avenues of trees are frequently planted in rows, with the same formality adopted in western gardens, while in the true landscape gardens such formal arrangements are never resorted to. Not only are the trees arranged in open and irregular groups, instead of being planted in rows-when several are planted together-but the rules for planting these clumps or groups are rigidly determined. To the uninitiated it is difficult to understand just why these tree clumps must be disposed in double, triple or quadruple combinations, while these combinations may again be regrouped according to recognized rules based upon contrasts of form, line and color of 

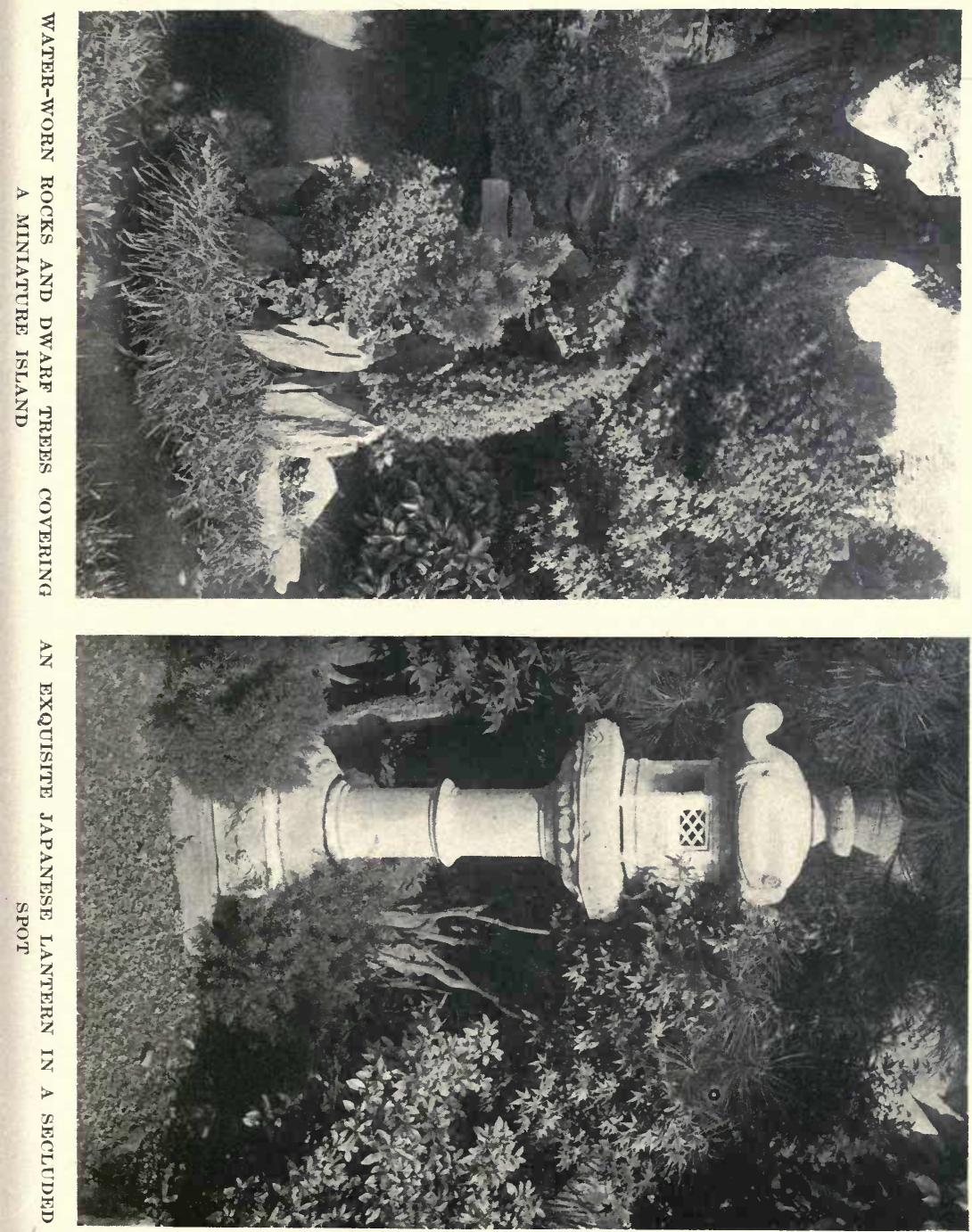
$\because v^{2} i i_{i} i i_{i} i$

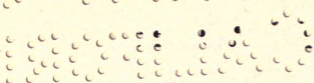




\section{JAPANESE GARDEN IN AMERICA}

foliage; but all these rules are understood and most carefully adhered to by the master of Japanese garden craft. And it is found, on comparing the grouping of tiny dwarfed trees of miniature gardens with the arrangement in large spaces, that the same rules have been followed.

The disposition and use of the various architectural accessories of the garden are also formally regulated, and the variety in garden building is found mainly in the form of these accessories, as the pagodas, lanterns, water basins, wells and bridges are fashioned in many curious and beautiful designs, while the enclosures in the form of unusual fencing of reeds, bamboo and twigs present many pleasing forms and combinations.

The famous Japanese landscape gardens that have been established on American country seats have been sufficiently large to give a fairly good idea of oriental landscape gardening on an extensive scale: and yet there is no reason why the owners of city homes, with small back yards enclosed by ugly high board fences, should not have them transformed by a bit of Japanese magic. Professor Morse tells in his talks on the Japanese, of how they utilize the smallest areas of ground for such effects. "I recall an example," he says, "of a cheap inn where I was forced to take a meal or go hungry until late 


\section{PRACTICAL BOOK OF GARDEN ARCHITECTURE}

at night. The immediate surroundings indicated poverty, the house itself being poorly furnished, the mats hard and uneven, and the attendants very cheaply dressed. In the room where our meal was served there was a circular window through which could be seen a curious stone lantern, and a pine tree, the branches of which stretched across the opening, while beyond, a fine view of some high mountains was to be had. From where we sat on the mats there were all the evidences of a fine garden outside: and wondering how so poor a house could sustain so fine a garden, I went to the window to investigate. What was my surprise to find that the extent of ground from which the lantern and pine tree sprung was just three feet in width! Then came a low board fence, and beyond this stretched the rice-fields of a neighboring farmer. At home such a strip of land would, in all likelihood, have been the receptacle for broken glass and tin-cans, and a thoroughfare for erratic cats ; here, however, everything was clean and neat-and this narrow plot of ground, good for no other purpose, had been utilized solely for the use of the room within."

There is no reason why the smallest of these back-yard gardens should lack any of the indispensable accessories; for they may all be reproduced on a miniature scale. In fact, the great majority 


\section{JAPANESE GARDEN IN AMERICA}

of the city homes in Japan have very little more scope for their gardening than that contained in the brick-paved or cemented space back of the average city homes of America. We can profit by many lessons in perspective, as well as in harmony and completeness, as taught by these miniature oriental landscapes, even though we may not be versed in the religious and symbolic relations of the various features of the little garden. There is no necessity for flat sameness in the little back yard to which we are to direct our efforts. The soil removed to form the ponds and streams will build the miniature hills. Whether we build a little wooden lantern or purchase one of the quaint stone lanterns of true Japanese origin, whether we dwarf and prune small cedar trees from a nearby wood-lot or import dwarfed pines at considerable expense from Japan, whether we have a natural stream running through our suburban place or must be satisfied with a hidden hose-supply from the city pipes, there are possibilities in every case of securing some very good results in healthful diversion, and considerable garden beauty when we conscientiously study and practise the best types of miniature landscape gardening as perfected in Japan. Our little artificial lake of pellucid brightness may have a corresponding waterfall and a quaint stone bridge; and the tiny artificial 


\section{PRACTICAL BOOK OF GARDEN ARCHITECTURE}

mountains, with their whimsical trees, should be kept in proportion to their surroundings. In the larger gardens of suburban places and country seats, the oriental garden that is to be carried out in true Japanese design should be given over to the care of genuine landscape artists from the Orient. To create the spirit of the landscape is the aim of the Japanese gardener-an aim too frequently overlooked in our modern American work. 


\section{XVIII}

\section{FRENCH FURNISHINGS FOR THE FORMAL GARDEN}

\section{PRACTICAL ACCESSORIES WELL ADAPTED TO FORMAL COMPOSITION}

In the shady sections of the garden, where flowers will not flourish, or where an abundance of tree roots continually sap the strength of the surface soil, interesting types of formal garden furnishing may take the place of bloom profusion.

Italian, English, and Japanese conceptions are the favorites in strictly formal gardening. Grecian and Egyptian accessories are appropriately grouped about the stately garden temples and architectural fragments in stone and marble gathered by zealous travellers who are ambitious to display novel effects on their American country seats.

It is seldom, however, that strictly French types of garden architecture and furnishing are grouped with good effect in formal spaces. This should be a source of regret when ore considers the admirable studies presented by French landscape artists that may be carried out in many forms of American garden building.

When for lack of space, or for any other reason, 179 
it is not desirable to have an elaborate formal garden constructed after the early French types, various accessories may be consistently grouped in secluded spots that will recall delightful glimpses of old-world gardens.

Quaint features typically French in conception readily may be carried out at little cost, in cement and mortar. Adornments for water gardening, unusual effects in wall gardening, characteristic screening for seclusion and "mystery" are all adaptable to our home gardens. Many of them are being introduced with such good effect that any one who has travelled in France readily recognizes the charm and distinction.

It is true that the French as well as the English types of garden furnishing follow closely the character of the Italian Renaissance; yet they have distinct features that are easily recognized. The treatment of garden walls presents a striking feature; also various architectural devices for enclosing nooks and corners (where one may build a garden retreat for meditation and inspiration) form studies of considerable interest.

On the beautiful hill gardens of many famous country seats along the Hudson, at Yonkers and Hastings, New York, and also on the New Jersey shore, there are garden walls, for instance, that are 


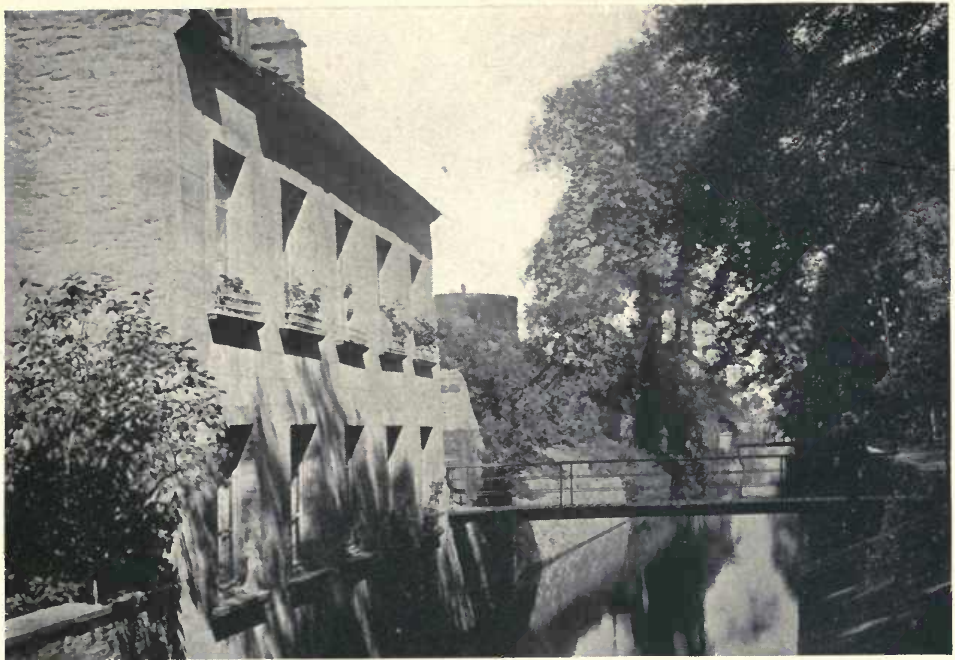

ATTRACTIVE, MODEST HOMES ALONG THE CANALS OF SUBURBAN PARIS

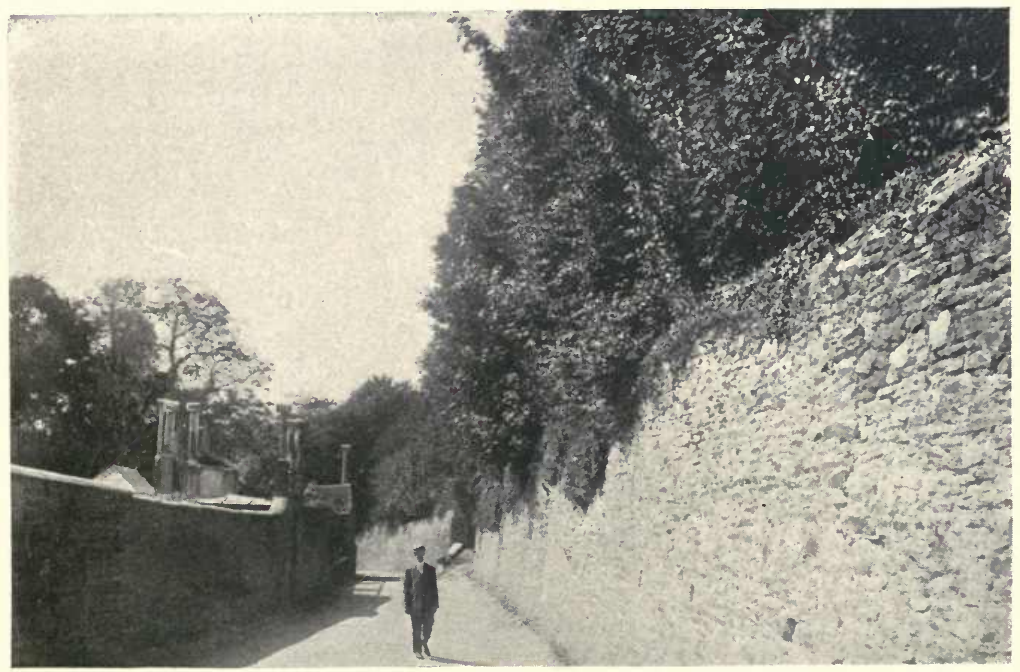

ONE OF THE NARROW AND CROOKED. FRENCH STREETS WITH BLOOMING PIANTS OVERHANGING THE WALL 
s. 
almost fac-similes of the fascinating flower walls of Cherbourg and suburban Paris. They possess the unusual feature of having considerable beauty offered to the public view.

The walled gardens of England, with very few exceptions, present only cold, straight, forbidding expanses of stone, brick and mortar to the public highway; while within, reserved only for the enjoyment of the owners and their guests, are the wall fountains, the profusion of blooms flourishing in the rock-bound earth-pockets, and the trailing beauties of wall terraces.

On the hilly country seats of France the protecting walls that confine the terraces, and prevent washouts on steep slopes, frequently have their smiling faces turned towards the public highway as beautiful as those within the enclosure. Bright blooms nod gaily to the passer-by. Little springs jutting from the hillside are caught by cemented wall basins, and form cool, refreshing drinking fountains, then ripple over the edge of little pools and trickle down the wall. By confining and separating, here and there, the spring-fed streams and ripples are adroitly managed until they are made to serve as little irrigating streams for causing water-loving plants to flourish in the walls, as well as to beautify the architectural features of wall and fountain with the sparkle of 


\section{PRACTICAL BOOK OF GARDEN ARCHITECTURE}

water. Where steep hillsides demand a straight, stiff, formal wall to confine the weight of soil, trailers are encouraged to flourish at the top; and drooping down over the outer wall they are caught on quaint trellises and made to transform the ugly spots of barren wall surfaces.

One of the most interesting types of outer-wall embellishment to be found in this country displays a succession of bloom and the fascination of running water, with comfortable seats at enchanting viewpoints, on the Woodward estate known as "Krisheim" at Chestnut Hill, Pennsylvania. With the house standing high on a hill top, and with the upper gardens out of view from the roadways winding through the grounds, there has been no necessity for erecting walls for giving privacy to the home surroundings. The walls supporting the various hill terraces have accordingly been turned to face the public in true French fashion. The result is truly fascinating. Few of the wall adornments of castle hill gardens of France can compare with those of the Woodward estate. From the time of the earliest spring-bulb blooms, before the snow has left the ground in sheltered places, throughout the heat of summer, and until snow flies again, these sheltered, moist earthpockets send forth their profusion of bloom from every known bulb and perennial that can be made 
is

isteris:

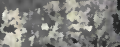

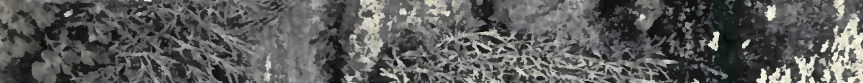

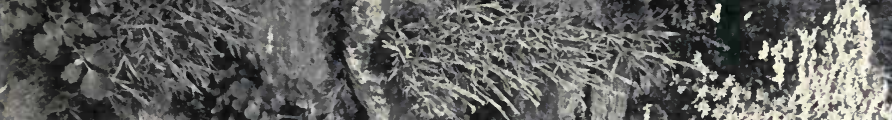

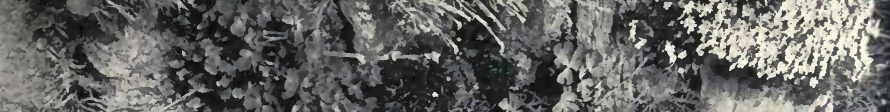

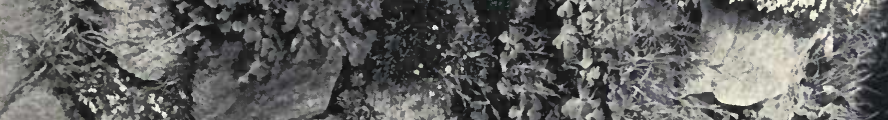

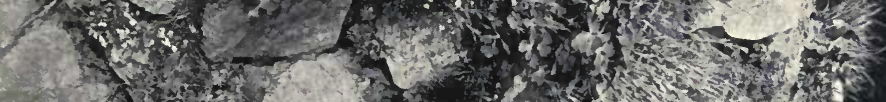

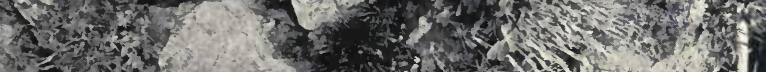

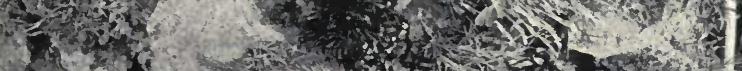

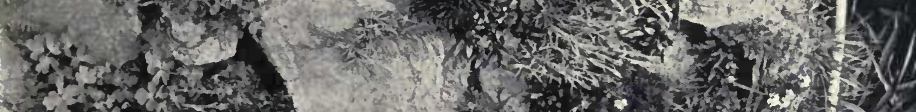

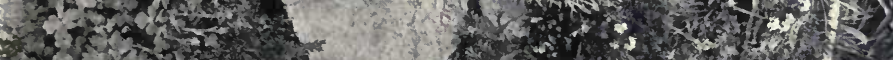

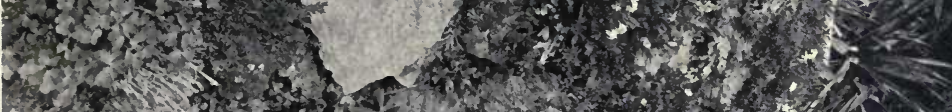

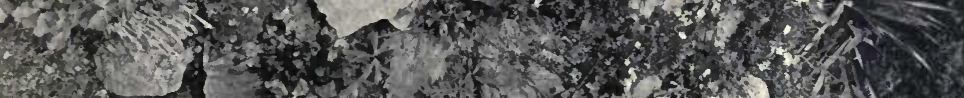

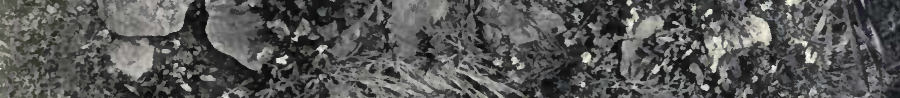

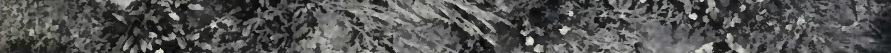

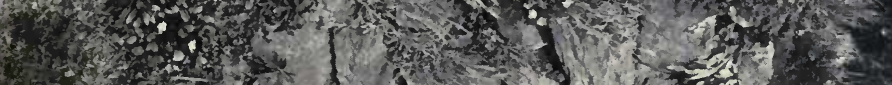

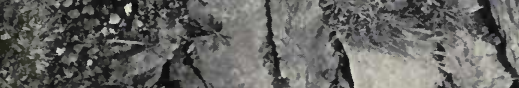

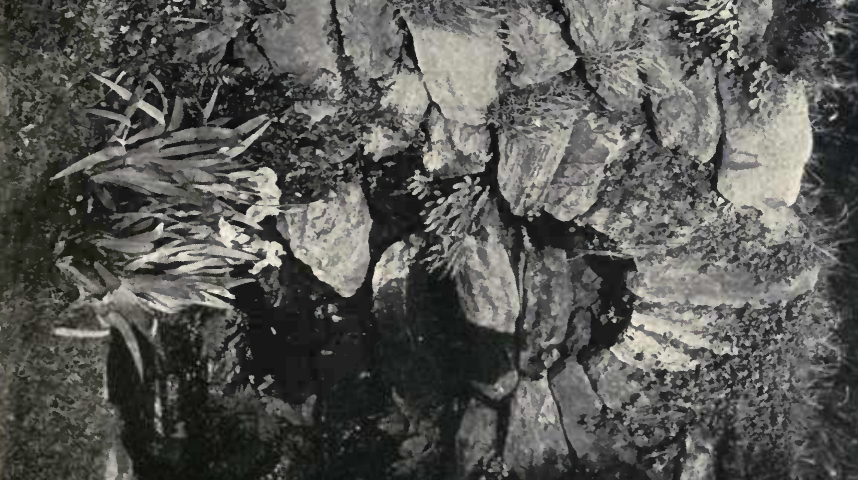

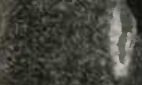

$x+2$

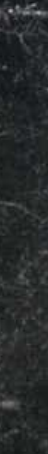


$\therefore \quad \because \vdots \because \because \vdots$

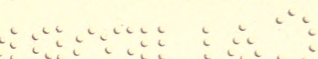

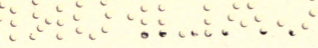




\section{FRENCH FURNISHINGS FOR FORMAL GARDENS}

to flourish undisturbed year after year. Hardy flowering shrubbery grouped along the upper surface of the terraces nods its blooms over the top of the wall. Quaint little trellises jut out to sustain frail beauties in wall crevices. And with clever manipulation of big bowlders, trowel and concrete, wall fountains are made to catch and hold basins of clear sparkling water, where springs bubble out from various sections of the walls.

A point of excellence noticed in the construction of the high walls and their adornments is as well wrought out in the Woodward gardens as in those of France. Straight lines are avoided so far as possible. In winding beauty and alluring curves, the great length of wall surface extending around and through the extensive grounds has been made to present fresh attractions at every turn. One never tires of walking on and on through the long vista of changing interests. Resting places are provided, however, to give completeness to the whole. These take the form of quaint garden seats, built with attractive curves and angles, with restful backs and arms, after the comfortable French type. These seats are placed at frequent intervals along the winding roadways; and in every case they stand at some distance away from the view-point which their presence emphasizes. Across the road from the wall, 


\section{PRACTICAL BOOK OF GARDEN ARCHITECTURE}

and facing some special charm of trellis, or fountain, or soil-pocket of bloom, they are ingeniously placed where the most attractive view-point holds the gaze, and then merges into the mystery of hidden beauties around another curve or angle in the wall.

Taken as a whole, the ornamental features of these extensive wall surfaces may appear to be quite beyond the reach of the average garden builder, who is inclined to lament his limitations in regard to space, as well as means. In reality there is no occasion for lamentation. Wherever there is neccessity or possibility of attractive wall building to confine terraced slopes or enclose hilly sections, varied attractions may be made to face the public highway, or the drives within the grounds, as well as to adorn the view from the house. The smallest length of wall surface may be so treated that it will add to the ornamental features of the grounds or the little home garden. Even a casual study of the manipulation of flowers, trellis, and running water, will satisfy one as to the possibilities of this form of garden adornment; and a careful study will disclose the fact that most beautiful effects can be wrought out at very little expense.

There are famous gardens along the rocky coast of Maine where broken stone mixed with concrete forms rugged outlines for garden ponds; and where 
the accessories of sundials, fountain figures, and huge shells forming basins to hold the soil for growing water plants, are appropriately blended after the type of early French gardening.

A visitor to these quaint gardens, if he has had the pleasure of visiting similar types in France, is reminded of what were once known as the "Palissy gardens." Although the earliest examples of this form were carried to extremes, the present-day types display much to be commended. It was the same Bernard Palissy who was afterwards famous for his work in porcelain, who first advanced quaint forms of adornments for water gardens. It is true that he was justly condemned and widely criticised for overdoing the matter when he allowed his unbridled imagination to carry him to absurd extremes; as when he built the famous gardens and pleasure grounds for Catherine de Medici at Chenonceaux. In this work he not only completely abandoned himself to his fancy for rockeries, basins and shell work, and similar appropriate adornments for water gardens, but he added to the list of concrete adornments, frogs, turtles, snakes, etc., in such variety that the beauty of his work was lost in the study of its absurdity.

Much that was really good in Palissy's conception is now carried out in the French treatment of water gardens, while his extremes and absurdities are 
avoided. The Maine gardens of appropriate rock and concrete boundaries and adornment have their rockeries and water gardens ornamented with objects in harmony with their surroundings. Noted water gardens of suburban New York show the same practical idea in harmonious treatment. For the fountain standing in a big lily pond, the sparkling water is sent up into the air by a mermaid poising gracefully on her concrete pedestal; and for the cement column for the sundial-stand on the margin of the pond, turtles very appropriately form the base; and throughout the treatment of the pond adornments there are many quaint suggestions of the Catherine de Medici garden.

The screening of garden corners for the display of statuary, and various contrivances for creating garden mysteries, form a later type of French treatment that has deservedly found favor in America. Many of the extreme features that opened to criticism the work of Bernard Palissy, Olivier de Serres, the three Mollets, and other garden architects of the Renaissance, were modified in later conceptions. During the early part of the seventeenth century, the professional gardeners of France began to exercise great care in securing appropriate effects; and architects were frequently employed to design the grounds to harmonize with their buildings. The 
famous garden of the Luxembourg is still recommended to visitors and tourists as one of the best samples of this form of garden harmony, although only a small portion of the original grounds now remains of the once extensive estate. The garden of the Luxembourg (which was laid out by Jacques Debrosse for Marie de Medici between 1615 and 1620), like the still more famous Le Nôtre gardens of a later period, possessed the fascination of mystery in addition to their harmonious treatment.

Various forms of garden architecture were then introduced among the French which had become indispensable in garden building among their southern neighbors in sunny Italy. Du Cerceau, in writing of the French gardens of this period, says: "Everywhere were great divisions, with avenues of high trees, fences of hazel, and hedges of hawthorn. Long, trellised arbors, opening out at intervals into shady summer-houses, ideally arranged for scenes of gallantry, surrounded the open central space, or divided it into several individual gardens. Marble basins with spouting water-jets and cascades, gliding from artificial rocks, made up the principal remaining features of the rather chilling and over-symmetrical decoration of the gardens in which everything seemed obedient to a single demand-coolness, shade, mystery." 
Andre Le Nôtre, who is now recognized as the most famous of all the men who influenced French gardening, doubtless drew his inspirations from these old gardens of charm and mystery, but instead of following in their footsteps he originated features that made all of his work impressive. As he was born in Paris in 1613 he was fortunate in living in an age when his conscientious work should be best appreciated-the age of Louis XIV in France. In this age of expensive luxury and devotion to pomp, ceremony, and various arts, Le Nôtre was encouraged by the king to give full sway to his artistic talent. Having been carefully educated by his father (who was head gardener to the king and who also held the position of Director of Works), it was intended that he should excel as an artist. He studied painting under the best known masters ; but his love for gardening made him dissatisfied with the life of an artist, and encouraged him to devote his life to artistic landscape architecture. During a visit to Italy to study the landscape work there, Le Nôtre superintended the laving out of several famous gardens, but he devoted the most of his time to French gardens of renown, after he had accomplished his masterpiece at Versailles to charm the beauty-loving Louis XIV.

The French ideas in garden architecture carried out on prominent American country seats of to-day 


\section{FRENCH FURNISHINGS FOR FORMAL GARDENS}

are largely the result of studying Le Nôtre's conceptions. His influence also may be traced in wellplanned gardens of unassuming suburban homes. How to control garden spaces to bring out their greatest beauty and impressiveness, and how to keep the seemingly insignificant details harmonious, are the important features in French gardening that may be as readily caried out in little home dooryards as in the landscape work on large estates. 


\section{XIX}

\section{AN UNUSUAL WOODS GARDEN}

A PLACE OF SURPRISES AT EVERY BEND OF THE WINDING WOODLAND ROADWAY

THE suggestion of a woods garden conveys the idea of converting rocky spaces and woodland lakes into beauty spots by means of "wild gardening," the cultivating of native wild flowers. The more novel conception is the transformation of open spaces in the woods by means of garden architecture. Thus a series of woodland pictures may be produced, each distinct in itself, that will act as a surprise to the delighted beholder coming upon it suddenly in the bend of the woods road.

The usual forms of wild gardening have been carried out in various ways to form fascinating woodland pictures in the garden groves of many noted estates. The same ideas are practical for the wood lot of farm homes, and may be made exceedingly attractive at slight expense. On the other hand, they may be made into costly botanical studies like the woods garden of Col. H. L. Higginson at his home in Manchester, Massachusetts. Here no expense has been spared to establish an elaborate rock garden, where alpine plants have been natural- 


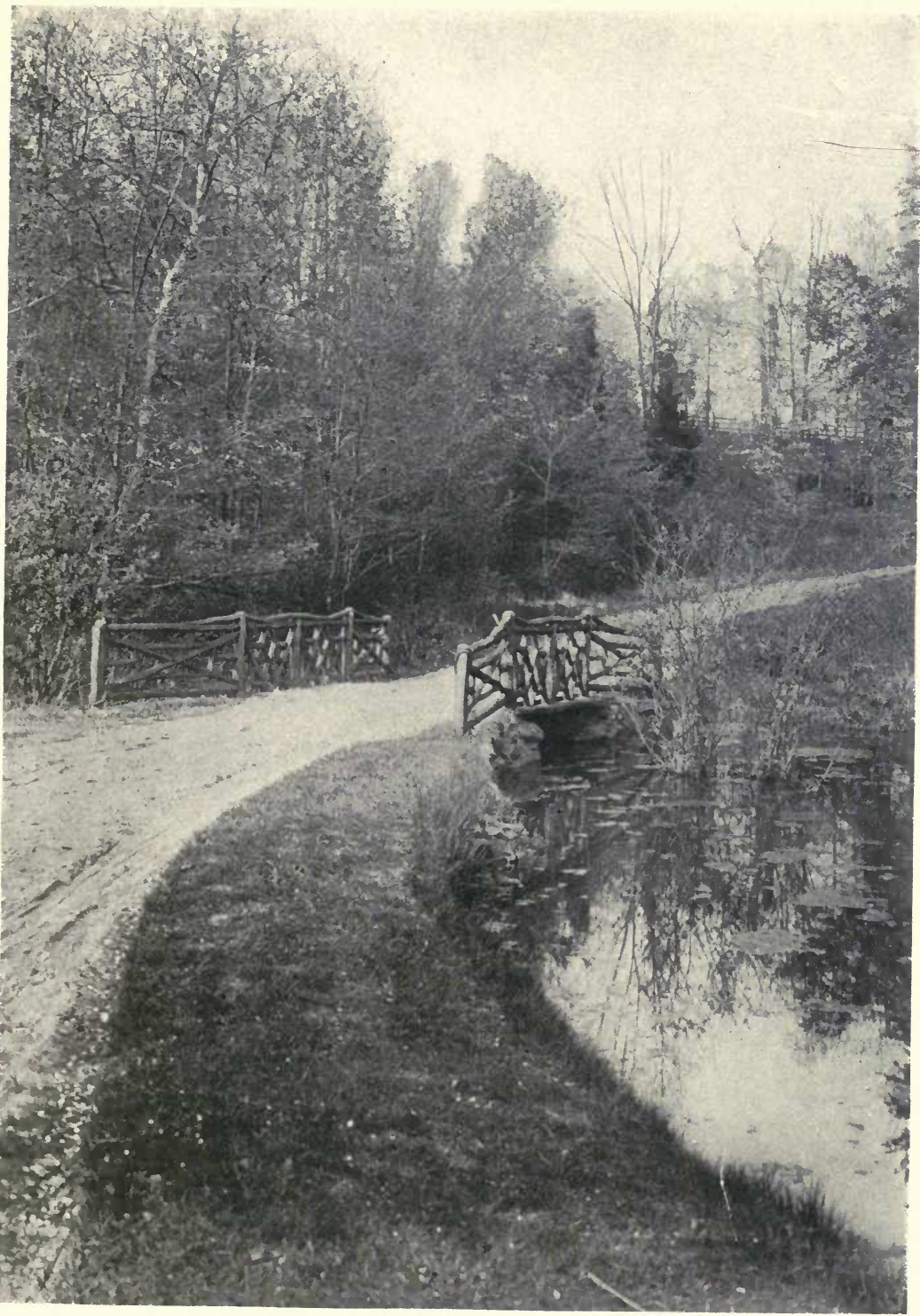

A RUSTIC BRIDGE PLACED WHERE THE DRIVE CROSSES A WOODLAND STREAM AT "THORN HEDGE" 


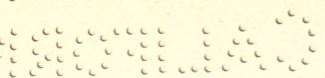




\section{AN UNUSUAL WOODS GARDEN}

ized and made to flourish as luxuriantly as when grown in their native rocks.

There is another famous woodland garden in Massachusetts: that of Gen. S. M. Weld, at Dedham, in the suburbs of Boston, where a woodland lake and bubbling brooks are utilized to present charming pictures of wild gardening; and rocks also contribute their share of rugged rustic ornamentation.

The unusual forms of woods gardens not only make the most of the material at hand in the form of rocks and pools and running streams making garden pictures, but introduce another feature-the establishing of a series of surprises in garden grouping. At "Thorn Hedge," the beautiful old estate of Mr. H. H. Battles, on the historic West Chester Pike, near Newtown Square, Pennsylvania, there is a pleasing development of woodland adjoining the lawns surrounding the house that may well be taken as a distinctive type of developing a garden grove.

Passing through a wide stretch of lawn and flower garden, and past the stately old country mansion, the garden driveway leads down into one of the most alluring stretches of woodland in all Delaware County-a woodland that has for centuries been taking on that perfect charm, serene and mature, which only time and the deft touch of unhindered 
nature can accomplish. Here are beautiful old vines climbing far up into the tree tops, and clumps of low-growing evergreen shrubbery, while spring-fed woodland pools, in the valley windings, mirror lordly old pines reaching out their evergreen branches from the steep hillsides above.

In many charming spots, unhindered nature has accomplished all that could be desired. In other places, where it has been necessary to remove briers and underbrush, some fascinating glimpse of an oldworld garden has been introduced. Although quaint architecture and garden craft have worked wonders in some of the open spaces, it is the succession of garden surprises, discovered in secluded sections, that appeal most strongly to the imagination and tempt one to explore every foot of the magic woods.

Fortunate is the visitor to this beautiful country seat who on his first view of the woodland gardens is charmed with the sight of an ox-team slowly wending its way from one of the woods roads-a genuine oldfashioned country cart, drawn by two plump, wellgroomed oxen, and driven by a sunny-faced Scotchman, who beams good-will on all visitors as they admire his charges. Not only are these splendidly developed specimens of cattledom the particular pride and delight of the owner, and also of all the employees of the estate, but neighboring property 


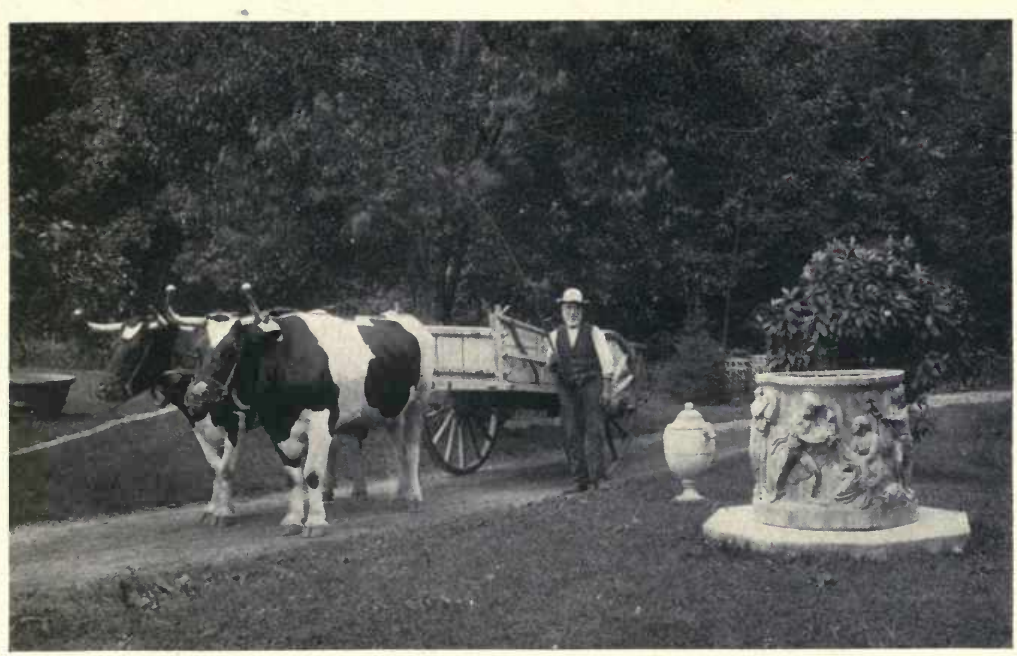

AN OX-TEAM AS A DISTINCTIVE FEATURE OF THE GARDEN GROVE

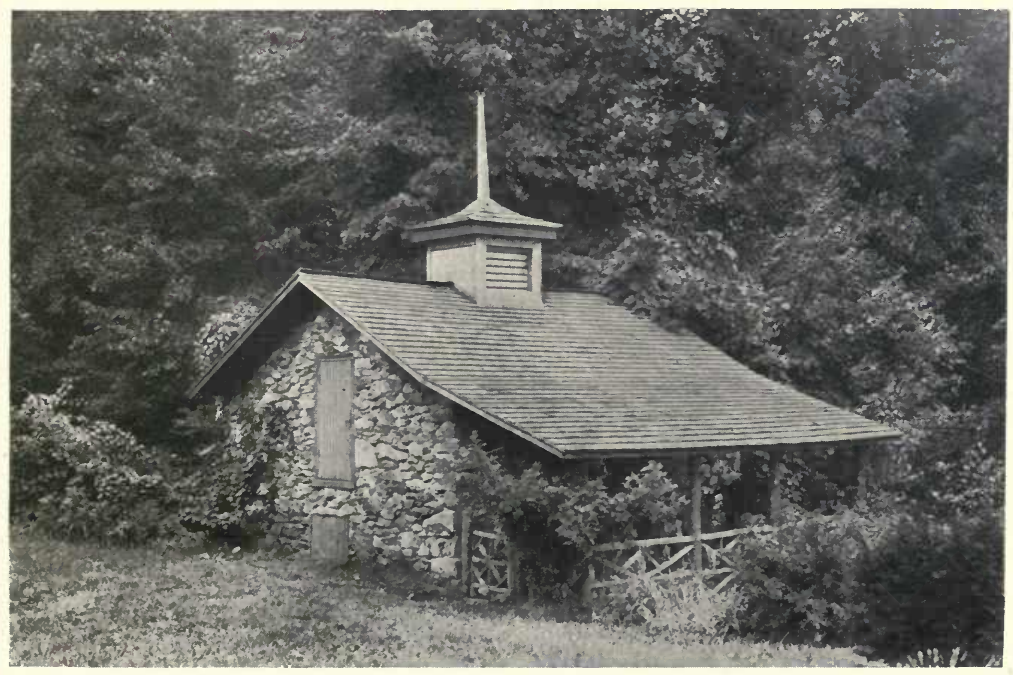

AN OLD SPRING HOUSE CONVERTED INTO A WOODS TEA ROOM BY EXTENDING ROOF AND PORCH 


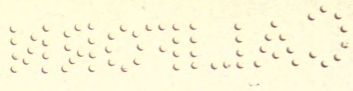




\section{AN UNUSUAL WOODS GARDEN}

owners declare them to be the finest team in Delaware County. After viewing the picturesque quarters for housing the oxen and noting the part they play in a decorative feature of the woodland (while also accomplishing occasional feats of usefulness), the appreciative garden craftsman must admit that this old-time country acquisition provides an additional charm for the woods garden, which could be secured so effectively in no other manner.

On the right of the drive on entering the woods road is a broad lake fed by a natural spring; the water reflects the native growths-wild flowers and bog plants along its margins, with the aquatics natural to the locality ornamenting its surface. Any attempt at artificial water gardening would have completely spoiled the effect, but the natural woods lake holds a charm of its own, and where the stream which feeds it passes beneath the roadway a simple and artistic bridge of rustic work has been constructed.

To the right of the lake is "The Abbey," fittingly named from its picturesque seclusion among the trees, and presenting an ideal spot for retirement and meditation. This one feature of the garden woodland is a study in itself, in showing what may be done in transforming the rusticity of ancestral spring houses or discarded ice-houses on the home 


\section{PRACTICAL BOOK OF GARDEN ARCHITECTURE}

grounds into cool and inviting summer-houses, with rustic-railed porches and comfortable lounging places.

A glimpse of "The Rockery," with its artistic lanterns and its wild gardening, next confronts the visitor threading his way through the woodland walk; and a rustic spring just beyond is reached by log stairs, with a comfortable bench for resting beside the cooling waters. The "Crow's Nest" is well named, as it is not merely a tree seat reached by a single flight of rustic stairs, but a succession of nests or landing places, supported by fine old forest trees, and presenting attractive vistas through the foliage with every turn. When the broad landingthe real tree room-is reached, one may rest amid the tree tops, secured from harm by the high firm railing, which also serves as a decorative feature.

Probably the most attractive characteristic of all this woodland garden, or "garden of surprises," is the "Swiss Cottage" nestled in an open space in the heart of the woods. One can well imagine that he has stumbled upon some huntsman's lodge in a secluded mountain fastness, when the quaint and picturesque log structure is discovered-possessing the ornamental features which distinguish the Swiss cottages, combined with substantial log construction of the mountain woodlands. The conception is still further emphasized by the rugged grouping of 


\section{AN UNUSUAL WOODS GARDEN}

rocks and bowlders about the "cottage," and only the hardy ferns and natural wild flowers are grown in the rock crevices.

There has not been the slightest attempt made toward mere display throughout the entire woodland; neither has its beauty been left to haphazard, but it is the result of intelligent study by experts. Each distinct view, each charming study, is in itself complete; and so perfectly does each bit of decoration fit in and blend with its surroundings, that it appears to have grown there naturally, an indispensable part of the whole. The plans of this extensive estate may be studied to good advantage in the treatment of other suburban woodlands : and many country estates, where heretofore little thought has been given to this method of home beautifying, may have their decorative value doubled by a little intelligent study and slight expense in the development of the garden grove.

In fact the country home with a garden woodland possesses fascinating possibilities in rural ornamentation and development. Not only are all the old forest patriarchs carefully preserved, fresh growths nurtured, with the unsightly underbrush cleared away, but a step farther has been taken in introducing decided novelties in ormamenting the woodland. A drive through such suburban districts will frequently tempt one to leave the public roadway to ex- 


\section{PRACTICAL BOOK OF GARDEN ARCHITECTURE}

plore fascinating woodland roads, where many of the fine old trees have rustic stairways leading up to secluded tea rooms built in their wide-spreading branches; where bits of artistic pottery and roomy marble garden-seats imported from sunny Italy call to mind the garden magic of the villa-cladi hills and woodlands of ancient Florence; where walks cut through stately avenues of trees remind one of the famous cypress alley of the Boboli garden, and intertwined branches of trees forming archways over secluded walks, vie in beauty with the ilex walk of the same celebrated Italian garden; where tall pedestal lanterns of stone are set, seemingly to light up dark places in the turns of the winding roadways, and to guard alluring bits of unusual landscape gardening. In fact these woodland gardens may well be called "surprise gardens," so varied are the quaint types of old-world attractions introduced, and so frequently does one come upon a delightful surprise at the curves in the drives and walks. In connecting the woods or garden grove with the lawns and flower gardens, bits of dry-wall gardening, rustic steps, and quaint old stiles have Florentine oil jars and unique bits of garden pottery set in secluded nooks; while quaint water jars and well heads are appropriately placed in permanent positions along the woodland lakes and streams. 


\section{$\mathrm{XX}$}

\section{NOVEL SPRING HOUSES}

\section{VARIED IN TYPE TO FIT REQUIREMENT AND SITUATION}

THE very suggestion of a spring house calls up recollections of quaint, low-eaved, "homey" farmhouses, the much-lauded simple life of old-time country homes, the solidity and picturesque simplicity of ancestral estates. The charm of this home accessory that was once considered a necessity from an economic standpoint-when it stood for more convenient handling and better prices for the milk and butter of the farm-has come to be an important factor in the home building of to-day. No country estate or farm home now seems quite complete without its picturesque and useful spring house. Historic structures of crumbling field stone and tiny frame shelters guarding the gushing waters of hill slope and valley springs are no longer hidden from sight by many years' growth of briers and bushes, but are cleared of obstructions to invite the traveller to refreshing waters, and to add beauty to the landscape. The useful spring house of the farm dairy is adorned with flowering vines and converted into the most decorative feature of the homestead; and even country churches delight in this additional attraction to their 


\section{PRACTICAL BOOK OF GARDEN ARCHITECTURE}

property, where the country members quench their thirst after their long "ride to meeting." In fact so widespread has the "fad" become that home builders in all sections are showing their appreciation of the restful beauty of this home accessory, until it gives promise of pervading every farm home and country estate that possesses a spring of clear, cold water worthy of appropriate shelter.

A landowner-whose beautiful country estate, with its spreading farm lands on every side, is far dearer to him than his palatial brown stone mansion in town-said to the writer: "The sight of one of these low-browed spring houses among the sheltering hills and trees, with old-fashioned shrubs and flowers in the nearby garden, connecting it with the adjoining farm-house, is heart-warming, and redolent of the wholesome life and good cheer that centred about the great stone fireplaces of the past. But I will never be content," he continued, "until I have actually built with my own hands a little spring house of field stone such as I used to love on the old farm back in Ohio."

And build that spring house he did! With huge delight and with the vim and eagerness of boyhood days, a joyous vacation season from down-town care was spent in constructing a crude but charmingly picturesque spring house on a hill slope, copied from 


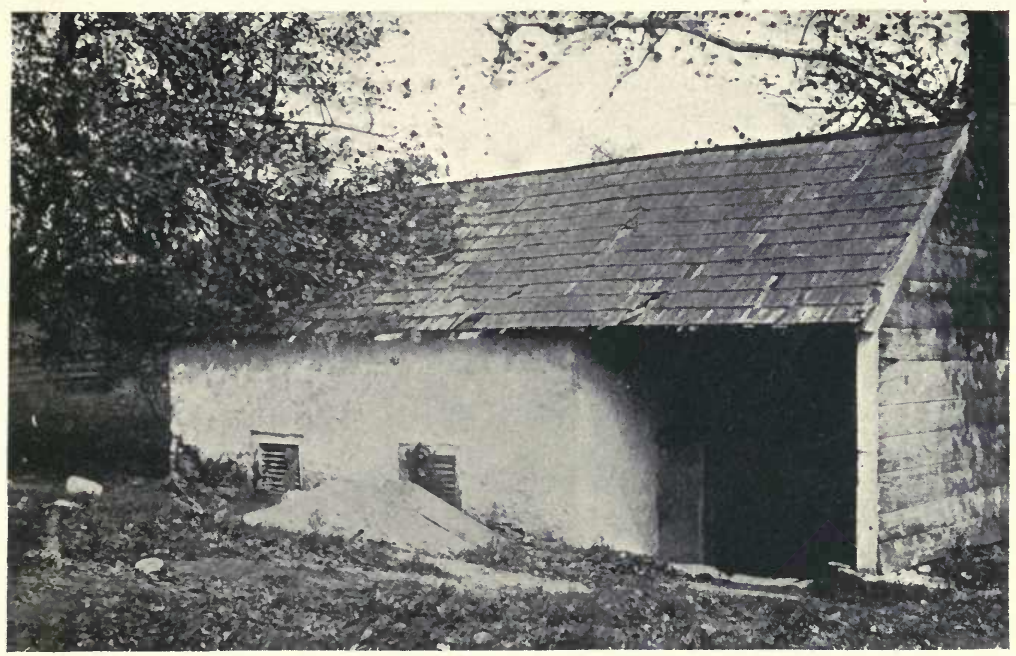

A TYPICAL OLD-TIME SPRING HOUSE DATING FROM REVOLUTIONARY DAYS

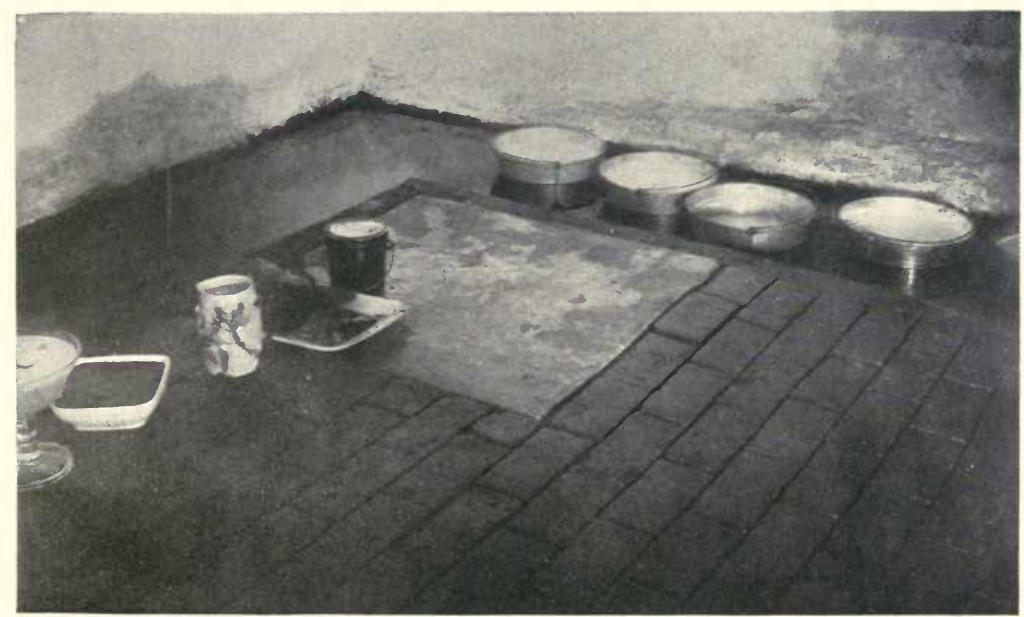

INTERIOR OF THE RYERS SPRING HOUSE, BRICK FLOOR, CONCRETE WALLS AND COOLING CHANNEL 


\section{NOVEL SPRING HOUSES}

a low stone structure which he had admired on the Old York Road, on his frequent travels from his country seat to the city office. "And its chief charm," he now gleefully states, "lies in the fact that it cost less than ten dollars complete, as it was built entirely from the rough field stone of the surrounding acres, the only cost being the cement and sand for mortar, and a few fencing boards, with hinges and lock for the door."

This offers a novel suggestion where cost must be taken into consideration. Such a spring house, built entirely by the owner at odd hours, will require little outside of cement if the field stone is at hand; as no other woodwork except the door and supporting scantling will be required, even the roof being a mere rounding over of the stone, with a rough cast finish of the cement.

On the Ryers estate, "Burholme," in suburban Philadelphia $\longrightarrow$ on the outskirts of beautiful Germantown-there is a spring house of note which has recently attracted considerable attention because of the gift of the estate to the city of Philadelphia as a public park. This might well be taken as a model for spring-house construction, because of its simplicity and convenience. The low stone walls are not remarkable, being simply rough stone and plaster cast, and the little frame addition built at one end for 
sheltering the milk cans is rather dilapidated, from being twisted out of shape by the roots of a mammoth buttonwood tree, for which the place is famous, but the principal charm lies in the interior arrangement. The big square floor of the main structure is laid with brick, with the exception of a space about eighteen inches wide extending along one end and side. This space has cemented bottom and sides and is from six to eight inches deep. It forms an ice-cold water-way in which milk cans are set, and - pans of cold custard, or whatever is to be kept or served deliciously cold.

The clear, cold spring that runs in at one end of the stone structure flows directly into this waterway, continues down one side of the house, and around the other end, where there is an outlet for draining off the surplus. The interior walls are plastered from floor to roof; and with the plain brick floor surface meeting the cement water-way and the plaster wall, there is no woodwork to decay from dampness; while for the periodical cleansing a thorough hosing of floor and walls, and the draining, sweeping, flushing and refilling of the water-way keeps this delightful food and milk room hygienically clean with little difficulty. The whole conception is ideal for the purpose it serves, and yet it is a simple and inexpensive contrivance within the 


\section{NOVEL SPRING HOUSES}

means, and possibly within the skilful handiwork, of the average landowner.

For twenty-five dollars-or even somewhat less, it is asserted-a spring house has been built on the Dickinson estate, near Crescentville of patriotic fame. As it is of generous dimensions-about fourteen by twenty feet-with deep underground walls and peaked roof, and with sheltering porch at the entrance-way, one readily surmises that this. price necessitated an abundance of field stone to be had for the gathering, and also owner-building. In this instance, however, a stone mason's apprentice made a slight expense for work; a tight shingle roof, an extra door at the back and flooring boards for the interior, brought the cost of material and stonelaying near the twenty-five dollar mark, while the carpenter work as well as the greater part of the stone-work was finished by the owner. This structure presents the novel feature of a second story. The entrance beneath the sheltering porch at the front leads down a few steps into low, cool depths, with a comented floor; just above this entrance-door flooring boards have been laid to form a ceiling for the lower story and floor for the upper. The boards, however, are laid in the form of slats instead of closefitting, thus forming a cool upper storage room with a narrow upper entrance at the back. 
Another two-story spring house found at Hartsville, Pennsylvania, is of novel type, as the roomy, old-time structure where Washington and his army quenched their thirst in revolutionary days has of late years been divided into three small rooms-one of the lower ones, now a mere corner of the structure, containing the spring, the adjoining room being a tight, well-ventilated, window-lighted store-room and the upper floor or loft room being fitted up as a store-room or children's playhouse.

In the Blue Mountains there are many low stone spring houses thoroughly characteristic of the mountain homes adjoining-long and rambling, built substantially of stone, with overhanging eaves, and nestling down in the wildwood shrubbery of rhododendrons and laurels, close beside a gushing, singing, sparkling mountain stream.

A good type found on many country seats is the dome-shaped spring house. These are frequently banked up with earth and sodded to form a mound of green that is kept smooth and velvety by frequent mowing, like the famous Andalusia spring house illustrated; or the banked-up earth is planted with some low trailing and blossoming annual, or allowed to "grow wild" with perennial vines, and brier and wild rose. In the mound houses the entrance side is either walled up with stone, or there is a plain wooden 


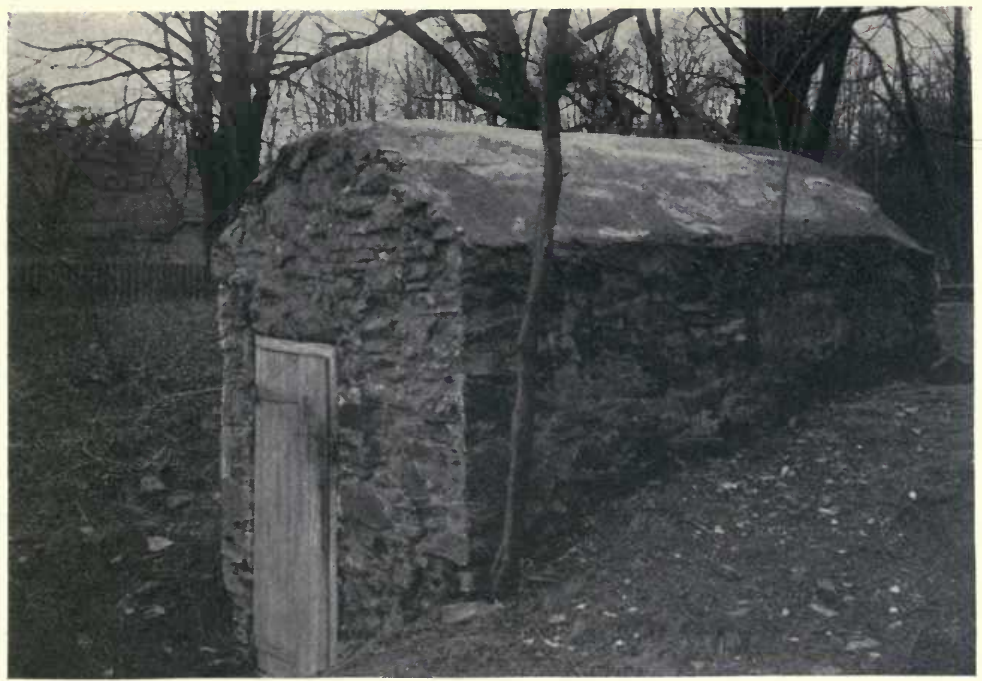

AN INEXPENSIVE SPRING HOUSE OF LOCAL FIELD STONE AND. HOME-MADE CONSTRUCTION

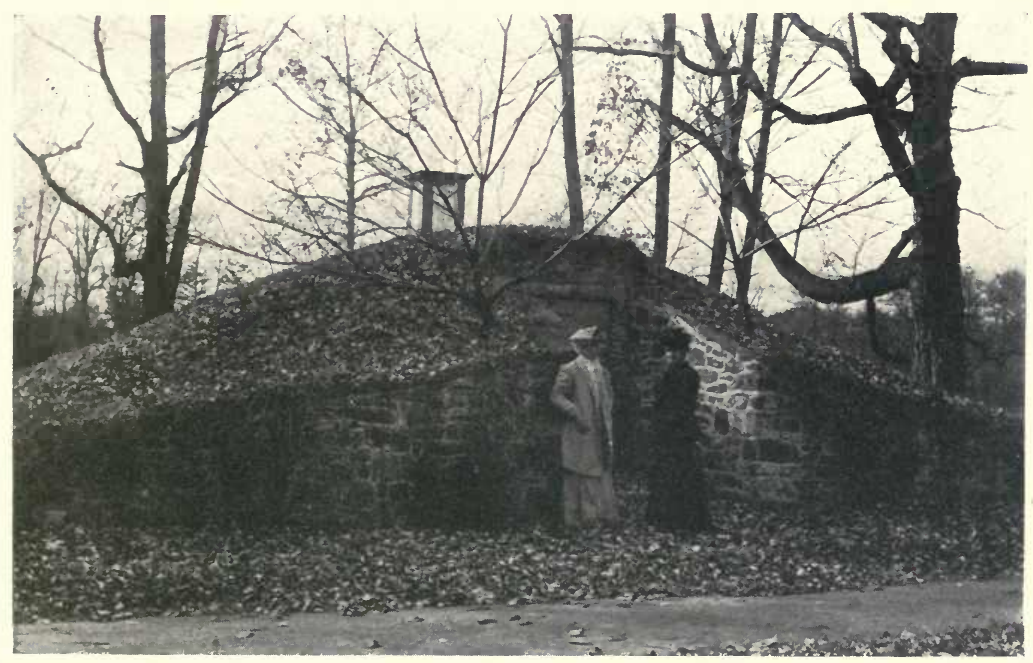

THE HISTORIC ANDALUSIA SPRING HOUSE WALLED ON BUT ONE SIDE 


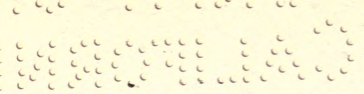




\section{NOVEL SPRING HOUSES}

entrance-way, with only the broad doors showing through the picturesque tangle of vines and shrubbery.

The more stately spring houses of the modern country seat are redeemed from undue "newness" when the spring which they are designed to shelter has an outlet near stately old trees-wide-spreading elms, or willows, or grand old buttonwoods, that have stood for a century or more.

In point of cost, the perfectly appointed dairy on the estate of J. Ledyard Blair, Esq., at "Blairsden," in Bernardsville, New Jersey, greatly excels the average structure devoted to this purpose. The thick stone walls display their use, however, in increased coolness for the interior. The picturesque chimney and the massive pillars of field stone, like the walls, produce the charm of local color.

The section of the beautiful H. J. Verner estate, at Bryn Mawr, that has been devoted to the dairy, might well be described as a spot full of natural suggestions which have been developed in a strikingly individual manner. Here, on an even more pronounced scale, is shown the delight in local color, in the typical setting of woodland shelter and rocky slope in the background, and green meadows with sparkling streams in the foreground. Here the fieldstone construction is hidden during the summer by 


\section{PRACTICAL BOOK OF GARDEN ARCHITECTURE}

a luxuriant tangle of flowering vines. The stone arches of the porch show through the vines suggestive of a cool resting place for the dairymaids, and additional vine shelter and seclusion are afforded by a stately pergola reaching out beyond the stone porch. Down in the meadow slope the charming picture-setting is completed by a shallow brook with stepping stones and a vine-covered rustic bridge.

Even the most elaborate and costly of these perfectly equipped modern dairies are never out of harmony with the old-time ideal of spring house construction when thus made informal and unconventional by fitting perfectly into the picture of their surroundings. Although types may vary greatly between the ten-dollar structure of rough field stone and the elaborate Verner structure, they each fit so perfectly into the landiscape that they seem to have grown there. In this lies, very largely, their peculiar charm. 


\section{XXI}

\section{THE CHARM OF THE WATER-FALL}

\section{HOW TO BUILD AND MAINTAIN THIS FASCINAT-}

ING GARDEN FEATURE

Is beautifying home surroundings there is probably no other feature so neglected as the establishing of water-falls. We are satisfied to form our artificial lakes with piping both at the intake and the overflow -plain, durable, serviceable piping, it is true, and entirely practical; but why not have the intake, at least, arranged to fall over the rim of the pond or lake in the form of a little water-fall? Or if the overflow is more picturesquely situated let a practical dam be built at this point, with possibly a series of low dams to form rippling cascades below the main water-fall.

The force of water required to operate the hydraulic ram or engine need not necessarily be hidden in the power house in some secluded part of the garden, as usually is done. The utilitarian feature can be turned to very good account by first passing over a dam designed on decorative principles. From a spring in a terraced garden sufficient water can be side-tracked to form a rippling cascade, or a rushing water-fall, from terrace to terrace, simply by form- 
ing a narrow channel of concrete to confine the water supply, give it greater flow, and guide it to the spots where its sparkle and foam will produce the greatest value in pleasing result.

We are gradually learning the great secret of success in making the most of the garden water supply by using the water over and over again; and in no other decorative feature will this be possible to such a satisfactory degree as in making the water that is to fill the lake, or take off the overflow, or supply power for machinery, or simply irrigate hilly gardens, first serve its decorative purpose in waterfalls before accomplishing the service end of its existence.

The Dutch can teach us many practical points in this method of utilizing water. Many of the beautiful homes in Rotterdam and vicinity display expert treatment in the handling of water. No matter whether it is the house supply, the lake, or the swimming pool that is to be built and maintained, the water required for the purpose is brought to its point of service in the form of cascades by the damming of little brooks, miniature canals, and the use of rough stones and bowlders to form steps in a slightly sloping stream-each step in the rush of the water to seek the lower levels, forming sparkling, dashing water-falls. There is no other form of fall- 
年

H. 3

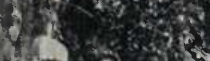

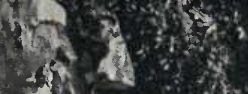
(1) 18

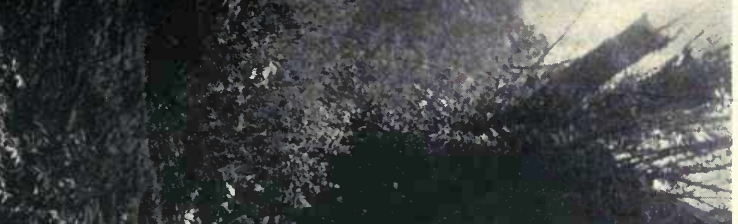

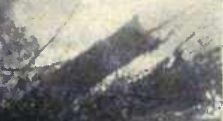
M. Mi s. Hit in

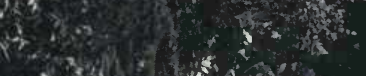
(2) M 1 . 2

1.. in $1.0 \%$ - 3 istors ditus 3 . $1 \times(x)$ m 2.

it) hants (3) 12 $-5$

(laik 1.

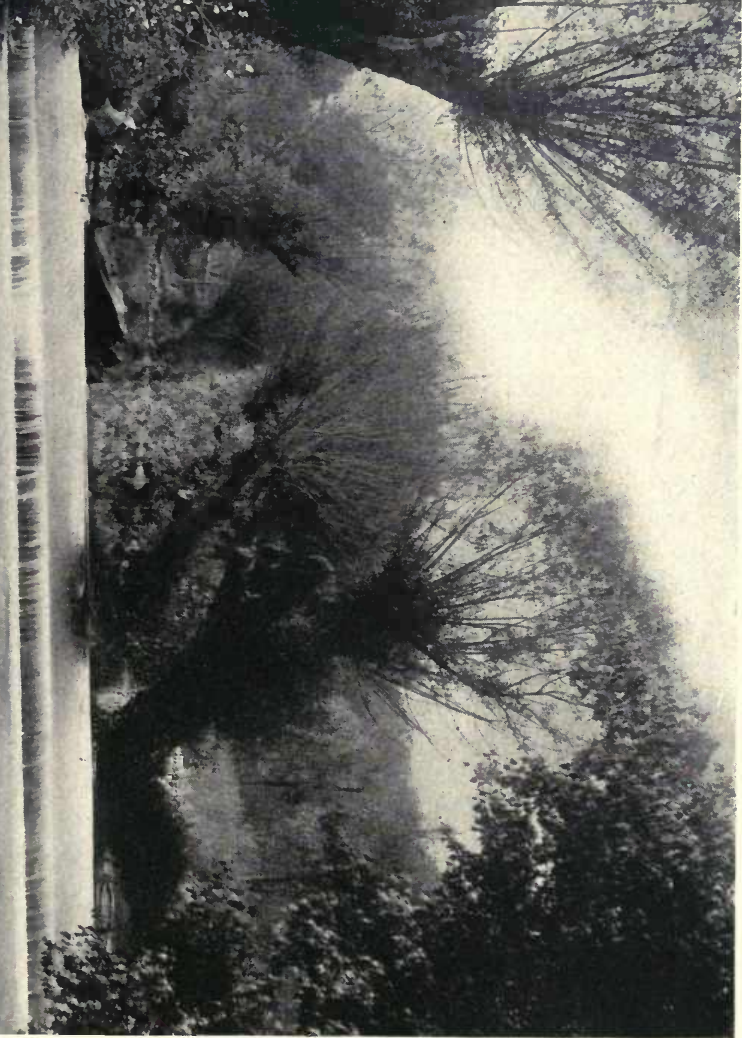




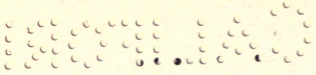




\section{THE CHARM OF THE WATER-FALL}

ing water so attractive as that which is made to rush over rough rocks.

When the garden has not sufficient slope to make the water-fall plausible (and it is never attractive unless there is an excuse for its existence) a terrace slope readily may be arranged by grading at the point of the natural water supply. Lacking this supply, it may be found that the artificial introduction of water will prove even more satisfactory from the decorative side of the question, as it can then be installed at the particular point where it will be most effective in the general design. On the terrace of made ground it is unwise to depend upon clay puddling or other insecure form of building the channel that is to conduct the water to the lower spaces. Instead of steps formed merely of rough stones set firmly in clay, build the channel of concrete, with concrete steps where the water-fall is to be formed. Then an arrangement of stones on these steps will break the flow of the water, and cause the dash and foam that are so desirable.

When necessary to build a dam for the big garden lake greater problems confront the amateur, and it may be found that the advice of an expert engineer will be required. Among the famous water gardens of California the dams for water-falls are constructed of concrete in keeping with the concrete finish of the 
Spanish type of many houses. With this material properly placed there is a certainty that the dam will not leak. Another satisfactory feature in using the concrete consists in the fact that it is an easy matter to construct the spillway large enough to carry off the rush of water without overflowing the side boundaries, even during heavy freshets. Among the country seats along the Blue Ridge Mountains, there are charming water-falls with dam breasts formed of huge logs cut from the adjoining timber land. The logs, chinked with concrete and banked with rocks, are thoroughly serviceable for an indefinite period; and no other form of dam could be more pleasing to catch the sparkle and foam of the water from the mountain springs rushing over it. On the Register estate, "Lynhurst," in suburban Philadelphia, there is a novel treatment of the dam breast. A high wall of masonry has been built to dam up a lake on the slope of the garden. Where the spillway has been formed into a water-fall, instead of simply having its rough dam of masonry continue in a vertical position like the wall, it is built out on a decided incline, throwing the water far out from the base of the wall. This gives the effect of having such an abundant flow of water over the fall that it foams and dashes out to form a breadth of three or four feet at the bottom of the fall. In reality the flow is quite scant, and only 


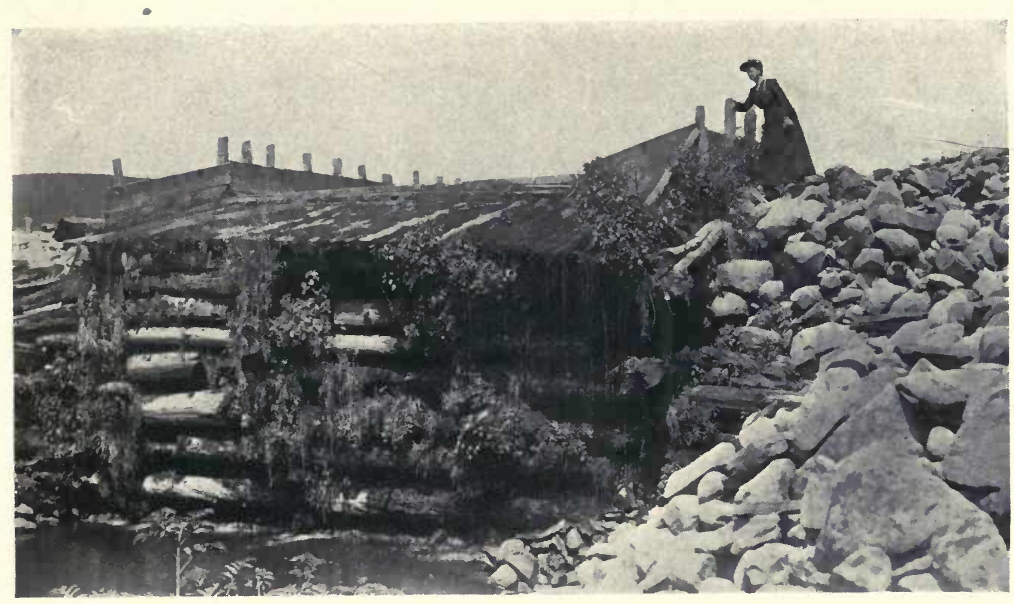

A DAM OF LOGS AND ROCKS IN THE BLUE RIDGE MOUNTAINS

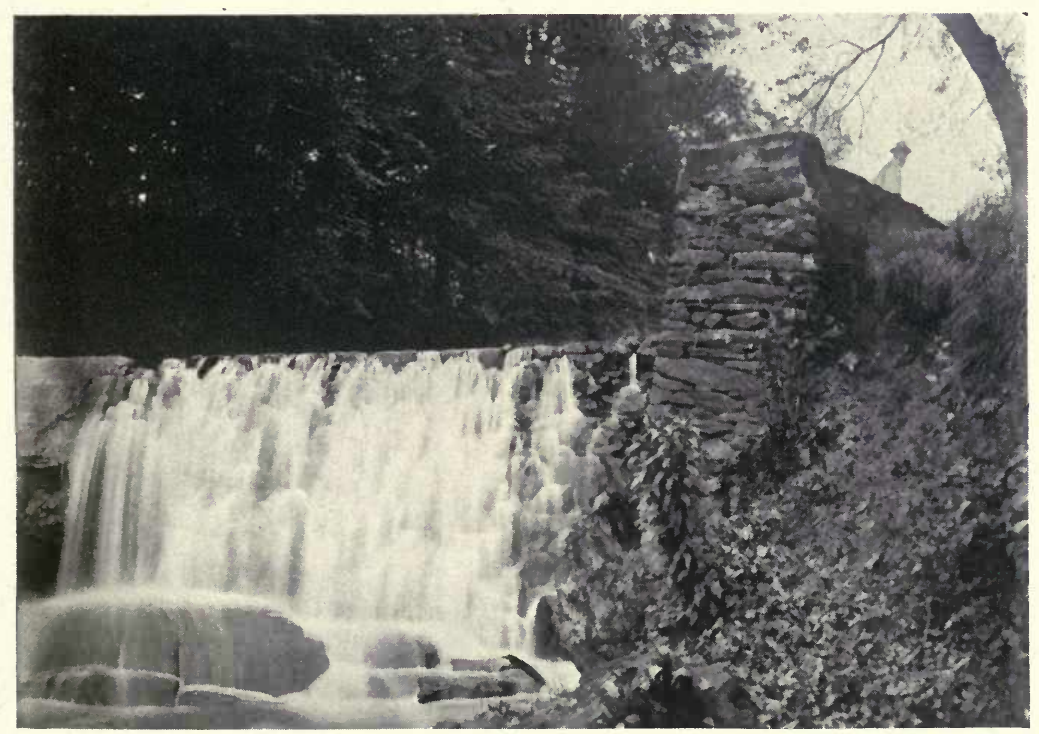

A WATER-FALL WITH MUCH STONE-WORK ADDING TO ITS VIGOROUS BEAUTY 
$\because \because \vdots \vdots \vdots \vdots \ldots$

$\because \because y=$

. 


\section{THE CHARM OF THE WATER-FALL}

the ingenuity of the engineer who constructed the dam has made this fascinating water picture possible.

For the long, low, shallow water-falls, where a garden stream or lake enters a creek, the amateur craftsman can build a pleasing bit of decoration at little expense. Costly stone or mason work will not be required, neither will the strong concrete surface be as necessary as when the fall of wataer is heavy and rapid. A simple arrangement of puddled clay, with one or two good-sized logs for the top of the dam, will be sufficient. Another pleasing arrangement for the long, shallow formation is made by piling up and packing the clay in place; then while the clay is still wet from the puddling set one or two rows of rough stones, with jagged edges, along the upper surface. Pack the clay well about the stones, and when it is set, and ready for the water to flow over it, the water-fall will be broken into many ripples and the effect produced of a heavy flow of water over a broad expanse of bowlders reaching across the stream.

When the bed is of sandy formation, do not make the mistake of using washed sand for dam construction. It should never be used for this purpose except as an ingredient for concrete. The thought of saving expense may induce one to experiment with the abundant material at hand, but the supposed saving will 


\section{PRACTICAL BOOK OF GARDEN ARCHITECTURE}

appear on the wrong side of the account book when the dam begins to leak. The sand will prove very useful, however, when it can be used with a suffcient mixture of clay, at the back of the dam where it does not come in direct contact with water. Earth and sand also may be used for the entire filling of a large dam, built with a concrete core. Mr. Claude Miller, an authority on the subject, recommends this treatment for large surfaces as being both inexpensive and satisfactory. According to his estimate a dam built of earth, with a concrete core, may be figured at about thirty to forty cents per cubic yard for filling, and from twenty to thirty cents per cubic foot for concrete work. In treating a leaky dam, he claims that "it often may be cured by facing it with clay or earth. If the lake cannot be drawn down, this facing may simply be dumped in the water, and allowed to find its own resting place." I would advise, however, that this should not be attempted by the amateur craftsman in dam building. It will be better to draw the water from the lake-even if the process is tedious and difficult-and thoroughly repair the leak in the dam with concrete, as a leaky dam is a constant aggravation in its serviceable features, and a decided failure when it is to contribute to the home attractions by furnishing an abundant water-fall. 


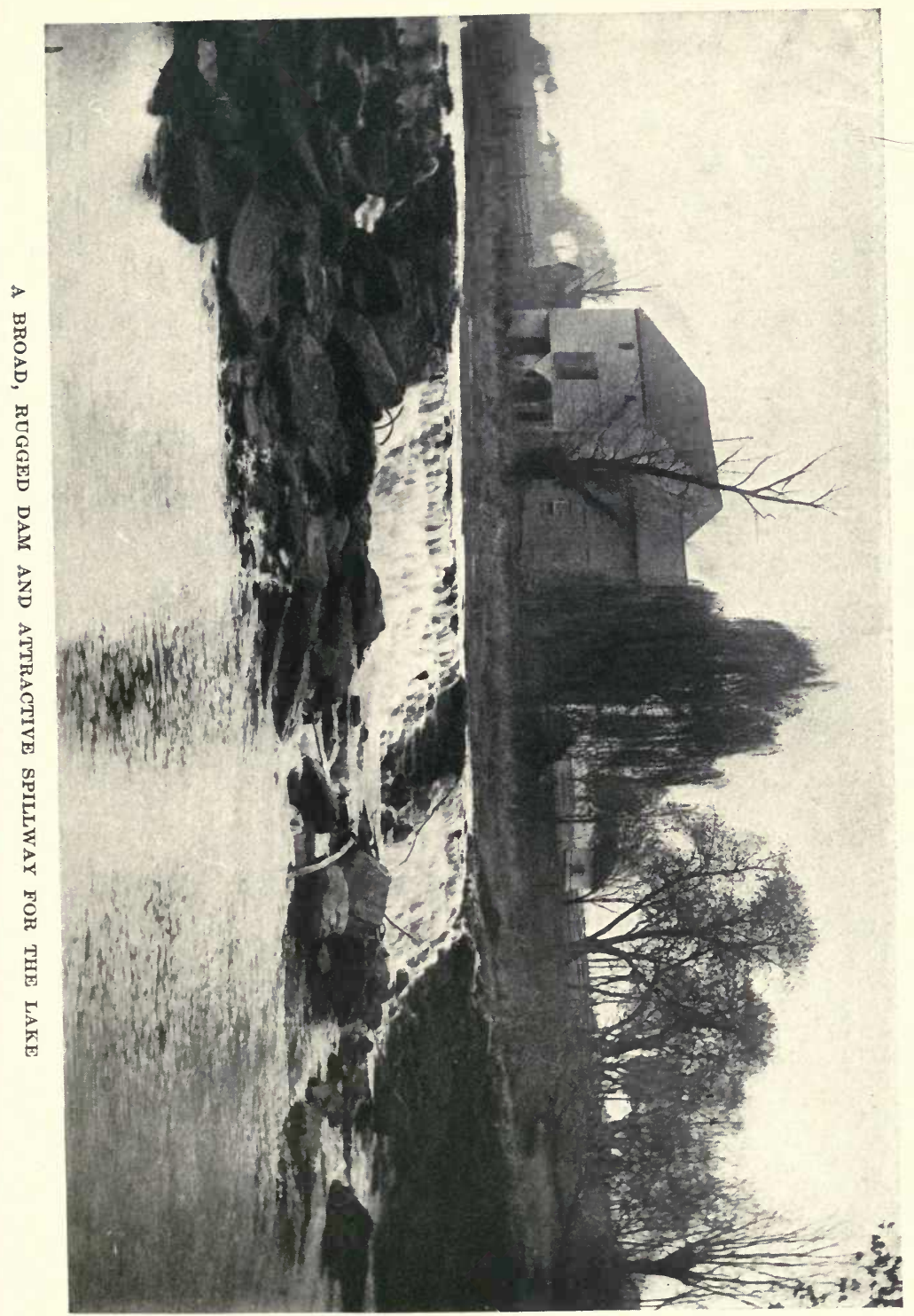





\section{THE CHARM OF THE WATER-FALL}

When a large lake is dammed to receive and hold the waters from a turbulent brook or creek, thorough construction is of first importance, but this feature, often requiring heavy masonry, may be made to contribute to the picturesque attractions of the water-fall. The stone-work, left rather rough and rugged where it catches the rush of the overflow, will add greatly to the "vigor" of the water-fall; and in this, after all, lies its chief charm. When we consult an engineer concerning the best form of constructing these dams of stone-work, we will probably consider the massive bit of masonry (which he will recommend) an unnecessary expense. We may argue with him, and call to mind the thousands of miles of earth embankments that are used in canal banks and in levees along rivers, and attempt to convince him that our half-acre lake, which seems quite a spacious affair compared with the average garden lake, surely cannot demand such costly masonry. But we will find to our sorrow when leaks occur in the big dam breast, that it doesn't pay to economize in the first cost; with a probability-in fact almost a certainty-of considerable after expense in patching. These big dams of firm masonry make the most charming water-falls. With the broad spillway, the water not only flows over a surface that seems well worth while 


\section{PRACTICAL BOOK OF GARDEN ARCHITECTURE}

from a decorative standpoint, but also insures greater safety in times of freshets.

Lakes of good dimensions, dammed to receive an abundant natural water supply, may give considerable cause for anxiety concerning a possible "bursted dam." There seems to be a general impression that a dam usually bursts in the sense that the pressure of water forces it out, and that therefore the garden lake should not be large enough, even on the grounds of an extensive country seat, to hold water sufficient to burst the dam. There need be no cause for alarm in this respect, for there will be little danger of the dam being forced out because of the pressure of water back of it. If it should give way, it probably will be because a leak has occurred, which has become larger as the water has seeped through, until finally the leak lets out the water in a rush. Another cause for a so-called "bursted dam" is an overflow wash-out, when the spillway has not been constructed large enough to carry off a great quantity of surplus water. The spillway built for only the usual strong flow that forms the water-fall, will be decidedly inadequate when streams and lakes are swollen from long-continued rain storms. When the spillway cannot carry off the greater flow that has been created, the surplus starts over the dam at some other point, where preparation has not been made for it. 


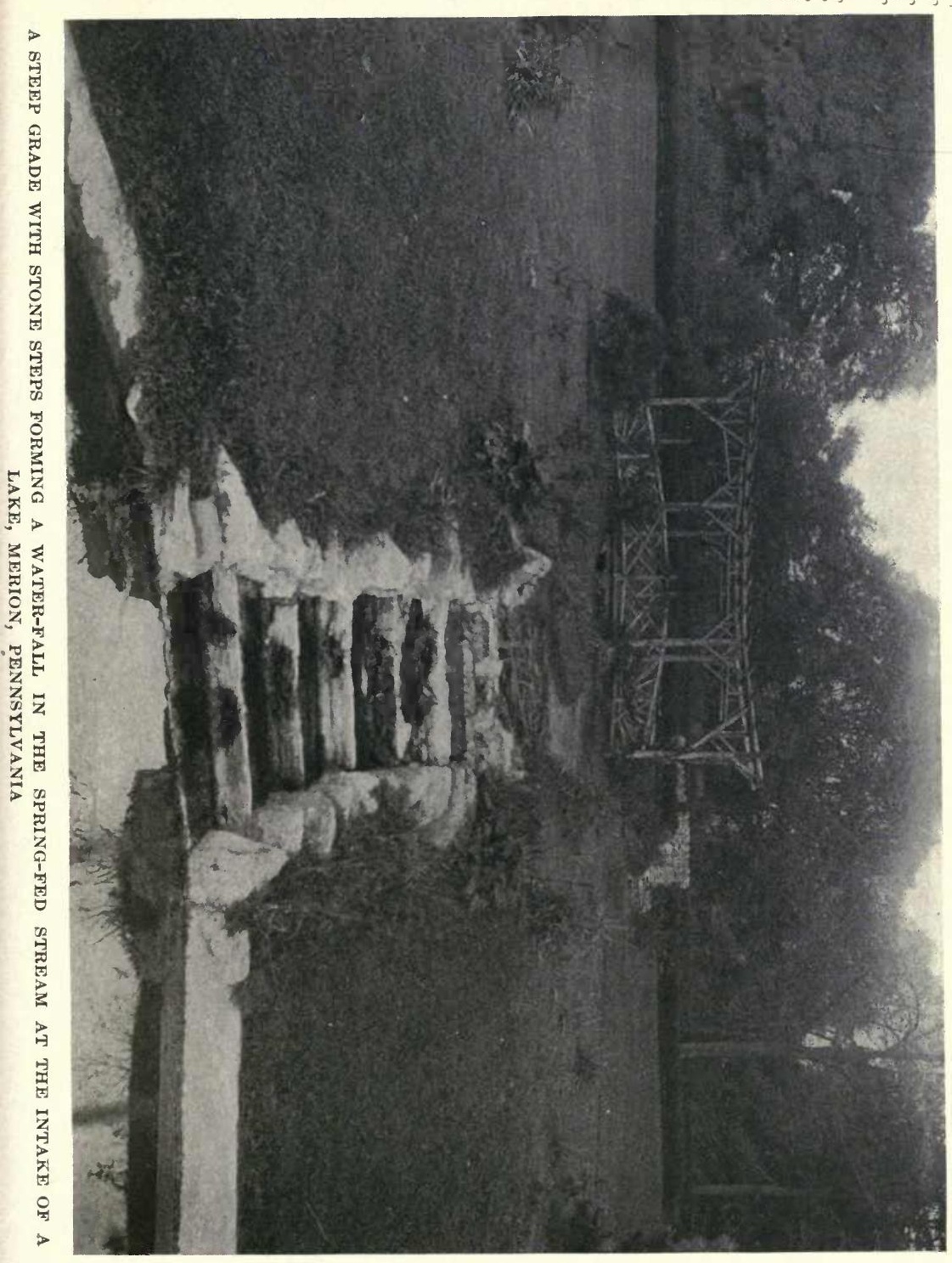




\section{THE CHARM OF THE WATER-FALL}

Naturally it causes a washout over the insecure portion where no provision had been made for an overflow. The washout broadens and deepens until the dam weakens and "bursts" at this point. The whole trouble might have been saved had the spillway been constructed to receive not alone the usual flow of water, but to provide for excess in every possible emergency.

To insure permanency of the water-fall, and a comparatively even overflow without extra dash and beauty (and consequent worry) in times of storm, it will be best to provide a gate in the dam of unusual dimensions. This will not only make it possible to let out the excess of water during freshets, but it is also useful for drawing off the lake when necessary. For the shallow lake and small dam, the gate will not be required. If the spillway is built of non-washable material, and is built adequate for abnormal demands, this will prove entirely satisfactory; and the gate will prove only an additional expense. There may be a temptation to have the spillway too narrow for emergency use, because it will provide an extra dash and rush of water to beautify the water-fall. But it will be better to provide for this dash and sparkle by having the overflow roughened with jutting stones, or some clever device in masonry, while 


\section{PRACTICAL BOOK OF GARDEN ARCHITECTURE}

keeping it of ample dimensions to provide for excessive overflow.

The picturesque water-fall of unusual height and vigor is often found to be serving a very useful purpose, while contributing to ornamentation. Investigation may show that it is running a water-wheel for one of the engines forcing the house supply to the receiving tank. When it is necessary to erect a little power house, or enclosed space for housing the small apparatus for pumping the water, let it be in the form of an ornamental garden building. Then with a water-fall attractively devised, it will give additional beauty while providing an adequate fall of water for running the apparatus. When constructed merely for the purpose of adding to the many fascinations of running water in the garden, the water-fall is sure to be a success. But it is even more pleasing when it serves a useful purpose. 


\section{XXII}

\section{APPROPRIATE BRIDGES}

GARDEN STREAMS AID CONSIDERABLY IN PERFECTING THE PICTURE OF HARMONIOUS HOUSE SURROUNDINGS

GARDEN streams and bridges in their artistic development are so well illustrated in notable estates of eastern Pennsylvania that some of them may well afford an excellent text in the treatment of this subject. There are two distinct types of bridge building on the Jay Cooke estate, at Ogontz, valued for their characteristic treatment. One presents a deep natural stream that in the long ago provided the water supply for an old mill which stands on a part of the estate. When the place came into the possession of the famous financier, he brought the same practical principles to bear upon his garden building that had brought about his success in the building of a fortune. Not one suggestion of natural beauty was allowed to be sacrificed in the resurrection of the dilapidated old mill and its neglected water supply. An open vista was arranged through the intervening belt of woodland in order that this picturesque bit of the lower slope of the grounds might be in plain view from the upper walks and 


\section{PRACTICAL BOOK OF GARDEN ARCHITECTURE}

driveways about the house; the ancient mill was sufficiently remodelled to preserve it without marring its quaint old-fashioned outlines; the natural growth of fine old trees, with stream borders of briers, waterelders, and other native shrubbery, has remained, undisturbed-since the property came into other hands-except for the narrow clearing for winding walks leading down to the stream.

No attempt at artificial planting or showy bridging of the stream has been allowed to spoil its wild beauty; only the natural wild flowers outline its shore, the hardy ferns and mosses cling to its steep banks, the sturdy milkweed nods its swaying bloom branches above its own showy reflection, and opens its brown pods to scatter its fluff-winged seeds upon the waters in the autumn; while the trailing partridge vine, with its small red berries and evergreen foliage, beautifies the spot throughout the winter. Rough logs support the wooden bridge, and plain wooden railings outline both driveway and bridge leading to the old mill and a natural bog garden in the hollow beyond.

Another section of the same stream was so shallow in dry seasons that it frequently dried away to an ugly expanse of mud in midsummer, and so was? deepened by the construction of a dam of ornamental stone-work. A broad stone wall reaches out from 


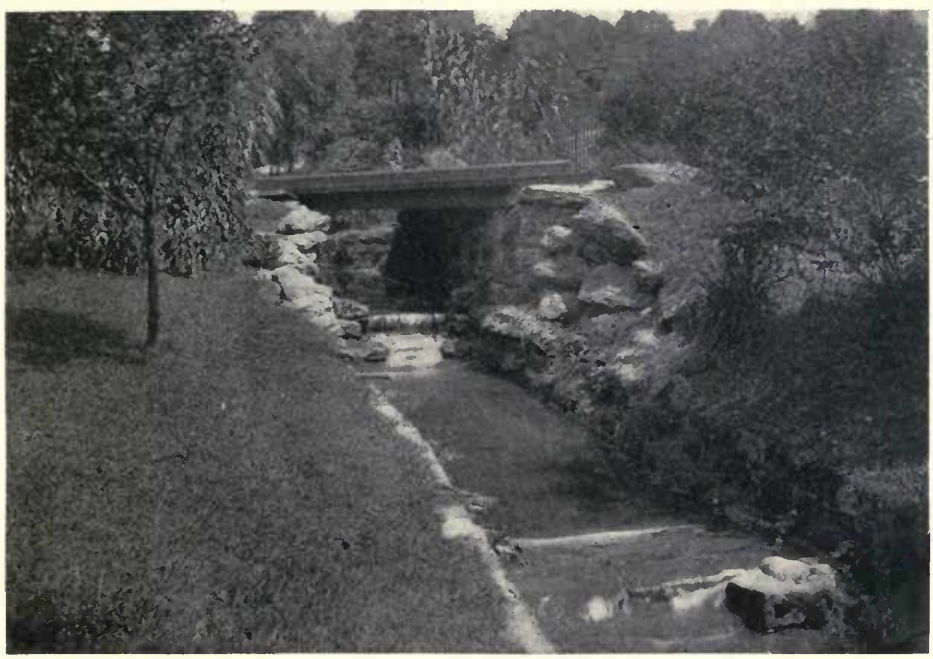

A FLAT BRIDGE ON A HIGH STONE FOUNDATION. PICTURESQUE TREATMENT AT "COMPTON," THE MORRIS ESTATE

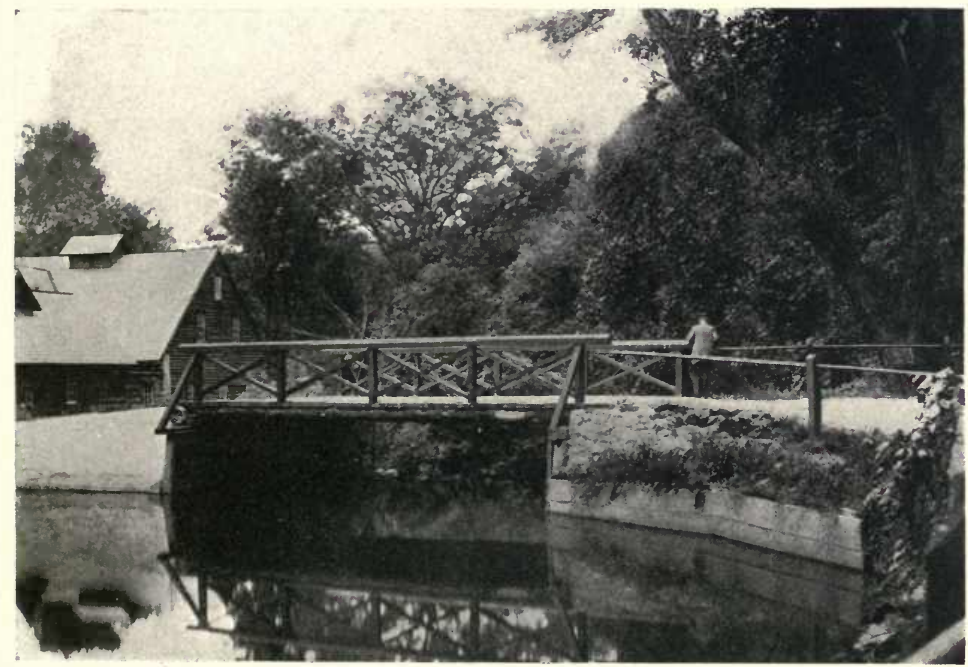

AN APPROPRIATE BRIDGE LEADING TO THE OLD MILI AT OGONTZ 


\section{APPROPRIATE BRIDGES}

either bank of the stream, making the waterway quite narrow at the overflow. On one side the wall has been left without vine planting; on the garden side, where a sheltered resting place has been formed close to the music of the water-fall, both vines and shrubbery have been planted to obscure the rough masonry, and the big trees springing from the water's edge have their trunks well covered with billowy vines that seem to sway and dance to the music of the dashing water.

The best hardy shrubbery for ornamenting such bridge structures is the giant knotweed. This is a tall growing plant, known botanically as Polygomum cuspidatum. It frequently reaches a height of from five to seven feet, and may be planted close to the edge of the stream, where, with one foot in the water and another on the land, it will take strong root-hold and cover its branches with billowy masses of foliage throughout the greater part of the year, displaying misty clouds of bloom during August and September, with numerous long drooping clusters of white flowers developed at the axil of each leaf along the upper half of the stem. This is a striking plant and especially beautiful when grown in its favorite moist situation.

The charm of appropriateness between the garden stream, its planting and its bridges is also shown 
in many pleasing types at "Compton," the Morris estate at Chestnut Hill. Here the beautiful Wissahickon Creek flows through the lower section of the extensive grounds, and numerous natural springs on the hill slopes feed smaller streams and shallow waterways. On a quiet level stretch, in a secluded portion where there is little swelling of the stream and no destructive dash and flow after heavy rains, an artistic stone bridge with steep archway has been erected, with big bowlders at the sides for stepping stones and resting places leading down to the water. A little ornamental drooping willow has been trained to spread its branches above the bridge, reach down to the water, and shelter one of the most alluring of these bowlder seats. Then along the banks on each side of the bridge the ornamental planting problem has been solved by the use of hardy irises and trailing myrtles.

A portion of the narrow stream in the Morris garden, where there is a steep slope to the ground, has been more severely treated, as the dashing flow of water after heavy storms would not admit of plant growth at the edge. In its rugged, rocky beauty, however, the result is quite as pleasing and appropriate as that of the sheltered and planted shores just beyond. A plain, strong, wooden bridge crosses the stream on heavy girders, supported by high stone 


\section{APPROPRIATE BRIDGES}

walls. Stately clumps of bamboo, planted near the bridge on the upper slope, form a characteristic decoration peculiarly pleasing, while the stonewalled banks of the stream have as their only decoration native water plants with floating branches not easily injured by rapidly flowing water. To increase the rugged beauty of this narrow waterway shallow dams have been formed at regular intervals all along the sloping section, so that even when the stream is quiet there are always the flow and gurgle of water, increased to wild dancing cascades in times of storm.

Where the Harrison estate slopes down to the Old Church Road, near Glenside, a shallow stream leading from the garden has been attractively bridged across the public roadway. Here, where the county allowed only the plainest of serviceable bridges, private means have been expended for the public good, and a handsome stone bridge arched above the stream extends its stone-work in an attractive curve to a mammoth stone gate-post; while, just beyond, the same stream has been dammed to form a garden pond, and the roadway bridge passing over the shallow portion has an ornamental railing. Clumps of hardy flowering shrubbery dot the grounds leading down to the stream, while trailers and bog plants flourish along its edge and cling to the stone-work of the bridge. 
Among the country estates along the Old York Road are many rustic bridges in the wooded sections of the grounds where the streams flow through bits of rugged beauty and past barns and outbuildings. Here the rustic form is especially appropriate, and when the bridge is slightly arched above the stream it will be found more decorative than the flat structure.

Interesting treatments are found among the larger bridges which span broad streams. As the measure of the strength of the bridge is that of its weakest part, special care is shown in the construction of the central portions. Where the strength of a plain wooden bridge resting upon timber stringers or cords does not provide sufficient sustaining power for the timbers in the middle of the span ornamental arches are built or other devices are used by which the strengthened portions also contribute to the decorative value.

Whether the bridge is a little rustic-railed structure in the garden grove or built of elaborate stonework amid decorative garden accessories, it is equally important to see that the foundations are so firm that they will not be undermined by the action of the water. Concrete foundations are often desirable even when the remainder of the bridge is of timber construction or mortared stone-work. 


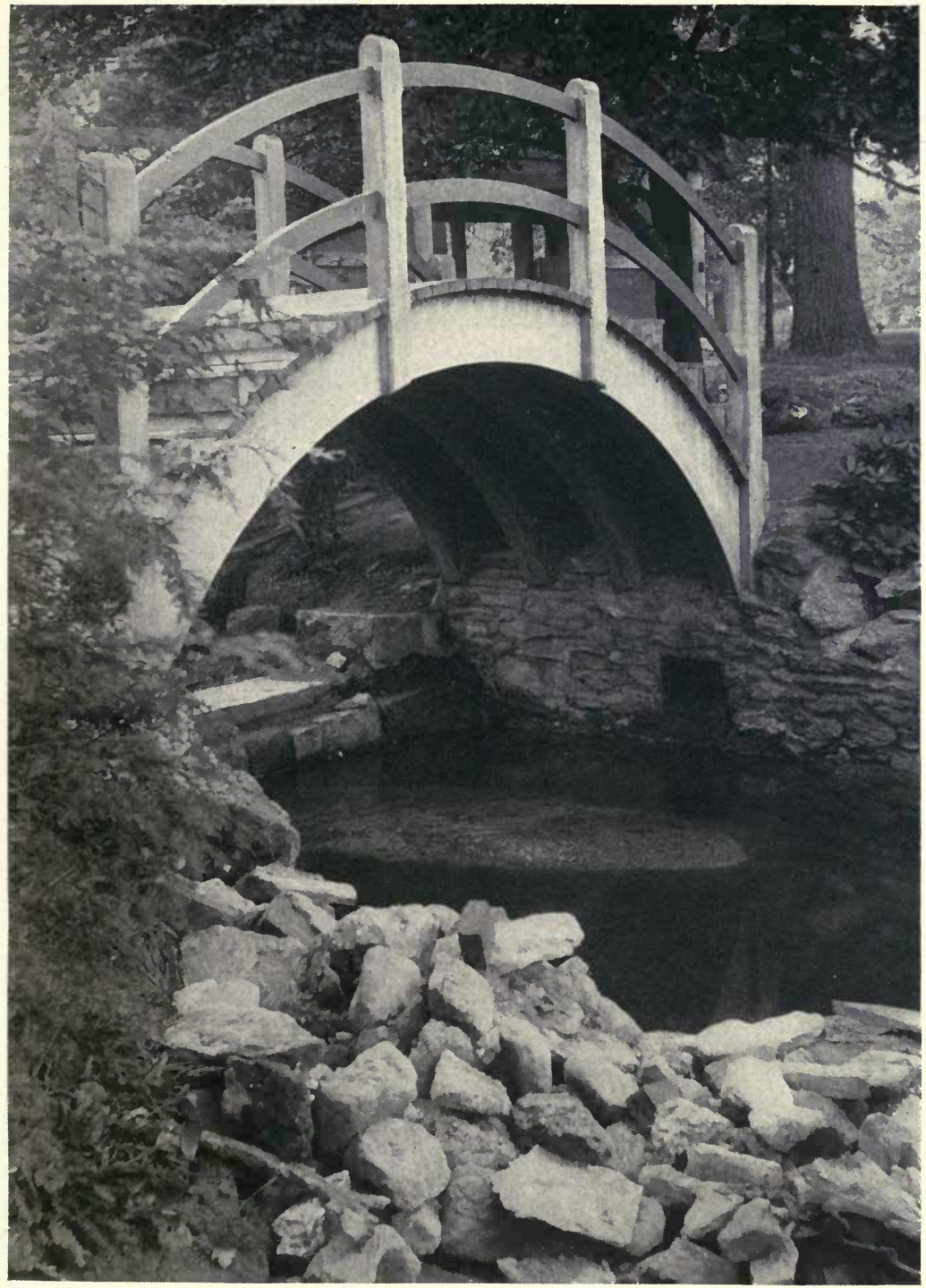

A STEEPLY ARCHED BRIDGE OVER A NARROW STREAM SUBJECT TO SUDDEN FRESHETS 



\section{APPROPRIATE BRIDGES}

Where a deep and narrow stream is subject to swift flow and dash of water after heavy storms it will be wise to have the bridge steeply arched, thus giving additional strength and raising it above the surging waters. Its ornamental value is also increased as the high arch is itself highly decorative. The stone foundation walls supporting the arched structure and the loose rocks outlining the banks and protecting them from the wash of water add to the artistic affect, so that, as in many other phases of garden work, the necessary overcoming of obstacles results in an added picturesqueness. 


\section{XXIII}

\section{PRACTICAL GARDEN FOUNTAINS}

\section{THE COMBINATION OF SCULPTURE AND WATER PLAYS AN IMPORTANT PART IN THE \\ DECORATIVE SCHEME OF THE OUTDOOR LIVING ROOM}

We are gradually awakening to the charm and the possibilities of the "poetic spray" in our garden pools. It is true that many landscape architects insist that fountain statuary is fitting only in formal gardens and parks. But all agree that the sparkling fountain spray-either with or without elaborate statuary-is appropriate and desirable for every form of garden. When introduced into the general decorative scheme of the home grounds, it not only creates a garden centre, but it may be made to perform valuable service if employed in the right way. With abundant water supply at hand from natural sources, there is little necessity for a costly structure or expensive operation to produce the continual charm of running water and fascinating effects in its disposition, before and after it enters the fountain basin. When it is necessary to introduce the hydraulic ram and various supply pipes to give the required flow the expense will be greatly increased. However, a practical study of ways and means will convince 


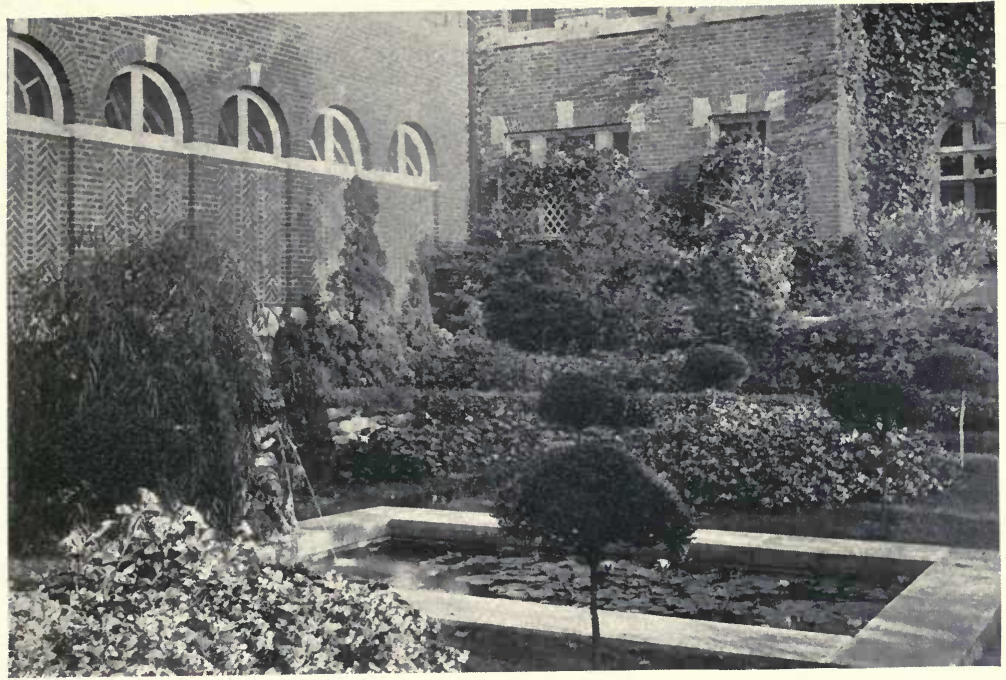

AN OBLONG TERRACE FOUNTAIN WITH SPOUTING FIGURE POISED ON THE RIM AND SHRUBBERY BACKGROUND

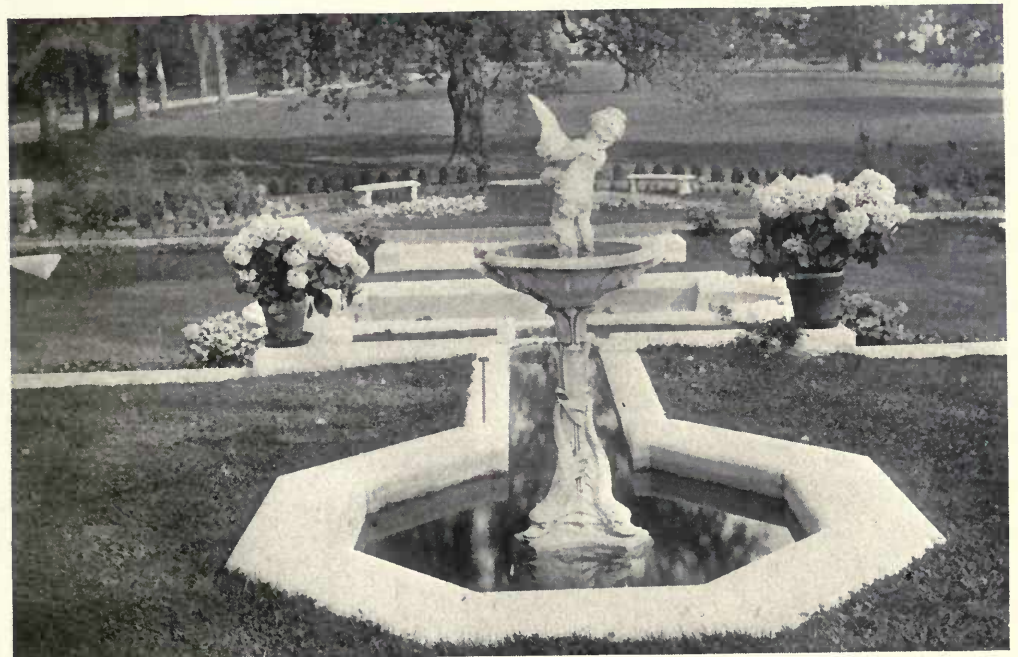

FOUNTAIN OF ROMAN TYPE, FEEDING OTHERS IN THE SUNKEN GARDEN 



\section{PRACTICAL GARDEN FOUNTAINS}

the ambitious fountain builder that there are many interesting devices within his reach which will be entirely fitting and ornamental for the garden which he is to beautify.

A study of fountain statuary in its varied forms, from the rare beauty of sculptured marble to the quaint charm of the grotesque concrete form spouting the fountain spray, will be of special importance, from the decorative view-point and that of suitability. A study of the best method of introducing and controlling the water supply, and of using the same water over and over when the supply is limited, also will demand careful attention if one would have the ornamental fountain and its accessories entirely practical.

In order to supply the home garden with a perfectly satisfactory fountain, constructed on simple lines, it will not be necessary to follow any arbitrary rules concerning the height of the spray or the breadth of the dome effect. Neither must these features receive any special consideration in regard to the flat garden spaces, the low-lying gardens, the hilly gardens, the open sunny spaces, or those closely encircled with trees and shrubbery. The little pool, with its quaint and appropriate figure of amateur construction and setting, may readily be kept in harmony with its surroundings.

The elaborate fountains designed by landscape 


\section{PRACTICAL BOOK OF GARDEN ARCHITECTURE}

artists and sculptors for show places on famous country seats offer very different problems. They are receiving considerable attention in the increasing desire to introduce the charm of old-world gardens on American estates. In connection with his knowledge of practical fountain requirements, the expert must go deeper into the study, and get in touch with all the old gods of mythology, especially with the enchanting race of water deities. He must secure an intimate knowledge of Neptune, with his trident and sea-horses, mermaids and mermen. He must possess the gift of discrimination in introducing dolphins, tritons, fishy tails, cupids and nymphs of every degree, frolicking in the gushing water, spouting it out through horns and shells and inflated nostrils, pouring it from reversed urns, and making a veritable water-carnival; from all which it will require fine artistic discernment to choose wisely in fountain combinations.

The study of fountains in old English gardens is worthy of special consideration in order to obtain good ideas in coloring, as well as design, for fountain construction. Naturally one turns first to the wonderful French conceptions, as portrayed in the famous Versailles fountains, or to Italian designs, in celebrated Roman types; but it is in the "Story" fountains of England that we find the true coloring 


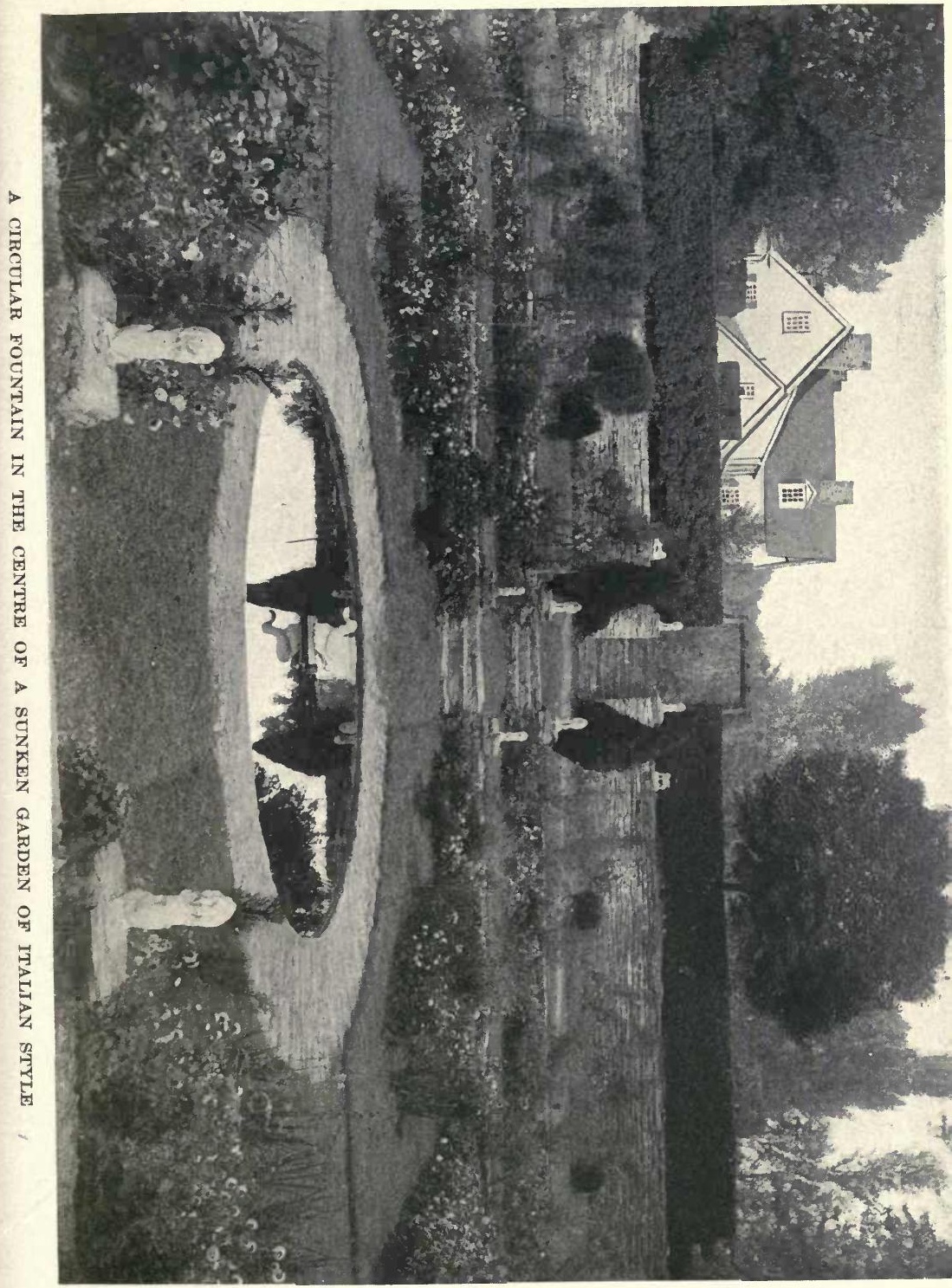


a 


\section{PRACTICAL GARDEN FOUNTAINS}

and design now gaining favor in celebrated American gardens.

There is very good reason for looking upon Mr. Waldo Story as an authority on the subject, he being widely known as one of the most successful designers of fountains for English gardens. He had many advantages to fit him for his work as a sculptor and art designer, as he was not only the son of the wellknown American sculptor, with the advantage of inherited talent, but was carefully educated at Eton and Oxford, and afterwards had a home in Italy, where he was in touch with the art which most appealed to him.

When Mr. Story turned his attention to garden decoration (after having achieved world-wide fame as a sculptor) he delighted especially in constructing wonderful fountains. Several years ago, during my first trip to England to study types of garden architecture, I was given a list of three gardens which it would be well worth while to visit because of their famous fountains. From the clipping describing these, I found that they were all "Story" fountains and represented some of his best work. A description of what he has done in these three fountains will give ideas of color and design helpful to other fountain builders. At Cliveden, the Astor's ideally situated place on the River Thames, he has laid out ter- 
races with stone balustrades and great vases for flowers; he has designed flights of steps which suggest the Villa d'Este, and are yet in perfect harmony with the English landscape, and has placed a circular seat just where it ought to be, under the shadow of the spreading trees. Here, too, he has designed a colossal fountain representing nymphs drinking from the fountain of love. This fountain is remarkable for its color secured by contrasting metals and marble. The figures are of green bronze, and stand on a shell of purple Verona marble, which is placed in a reservoir sixty feet across, lined with blue mosaic.

At Blenheim Palace is the fountain which Mr. Story designed for the Duke of Marlborough, which has a figure of Victory in golden bronze with green bronze draperies, holding high in air a crown from which the water sprinkles down into a basin of yellow Siena marble. This basin is supported by green bronze dolphins, with figures of nymphs and cupids sporting round, and its rim is hidden by carefully kept turf over which the water laps. In the original design the basin was to have been lined with pale blue mosaic.

It is, however, at Mr. Leopold de Rothschild's place, "Ascott Wing," that two of the finest examples of Mr. Story's designs of fountains are to be found. The larger represents The Triumph of Gala- 


\section{PRACTICAL GARDEN FOUNTAINS}

tea. "The nymph and the water turtle on which she stands are of dark bronze, her drapery is green bronze, and the shell on which the turtle is placed is composed of one splendid piece of yellow Siena marble. This shell, especially in its reflection in the water, rather resembles the prow of a gondola. The whole composition is full of breezy motion, the bronze sea-horses drawing the shell rear and plunge in the water; the young Triton is grasping the broken reins which they have snapped in their impatience, while. the amorini behind the nymph urge on the horses with arms uplifted and countenances expressive of laughter and mischief. Galatea alone, in a pose of classic grace, is quite calm and unmoved in the midst of all this tumult, which is increased by the splashing of the water spouting from the sea-horses' nostrils, from the water-turtle's mouth, and from the cascade which pours over the ribbed edge of the shell.

"The smaller fountain at 'Ascott Wing' is composed of two yellow Siena marble tazze, the lower of which is lined with rainbow-hued, tinted mosaic, and supported by four twisted bronze dolphins. In this larger basin stands a sheaf of green bronze bulrushes with golden tips among golden acanthus leaves. It is confined by a golden snake and supports the upper tazza, on which a winged figure of Iris is poised on one foot, with a gold-tipped arrow in her 


\section{PRACTICAL BOOK OF GARDEN ARCHITECTURE}

outstretched hand. The quatrefoil shape of the tazza is repeated in the flower beds which surround the fountain and so form part of the design."

Other fountains of English gardens which have been quite as carefully and wonderfully executed by Mr. Story might be described; but these are sufficient to give the suggestion of color combinations and design which play an important part in perfecting elaborate fountains for large garden spaces. For the little fountains, suitable for small gardens and secluded nooks in fascinating outdoor retreats, it will not be necessary to have any color scheme. The iron fountains (which will require painting to aid in their preservation) may have the entire basin and spout and figure of the same color-preferably white-in contrast to the green turf surrounding it, or a color that will blend with its decorative surroundings. The concrete and stone basins should be left in their natural color, with the fountain accessories tinted to correspond.

A little low figure of a swan, a nymph or a dolphin, poised on the water in the centre of the basin or pool is the simplest form of fountain; and it is especially pleasing in a low-lying garden with slightly rising terraces. The fountain with tall figures requires a green background of trees or shrubbery to bring out its beauty. The planting about the pool 


\section{PRACTICAL GARDEN FOUNTAINS}

must be carefully considered, according to the layout of the grounds. The low-growing plants and blooms of the comparatively flat garden should have a low, broad spray to the fountain jet. The fine, high stream spouting up from a tall figure will show to good effect through a vista, or from garden structures on upper terraces.

For the stone or concrete basins of amateur construction, shape, depth, and proportion should be considered. Entirely satisfactory basins may be constructed at slight expense by any one who is capable of building a little garden pool or lake. It is best to keep the basin round where it is to have a small central figure, rather than to attempt any fantastic design. A square or oblong basin may have the figure poised on its edge with a clump of evergreen shrubbery in the background to throw it in relief. A long, square-cornered basin, with jets of water spouting up in many places, over the surface of the water, will not require figures. For decorative value these various sprays should glint and sparkle to a height of only a foot or eighteen inches, and then fall into the midst of water-lily clumps, or other aquatic plants, which are apparently benefited by the overhead watering.

When the fountain basin is to serve as a waterlily pond in the garden of limited space, it should be 
made sufficiently deep to provide for the boxes of rich soil in which the lily roots are planted. The basin that is not intended for growing aquatic plants may be quite shallow; but it should have a good, solid foundation beneath the concrete or stone-work, to prevent cracking or sinking. Both the deep and the shallow basins should have a slightly outward flare at the brim, so that it will not be cracked with sudden freezing; and provision should be made for thoroughly draining the basins when there is danger of hard freezing.

Iron basins in various forms, which may be bought at little cost, ready for setting in place, and with iron or terra cotta figures in keeping with the basin and its position in the garden, require very little work except the annual cost of paint necessary to preserve the iron work and give the whole a fresh, well-kept appearance. Low flower planting close around the rim of an iron basin will be desirable to give dignity to what would otherwise present a frail appearance. For an inexpensive fountain that is easy to install, an iron basin may simply have its central pipe for spouting the water, emerging from a rockery with floating water hyacinths among the stones and the exposed rocks glistening in the fine spray constantly showered over them. 


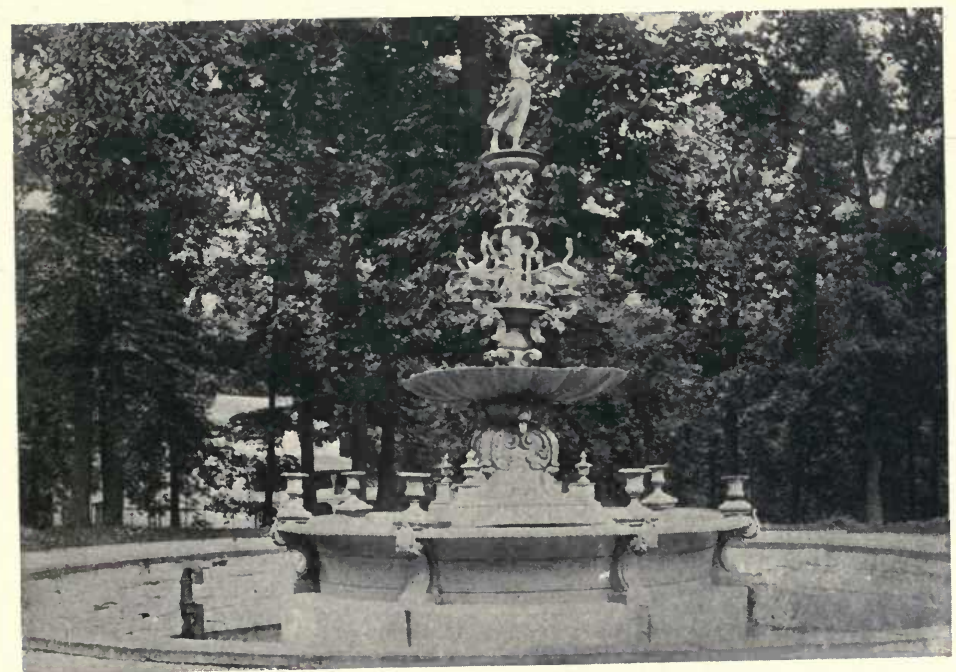

A TALL, Elaborate Fountain With THE ADVISABLE BACKGRoUND OF FOLIAGE

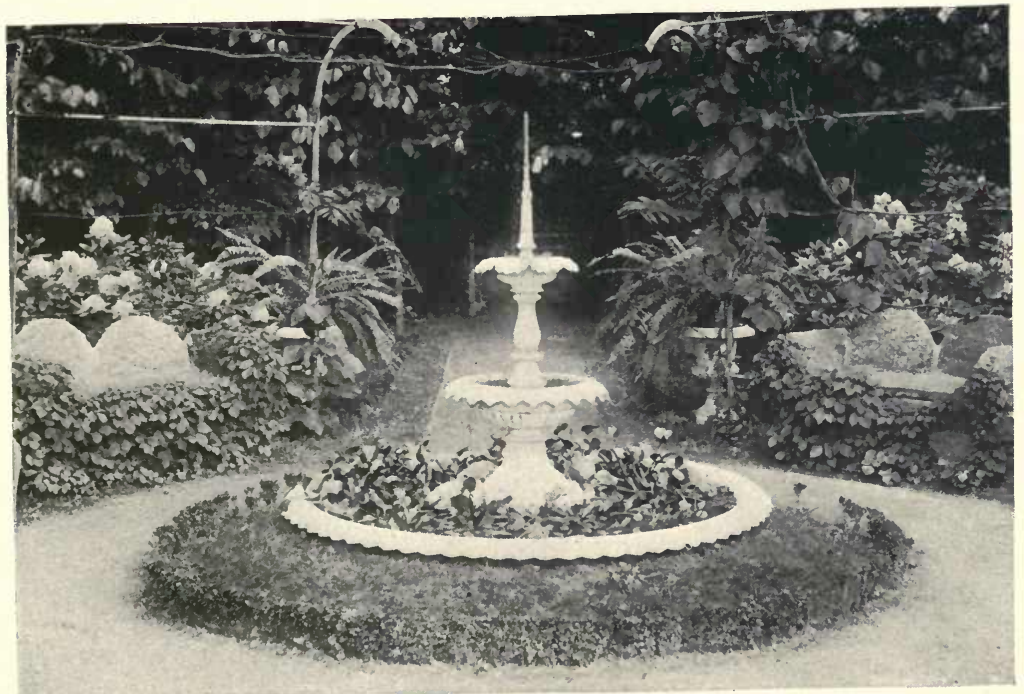

A SIMPLE IRON FOUNTAIN, EASILY INSTALLED AND ATTRACTIVE 



\section{PRACTICAL GARDEN FOUNTAINS}

Whether the simple fountain of home-made.construction or the elaborate affair of rare sculpture and coloring is considered, it is of first importance to have a satisfactory water supply. When there is a copious spring or stream on the grounds to provide this with sufficient pressure, the plumbing and the piping will be very simple and well within the capability of the home gardener. The fountain that is fed from an adequate house supply will be equally satisfactory at little cost. When it is necessary to provide additional sources the hydraulic ram with pneumatic tank is considered the best means of accomplishing the purpose, and expert advice will be required to insure satisfactory results. Mr. Dalton Wylie, who is an authority on the subject, supplied the facts which were especially helpful to me in establishing an interesting garden fountain several years ago.

The fountain described was a practical type that beautifies the home of William Trotter, at Oyster Bay, Long Island. "'This fountain," said Mr. Wylie, "is peculiar in that it is run by the direct force of an artesian well, and in that it serves rather as a means than as an end in the water-supply system of the estate. Water for the place is supplied by an artesian well-a three-inch pipe driven down eightythree feet to pure water. The geological formation 


\section{PRACTICAL BOOK OF GARDEN ARCHITECTURE}

of a large portion of Long Island, by the way, makes an artesian well a pretty sure way of securing a continual stream of fresh water.

"Originally the water rushed up into an unadorned stand-pipe, connected at the top with another stand-pipe through which the water flowed down with some force into a nearly horizontal drive-pipe running to a ram hidden in a pit. There is a nine-foot fall from the top of the stand-pipe to the ram, giving enough force to pump the water to a reservoir tank on a hill of one hundred and five feet elevation. From the reservoir is obtained the water for the entire place. The supply is unremitting all the year, thirty-five gallons flowing to the minute when the tide is low in the bay, and ninety gallons at high tide. The tide probably backs the water up in some natural outlet, causing the difference in quantity and pressure.

"Such a system was entirely satisfactory except for one thing - the stand-pipes were an eyesore. Mr. Trotter conceived the idea of converting them into a thing of beauty-a fountain. Around the base he built a concrete basin three feet deep, with an overflow into a little brook. The stand-pipes he surrounded with a pillar of rolled copper, filled with cement. At the top he placed a copper jardiniere, picked up at an auction sale, first punching a hole in the bottom. The supply pipe now empties into this 


\section{PRACTICAL GARDEN FOUNTAINS}

bowl, flowing into the receiving pipe and also into smaller pipes, leading to the leads at the sides. In the summer a glass pipe is attached to the supply pipe, causing the jet of water to rise several inches above the top of the bowl, giving a graceful dome effect.

"In the winter this is taken off, and all the surplus water is allowed to flow through the vents at the sides. As the water maintains a consistent temperature of fifty-two degrees the fountain never freezes."

This fountain has attracted considerable attention because of its unique beauty and utility. Around the basin is a plot of hard gravel surrounded by a ring of lawn. At the border of this irises bloom gaily in their season. The weather has turned the copper to a beautiful color. The result is a most attractive fountain instead of a pair of unsightly pipes. Practically no changes in piping and no extra supply were necessary to bring about the result. The fountain is operated incidentally-in transit, so to speak. This is only a single example of what might be done in converting an unsightly utilitarian feature of water supply into an ornamental garden feature. It is only another example of the fact that the object whose beauty is most appreciated in a well-designed garden is the object that gives the greatest value. 


\section{XXIV}

\section{REVIVAL OF THE WALL FOUNTAIN}

\section{A SUGGESTION FROM THE VILLAS OF ANCIENT ROME FOR BEAUTIFYING AMERICAN GARDENS}

MaNy novelties in garden decoration that are finding favor have come to us from famous Italian gardens, and charming and practical ideas in water features are among the most prominent. In the translation of the Italian garden cult to America, it proceeded by way of England, France, and Holland. After long use in these countries, great changes have taken place, and many features have been introduced that scarcely can be called Italian in design, although the thought may have originated in some beautiful villa of Rome or Florence.

A wall fountain in artistic form was invariably a part of a well-furnished outdoor living room represented by the formal gardens of sunny Italy, and there is no reason why its introduction at beautiful American country seats should not be widely appreciated.

At "Thorn Hedge," the country home of Mr. H. H. Battles, there is to be found an exquisite design of wall fountains. It is fastened directly on the rough stone wall which encloses a secluded section of 
י

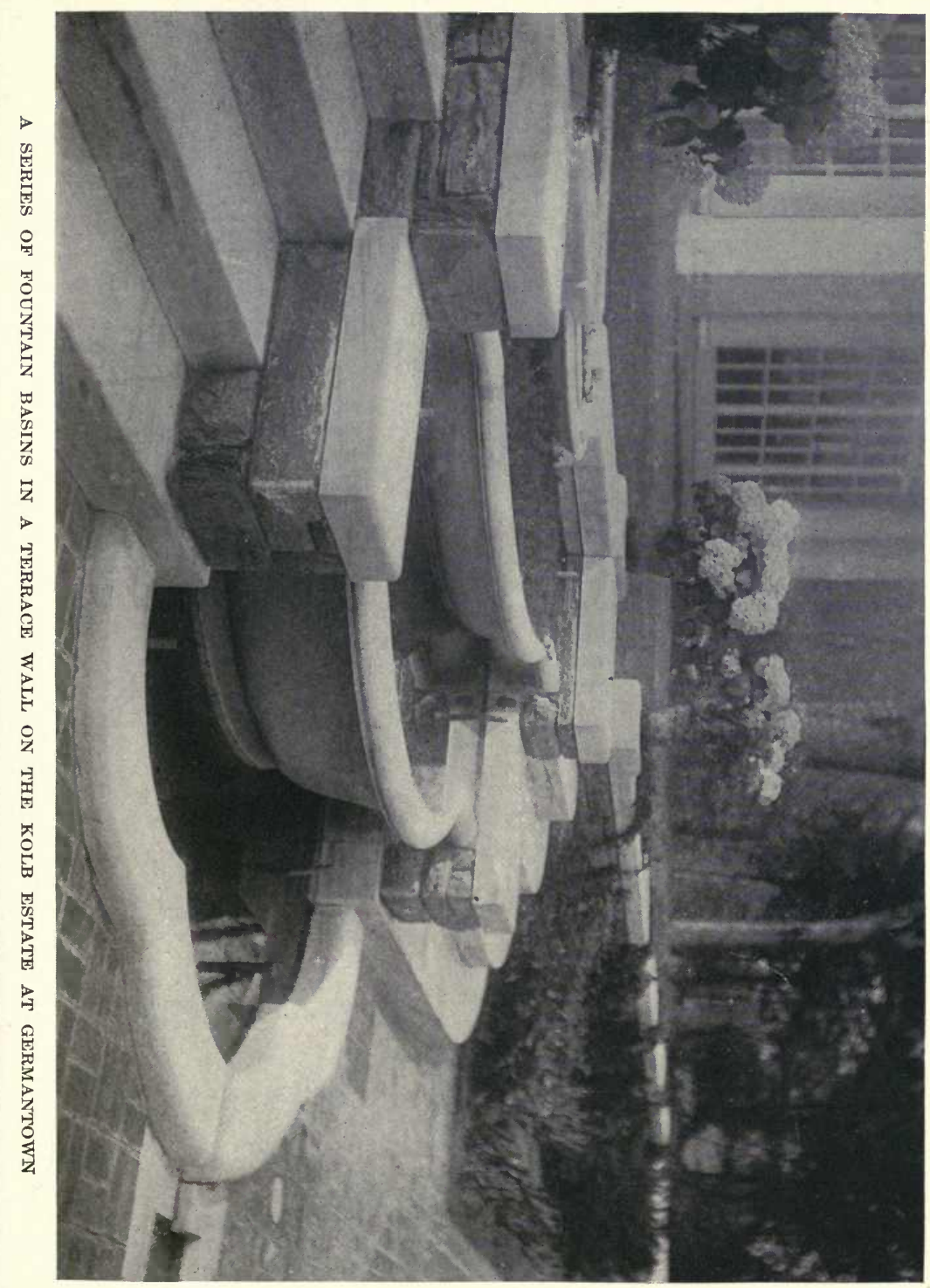




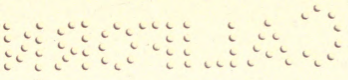




\section{REVIVAL OF THE WALL FOUNTAIN}

the wide-reaching gardens of the big estate. It is designed in correct Italian style with wonderful carvings, and its accompaniment of luxuriant fern growths at the base of the wall, its trailing ivy and bits of statuary and flower vases, form a fascinating picture that might have been lifted bodily from a Florentine villa, and set down in this garden nook of an American country home, so accurate is the whole both in design and setting.

Other suburban estates whose owners appreciate the beauty of wall fountains in old-world gardens have had duplicates of old designs executed in concrete, instead of importing the costly marbles direct from Italian gardens.

A practical garden architect has made this thought of special prominence in urging the owners of attractive country homes to take advantage of the lessons taught us by ancient gardeners concerning the use of running water. The claim is put forth that "many kinds of labor-saving devices unknown in Europe three centuries ago now help to lessen the expense of garden-making and maintenance. Fountains, sundials, garden seats, balustrades, steps, and other garden accessories are by no means essential to a lovely garden; but if one wants them and cannot afford them in stone or marble, excellent reproductions in cement may be had at a small fraction of the 


\section{PRACTICAL BOOK OF GARDEN ARCHITECTURE}

cost of classic models. Thus a man of very moderate means may enjoy a duplicate of the fountain of Lions at the Vatican."

The illustrations show practical devices for constructing and setting the fountain in the garden wall. The circular basin is molded separate from the curved back, with its varied decorations and fountain head. When the fountain is ready to set in position, a cavity is made in the stone-work, considerably larger than is actually required. This allows the insertion of timbers to hold the fountain in place. When constructed of concrete, and set directly in the stone-work, the heavy fountain might show a tendency to pull from its fastenings. When firmly fastened in its supports, there is no necessity for anxiety on this score.

After being firmly placed, its ornamental features are added. With cement and plaster, the basin and its background are carefully joined to give the appearance of a single piece of sculpture chiselled in its decorative form. The head from which the water flows into the fountain basin, and the carvings in relief, are touched up into naturalistic finish; and the roughened surfaces of the timbers are given a coat of plaster matching the finish of the surrounding stone-work. The fountain is then ready for its vine decoration and, no matter how attractive in other re- 

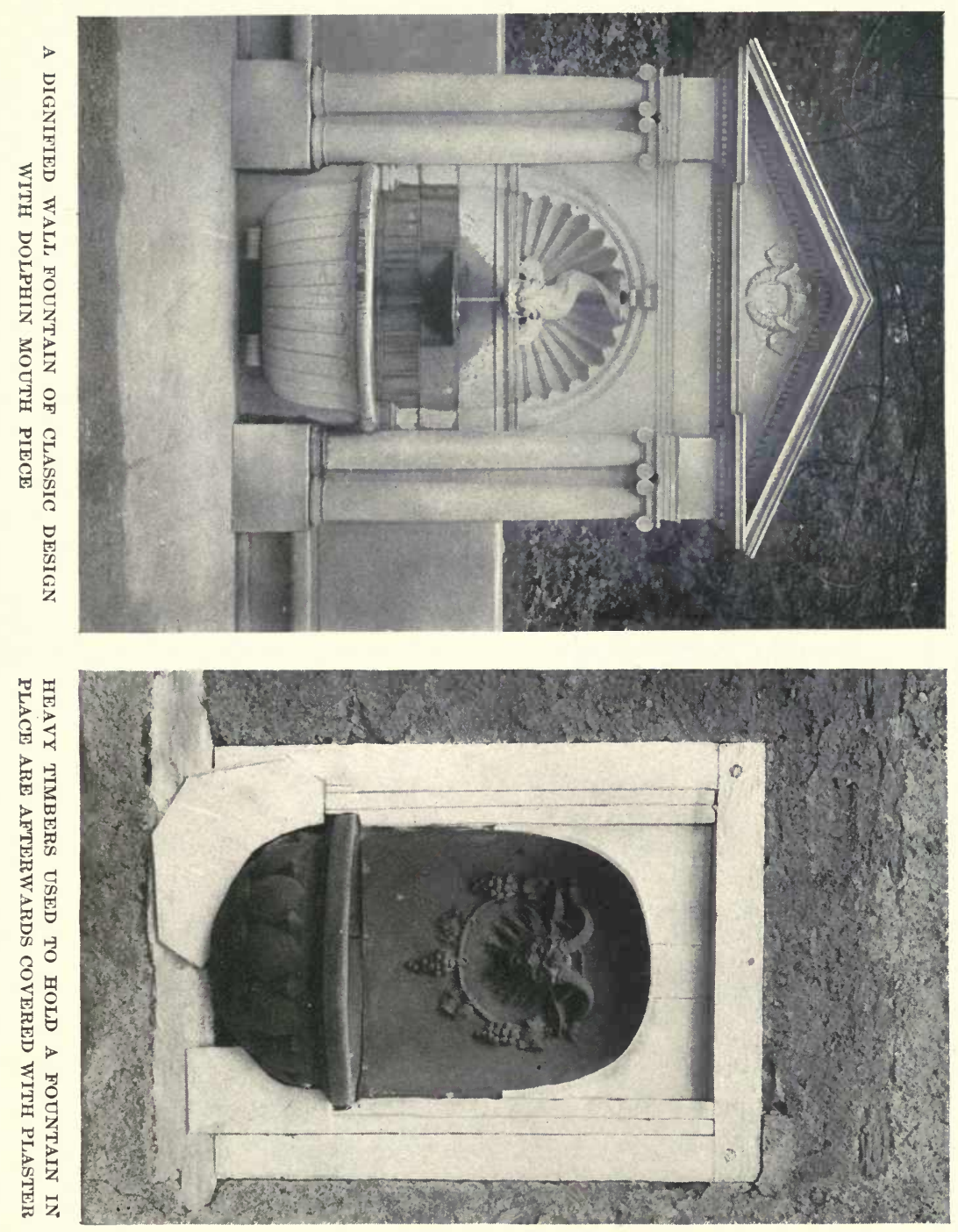



\section{REVIVAL OF THE WALL FOUNTAIN}

spects, the wall fountain will not display its full beauty unless surrounded by greenery. Ivies, ampelopsis, and other climbing vines that cling close to the stone and plaster surfaces of the surrounding wall should be planted beneath the fountain and carefully trained to hide its connection with the wall. The vine drapery will act not only as a screen, but also will soften and beautify the cold, hard outlines of concrete or cement. When the fountain is set low, tall ferns and other feathery foliage plants that flourish in the damp wall surfaces may be grown in great luxuriance at its base.

There is no reason why there should not be more of these charming wall fountains in our conservatories and courts, and along the stone, brick and concrete enclosures of outdoor living rooms. There seems to be a general impression that great practical difficulties stand in the way, especially when one must depend upon an artificial supply of water. In fact there is none that cannot readily be overcome. A designer who has had wide experience in establishing these fountains states that there is no more difficulty or expense in installing the plumbing for a simple wall fountain than for an ordinary wash-basin faucet.

"Nothing more is required," he says, "than a small supply pipe, and a slightly larger one to drain the basin or pool. And, contrary to the wide-spread 


\section{PRACTICAL BOOK OF GARDEN ARCHITECTURE}

impression, the supply pipe seldom needs to be larger than one-half inch in diameter, and may often be even less."

In a series of wall fountains in the California home of Mr. Gillespie-which is frequently quoted as an interesting type to follow-a three-quarter supply affords sufficient water to keep the whole system running. Here, with a natural scarcity of water, the fountains are arranged at various levels so that each one, after the highest, is fed by the one next above it.

Where there is a spring or some other natural water supply, there will be every incentive for the wall fountain, which was the secret of garden enchantment in many outdoor living rooms of Italian villas. With this natural source, the extra supply pipe for the fountain will entail no expense for maintenance. Even where it is necessary to employ a city main, and it is not practicable to secure a special fountain rate for the water used, one need not be deprived of this desirable garden feature. By means of a stopcock one may be enabled to have a fountain jet flowing during that part of the day when it is wanted. In this instance, care should be taken to have the outlet near the top of the basin; and thus it need not be empty when the water has stopped flowing.

It scarcely matters whether one has established a wall fountain in the form of a simple lion's head 
T)

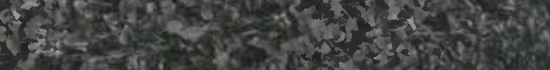





\section{REVIVAL OF THE WALL FOUNTAIN}

and a basin in concrete, for a few dollars, or an Italian fountain of carved marble for a few thousand; the general effect is the same in combining motion and music, and the play of light and color in the running water. When the wall fountain contains a series of basins, the beauty is sometimes enhanced without extra cost in the water supply. In the most practical forms of wall fountains, as in other ornamental water features of the garden, the great thing is to get the desired effect with as little water as possible, using it several times over whenever this can be done. It is claimed that the important point is to get a thin sheet of water rippling over a corrugated surface, or in some other way, so that it will attract the sunlight. When the wall fountain consists of a single basin, and there is no play of light and color in bounding from one basin to another, the supply is sometimes arranged to spout from the lion's head or other ornamental source of supply, in the form of divided jets or sprays. The garden architects of sunny Italy seldom attempted or desired the roar and agitation of powerful masses of water. A very small volume is made to produce a maximum of decorative effect, and the greatest possible variety, by repeated interruptions and changes of its movement. It is when we follow most closely this practical principle that we secure the greatest satisfaction in the treatment of our picturesque wall fountains. 


\section{XXV}

\section{THE PRACTICAL SIDE OF THE TENNIS COURT}

\section{THE BEST MATERIALS FOR A DURABLE COURT AND APPROPRIATE ARCHITECTURAL FEATURES}

No country home is considered complete-in these days of catering to the cult of outdoor lovers-without some form of open-air recreation. It is acknowledged that one of the most important secrets of success in professional, in business, and in home life, is knowing when to stop, when to side-track, when unremitting industriousness should be changed to intelligent idleness and play.

When the invitation to recreation lies just outside the home, in a shady tennis court, a charming bowling green, or well-laid golf grounds, the members of the household will soon learn to appreciate the therapeutic value of fresh air. In the planning and the building of the tennis court, while contributing to the permanent good health of its promoters, it may be made one of the most decorative notes of the garden harmony.

But no matter how simple or how elaborate its plan, the practical durability of the court itself 


$$
\text { נ, }
$$

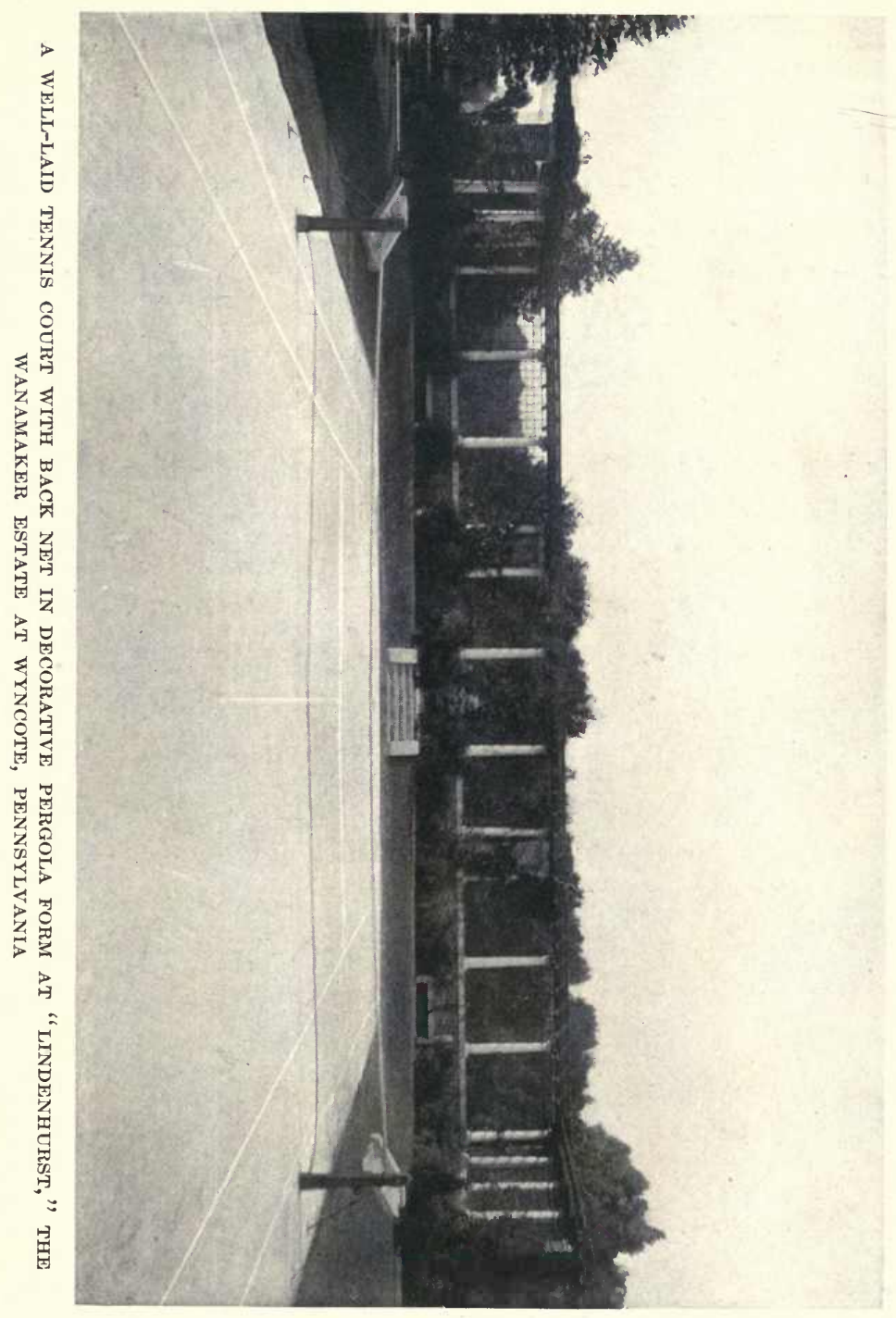





\section{THE PRACTICAL SIDE OF THE TENNIS COURT}

should be of first consideration. It may be simply a plain, well-drained dirt court, a hard, fine clay court, or a closely trimmed turf court. It may have an enclosure of the simplest form of open-mesh chicken-wire, or an elaborate pergola and trellis arrangement for the back net. It may be situated on a broad terrace, with flower-bordered walks connecting it with the garden, and a tea house invitingly situated at the end of a vista, where it will add to the decorative scheme. Whether it shall be a dirt or turf or clay court will depend largely upon the locality in which it is situated. A well-laid clay court is usually given the preference where the right quality of clay can be obtained without too much expense. There is a combination of gravel and clay in the New England states which is known near Boston as "binding gravel" (consisting mainly of gravel with just enough clay to make it pack hard) that forms one of the best and most durable surfaces. Lacking the clay and gravel soil, a good turf court can always be depended upon when well laid.

In England the grass or turf court is the favorite. No expense is spared to have the deep, rich soil so thoroughly trenched in its preparation that there is no danger of the grass dying out and the turf becoming inferior. Abundance of water is considered an important factor and it is necessary for us to give 
this special consideration in this country, where long droughts sometimes permanently injure the best of well-planned turf courts.

In planning the grassy courts in England arrangements are frequently made for flooding with water two or three inches deep in times of drought. Another English plan for keeping them in good condition is to underlay them with irrigating tile, which in dry time can be filled with water and allowed to seep through the joints. By means of these pipes or tile, the turf can be more effectively watered from beneath than it could from the surface. For the small home court the tile need not be more than three inches in diameter, laid about sixteen inches deep. The best plan is to lay it crosswise of the court, and about six or eight inches apart, connecting the ends of these crosswise tiles with a line of sixinch tile, and having a central opening for connecting a two-inch hose. The large English courts will sometimes display an elaborate system of irrigating tile, with connecting drains and gate valves. But for the small home court the arrangement may be more simple - the cross drains being given a slight slope from the side of the hose connection to the connecting drain on the other side. With a gate valve in the connecting drain, to be closed in times of drought, it will be possible to keep the pipes filled with water, which will 


\section{THE PRACTICAL SIDE OF THE TENNIS COURT}

gradually seep through the joints. On the other hand the gate valve will be valuable in very wet weather, when it may be left open to allow the tiles to act as drains.

The best laid tile and the most perfect system of irrigating will not secure good turf, however, unless the soil is deep, rich, and carefully prepared to insure permanency.

Deep ploughing is usually considered sufficient preparation of upturned soil for the court with a good quantity of rich manure ploughed under. In England the spade is considered better for fine deep soil preparation, either for the gardening or for growing thick green turf. They claim that the tennis court prepared by hand is always best because the spading is more thorough.

What is known as "trenching" is a system of court preparation still more strongly recommended. The practical English court builder begins by digging a trench at one side of the space to be occupied by the court. He then removes earth adjoining the trench, filling the first trench with the earth taken from the second, and thus continuing across the court.

This system is practical in any section of the country where there is a good rich soil to a depth of a foot and a half or two feet. Where there is 
only a few inches depth of rich top soil, and then a poor subsoil, deep, thorough trenching will prove an expensive operation without satisfactory results. In this case the poor hard-pan can be stirred up with a subsoil plough without bringing the poor soil to the top, and the good surface soil can simply have the sods turned over to rot.

After thorough preparation of the soil, including a plentiful supply of fertilizer, the small tennis court may be sodded to insure quick growth of turf for use the first season. When seed sowing is preferable, for larger courts, fall seeding will form a good turf for the following spring.

Various chemical fertilizers are used for soils rich ir $\iota$ humus, when it is difficult to obtain barnyard manure. Peruvian guano, agricultural lime, ground bone, superphosphate of lime, nitrate of soda, etc., etc., probably will be recommended, used alone, or mixed in various proportions according to the amount of humus in the soil. For the tennis court of the average country home, where stable and barnyard manure can readily be obtained, one need not worry about suitable combinations of chemical fertilizers, but may simply spread on and work under a good amount of manure. From twenty to thirty cart loads to the acre will not be too much for insur- 

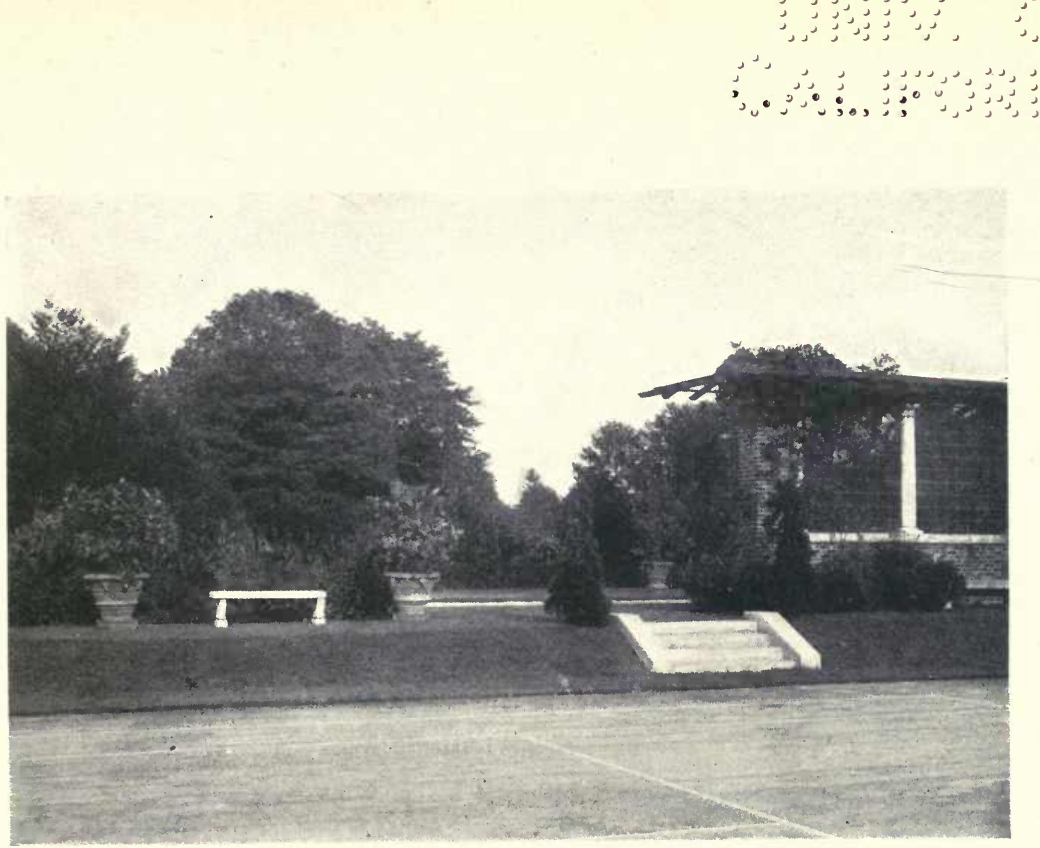

A LOW, ORNAMENTAL TERRACE ABOUT A TENNIS COURT

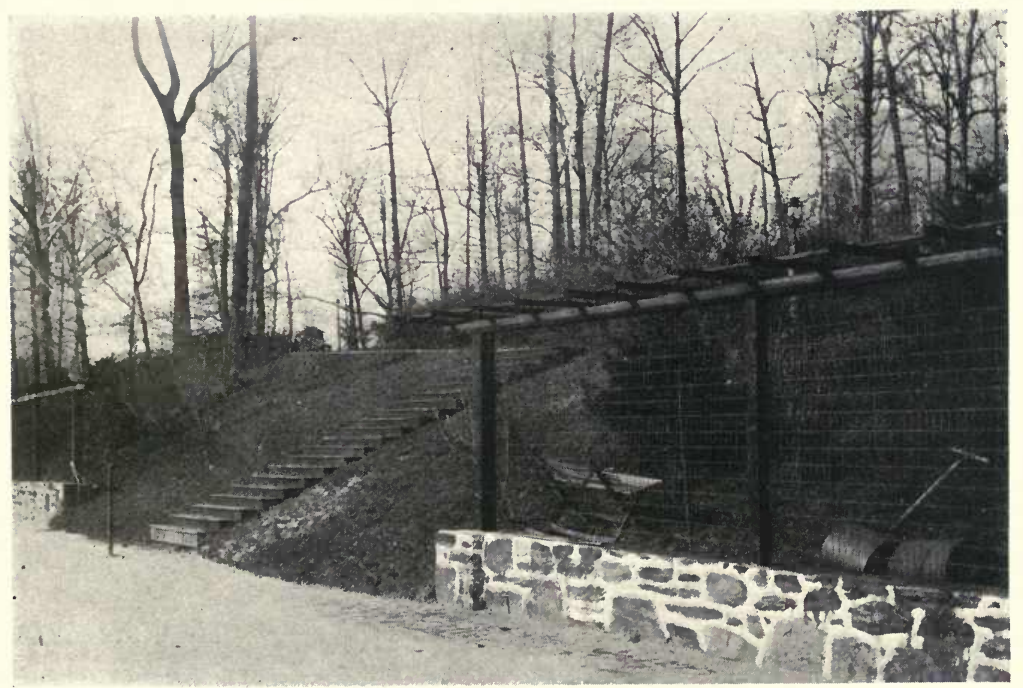

A LONG FLIGHT OF STEPS TO A LOW-PLACED COURT 
的 (2) 


\section{THE PRACTICAL SIDE OF THE TENNIS COURT}

ing good turf. One to two bushels of good lawn seed to the acre will be sufficient for sowing.

It is a wise plan to lay some sort of drainage ditch or trench in the centre of the court beneath the net. This precaution is advisable no matter how carefully the court has been built, to avoid large puddles, which are apt to stretch away from the net after heavy rains. Layers of ashes, straw and broken stone may prove sufficient. When pipes are required, the common two-inch land-draining pipes may be used, laid an inch or two apart, so that the water seeping down through the layers of cinders and straw may enter the pipes and find an outlet. The drainage trench should be filled up nearly even with the surface of the court, leaving only a slight depression its entire length beneath the net. It should have a fine broken stone or gravel instead of clay surface to quickly absorb all rain water.

It is a mistake to build the tennis court in a prominent position, either on the front or back lawn. It will quickly spoil the decorative features of a smooth stretch of lawn no matter how attractive it may be in itself. Where there is a bit of woodland, or garden grove, near the house or a secluded section of the garden, this will be the best place for the court. A level section of a broad terrace will also prove a pleasing location. Instead of the usual judge's stand, 


\section{PRACTICAL BOOK OF GARDEN ARCHITECTURE}

or the grand stand for the "gallery," desirable for public tennis courts, the home court should be so placed that there will be a good situation for a garden tea and rest house, where refreshments may be served, and where onlookers may be comfortably seated during the progress of the game.

The court should also be situated in a spot giving ample room for a broad walk surrounding it, and various forms of architectural embellishment to make it a decorative feature of the home grounds. The court itself should if possible be built at least a hundred and twenty feet long by sixty feet wide. Otherwise there will not be room for the free run back of twenty feet or more sufficient to take the fastest balls, nor the necessary space beyond the side lines to enable one to cover cross-court shotsa space demanding from twelve to fifteen feet. When it is convenient to locate the court to lie north and south, this will prove the best plan. Then the seats for spectators or the tea rooms should be on the west side looking away from the afternoon sun while watching the game.

There are many forms of so-called clay tennis courts that have inferior brown clay or yellow hardpan. The genuine clay - the sort that will be found so resilient that it can be rolled in the hands without breaking-is of entirely different nature, and it is 


\section{THE PRACTICAL SIDE OF THE TENNIS COURT}

the only sort that will make a satisfactory tennis court without special drainage foundation. It is usually secured in swampy sections. A few inches below the muddy surface will be found the putty-like layers of blue or yellow clay that is well worth the expense of carting to the home court, as it will save many dollars in expensive excavations, drainage materials, and piping.

With this clay, or the equally desirable "binding gravel," only the firm soil foundation will be required. All the sod should be removed from the court, with sufficient top soil to reach a hard packed foundation, and allow a clay surface from four to six inches in depth.

The court must be carefully levelled, using grade stakes at regular intervals to insure success. Then instead of merely dumping the clay on the court and working it up to uniform levels by chopping and pounding it on the court, it will be better to have the clay prepared outside of the court. When it is brought from the swamp or clay bed, the putty-like lumps will be too large to place directly on the foundation. Both the clay and the surface of the solid soil will require separate preparation if the court builder is to be certain of perfect amalgamation and keying of the clay. First the foundation surface is slightly chipped all over with a spade. Then the big 


\section{PRACTICAL BOOK OF GARDEN ARCHITECTURE}

lumps of clay are thoroughly chopped with hatchets and spades into pieces of about the size of a hen's egg. The chopped clay must then be spread, a narrow section at a time, to a uniform depth all over the court. Each section will require thorough pounding and tramping down, until the lumpy clay surface becomes well packed to a tough, firm smoothness. It is then ready for screeding down with what is known as a straight edge, in the same manner as cement floors are treated, to fill in all depressions and smooth off the surplus clay and projections.

When it is impossible to obtain a good grade of the "binding gravel" mentioned or the yellow or blue clay of putty-like characteristics, it may be necessary to compromise on a "dirt" tennis court. This term applies to any dirt or brown clay surface which requires a special preparation of the foundation to insure a good firm surface without puddles in time of rain, and without dust in times of drought. The usual excavation of two feet or more in depth, recommended for country club or other public courts subjected to frequent and heavy play, will not be required for the home court. The two-foot excavation usually calls for nearly a foot of tilford, with a sixinch covering of cinders, and the six-inch topping of prepared clay or dirt. The home court will be durable with an excavation of about twelve to sixteen 
$\because, j, j, j, j, j, j$

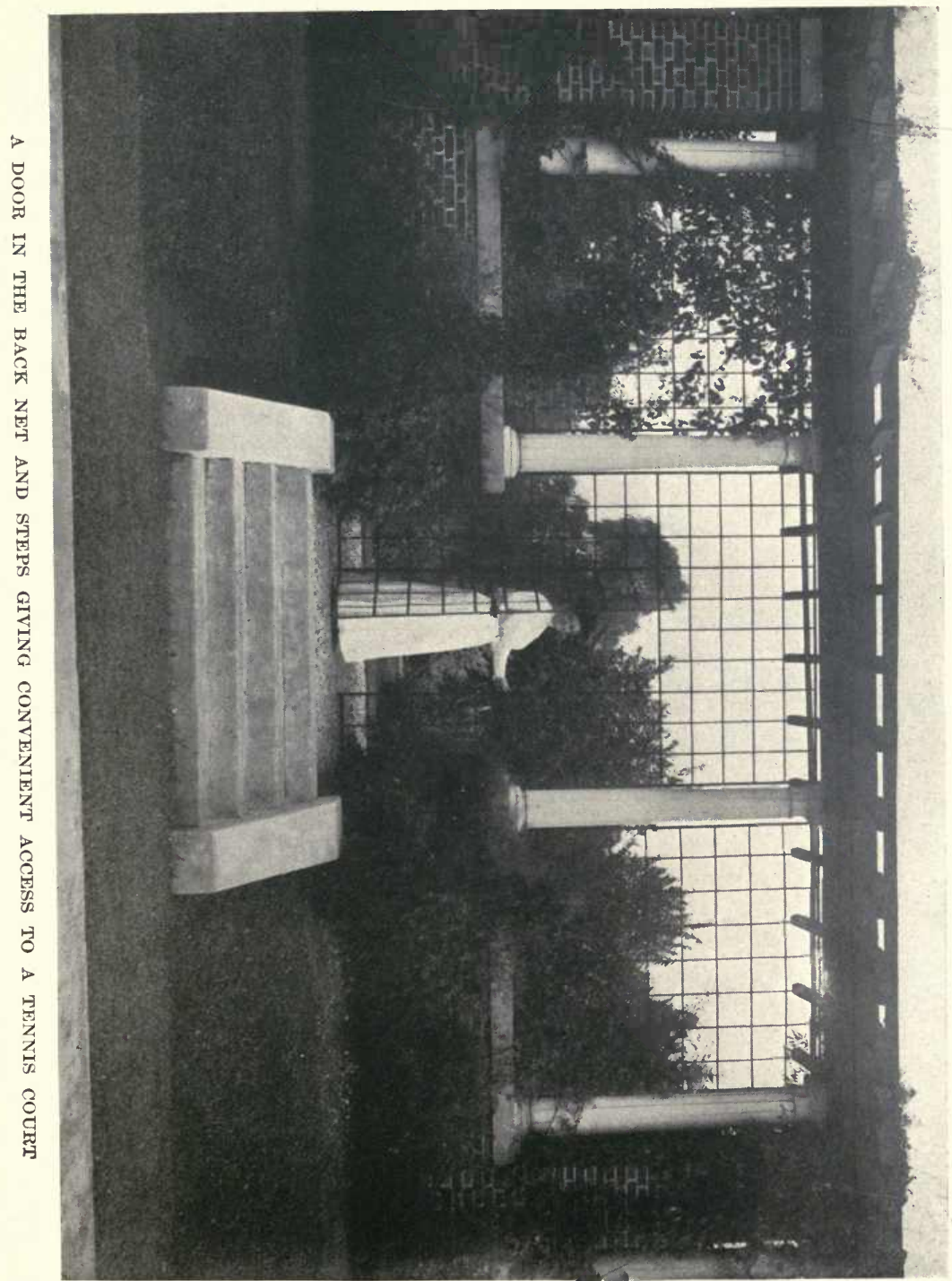



inches, with six or eight inches of cinders well packed down, watered, and thoroughly rolled, before packing on it the six or eight inches of firm dirt surface. A three- or four-inch layer of broken stone under the cinders will improve a dirt court. It not only will provide better drainage and cause the court to dry off quickly after a rain, but it also will prevent the surface from heaving during winter frosts, and destroying the evenness. Both the stone and the cinder layers will be improved by being bound with earth and rolled firmly down with a heavy roller. A good foundation that will quickly carry away all water will keep the dirt surface from becoming sticky or muddy after a rain.

Not only must the stone and cinder foundation be carefully laid to provide permanent and satisfactory drainage, but it also is important slightly to slope the firm upper surface to facilitate drainage, and prevent puddles from forming in the centre, or where the play causes special wear and tear. The hardpan found beneath the top soil in many localities will give a good surface for the dirt court, as will any other soil of a cohesive nature. A slight mixture of sand also will improve it. Thorough watering, sanding, and rolling will prove the chief secret of success in packing the dirt on the foundation, and giving the court a hard, smooth surface. 


\section{PRACTICAL BOOK OF GARDEN ARCHITECTURE}

Seats, terraces, balustrades, retaining walls, pergolas, vine draperies and various other architectural embellishments will be found serviceable as well as decorative features of the tennis court. A pleasing location, well laid and thoroughly drained, and a clearly marked surface for the players, while of the greatest importance, do not end the possibilities of the enthusiast who would make the tennis court a decorative and altogether delightful gathering place for various outdoor functions. Every requirement of the game may readily be turned to good account in ornamenting the grounds. The net-instead of being a mere back net of iron or wooden posts and ordinary chicken-wire-may be formed of lattice or trellises, with masonry or decorative posts. The top of the net, with its three-side enclosure, may be finished to good advantage with pergola roof. The wire net will be just as effective in stopping the balls when covered with vines as when left in crude bareness. A slight terrace from one to two feet in height surrounding three sides of the court will give a raised space for garden seats, ornamental urns, Florentine pottery, box and bay and other tub plants; and the concrete steps mounting the terrace will be improved by a setting of dwarf evergreen trees and shrubbery.

Brick pillars at the corners, a brick retaining wall from three to four feet in height, surmounted by 


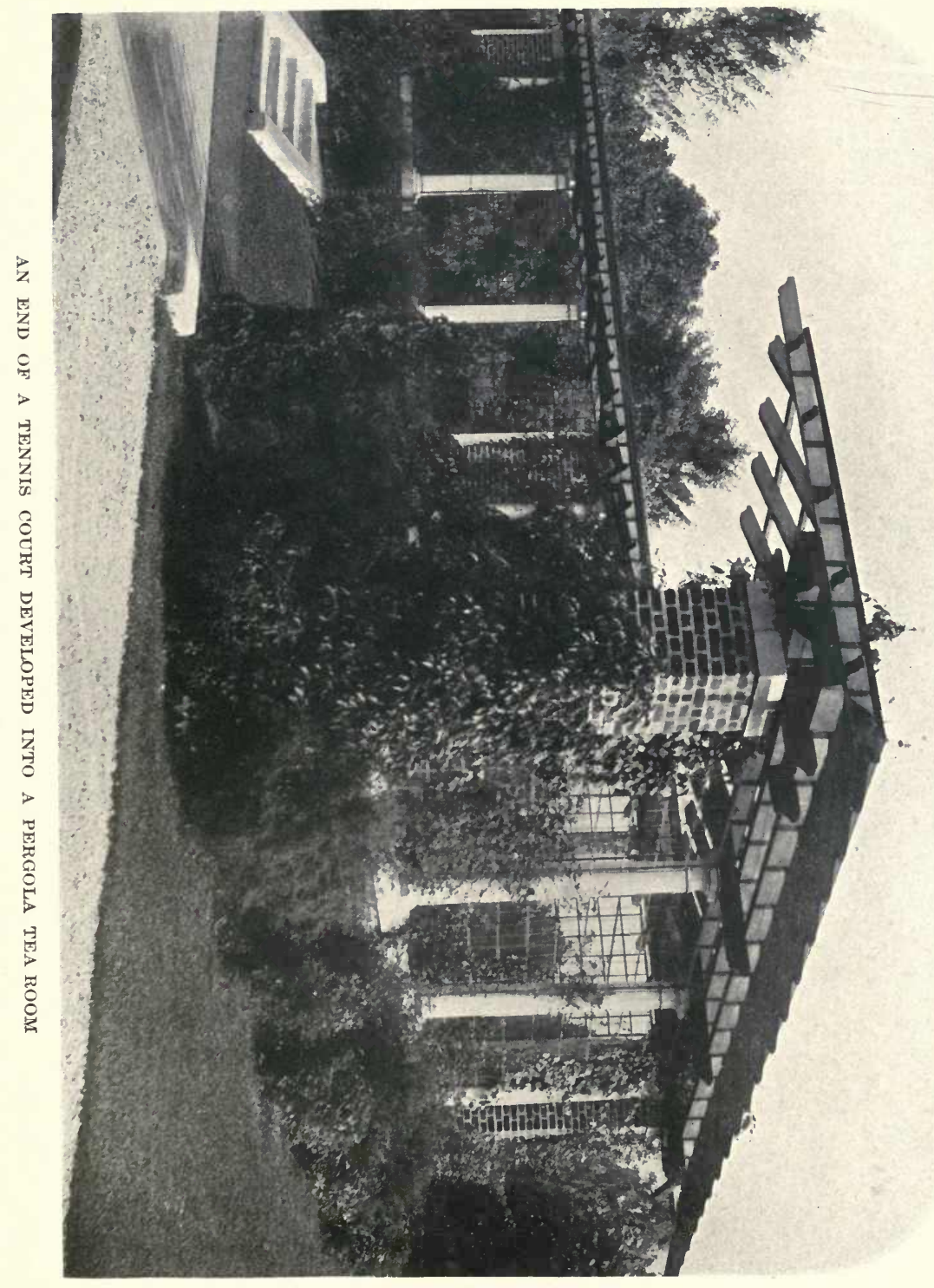





\section{THE PRACTICAL SIDE OF THE TENNIS COURT}

white columns, and topped with a pergola extension combine to form an ideal court enclosure shown in one of the illustrations. Within the retaining wall are found the seats and shrubbery. On the outside of the wall a mass of dwarf evergreens and blooming plants, with blooming vines climbing over the wire panels between the columns, produces the effect of a flower-banked garden pergola, without a suggestion of the court from the house view. Another good plan that has been effectively carried out is shown in the court situated on the level of a steep terrace, with the pergola roof of the net enclosure on the level of the upper lawn and the view from the house of the vine-draped roof, giving the appearance of a flower border. An attractive layout, with casual and unexpected features, will go far towards making the tennis court an architectural success. 


\section{XXVI}

\section{ESPALIER WALLS AND TRELLISES}

\section{A PRACTICAL HORTICULTURAL HOBBY DEVEL- OPED INTO AN ORNAMENTAL GARDEN FEATURE}

WALLS of brick, stone, concrete and glass, and trellises of wire and woodwork in various decorative forms, are being introduced by enterprising landowners for the express purpose of experimenting with the fascinating hobby of growing dwarf fruit trees. The art of espalier work reached a high degree of perfection among the Swiss and the Italians many years ago; then the English, the French and the Germans made excellent progress in achieving a practical success of what was at first considered but a quaint and interesting hobby. Since its introduction into American gardens it has served a twofold purpose. The propagation of luscious fruits of unusual size, under peculiar conditions, is primarily the object of espaliers. Their use as architectural features, in garden formation, though of a secondary nature, in reality gives them their greatest importance in American gardens.

The term espalier has come to be used in a broad sense, applying to the dwarfed trees trained in various forms against walls and trellises, and also 
to the various architectural devices on which the trees are trained. In the early European gardens, an espalier meant simply the tree itself, spread out on a trellis; while the trees spread out on a wall were known as fan shapes or palm shapes; and those trained to form a single stem, without side branches, and fastened to stakes or walls, were known as cordons.

Espaliers, fan shapes and cordons are still given their separate designations, but they are now commonly known collectively as "garden espaliers." The varied methods of training them, and the decorative use to which each form is put, constantly increase their possibilities in decorative value for both large and small gardens.

At "Thorn Hedge," near Newtown Square, Pennsylvania, there is one of the finest collections of ornamental espalier forms to be found in this country. There are curious wire frames of vase-like forms. There are quaint wire trellises outlining garden walks. There are numerous frame trellises both in upright and lattice form built to give privacy for service yards, and seclusion to cosy garden sitting rooms. The fact that all forms of espaliers bear model little specimens of dwarfed and quaintly trained trees and bushes appears of secondary consideration when one notes the extremely decorative features which 


\section{PRACTICAL BOOK OF GARDEN ARCHITECTURE}

espaliers may be made to attain. Another Pennsylvamia estate, famous for its espaliered form of fruit growing and the architectural beauty of garden walls and trellises, is the country seat of Mr. Henry A. Laughlin, at Chestnut Hill, where the noted English landscape engineer, Mr. Stephen Ager, has been given full charge of the work, and has accordingly introduced the most practical methods of English espalier work. In New Jersey one of the most successful espalier gardens is owned and conducted by $\mathrm{Mr}$. Otto Jaeger; and there are other gardens which are rapidly developing into models of espalier work.

The glass espalier wall is one of the newest features. American horticulturists and landscape artists travelling in Europe have of late years been greatly attracted by this novel form of espalier work, which has reached a high degree of perfection among French nurserymen. Probably the place most frequently visited for the study of glass espaliers is the nursery of MM. Croux and Sons, at Val d'Aulnay, in the Department of the Seine. On private estates, probably the most interesting experiments in glass espaliers are being conducted at the country seat of Count Horace de Choiseul, at Viry-Chatillon, in the Department of Seine-et-Oise. It is difficult to imagine a more fascinating type of garden decoration than that of a heavy glass wall, somewhat over 

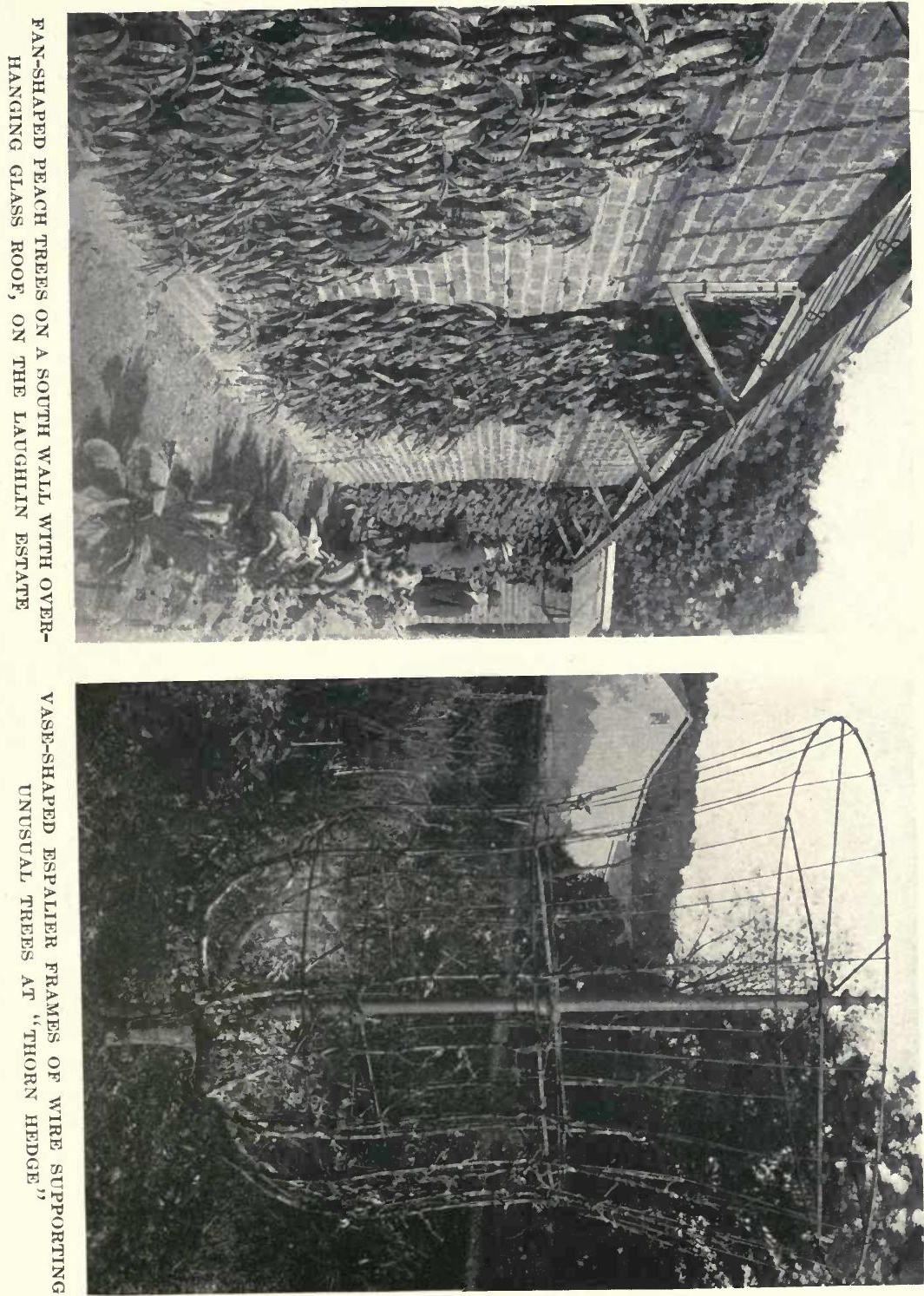

six feet high and about sixty feet long, covered on both sides with different varieties of apples, pears, cherries, peaches, apricots, and other dwarfed trees. The ornamental feature of this unusual form of espalier is increased by the fact that the utmost care has been given to the training of the severely pruned trees. The long glass walls which extend in an eastern and western direction, in order to give both northern and southern exposures for experimenting in fruit development, have trees of the same nature and variety planted opposite, on either side of the wall. Quaintly dwarfed apple or pear trees, with their numerous fruit spurs flourishing on opposite sides of the wall, each give the appearance of a single tree with a vivid reflection through the glass. The purpose of growing them opposite, and giving exactly the same training in root and branch pruning, is to discover by actual and accurate comparison whether northern or southern exposures are best for this form of espalier work. But this practical reason for the planting does not lessen the ornamental feature of the device.

Glass espalier walls have not attained any degree of success in this country either in ornamenta? or horticultural value, although it is claimed in France that they are superior to any other kind, as neither side of the wall is wasted and twice the quantity of 


\section{PRACTICAL BOOK OF GARDEN ARCHITECTURE}

fruit can be grown. Through the transparent wall, the light of the sun can penetrate to the north wall, making this of equal value to the south side, instead of being barren of results, as it necessarily is with other formations. These French gardeners will explain that there is little difference between the north and south faces of the glass espalier-that the north face is heated by the solar rays, which traverse the glass, and the south face is cooler than the south side of a masonry wall, "for the very reason that some of the incident solar radiation is transmitted through the glass, and consequently less is reflected and absorbed.' A glazed roof projecting a foot or more over each side of the glass wall, helps to reflect the sun's rays, and provides additional attraction as an ornamental garden feature. Only those who have travelled in France, and visited the gardens in which glass espaliers are given a prominent place, can appreciate their architectural attraction.

Masonry walls are the favorites in England. Accordingly the American country seats under the care of English gardeners show the best types of fanshaped trees. The brick and stone walls have an overhang of eighteen to twenty inches of glass roofing. This projects over the south side, against which the trees are trained to reach nearly to the roof. The usual argument in favor of the masonry wall, 


\section{ESPALIER WALLS AND TRELLISES}

in place of glass, lies in the fact that the difference in absorbing powers of the sun's rays has its advantages in the masonry wall, in the matter of protecting the plants from frosty nights, as well as in keeping them warmer through the day. It is known that a masonry wall absorbs a great deal of heat during the day, and gives it off at night; and this has its advantages in cool climates, although only one side of the wall can be used for the fruit growing. The south side of any high garden wall, whether in a modest suburban place or the extensive country seat, may be made of great ornamental value as well as of commercial profit. For further decoration, luxuriant growths of hardy ivies cover the north sides of the high wall.

Espalier trellises of wire and heavy metal frame work, extending entirely across the garden, frequently have the dwarf trees grown so close together that they form a continuous screen of great beauty. It has been stated by experts in this work that where only ten apple trees of ordinary kind and manner of growth can be accommodated in a small garden, about five hundred dwarf trees, properly selected and disposed, can be grown in espaliered form. It is needless to assert that the hundreds of quaintly dwarfed trees covered with fruit, and the forms on which they are supported and trained, will call forth 
greater admiration in regard to the decorative effect than the ten lusty apple trees that would occupy the same space under usual conditions.

Opinions differ as to the ornamental value and the profit yielding of the three distinct forms of dwarfing the trees-the closely pruned espaliers, trained on trellises, the cordons trained to a single stem, and the fan shapes trained against walls.

The true espalier - the dwarf tree trained on its trellis, and literally covered with luscious fruit, requires little in addition to make it extremely ornamental. From its very first start-its propagationthis feature is assured. As it is grafted on slowgrowing stock, and both root and branch pruning is given careful attention, it is certain to put forth its fruit-bearing surface in systematic order. For the prolific pear tree grafted on the slow-growing quince stock, and the apple-tree growing on Paradise stock, the correct start in life as an espalier has been effected. The Paradise being simply a very dwarf apple of sturdy type, that seldom grows to more than six or eight feet in height, and the quince tree being naturally of dwarf growth, the different varieties of apples and pears grafted on this stock will receive the correct early training that will be of benefit throughout their lives in ornamental and prolific bearing qualities. Intelligent ' root pruning-pre- 


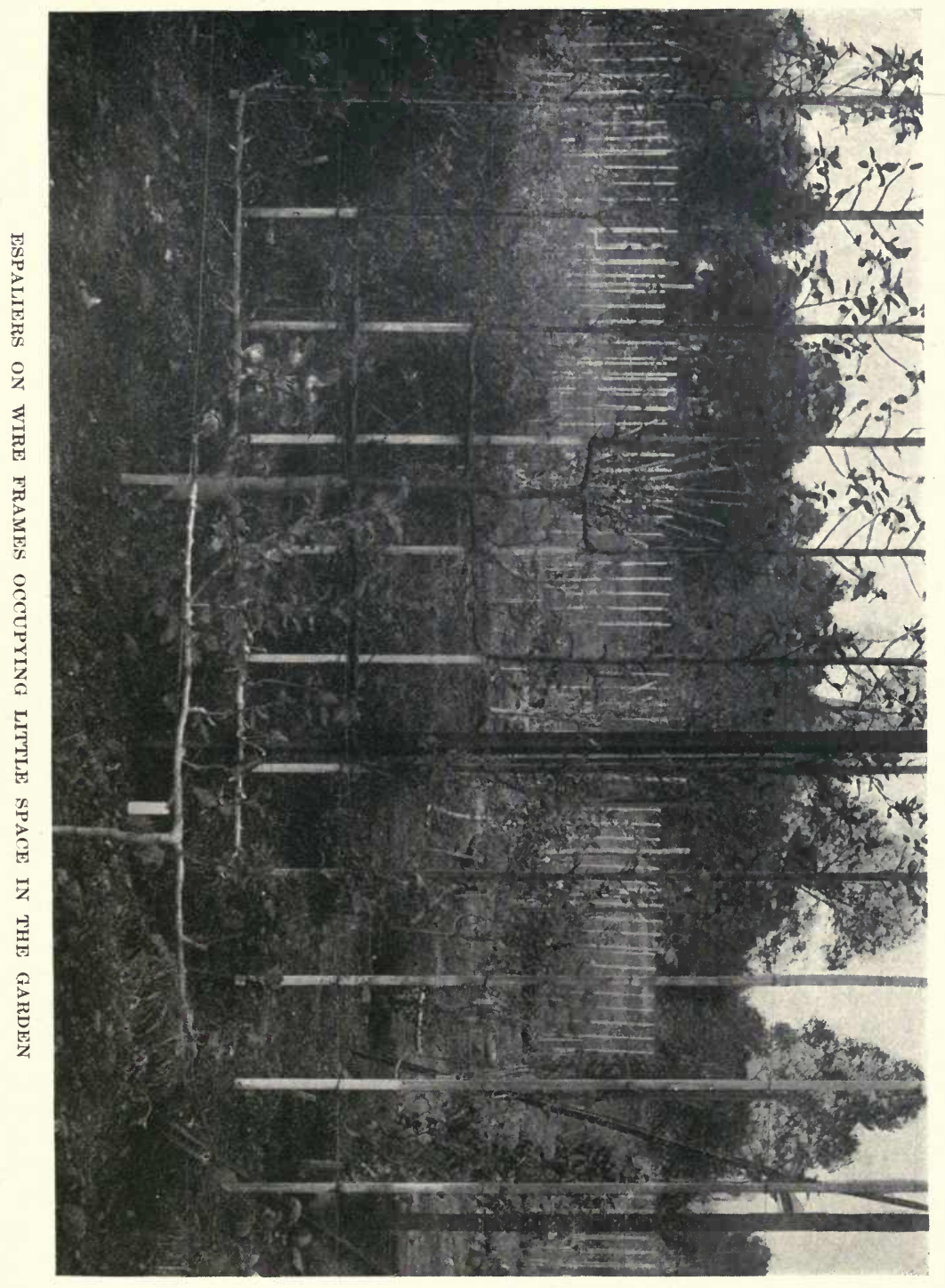





\section{ESPALIER WALLS AND TRELLISES}

venting the deep rooting of the long tap-root, and encouraging the formation of numerous clusters of short feeding roots-is of next importance. Then comes the later work of branch pruning-cutting back each branch to form about three fruit spurs, and the training against the supporting trellis. These trellises, which may be formed of decorative lattice, for screening the service yard, or of long stretches of metal frame work extending in rows across the garden, are about six feet high when built in the best form. The highest branch of the dwarf tree is never allowed to extend above the top of the trellis, but is pruned severely back to keep all the trees uniform along the trellis row. For the best shape of espalier apple trees, planted in long, parallel rows (and making the garden a veritable place of enchantment when grown in quantities), the little trees are planted twelve feet apart along the trellises. Then each tree spreads out six feet on each side of the main trunk, and six feet high, and with careful pruning this uniform spread with each compact tree reaching out to touch the trellis-tied branches of its neighbor, is formed of masses of fruit spurs.

In the blossoming season, when the numerous thrifty fruit spurs contain well-developed blossoms, and again in the time of fruiting, when the long 
trellis is literally hung full of luscious fruit, one cannot imagine a greater beauty in garden formation than that afforded by numerous espalier trellises.

The fan-shaped trees, trained against the boundary walls of the garden, are equally attractive, although they present an entirely different effect. The fan-shaped tree, instead of having side branches springing out from the trunk, up its entire length, and then pruned back to a uniform number of fruit spurs, has all its branches radiating from the stem. or trunk of the tree, near its base; and then spread out on all sides to form a perfect fan shape against the wall. It may seem difficult to furnish this form of espaliered tree with sufficient fruit spurs, while adhering to the training that is to form the ornamental fan. To encourage the growth of fruit spurs in this instance the leaders are all pinched back during the process of growth. This forms sufficient breaks on the sides of the fan-trained branches to develop into numerous fruit-buds. Whether peach, pear or apple trees are thus trained, a long garden wall, supporting numerous green fans, well covered with luscious fruit, of unusually large size, will be a sight worth travelling long distances to see.

Cordons have been developed into very ornamental features on American country seats. The cordon is considered the simplest form of training dwarf 


\section{ESPALIER WALLS AND TRELLISES}

trees, as it is primarily a single stem of leaves and fruit, proceeding from the root. As originally grown in French and English gardens, it was customary to train them only in vertical and horizontal positions against walls and trellises. In the vertical position the single stem is trained upright to a height of eight or ten feet, and is pruned back until furnished throughout its entire length with short fruit spurs. To form the horizontal cordon the upright trunk is bent over sharply a few inches above the ground and then trained in a horizontal position. The cordons can be planted much closer together than any other form of espaliered tree. From a foot to eighteen inches apart in the row will be sufficient for most trees grown in this form. The horizontal form is more ornamental than the vertical, and it is claimed that the fruit is even better when grown on the stems that have been sharply bent out of their upright position. For furnishing a long wall of horizontal cordons, the first tree has its stem bent over only a few inches from the ground. The second is bent over about six or eight inches higher up the stem, and follows the horizontal position along the wall, parallel with the one below it. The bends are thus continued higher up the stem, with each succeeding tree, until the entire wall is covered with the 


\section{PRACTICAL BOOK OF GARDEN ARCHITECTURE}

uniform growth, trained in parallel lines, producing a quaintly unique effect.

During recent experiments with cordons as an ornamental garden feature, many curious designs have been produced without in the least interfering with their fruit-producing qualities. Instead of merely the simple forms of vertical and horizontal cordons, we find the double cordon, in which two horizontal branches are trained from one stem, the two extending in opposite directions on either side of the little trunk or stem, only a few inches above the ground. The more elaborate ornamental effects are the oblique, spiral, vandyke, and diamond shapes. In these arrangements the single-stem trees, planted about eighteen inches apart along the trellis, are tied neatly in place as they develop, to reach the top of the trellis. The diamond shape is the favorite. Every other tree is bent in the opposite direction from its neighbor, to form neat diamond shapes where they overlap; and the closely pruned fruit spurs along the individual trees produce a wonderful charm set in diamond pattern, at the blossom and fruit-bearing seasons.

Espaliers trained in vase-like forms make a pleasing picture in the garden. The wire retains the vase shape, and the different branches radiating from the little trunk, about a foot from the ground, 


\section{ESPALIER WALLS AND TRELLISES}

are trained up on all sides of the vase form, and are pruned off evenly at the top.

Espaliers in various forms are frequently trained against the sunny side of the house or garden building. The effect is always more pleasing, from an ornamental stand-point, when the dwarfed trees are trained on garden walls and trellises. In the formation of the trellis, special care must be taken to have it set firmly in the ground, and held securely upright. The most unique and interesting espalier will be quickly spoiled, as a decorative feature, if the support has an uncertain and "wabbly" appearance. Firm iron supports, kept well painted to avoid rusting, are desirable where a thick growth is to be held in place. With the standards about six feet high, and the wires from nine to twelve inches apart, the best results are secured. With the end standards made of angle iron, with self-fixing bases, there will be little difficulty in keeping the row of espaliers shapely. Then, after firmly securing the end standards, there should be placed at intervals of about two feet, intermediate standards with pronged or anchor feet; and straightening posts may also be needed to keep the whole steady. The wooden trellises and lattice work, in square or diamond patterns, should have stout posts set firmly in the ground at intervals of eight or ten feet. 


\section{XXVII}

\section{PERGOLAS AND ARBORS}

\section{THE USE AND ABUSE OF ADAPTING THE ITALIAN}

PERGOLA TO AMERICAN IDEAS

LoNg double pergolas, extending parallel for a hundred feet or more, with a sunny open space between the broad shaded walks, form a distinguishing feature of "Lyndanwalt," the Hering estate at Abington, Pennsylvania. This is an unusual type, peculiar to Italian terraces, and seldom seen in this country; where the single shaded walk is usually followed in both pergola and arbor construction.

The best proportion for any form of well-built pergola, as followed by practical architects and garden craftsmen, is a slat or beam-roofed structure eight feet high, eight feet wide, and eight feet between the posts. This rule of proportion may be followed to good advantage whether the shady walk extends for a short distance from the house, to lead to a garden picture of special charm, or whether it extends far out into the garden to some secluded retreat or serves as a screen, with its vine draperies, dividing the service yard and kitchen garden from the lawn and garden living room. The same proportions will also hold good whether the pergola sup- 

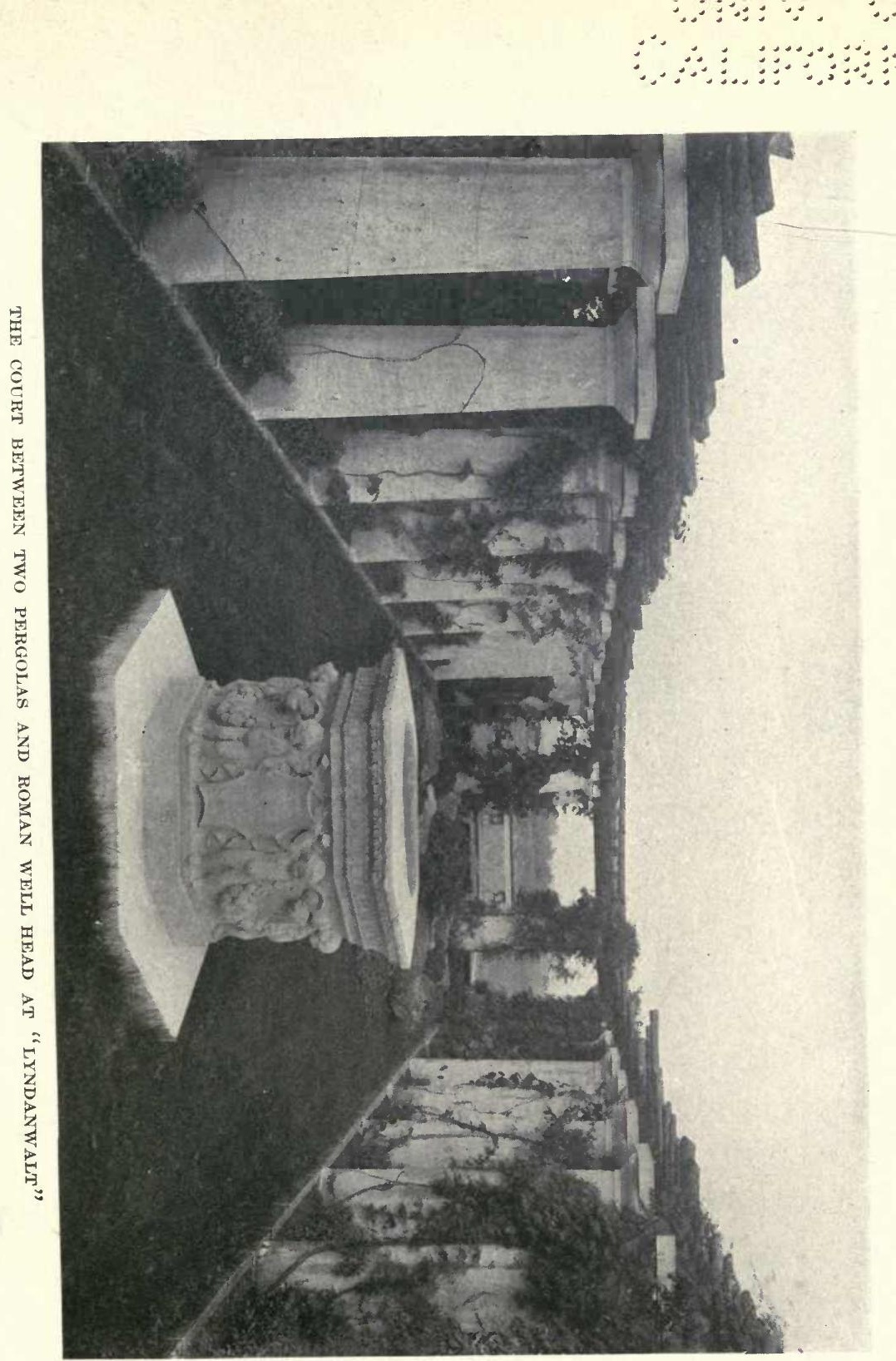



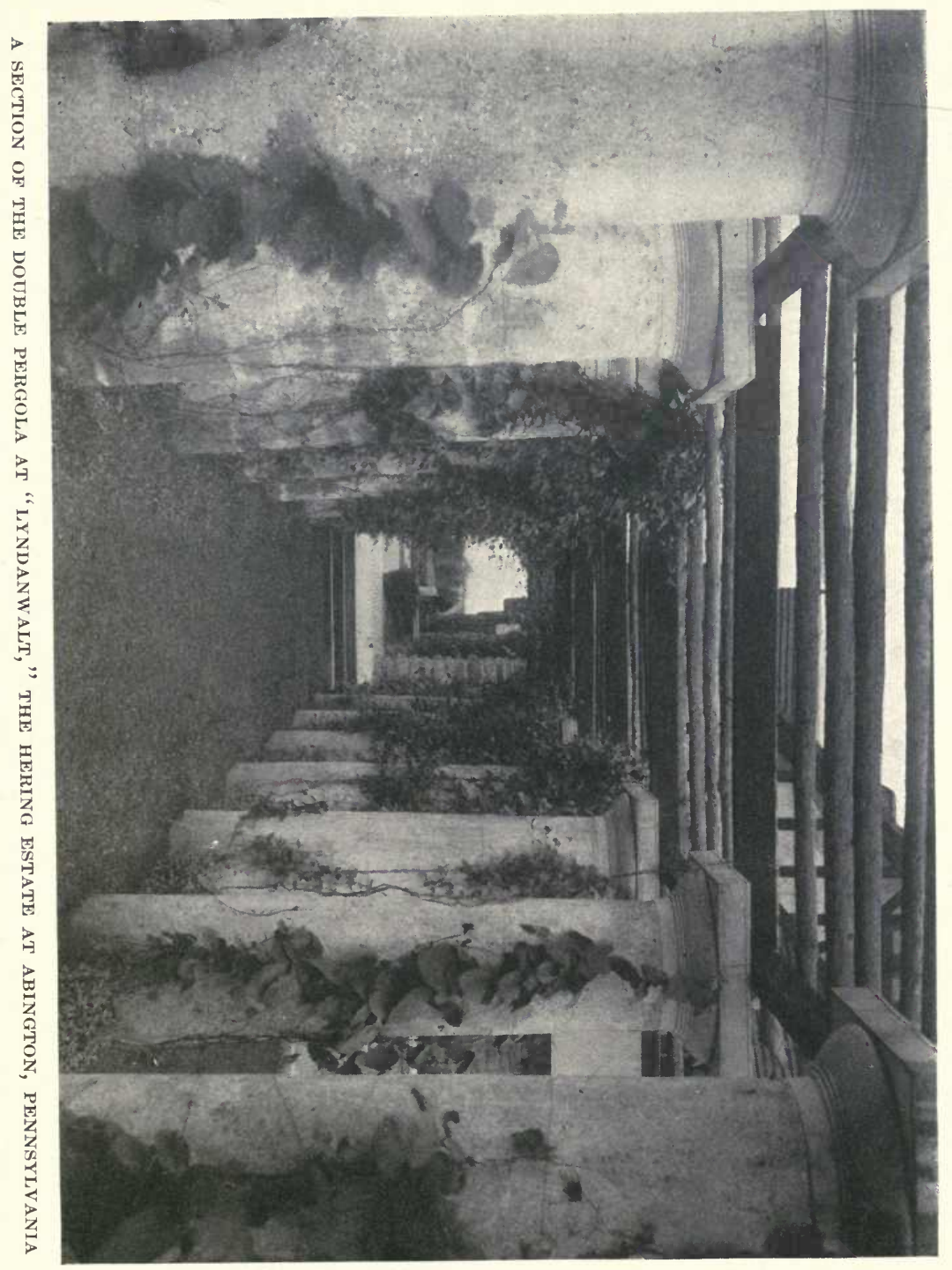




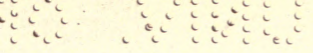

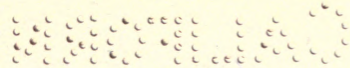




\section{PERGOLAS AND ARBORS}

ports are of rough stone, concrete, bark posts, or other rustic design; or whether it is built after a stately colonial plan; or with Doric or Tuscan columns, with the overhead beams of the same architectural type. It is lack of care in proportion and detail, more than anything else, that has brought disfavor for the average pergola that is carelessly constructed.

When ten or twelve of the big white columns, with the eight-foot distances between them, carry the shaded path out for nearly a hundred feet into the garden with the eight-foot width of pathway beneath the overhanging roof vines, there is ample space for seats and tables and charming nooks for resting along the walk beneath the vines. When two of these long pergolas are built side by side, to enclose a garden court, extending out from a sun parlor connecting the house with the garden-as they do at "Lyndanwalt" - a fascinating garden retreat is achieved that is unusual in its treatment. The court or open space between the two pergolas is left without any attempt at roofing with beams, or slats, or vine shelter. Following the type of the Roman villa (from which the inspiration for this double pergola and open court was secured), the central open space is carpeted with closely trimmed turf of velvety smoothness, instead of being paved like the pergola 


\section{PRACTICAL BOOK OF GARDEN ARCHITECTURE}

spaces. In the open court is a collection of wonderful Italian marbles, with long table and benches elaborately carved, while in the centre is the typical Italian well, surrounded with blooming plants and a rockery covered with bloom and bright-leaved trailers.

The broad pergolas that are well paved as well as quaintly roofed, that provide resting places as well as shady walks, are the structures that are coming into prominent use in this form of garden decoration; whether they are the elaborate double type, enclosing a picturesque court, or simply the usual form of paved walk and vine-covered roof.

The difference between a pergola and an arbor lies chiefly in the fact that the arbor invariably has horizontal slats, nailed at regular intervals along its sides, from post to post; while the pergola does not require slats to support vines but has the spaces left open between the posts. A single vine, climbing up each post, confines its shade to the roof of the structure. The handy man of the home need not fear to attempt the construction of an attractive pergola, even though his ambitions, heretofore, may not have soared higher than a simple form of arbor. There are no great structural difficulties to contend with when one is blessed with a good sense of proportion and a natural aptitude for keeping various details harmonious. 


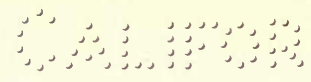

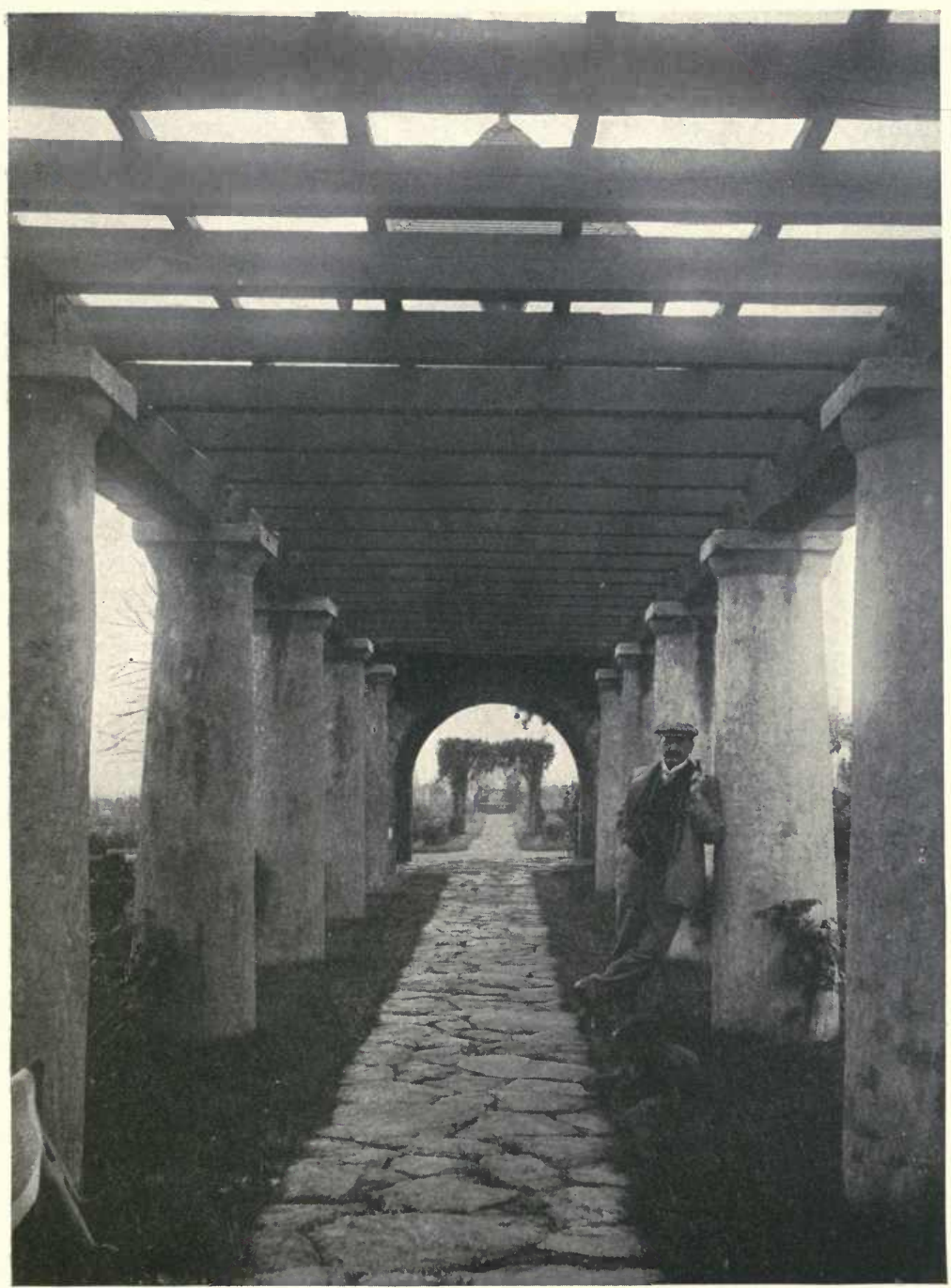

THE LONG PERGOLA AT "ROSE VALLEY FARM," MOYLAN, PENNSYLVANIA OF GOOD DESIGN WITH ATTRACTIVE PAVING 



\section{PERGOLAS AND ARBORS}

Naturally such a gardener, even though an amateur in handicraft, will remember that the garden structure must also be kept in harmony with its surroundings. It must be especially emphasized that though the stately columned pergola may be satisfactorily finished, with broad beamed roof, and square tile paving; and the concrete supports and bark-covered posts may be accompanied by a roof of rustic limbs, and a paving of concrete, or gravel or stepping stones set at intervals in the sod, the most charmingly finished structure, in itself, will not be pleasing unless it is in keeping with the home.

A rambling bungalow of rustic design, set in the midst of a wildwood garden, will appear crude, and will lose much of its picturesque charm, when a classic Italian pergola, of stately columned type, is set in the midst of the garden. In like manner the handsome Colonial house appears to lose its dignity when it joins hands with a rustic, bark-covered, coquettish pergola.

The structure that reaches from the house to a garden retreat, or from one garden building to another, is particularly pleasing, as it then serves an effective utilitarian purpose, instead of being merely set down in the midst of a garden for decorative purpose only. On the Schoen estate, "Rose Valley Farm," at Moylan, Pennsylvania, the handsome per- 


\section{PRACTICAL BOOK OF GARDEN ARCHITECTURE}

gola of almost classic severity of design is in perfect harmony with the remodelled mansion from which it leads to the equally stately water tower and garden workshop. Among the camping colonies of the Maine woods there are harmonious designs serving equally useful purposes. Accompanying a log bungalow is a pergola with posts of the same rough $\operatorname{logs}$ that form the walls of the little house, and with overhead beams of the same rustic formation. The garden structure leads from the kitchen door of the house, through a tangle of wild roses and honeysuckle, to a rustic covered spring which supplies the water for the camp. On the rocky Maine coast, where another camp reaches down to the water's edge, for the pergolas and combination summer-houses and arbors the supporting posts are massive square columns of small rough field stones, picturesquely constructed in the same order as the massive outside chimneys of the low, rambling houses.

For the decorative features of the structure, no matter what the form of its design, it must be remembered that the pergolas should have very little vine drapery at the sides, and a good heavy shelter of foliage over the top. An arbor, on the other hand, should have the thick screen of foliage on both sides; with the vines fastened securely to the horizontal slats extending from post to post, from eighteen 


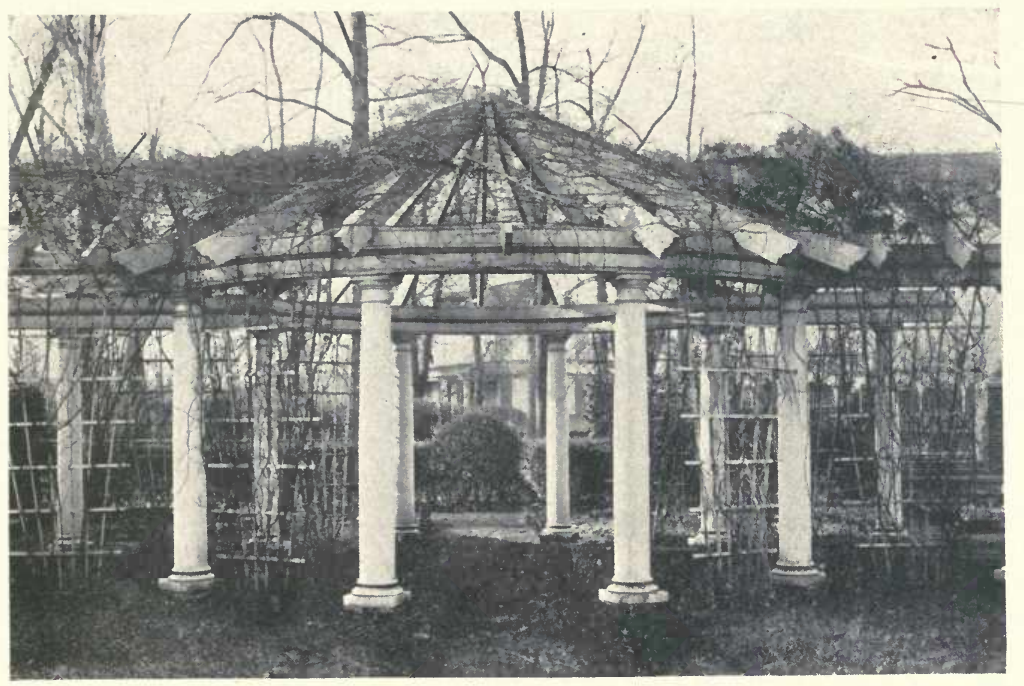

A PERgola WITH CIRCULAR CENTRE AND ROSE TRELLISES

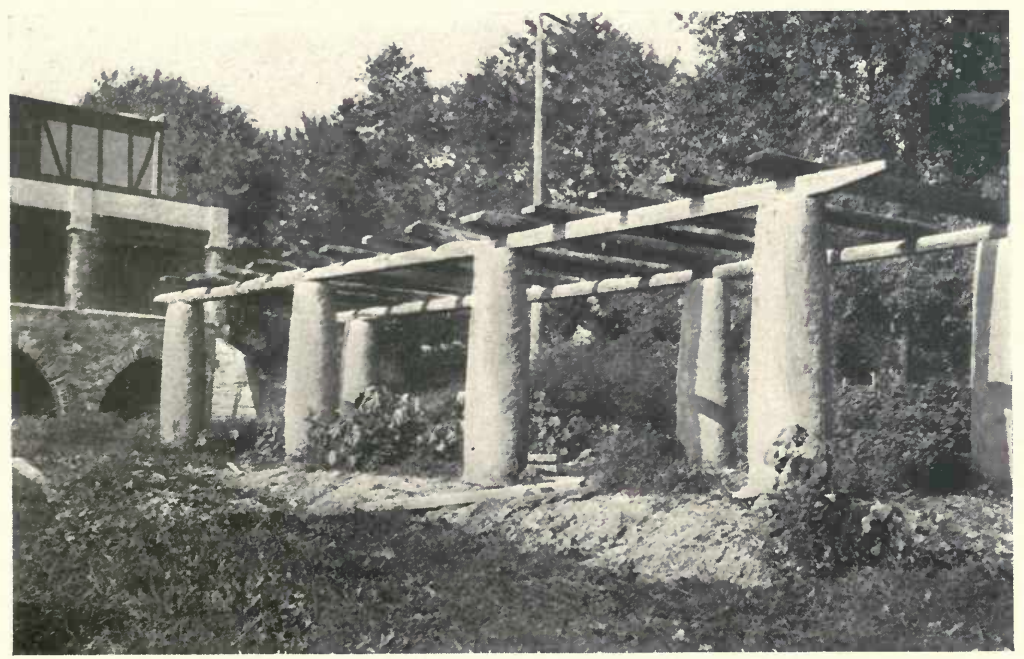

A RUGGED PERGOLA OF HOME-MADE CONCRETE CONSTRUCTION 



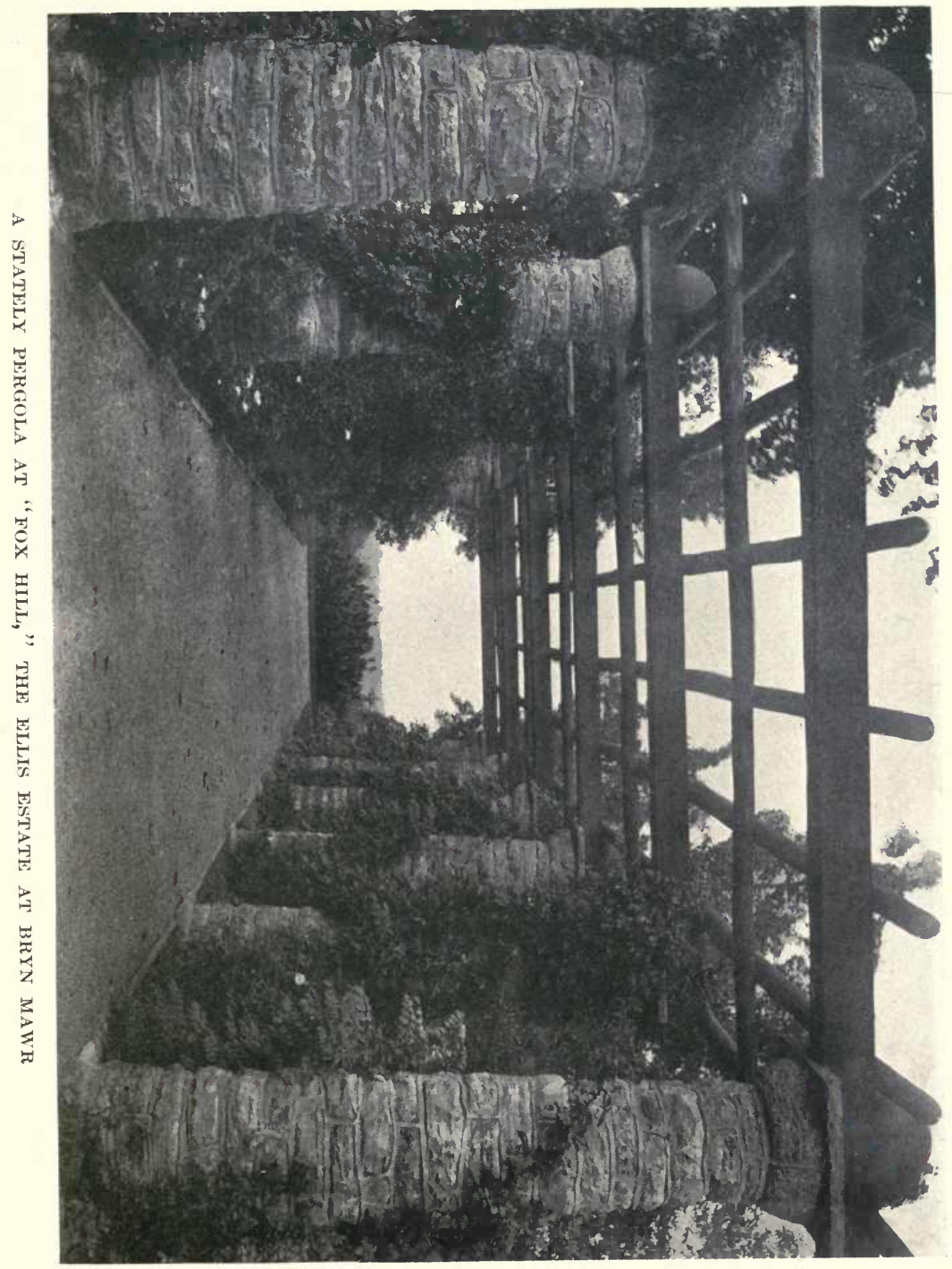





\section{PERGOLAS AND ARBORS}

inches to two feet apart. The arbor can be left without a top if desired, when the posts are high and imposing, or it may have an arched roof, or a plain slat roof; but overhead vines will not be necessary. The glint of sunshine from above will make the seclusion of the side draperies more effective. Neither an arbor nor a pergola should be left without its vines, no matter how ornamental the structure may be in design ; for it will lose half its charm when it is robbed of its usefulness.

Massive concrete columns of home-made construction are effective in design and are always good because of their durability. By following practical details they may be constructed with little difficulty by anyone who has a liking for architectural experiments. The molds should be sunk at frost-proof distance below the ground and the columns cast in the place where they are to remain. It is important that they should be reinforced with iron or expanded metal to give them durability. A double wrapping of rather close-mesh chicken-wire within the molds, to outline the columns, will also strengthen the big posts. After the concrete has set, and the molds have been removed, an outer coating of cement should be used to smooth off the natural roughness and entirely cover the wire coating.

After the concrete columns are set in place-be- 


\section{PRACTICAL BOOK OF GARDEN ARCHITECTURE}

ing built about eight feet apart and eight feet highthe finish of the roof will determine whether the structure is to be of rustic design, or expressive of simplicity and dignity. When built amid rustic surroundings, the surface of the posts may be left in the rough, and bark-covered beams and rustic saplings may form the roof. For the home and garden of stately type, the posts should be smooth-finished, the overhead cross pieces being planed lumber and the heavy rafters overhanging each side of the pergola from one to two feet, with their ends carved in true pergola fashion.

There is no regular rule for cutting the rafter and girder ends. Neither do the pergolas of classic design, built in harmony with a country seat mansion, adhere to any set rule of classic construction. It is true that experienced architects will talk learnedly of Greek Doric columns, that should be built to a height of seven times the bottom diameter of the shaft; and be equally precise in regard to the Tuscan and the Roman Doric as regards their height and their capitals. But hard and fast rules of classic porticoes and loggias need not be applied to pergolas and arbors. Good taste and good sense should be exercised to keep the structure in harmony with the house and its surroundings and the result will be pleasing. 


\section{XXVIII}

\section{THE POPULAR PORCH PERGOLA}

COMBINED WITH THE TILED TERRACE IT FORMS AN IDEAL OPEN-AIR LIVING ROOM

" OAK Knoll," near Los Angeles, California, the picturesque home of Dr. F. K. Ledyard, presents an interesting type of porch pergola which is characteristic of California bungalows. It is of rustic design, long, rambling, vine-draped, and built in harmony with the Swiss chalet type of architecture which distinguishes this charming home.

At the residence of Mr. Louis J. Kolb, at Germantown, and at "Kathaleen Farm" on Bethlehem Pike, Pennsylvania, there are handsome designs of porch pergolas of stately Italian type. Between these two extremes, quaint, practical, elaborate, and fantastical coverings of house and garden terraces are being constructed in the form of porch pergolas.

This is supposed to be a comparatively new form of pergola arrangement. In reality, according to the old dictionary definitions, one of the early uses of the pergola was in connection with the house. The early Italian form, spelled pergola, and the Latin form, spelled pergula (both with the accent on the first syllable), applied to a sort of gallery or balcony 


\section{PRACTICAL BOOK OF GARDEN ARCHITECTURE}

connected with the house, as well as to the structure of greater extension.

On the sunny garden terraces of old Roman villas, the necessity for shaded walks made the pergola of special prominence; and on its introduction into other countries it has been confined largely to such uses. Of late architects have come to realize that it lends itself to the artistic decoration of porch and veranda terraces and serves a double purpose in admitting light and air to outdoor sitting rooms that the old type of porch cannot supply.

The evolution of the porch pergola as a now recognized and important architectural device is worthy of study. Until very recent years the covered porch, with dark overhanging roof shutting the light and air from the most.important rooms in the house, was the rule. The open terrace, with its paved floor and its unobstructed view from the living rooms, was the exception.

As originally used, the high terrace embankment thrown up about the foundation of the house, with its broad paved floor of tile or brick, was left without any form of roof or vine screen. Decorative plants and evergreen shrubbery along the boundary wall of the high embankment and along the floor of the terrace against the house foundations were the only ornamental features. The broad floor of this out- 

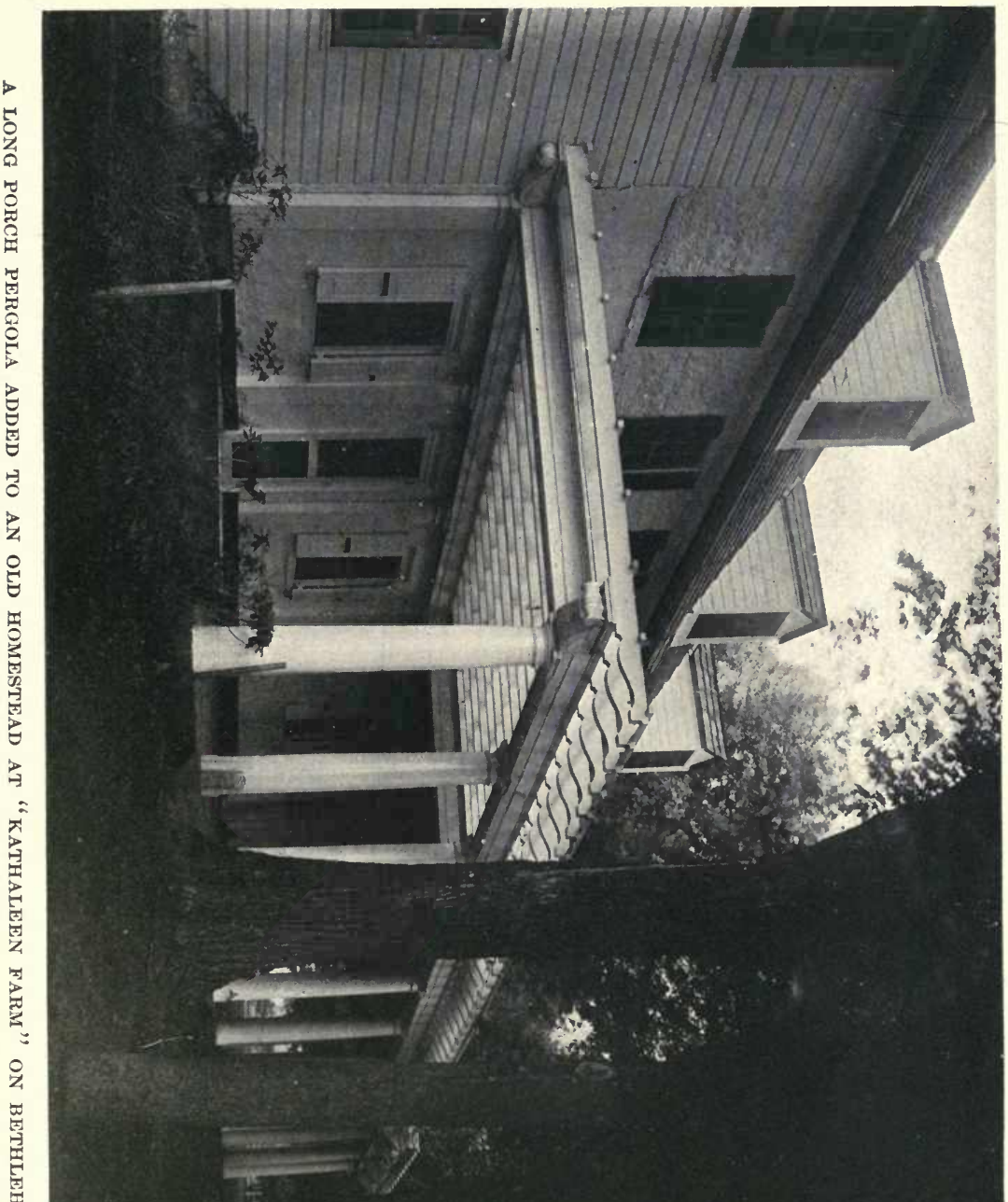


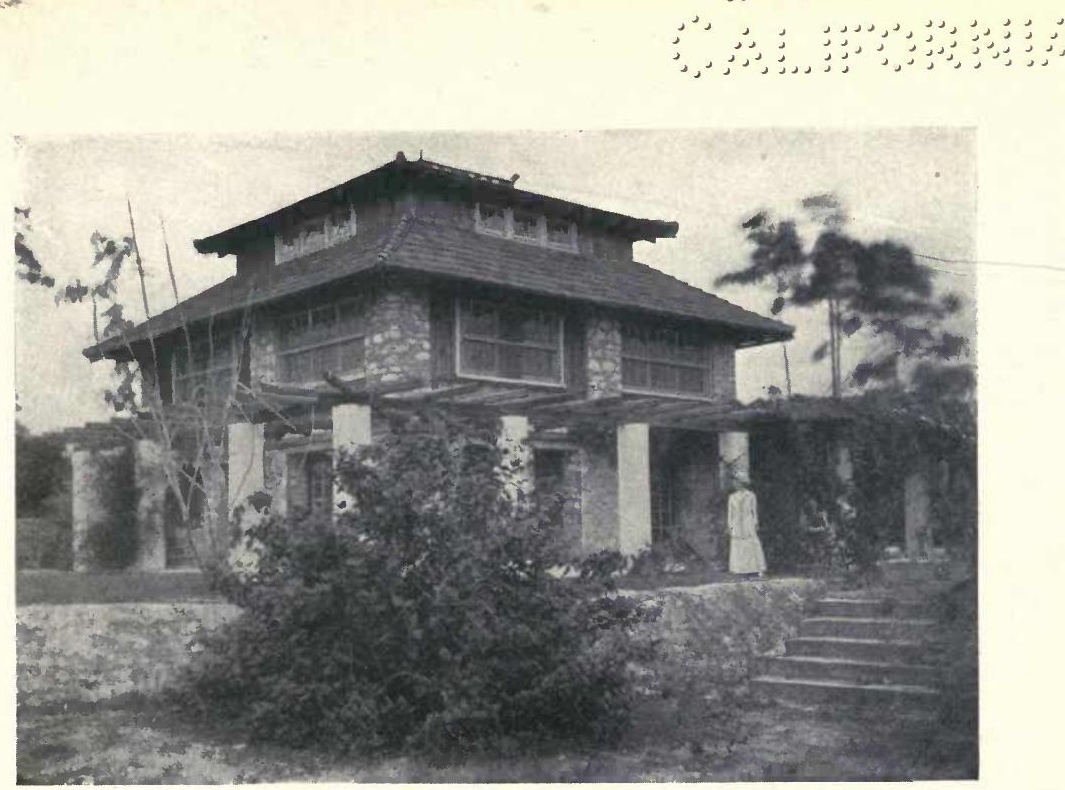

A PORCH PERgola sURROUNDING THE HOUSE OF DR. JOHN GRIFFith, NEAR MIAMI, FLORIDA

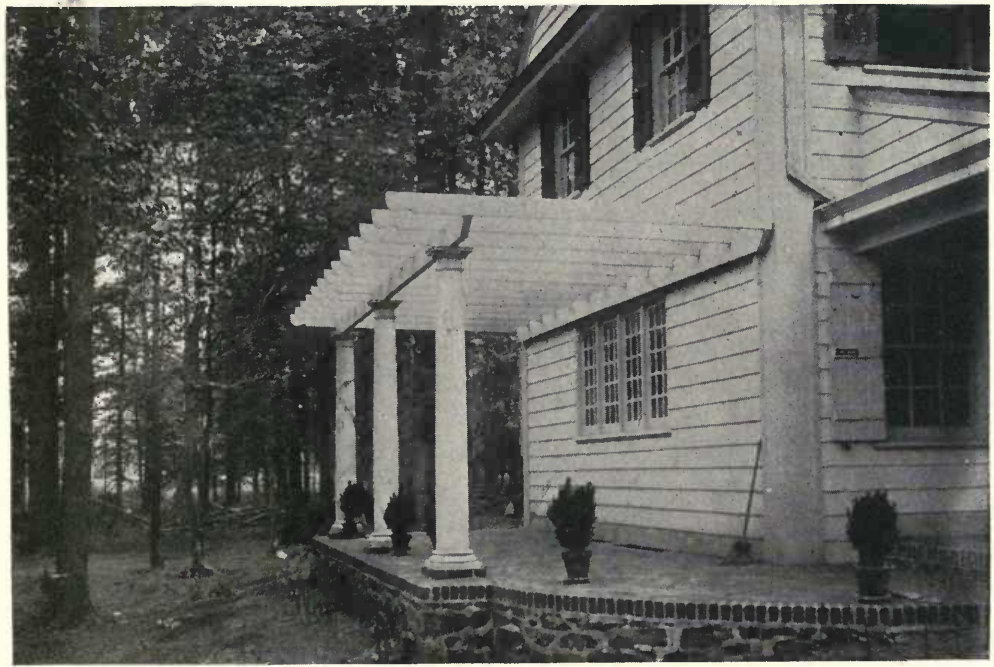

A SIDE PORCH PERgola, WITH CONCRETE FLOOR CONNECTING WITH THE FRONT PORCH 


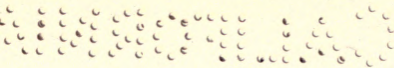




\section{THE POPULAR PORCH PERGOLA}

door sitting room, when covered with grass rugs, and fitted with porch furnishings, was entirely satisfactory except when the sun shone upon it. Then came the desire for vine shelter at the sides and overhead. Instead of a heavy porch roof to make the adjoining rooms dark and gloomy, and thick porch screens to shut out the air as well as the sunlight, the terrace which had replaced the old porch was fitted out with stately pillars or rustic posts (as the case demanded) and an open pergola roof of beams and slats. The porch terrace then became the porch pergola. Instead of an outdoor room completely open to the sky and to the view of passers-by the vine-sheltered sitting room was provided with overhead shade and vine-screened seclusion.

So rapidly has the porch pergola grown in favor during recent years that it is not unusual to find it enclosing all sides of the house, to the complete exclusion of the porch. This is a favorite method of finishing the houses in the tropical sections of Florida, where it is desirable to give free access to every passing breeze, and to shut out the glare of the sun. Many of the beautiful homes of Palm Beach, Miami, and Cocoanut Grove have broad, tile-floored pergolas extending around the four sides of the house; with stately columns supporting an open pergola roof lightly covered with vines. The charming home 
of Dr. John Gifford, in the suburbs of Miami, has one of the most pleasing types of this form of pergola. There are no lattice panels or wire trellises to support vines and shut out the air at the sides, simply one climbing rose, or rapid growing vine, trained about each pillar, and allowed to spread only on the roof of the pergola to provide the desired shade.

When a porch and a pergola are both desirable (the porch being especially appreciated for rainy days), the terrace is sometimes omitted. The lattice panels and stone foundations of the porch are extended out to provide the flooring for the pergola. Columns, flooring and railing follow the plan of the porch fittings, the only difference appearing in the roof of the pergola extension.

For the terraced pergola which does not connect with a porch, there are various methods of building up the embankment to the height of the average porch floor. When the house stands on an elevation, and there is a broad terrace formed by the natural grade of the surrounding ground, the only requirement is levelling off and packing down the broad space to receive the brick or tile paving. When it is necessary to build up the terrace from a lower grade it is important first to build a firm retaining wall. The sloping earth and sodded terrace will be difficult to 


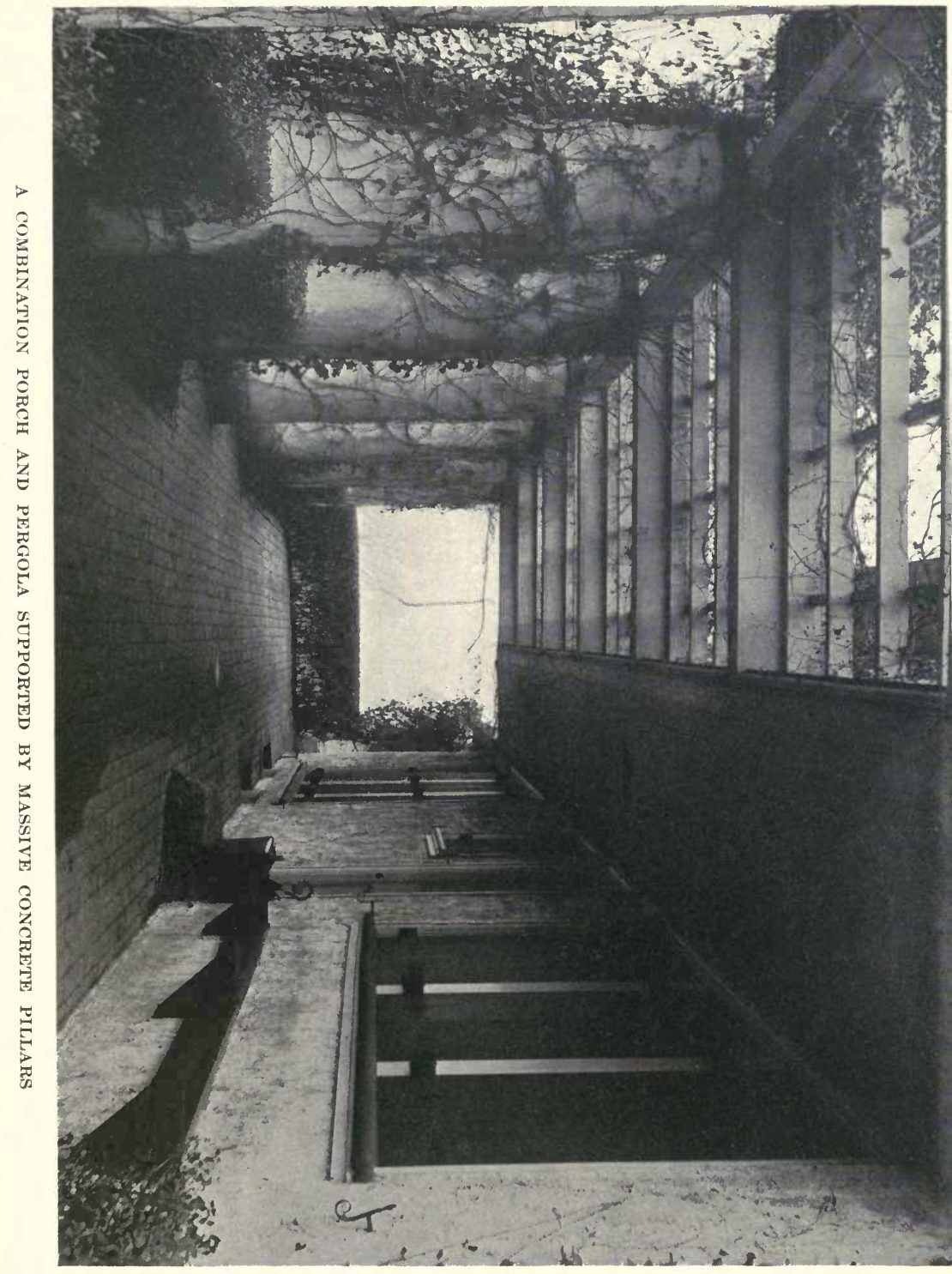





\section{THE POPULAR PORCH PERGOLA}

keep in order. There is also danger of washouts in times of severe storms tearing away the terrace boundaries and causing the paving to sink.

With a brick, concrete or stone retaining wall, the terraced floor of the pergola will stand indefinitely. After filling in with earth, there should be several inches of well-rolled cinders on the top to give a good foundation for the paving. When the retaining wall is of stone, earth-pockets in the stone-work will give sustenance to many creeping plants and gay blooms. The brick or concrete wall, with trailing plants and vines trained over the surface, will produce a cool, restful green effect as well as a sodded terrace without any of its inconveniences.

Stationary tables of rustic design, with seats of the same character, are the best furnishings for the airy rustic porch pergola. Accompanying the stately columns and tile flooring, the fine old highback Colonial seats, with quaint arm "wings" or "pew ends," will be desirable. Concrete tables and seats may furnish the rugged pergola, with concrete pillars and flooring. For the stately old-world types, furnished after the plan of Roman villas, importations of tables and benches in Italian marbles are admired on many American estates, for the porch pergolas of the home and various garden retreats. Decorative urns and flower vases of Florentine pottery outline the floor terraces. 


\section{XXIX}

\section{THE QUAINT AND DURABLE THATCHED ROOF}

\section{AN INEXPENSIVE FORM OF GARDEN HANDI- CRAFT THAT IS EASILY EXECUTED}

THERE is a growing appreciation of the softness and picturesqueness of the thatched roofs of English country houses and their garden buildings. Quaint thatching with cedar shingles forms a favorite method of covering the roofs of long, rambling buildings. These pliable shingles, laid with varying exposures to the weather, are particularly well adapted to picturesque spring houses, garages, tea rooms, and summer-houses, with broken eave-lines and decorative gables. For the smaller garden houses, the crow's-nest rest rooms built among the trees, the circular and octagonal summer-houses and shelters, thatching with straw or reeds will be more appropriate, or with palmetto as used in Florida. Japanese types are especially desirable in finishing a quaint and picturesque roof of the latter form. The thatching of Holland offers many striking examples of novel roofs. Where the ridge poles are of split rods or bamboo, or curious tiling, and fertile soil-pockets, in the thick straw, support low growths of blooming 


\section{THE QUAINT AND DURABLE THATCHED ROOF}

plants, the charm of the heather-covered roofs of rural Holland is readily achieved. The practical points concerning durable thatching are of most importance, however ; the decorative touches are merely a pleasing afterthought.

We are inclined to look upon a thatched roof as a temporary affair in this country. But with the wider experimenting during recent years, it has been found that even with our unskilled thatching, intended merely for garden decoration, a well-laid roof of straw or reed can be depended upon to last from fifteen to twenty years with very little repair. Many of the thatched roofs of England and Holland last for thirty or forty years with care in renewing the weak spots; while in Japan, where bamboo strips and tile ridges are used in connection with thatching of tough reeds, the roofs frequently outlast the structures which they cover.

The usual grades of soft meadow hay should not be used for thatching. Many dilapidated specimens of unsatisfactory roofs are failures merely because the thatching material was unwisely chosen. Good, firm straw is dependable, especially rye, wheat, and oat straw. There are various tough reeds and rushes that may be plentifully gathered in our marshes, that will provide a roof practically indestructible when carefully laid. 


\section{PRACTICAL BOOK OF GARDEN ARCHITECTURE}

For a summer-house, a tea room, or a crow'snest, a thatched roof laid directly on the rafters without a solid board foundation will be most pleasing, as the effect of the thatch will be seen from beneath the roof, forming the ceiling of the room. For the quaint carriage house, garage or chicken house, with low-drooping eaves and gables, a board foundation will carry a more durable roof. For covering any sort of roof that requires repairing, whether of old shingles, the rubberoids or other patent roof coverings, a heavy thatching of straw will quickly put it in rainproof condition, and serve the double purpose of making the garden building extremely decorative as well as durable. It is important, however, to apply the thatch to the old roof only when it has a sufficient pitch. It will not do for a very flat roof. Any sort of thatched roof should have a pitch of at least four or five inches to the foot.

A practical knowledge of this old-world handicraft is desirable for the best results in thatching. The main points in preparation and the laying of the straw are easily understood. Then practice will soon give a very satisfactory degree of perfection.

A home-made mallet, with a broad, firm pounding surface should have its handle so adjusted that it can be used to best advantage when crouching or kneeling over the roof. A good grade of marlin or 


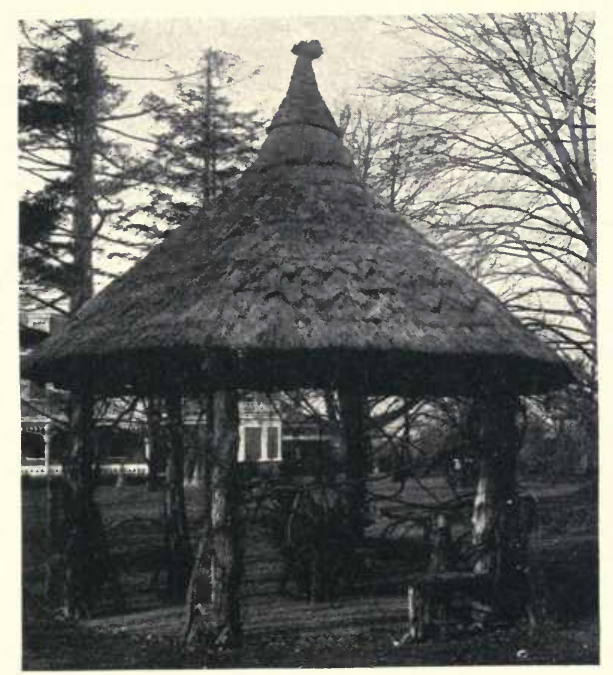

A TIGHTLY BOUND ROPE-FINISHED APEX TO A THATCHED ROOF

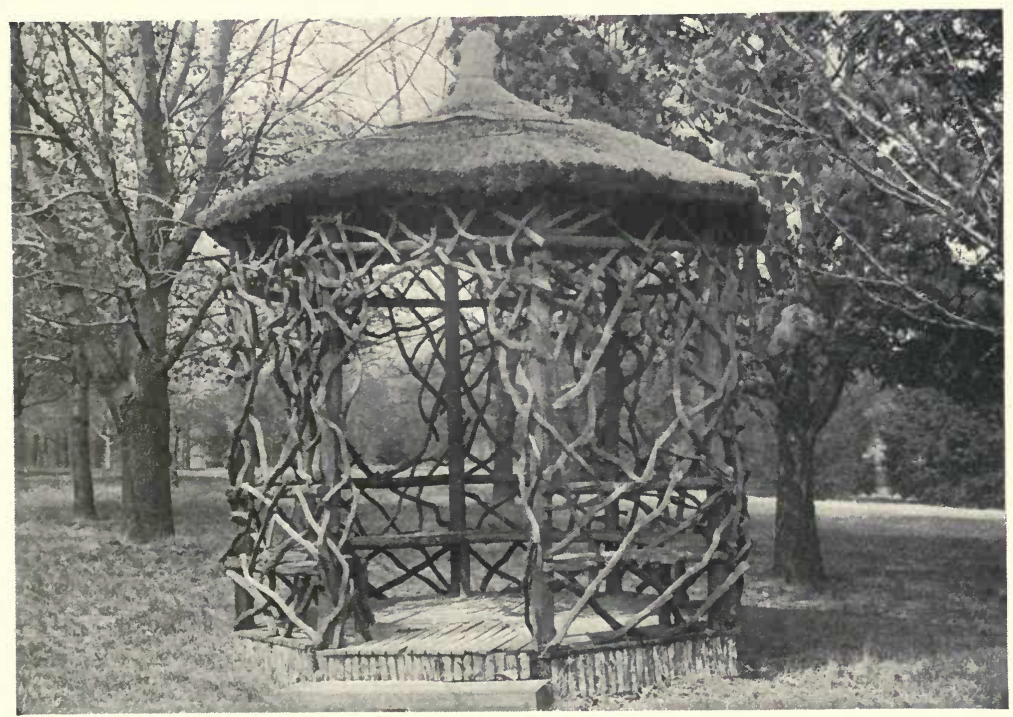

A GOOD APEX, BUT POOR THATCHING, THE ROOF BEING TOO FLAT 



\section{THE QUAIN'T AND DURABLE THATCHED ROOF}

tarred twine should be provided for the thatch to be applied directly to the rafters. A needle required for the rafter thatching-or what is known as the "needle method of thatching" -may also be home-made if one has the facilities for sharpening an iron fencing rod at one end and drilling a smooth eye in the other end, large enough to thread the tarred twine. An iron worker can prepare the needle at small expense, if there are no facilities for its home manufacture. The half-inch iron rod should be about two feet or thirty inches long, for easy handling through a thick thatch; and it will be well to have two or three of these needles prepared, as the cost for the extra ones will be very slight, and they will be ready for an emergency should one become misplaced, or when two sets of workmen are engaged in the thatching on opposite sides of the roof.

Two workmen will be required for operating each needle; one above the roof to lay the straw and push the needle through at proper intervals to hold it in place, and one below to receive the twine-threaded needle, form the tie stitch or slip knot that is to hold it firmly to the wooden support of the roof frame, and pass it up to the worker above.

The best roof frame for thatching consists of narrow strips, or lathing battens, fastened to the rafters, from eight to ten inches apart. The straw 


\section{PRACTICAL BOOK OF GARDEN ARCHITECTURE}

should be used of sufficient length to be tied to at least two of the battens, three ties will be still better, for a heavy roof; and in nailing the battens to the roof, the distance between them should be regulated according to the length of the straw used.

Beginning at the eaves, a heavy over-hang of double thickness of straw should be allowed to give a firm eave-line, extending out about three or four inches' beyond the lowest batten after the straw has been trimmed. This first thick layer is securely fastened to the lowest batten by tying at intervals of four or five inches. The progress may seem discouraging at first, as the thick roll of straw when tied at the bottom will spring into an upright position. But when the next course of straw is put on, shingle-fashion, above the first the springing tops of the under layer will be caught and held firmly in position by being tied to the second row of battens. When tied a third time, in connection with the continued upper courses, the finish from beneath the roof will be more pleasing. For the exposed rooflines of a decorative summer-house rather long straw will accordingly be most desirable.

The straw will prove more pliable for handling, and the thatch will be tougher when finished, if the bundles are spread out in uniform layers, and thoroughly sprinkled with water a day or two before 


\section{THE QUAINT AND DURABLE THATCHED ROOF}

using. It may be laid while still slightly damp, and the straw in laying should be drawn into uniformity by being combed with the fingers, to remove all broken and tangled particles, and make the thatch straight and firm throughout.

For laying the thatch over boards, or over an old roof that is to be repaired in this picturesque manner, the needle method will be useless; but various other means are used to keep the layers of straw firmly in place. In following the Japanese method, layers of split bamboo are laid along each course of the thick bundles of straw. Saplings, or narrow strips of wood, are used in the same way in thatching our garden buildings. After nailing the wooden strips firmly through the straw into the board or rafter supports beneath, the next course of thatch overlaps sufficiently to entirely hide the strips and present a uniform appearance of smooth thatch, without showing how it is kept in place. Whether the straw is nailed or stitched to the roof supports, it is important to have a smooth, even appearance when finished. In order to accomplish this, the separate bundles are flattened out and pulled into smooth layers, so as not to show where they join. When the entire roof is laid, the thatch receives a final combing, by carefully smoothing it down from ridge pole to eaves with a long wooden rake. 


\section{PRACTICAL BOOK OF GARDEN ARCHITECTURE}

For some of the flat, evenly covered surfaces, it is a good plan to lay the first course of straw with the butt ends down, to form the eaves, and the other courses are laid with head ends down. For the roofs trimmed in fancy shapes to give the appearance of heavy layers of shingles, etc., each course of straw is laid with heads upward, with the lower ends trimmed evenly. The thick, shingle-like projections extend entirely around the circular roofs, in uniform layers, ending in a tight knob of straw or rope at the peak of the roof.

For building houses for fancy poultry and decorative home aviaries, many country seats show charming little houses roofed with thatch. In pheasant yards, for instance, the favorite method of providing shelter for the gay-plumed fowls is an arrangement of long, low buildings extending across the end of the pheasant yard, with the thick, warm thatch not only covering the roof, but also reaching to the ground on the northern exposure, with the sunny southern exposure left open. The larger houses, standing high above the ground, are frequently built with bark-covered walls and thatched roofs.

Finishing the peak of a circular roof, or the ridge of a long building, will call for considerable skill and ingenuity if it is to be strictly water-tight as well 


\section{THE QUAINT AND DURABLE THATCHED ROOF}

as decorative. On the small square buildings, and those which are slightly oblong in form, as well as those that are circular or octagon-shaped, the thatch is most securely finished when brought to a peak in the centre. The upper courses of straw are gradually made shorter and all brought toward the central point, where they finally meet and are tied about a stake that is fastened firmly to the centre of the roof. The straw is made especially thick, close and rain-shedding at the stake; then bands of straw are twisted horizontally round and round the vertical layers. Rope is frequently used in place of straw, to give the final tight finish at the apex. Another novel method of completing the roof of the decorative tea room is to have the central stake extend for some distance above the roof, and after the thatch is made waterproof about the stake, other wooden supports are fastened to it, holding aloft a bird box, that provides a charmingly decorative ridge or peak, while attracting the birds to a spot rich in nestbuilding material.

For the ridge extending the entire length of a long building, lengthwise rolls of straw are pressed compactly down, and roped into place, forming a rounded ridge. Another plan is easily carried out by using plain boards, eight or ten inches wide, on each side of the roof peak, the entire length of the 
building, with a caat of paint and careful joining to make them weather-proof. An English method, of ridge finish, may easily be followed by thatching with very short straw on approaching the ridge, and then using long bundles of carefully selected straw for laying first lengthwise, and then crosswise, over the roof angle, from one side to the other. These rainproof layers are then secured by narrow strips of wood, extending all along the ridge. In England, these strips are split hazel rods and are known as sways. Smaller split rods, bent hairpin shape, are used to keep the lengthwise rods in place.

For the summer-houses, tea rooms and well houses that are to be finished in fanciful Japanese effects, various forms of tiles are used. These are closely joined along the ridge pole, with a layer of mortar and chopped straw beneath.

To form a still more strictly Japanesque effect, a long ridge pole may extend the entire length of the building, with its edge projecting beyond the end gables, and then wrought in a quaint upward curve, with one of the many ornamental attachments common to Japanese architecture. The curved adornments readily may be patterned after types studied in pictures of Japanese buildings, and they will give a light, buoyant, oriental appearance to the roof, that might otherwise seem clumsy and top-heavy. 


\section{THE QUAINT AND DURABLE THATCHED ROOF}

With an arrangement of stakes projecting from the peak of the roof, and sustaining an over-hang of slender rafters and battens, about a foot above the roof, an ornamental ridge may be formed that will serve as a sort of supplementary roof. This form of roofing the ridge is frequently seen among the best houses in Japan, and the decorative value is considered well worth the extra work required to complete it. The thatch of the ridge-roof is left very thick at the edges, and trimmed squarely off. Strips of bamboo are laid in various fancy forms to confine the close-laid thatch at the peaks and ridges of these oriental roofs. And now that bamboo is so commonly grown among the ornamental shrubbery of our lawns, it readily may be secured in sufficient quantity to be used extensively in various forms of thatching.

What is known as "pine-thatching" is becoming popular in the mountain regions, where quantities of pine needles may be gathered for use in garden architecture. The favorite method of preparing a quaint roof of the pine needles is, first, to roof the building with boards covered with water-proof roofing paper. Then with broad, flat brushes, the paper is given a heavy coating of tar or pitch paint and the pine needles are generously sprinkled on, while the tar or pitch is still fresh, and evenly distributed as thick as the tar can be made to hold them. This 


\section{PRACTICAL BOOK OF GARDEN ARCHITECTURE}

gives a curious appearance of thatching, and proves quite durable if the needles are well coated with the tar or paint when applied.

The heather-covered roofs of Holland and England, and the floral roofs of Japan, with red lilies and blue and white irises blooming along the ridges of the sombre-colored thatch, may also be imitated in our garden buildings. The objection may be raised that the flower-decorated roof is apt to give the appearance of age and decay, and is therefore undesirable. On the other hand, the appearance of age may be considered a commendable quality. Many of the ancient thatched roofs of Japan, and those found in old village gardens of England, have become so filled with dust that they are well matted down, have assumed a dark color, and show extensive patches of mossy growth. Birds carry seeds that fall into the soil crevices of the thatch, until blooming plants and luxuriant mosses flourish over the entire roof surface. Like many other spurious imitations of antiquity, this effect readily may be imitated in completing the decorative thatch-covered garden buildings.

An argument in favor of the flower and mosscovered thatch is that roofs so decorated are less liable to be subject to danger of fire from flying sparks. The close-matted straw, with its layer of green, low growths, will not so readily fall a prey to 


\section{THE QUAINT AND DURABLE THATCHED ROOF}

conflagration as a thatch of loose, light straw. When thatch-roofed buildings are situated near the house they may be considered objectionable as firebreeders. It is very seldom, however, that they prove dangerous. The straw soon becomes closely matted, and does not attract sparks more readily than the usual forms of roofing. But in order to take extra precautions, and give a feeling of perfect safety, many expert thatchers sprinkle the damp straw with cobalt water the day before using it. This is prepared by making a strong solution of cobalt acetate, using one pound to about one and a half or two gallons of water. The damp straw is thoroughly sprayed with this solution. With a thatch thus treated it is claimed to be practically fire-proof, so far as flying sparks are concerned. But the danger of fire is no greater for a thatch roof in its natural condition, when well packed down, than it is for the average patent roofings or dry shingles.

A thin coat of hot, melted paraffine, quickly applied with a wide brush to the smooth, rake-combed thatch, is sometimes recommended to insure rainproof quality. But this precaution, like the various fire preventives, will seldom prove necessary. A neat, uniform covering of well-laid thatch, squarely trimmed at the eaves and quaintly finished at the ridge, will produce the best example of this oldworld handicraft. 


\section{$\mathrm{XXX}$}

\section{TEMPLES AND BELVEDERES}

\section{APPROPRIATE SITUATION AND GREEN BACK- GROUND ARE IMPORTANT}

THE classic beauty of the Greek temple and the Italian belvedere has been practically established in many of our American gardens by two distinct methods. The man of small means and great ambitions for his home garden has carefully studied the best types of this increasingly popular form of garden embellishment, and with clever manipulations of trowel and home-made molding boards and concrete mixtures, he has built his charming garden temples in harmony with the concrete or plaster house on his suburban place. On the other hand, the man of wider reaching ambitions, and with wealth to gratify them, has spent considerable sums of money in travel and research among the antiquities of Grecian and Egyptian gardens and among Italian villas for costly temples of beautiful marbles and rare carvings. Thousands of dollars have thus been expended in the purchase of these treasures as garden embellishments, and in importing and placing them on the American country seats of aspiring garden lovers. 


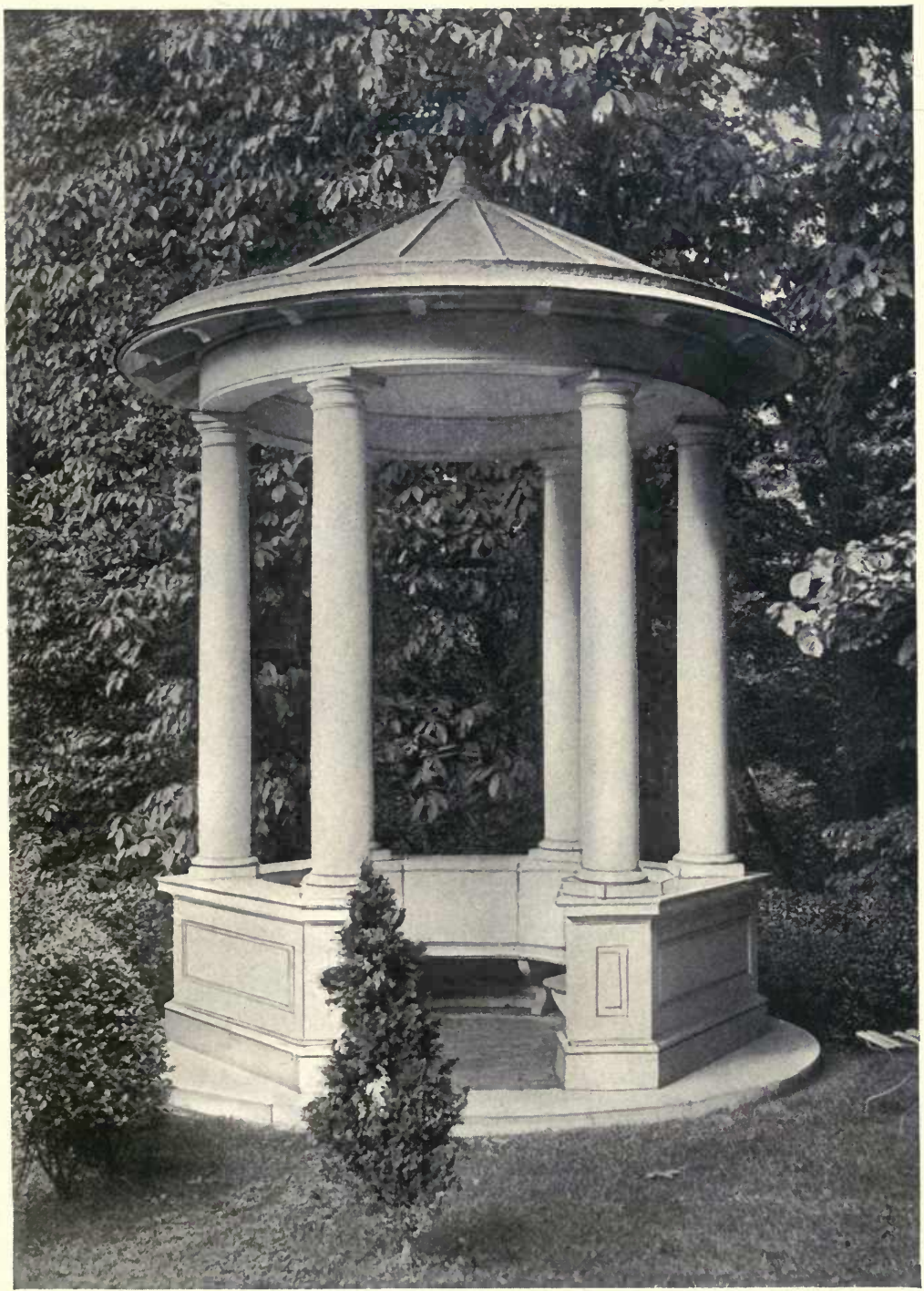

A STAtely Temple on THE VAN Rensselaer estate, "CAMP hill hall," OVERLOOKING THE WHITEMARSH VALLEY 


\section{TEMPLES AND BELVEDERES}

Both methods of acquiring the desired result are satisfactory, according to the wisdom and good taste shown in keeping this somewhat unusual form of garden architecture in harmony with its surroundings.

The Grecian or Egyptian importation, of classic design and stately dimensions, should never be found in a small garden or closely adjoining any form of rustic work or any other form of garden furnishing that is merely picturesque and quaint in design. When placed on the border of a beautiful garden lake, and forming the main attraction of the section of the grounds immediately surrounding, it imparts the classic severity of the early Greek gardens.

The same care must be exercised in the form and the position of the less costly temple of concrete or wood, of home construction, to keep it in harmony with its surroundings.

Wood may be used to good advantage in place of concrete in adapting stately types of these old-world temples to our modern architecture. The big white columns and quaintly domed roofs of stately temples in famous Colonial gardens show very pleasing reproductions in wood of beautiful marble originals.

The garden temple of Italian design, known also by the name of belvedere, demands careful consideration of its site as well as its workmanship. As its 


\section{PRACTICAL BOOK OF GARDEN ARCHITECTURE}

name indicates, it is most appropriately placed not only on an elevated situation but also where it can command a good view of well-planned grounds. It must have a beautiful "sight," as well as a prominent "site," as the name comes from the Italian bello, bel, meaning beautiful, and vedere to see. The name originally applied to a small open building or view tower erected on the top of another building, like the belvedere of the Vatican at Rome. But finally it extended to the summer-house, pavilion, or temple on the hill slope or terrace of the Italian garden.

The majority of the temples erected in American gardens to-day, whether merely copies of old-world types or the original marble structures, carefully taken apart and shipped across the water to be reerected on the bank of a garden lake or a prominent terrace of an American country seat, show the same general characteristics, with four, six, or eight huge supporting columns, an eave finish of deep mouldings or beautiful carving, and a domed roof of stately simplicity. Although they stand out prominently on their commanding situations, they seldom show any railing, balustrade, or enclosure about the base of the structure.

When situated on the bank of a garden lake like the beautiful temple at "Compton," the Chestnut 


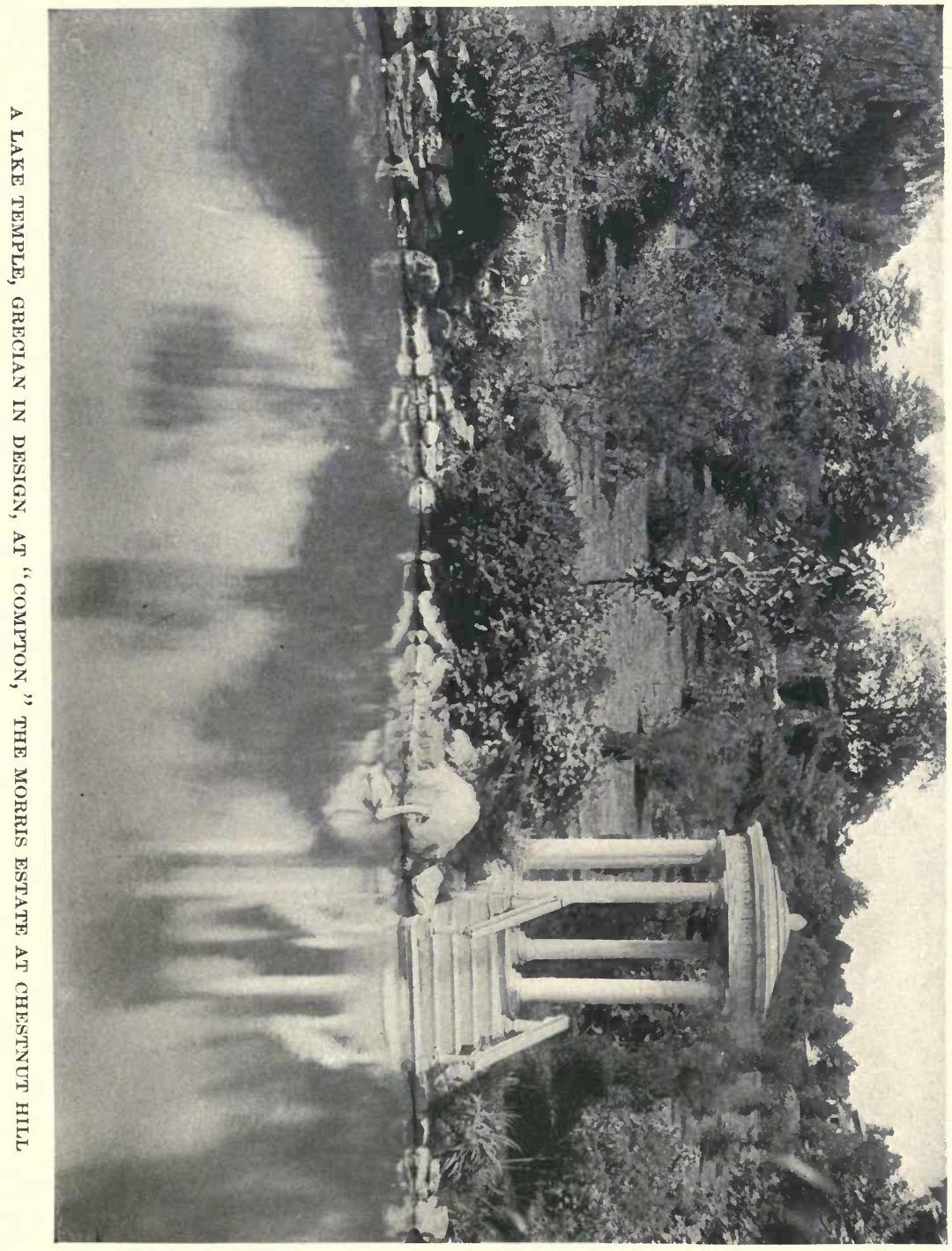




\section{TEMPLES AND BELVEDERES}

Hill estate of Mr. John T. Morris, a short flight of steps leading down into the water proves an additional attraction. These steps give access to boats, and with distinct reflections in the still water, the architectural value of the temple steps will be appreciated.

An absurd fashion is occasionally found in the erection of garden temples on the estates of millionaires whose lack of good taste is in proportion to their great wealth. It is that of counterfeiting ancient ruins in the form of square or circular garden temples. This is supposed to give a desirable air of antiquity to the garden, which is certain to be of questionable taste, unless it can be harmoniously carried out through the entire scheme of architectural embellishment. The effort to outdo the splendors-or the antique treasures, as the case may beof a neighboring estate has caused many a garden builder to commit absurdities where he had hoped to achieve architectural renown. Aspiring to possess an antique temple of early Grecian or Egyptian fame, the credulous purchaser may be persuaded that the excavated ruins which are finally to take the form of a garden temple when established on his home grounds originally belonged to one of the Egyptian noblemen described by Maspero in his "Dawn of Civilization." One of these ancient Egyptians estab- 
lished a famous garden of formal architectural design fully four thousand years before Christ, and he became so fond of his beautiful garden that he had it described upon his tomb. Marble ruins of stately temples are also claimed to have been derived from Grecian gardens of the same age; and their value is supposed to lie in their antiquity rather than in their architectural beauty. The more sensible garden builder does not strive after questionable antiquities of these ancient Grecian and Egyptian gardens, nor after the excavations dating from the later period, when the darkness of the Middle Ages settled down over Europe, after the fall of Rome.

The clasisic marbles of Grecian, Egyptian, and Italian fame that are most frequently imported for garden adornment seldom date from the earliest forms of garden art or from excavations of mediæval gardens, but from the time of the cessation of wars, and the awakening of artistic activity, during the period now known as the Renaissance. Many of the importations for adorning American gardens are modelled after suggestions offered by ancient ruins; but in their stately simplicity there is no trace of exaggerated display.

When the type of garden temple has been wisely chosen, or whether it is the costly importation or the work of the ambitious wielder of trowel, stone, and 


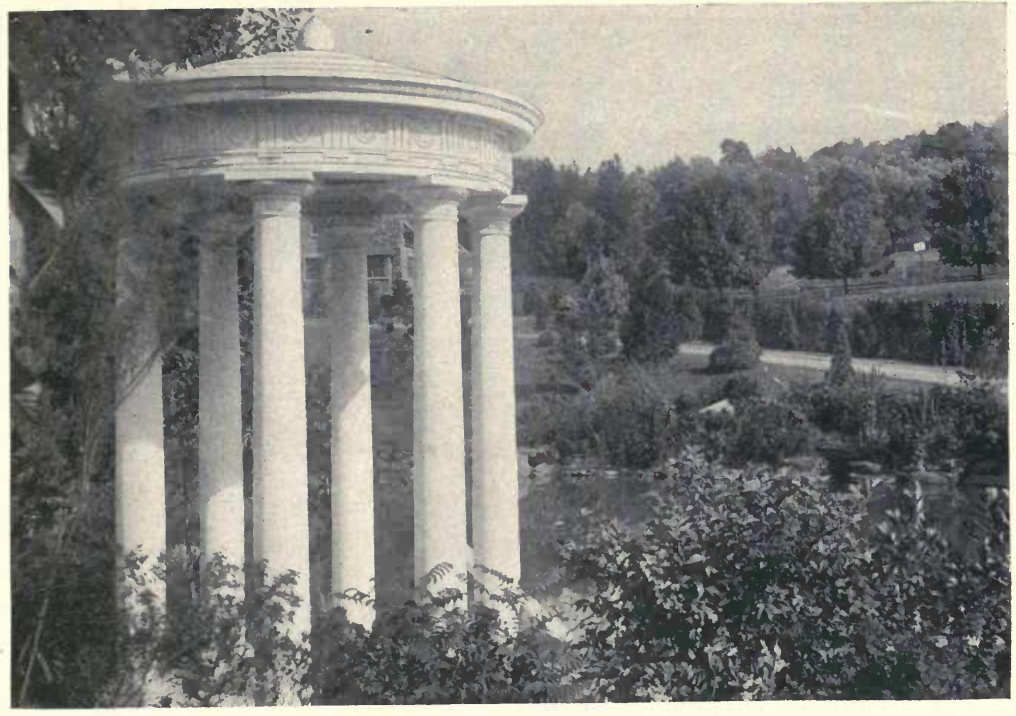

A GRECIAN TYPE OF GARDEN TEMPLE WITH MANY COLUMNS

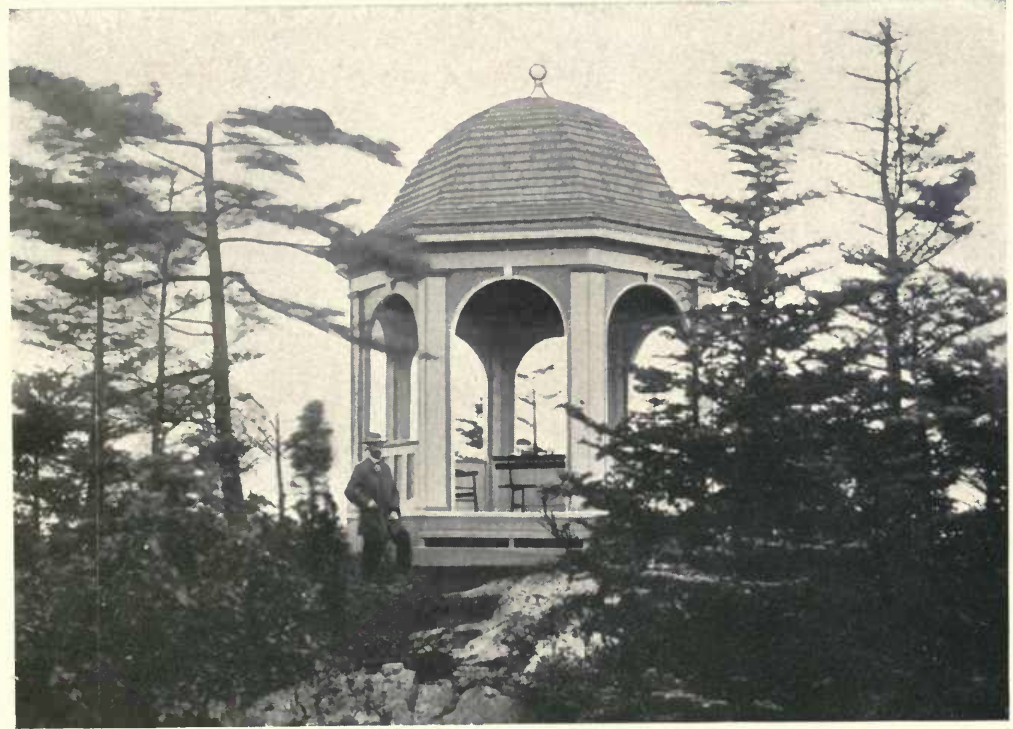





\section{TEMPLES AND BELVEDERES}

concrete, it is equally important to select an appropriate site with fitting background. Both the classic temple and the dainty garden house known as the tempietto or the garden pavilion are carefully placed in a commanding position against a background of green. The heavy foliage of dark evergreen trees brings out the beautiful finish and the carvings of these stately white buildings in all their charming detail. With the dark green background three sides of the buildings are exposed to view from three approaches along the garden paths. When approached from the woodland thicket or the massed evergreens that form the background, the presence of the pure white building comes as a delightful surprise to the chance visitor; and its commanding view overlooking the terraced gardens possesses a fascination that never palls.

The mistake most commonly made in the setting of these garden temples, belvederes, or tempietto, is the attempt to enhance their beauty by vine draperies. No matter how delicate the vine tendrils or how beautiful the climbing rose that is trained about the white columns and over the arched or domed roof, the very presence of the green drapery shows lack of taste and lack of knowledge of the original settings which established true temple beauty. A wealth of flowering shrubbery and brilliant perennials may be 


\section{PRACTICAL BOOK OF GARDEN ARCHITECTURE}

massed about the base of the temple, to take away the bareness of the approach when it is situated on a high terrace; but the remainder of the building should stand in bare, unadorned beauty, against its background of green.

Another mistake in the finish of the building is frequently made in overfurnishing. The presence of rustic chairs, benches, and tables, filling the floor space, will be entirely out of harmony with the stately white columns and their broad open spaces. Naturally, one will desire that his favorite type of garden architecture shall be inviting and comfortable to those who enjoy the view from its elevated position; but that does not necessitate lack of taste in its furnishing. If one would follow closely the finish of Italian and Greek temples, one should make the floor of marble when marble columns complete the structure; and a long marble bench with ends quaintly carved and an oblong marble table made stationary in the centre of the building, within easy reach of the bench, should be the only furnishing allowed in the purely classic building. All suggestion of cold formality may be avoided by the floral beauty about the base, by the green background, and by the low formal hedges of approaching paths.

For the cheaper structures of concrete, or the white-wood finish of Colonial types, the same general 


\section{TEMPLES AND BELVEDERES}

plan of flooring and furnishing may be carried out. A quaint flooring of small tiles is also in good taste for the concrete structure, and the decoration of the eave projections may appear in the same design to good advantage.

A structure of heavy rustic work, with barkcovered posts and a decorative form of overhanging roof, is sometimes set upon a garden eminence overlooking a vista of fountain, lake, flowers, trees, shrubbery, and graded and balustraded terraces; and from its position and its commanding view it is designated as a garden temple. This is an evidence not only of poor taste, but also of lack of the correct knowledge of temple requirements. This same rustic structure, given the position of a garden retreat or summer-house, with vine draperies and appropriate rustic furnishing, will prove an architectural success. In its pose as a garden temple it is simply a failure.

The garden architect who proposes to build his own temple from concrete or wood should not be content with reproducing the work on a neighboring estate. No matter how true to Grecian and Italian ideals this may be claimed to be, it will not be wise to take it as a model for a classic reproduction until one has carefully studied authentic forms. In these days of photographic reproductions, it is not difficult to study types as they stand in stately beauty in old- 


\section{PRACTICAL BOOK OF GARDEN ARCHITECTURE}

world gardens, and one is always safer in following original models in his reproductions.

Great care must be exercised in setting up imported marble temples. The fine finish of columns, and the eave carvings, may be easily marred by careless handling. A covering of heavy builder's paper should be used for all sections until they are finally placed in position. The home-made concrete and wooden structures also require careful finish to achieve worthy distinction. 


\section{XXXI}

\section{DECORATIVE GARDEN LANTERNS}

\section{IILUMINATING CONVENIENCES FOR THE HOME GROUNDS THAT ARE PRACTICAL, INEXPEN- SIVE AND ORNAMENTAL}

THE garden lamps and lanterns: of country and suburban homes seldom add decorative features to their surroundings. Hung upon a rough post near the gateway, or the stable door, or suspended from a hook on stable walls, they serve the purpose of utility, but there their mission ends. Why not make them add their share to the general ornamental scheme of the home grounds?

There will be no necessity for furnishing elaborate settings, nor for purchasing costly lamps. Care in producing attractive effects in mounting the lanterns, on rocky terraces, at secluded entranceways, in suspending them from trees, or in other quaint positions; and care in floral planting about the post and wall supports will produce the best results in promoting ornamental characteristics at little cost. For the suburban home near city improvements, the gas lamp of the streets may be introduced into the home grounds; and on country estates, and for farm homes, any inexpensive stable lantern of 


\section{PRACTICAL BOOK OF GARDEN ARCHITECTURE}

pleasing design may be used upon the walls of the out-buildings. The square and oblong forms are more attractive than the commoner circular lantern, at little extra expense.

Having selected the light producer, its decorative possibilities will depend largely upon its mounting. Rough cedar posts are in keeping with almost any scheme of informal garden decoration, where the rustic element is pleasing; and this is one of the most desirable supports that can be given to an unpretentious garden lamp. Close-clinging vines trained about the post apparently offer the best decorative suggestion, judging from the setting of the average garden lantern. But for novel ornamentation many quaint designs have been carried out with good effect.

The uses of kerosene, gasoline, home-made electricity and acetylene gas are being carefully tested on many farms and suburban estates out of reach of public-service corporations for supplying lights for these garden lanterns. The common use of gasoline generators, which have now reached a high state of perfection, has brought them into prominence for outdoor lighting, as well as providing brilliant lights for the house and for cooking purposes. Gasoline lamps for the entrance gateposts, for lanterns set permanently on stable walls, and for use within the stables and dairy barns, may be enjoyed at little cost 


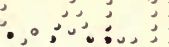

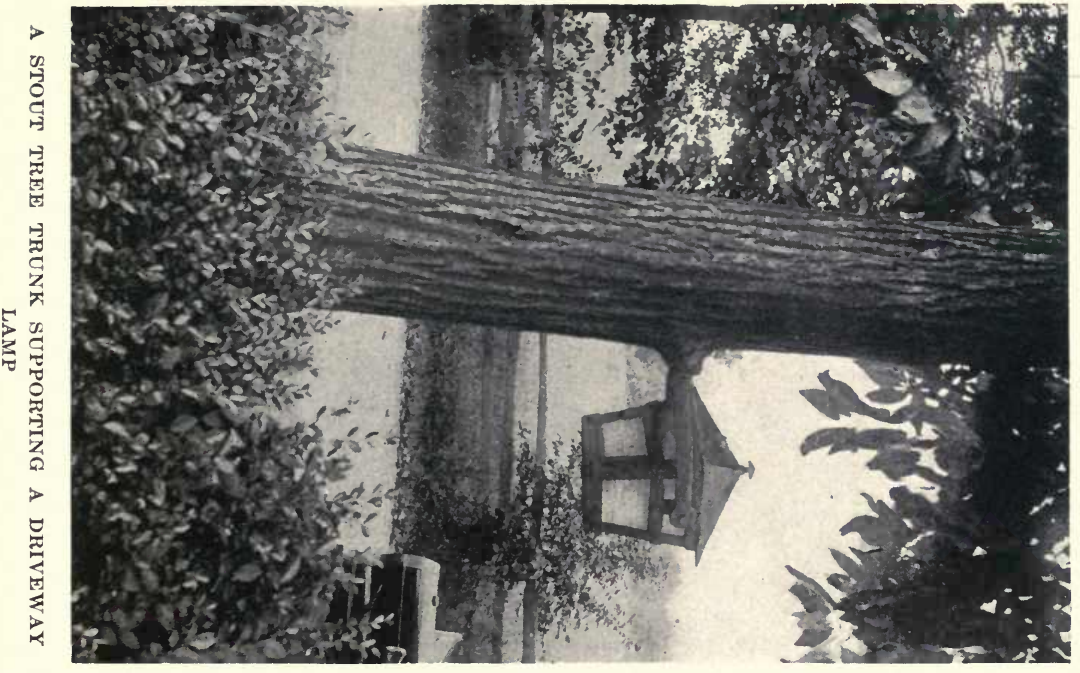

D

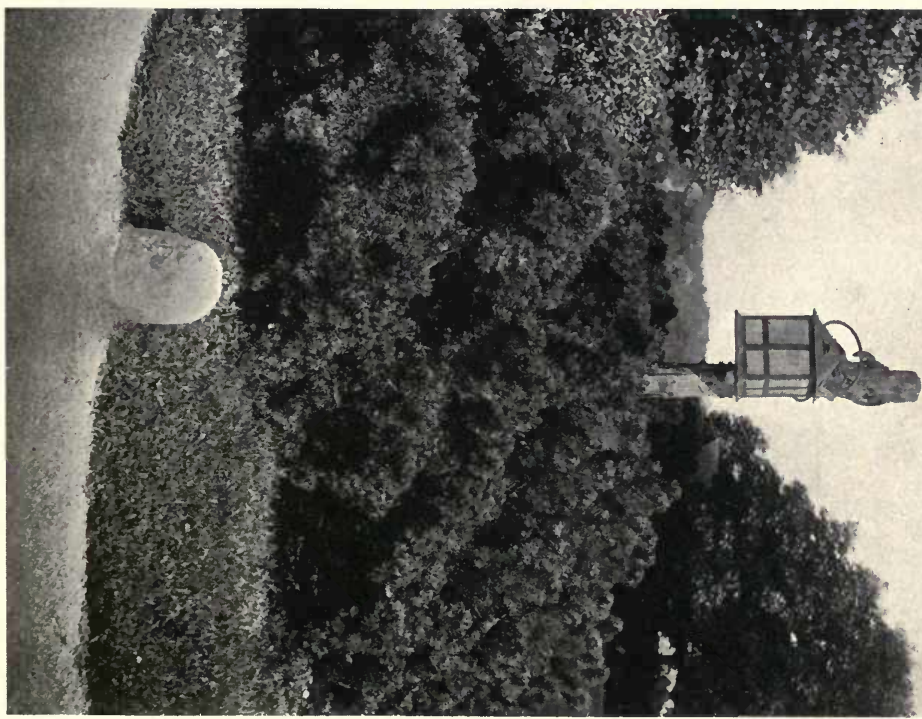


的 


\section{DECORATIVE GARDEN LANTERNS}

when one of these practical gasoline-gas generators has been established for illuminating the home and the grounds. Without this plant for general use, the plainest types of gasoline lamps, filled and lighted the same as coal-oil lamps, may serve as the source of dependable lights for yards and stables.

Many practical and enterprising farmers, who are blessed with streams on the home grounds that can be harnessed for the development of power, are experimenting with home-made electricity with very satisfactory results. By establishing a turbine, a governor and a $11 \mathrm{k.w}$. generator, and damming up the stream for satisfactory water power, an inexpensive electrical plant may be thoroughly practical wherever there is a stream of water of sufficient size and fall to turn a water wheel. One of the most interesting features in establishing this form of home illumination is the fact that the turbine used to furnish light will not be thus exhausted in its power of usefulness, but also will provide power to run various sorts of farm machinery, including the feed mills, the wood saws, corn shellers, etc., etc.

The use of home-made acetylene gas has found great favor in country and suburban places, because, when once established, it is claimed to be one of the most economical illuminants for isolated districts. It is also claimed by those who have given the subject 


\section{PRACTICAL BOOK OF GARDEN ARCHITECTURE}

practical study, that the light furnished by acetylene is remarkable because of the fact that its spectrum is nearer to the spectrum of the sun than that of any other illuminant. This makes its use of special advantage in lighting country homes, and when the plant is established it is a small matter to provide the extra lights for the barns and various out-buildings, as well as along the walks and the garden driveways. One who has thoroughly tested the use of acetylene gas in lighting the homes and the grounds of village and country homes, gives still another feature of its usefulness, by stating that the residuum of the carbide, which must occasionally be drawn from the generating tank, is in reality a lime, and that it can be used in making whitewash, or on the land to sweeten the soil.

"Once in position, an acetylene plant requires but little attention," he says. "At intervals, which vary according to the amount of gas burned, it is necessary to fill the carbide-holder at the top of the machine with carbide, which comes in cans ready for use, and to fill the generating tank with water. No further attention is necessary until the carbide is exhausted except the occasional drawing of the residuum of the carbide from the generating tank." The principle involved in establishing the use of acetylene gas in country districts is very simple, 


\section{DECORATIVE GARDEN LANTERNS}

claims this same enthusiast. A piece of calcium carbide, a product of the electric furnace, is dropped into water where it almost immediately decomposes and unites with its oxygen, the carbon and hydrogen forming a union by which acetylene is generated.

Another enthusiast, from whom I secured very practical information and statement of tested facts in my search for "light" on the subject of country home illumination, says: "It is easy to get calcium carbide at the present time, as there are several companies now making it, and it costs three dollars and seventy-five cents a hundred pounds when bought in less than ton lots, and seventy dollars a ton when bought in lots of one ton, or larger. One hundred pounds of calcium carbide will generate about four hundred and fifty feet of gas, which makes it look at first sight as if it was an expensive form of illuminating, but when you take into consideration that it requires only one-tenth in volume of acetylene to produce the same amount of light as ordinary city gas, it is easy to see that it is not expensive at all." An acetylene plant that may be used to light the home, the grounds and various farm buildings may be economically established at a cost of about two hundred dollars, not including fixtures; and after the installation of the generator the entire future cost of making the gas will average 


\section{PRACTICAL BOOK OF GARDEN ARCHITECTURE}

only about twelve dollars a year, or one dollar a month, for generously lighting a big country house, with its grounds and its out-buildings.

The subject of providing inexpensive and picturesque lanterns for yards and stables, however, need not depend upon the installation of extensive plants; or even the simplest of apparatus for homemade gas and electricity. The simplest form of steady-burning kerosene lamp, set within a lantern of good type, and with a good reflector, is within the reach of every farm owner and renter. A picturesque setting will cost no more than a lantern position carelessly selected. An ugly post set close beside the driveway, at a dark turn in the garden, leading to carriage sheds and stables, will doubtless give just as satisfactory results in the mere form of illuminating as the one set within a clump of flowering shrubs or evergreen hedges or dwarf spruce trees, but there will be no comparison in the decorative value. A group of native cedar trees, and the little pines that may be transplanted from farm wood-lots and planted along the home driveways, and grouped about the entrance-ways to yards and gardens, will add much to the home value from a decorative point of view, and these beauty spots will prove ideal places for screening the rustic post that supports the garden lantern. 


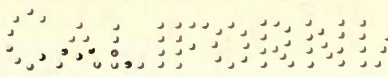

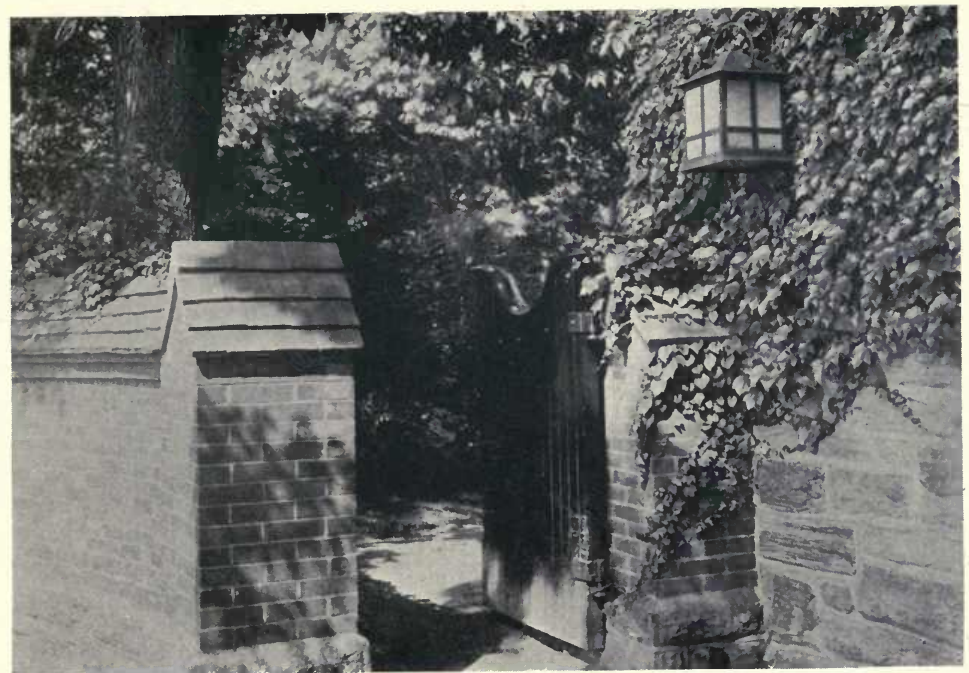

A STABLE-WALL LANTERN WITH BACKGROUND OF AMPELOPSIS VINE

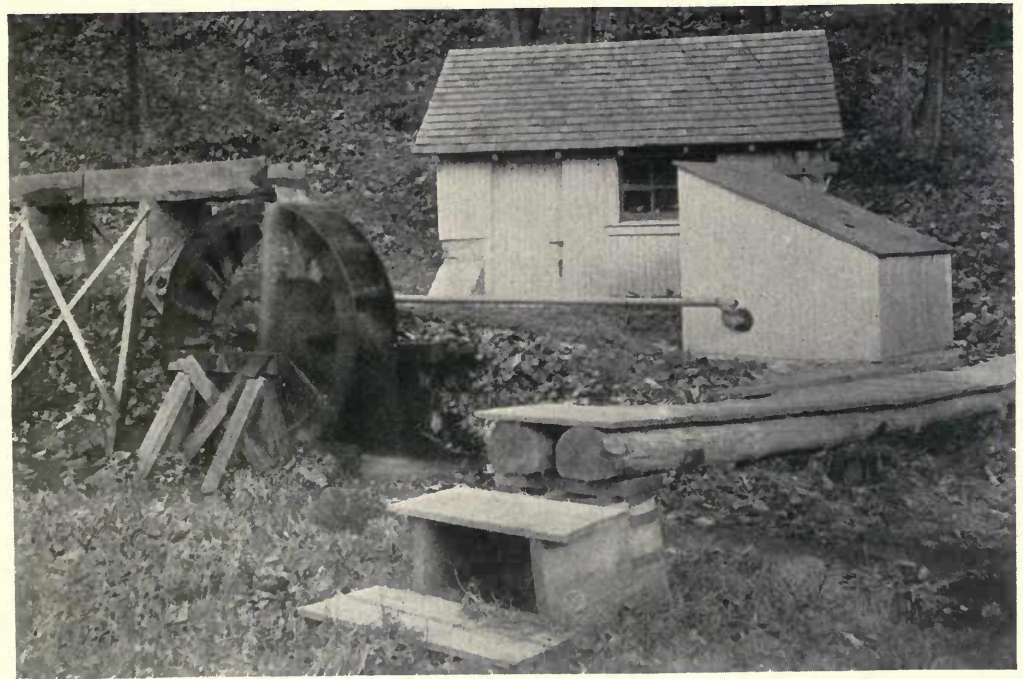

A SIMPLE FORM OF WATER POWER FOR GENERATING ELECTRICITY 


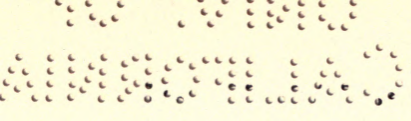




\section{DECORATIVE GARDEN LANTERNS}

A stately old tree trunk standing close to the garden roadway, or near the entrance gate, offers another picturesque support for the garden lantern. A stout iron bracket will be required to hold the decorative lantern-lamp in position. When hung upon the stable walls a background of thrifty ampelopsis or other rapid-growing hardy vine will provide a permanent and attractive setting. It is really an easy matter to have the details of yard and stable illumination beautiful as well as useful without adding appreciably to the cost. Good taste must be exercised to avoid over-decoration of the lantern support. Vines will be superfluous and out of place for training about the support when there is a permanent decoration in the form of a clump of evergreen trees of dwarf growth about the base of the rustic post or the mound of rocks. A single bushy specimen of one of the globular-shaped evergreens, or a dwarf pine of spreading growth, is sufficient in itself, and should not be combined with vine or floral decoration. In planting, allowance must be made for future growth. As the first essential of the lantern is to light the path or drive, care must be taken that no heavy shadows shall fall-because of the decorative planting-where the light is most needful. At a point away from the garden view, a little path may be made through the evergreen grouping, or stepping 
stones may be provided among the bedding plants, to be used each time the lantern is lighted, without risk of spoiling the banks of green.

In choosing the vine draperies for the stable walls, where lanterns are to be hung, it is important to secure only the close-clinging varieties, like the hardy ivies, the ampelopsis, etc.; otherwise swaying vine tendrils will obscure the light and the lantern will become entangled. The showy trumpet creeper (bignonia) and the hardy honeysuckles frequently trained over stable arbors, and about big stable doors, do not offer a good background for the lanterns for this reason. But the Ampelopsis Veitchi (Boston or Japan ivy) or the Ampelopsis tricolor (Vitis heterophylla variegata) will form a closeclinging, well-covered surface against the stable walls that will not interfere with the light or the lighting. The hardy English ivy is also good for wall draperies that form the lantern setting; and for a novelty among ivies, Hedera Maderensis variegata may be used. This is the finest of all variegated ivies for this purpose, as the glossy foliage, which is somewhat larger than that of the common English ivy, is beautifully edged and mottled with creamy white.

The ivies have the advantage over sun-loving vines, as they thrive on the walls overhung by shade trees; and it is in such positions, beneath a beautiful 


\section{DECORATIVE GARDEN LANTERNS}

old shade tree, with a wall background of glossy green, or variegated foliage, or hung above an entrance gate to a secluded garden walk, that the lamps and lanterns of country and suburban grounds will enhance to the best advantage the general decorative effect.

It is possible to secure various quaint forms of Japanese lanterns, in stone, in oriental shops that will not require any great expense; but care must be taken to give them appropriate surroundings. The tall stone lanterns require only appropriate grouping of dwarf trees or gaily tinted shrubbery to form a fitting background. Quaint, old-world types of garden lanterns, without the tall stone base and pedestal, are effective when placed upon mounds of rocks to elevate them above the garden walks or drives which they are to illuminate. Wooden lanterns in Japanese design, which are within the oapabilities of the amateur craftsman, may be set upon rough cedar poles, and banked with little bright-leafed Japanese maples or evergreen shrubbery. When lighting a walk or driveway near a garden pond, the lantern should be so placed that it will be reflected in the water. 


\section{XXXII}

\section{ORNAMENTAL WELLS AND WELL}

\section{HOUSES}

\section{MANY ARE PURELY DECORATIVE, OTHERS COM- BINE THEIR BEAUTY WITH UTILITY}

THe majority of the unique well heads in Italian pottery and rare types in costly marbles, found in American gardens, appear as an absurdity, as they have no connection with any form of water supply. Others are connected by piping from some natural or artificial source, brought to the spot where it is desirable to display the importation. Again, there are wonderfully beautiful well heads and well curbs standing several feet in height, and formed of splendidly carved marble, connected with wells of pure water. Delicate iron work supports the carrier, of true "old oaken bucket" type, and the well that gives the appearance of merely an excessively costly bit of garden decoration serves its useful purpose in providing an abundance of good water.

It is only during recent years that Italian types of decorative garden well heads, in connection with unique forms of Florentine oil jars and similar forms of garden pottery, began to be widely distributed. 


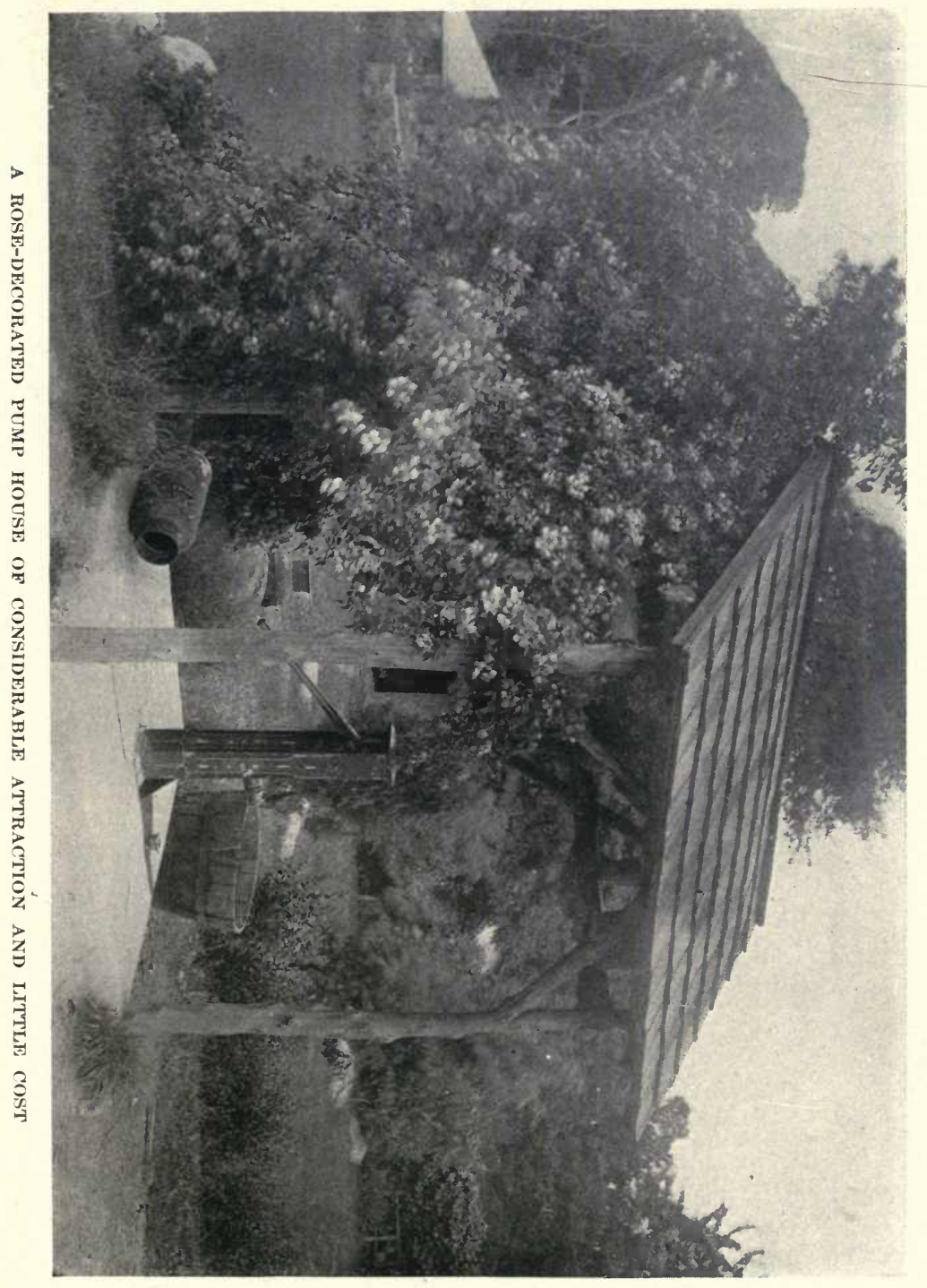




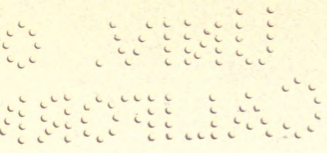




\section{ORNAMENTAL WELLS}

But little more than a decade has passed since Italian well heads became a prominent feature among forms of garden pottery; and they are now found in all parts of the country. Not only were the marble and stone and terra cotta well heads pressed into service, but quaint Italian oil jars were used to produce the effect of an overflowing well. Probably the first one to attract attention was established in the garden of Mrs. Archibald Alexander, at Bernardsville, New Jersey, about ten years ago. Mr. Daniel W. Langton, the landscape architect, carried out the combination by partially burying a big Italian oil jar, of rare form and coloring, on a hill side in the Alexander garden. Water was then introduced at its base through a buried pipe, and, flowing into the quaint receptacle, it gave the appearance of an overflowing well. The overflow, running down the body of the receptacle, forms a film that flashes back the sunlight and brings out all the beauties of the novel well.

It is generally supposed that the ancient well heads imported from old-world gardens are the only types desirable for garden use, as representative of the waning glories of Roman and Florentine villas. It may be a matter of surprise to know that modern. potteries of Italy are at work to supply the demand for characteristic types. An authority on the subject 


\section{PRACTICAL BOOK OF GARDEN ARCHITECTURE}

of old-world pottery states that 'Italy's artistic creative force, in most of its manifestations long since spent, keeps in one of its humbler phases at least a remnant of its old-time power. As the source and inspiration of pottery used in landscape gardening, no other country can approach her. Though the best days of the craft are past, the Italian influence which helped to determine, three centuries ago, the shapes and colors and surfaces of French terra cotta, and also of English, is now at work molding the plastic products of the United States."

The manufacture of unique types of well heads is of special interest in this connection, because of their variety in form and decoration. The majority show the cylindrical form, standing from three to five feet in height, with figuresi in relief carved over the entire exterior, from base to rim. Others that are genuinely ancient importations, show quaint forms of mending where the terra cotta or marble has been broken. It is usually noticed that the break, and the unusual form of mending with bands of iron, is placed on the display side of the well head. Its great age, its evidence of long usage in some old Italian garden, and the old-world methods of repairing damage to the pottery, are considered worthy of a prominent place in the garden. The carved well heads, or curbs, that are fitted with bucket and windlass, are more decora- 


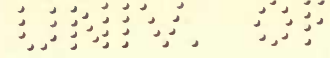

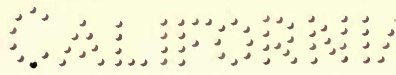

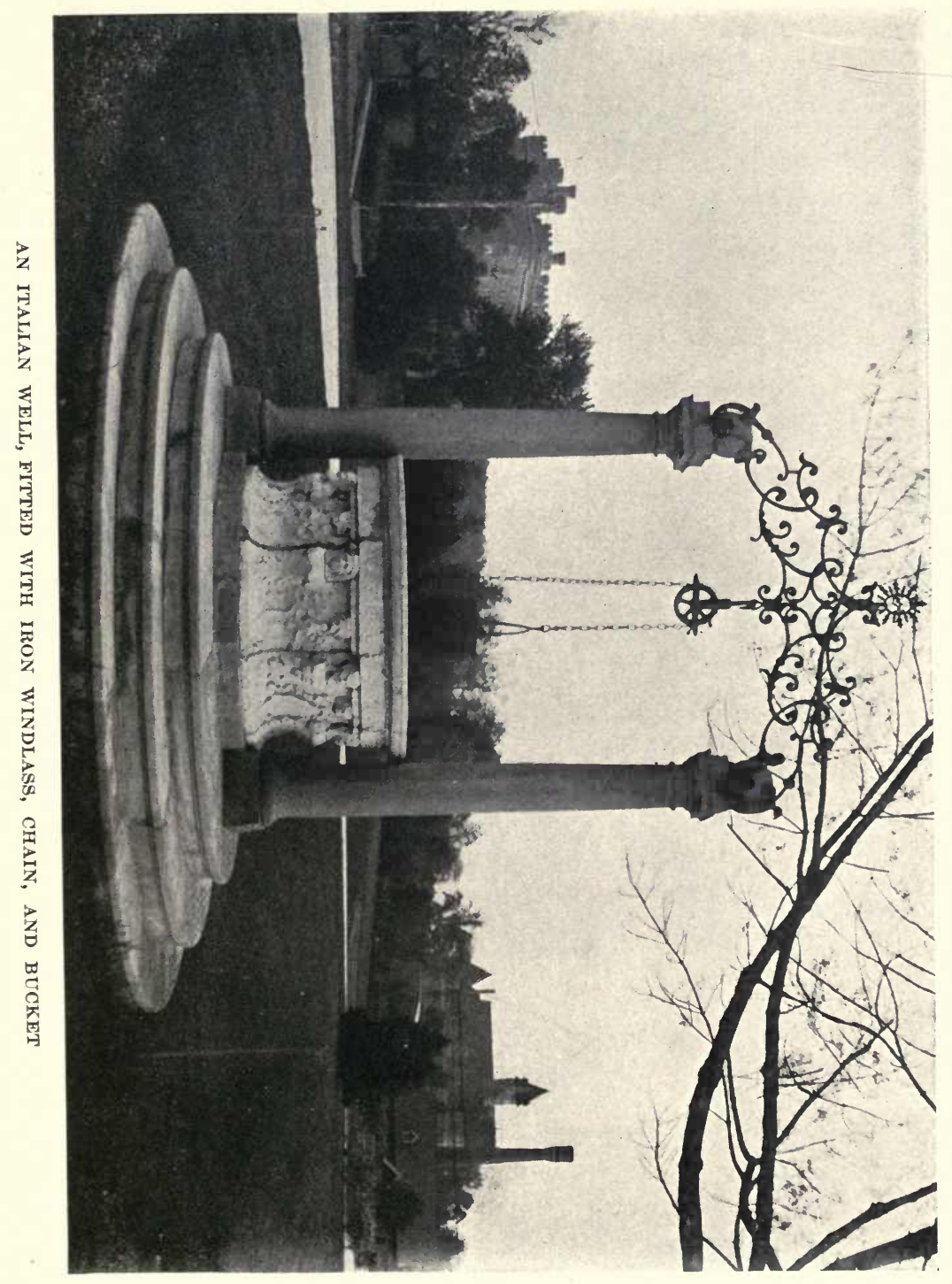





\section{ORNAMENTAL WELLS}

tive, but are seldom so highly prized as the rare old types.

In country districts, where the well with its pump is depended upon for the entire water supply of the home-without windmill or water-tower tanks, or engine-pumped reservoirs, kept filled for a convenient and continuous supply-the garden wells, placed as near to the house and the barn as possible, become important adjuncts to health and comfort. The decorative features become a secondary consideration. Although rustic well houses are built to shelter the pump, or pergola and arbors connect the well house with the kitchen, these forms of decoration count but little in the real issue, until a well of pure dependable water has been dug and walled up, free from contamination, or an artesian well driven to a good deep source of supply.

Although it is generally realized that this matter of establishing the source of the water used in the house is a matter of the gravest concern, many people seem satisfied to dig or bore a well, and use the water without making any attempt to discover whether it is pure and uncontaminated.

We frequently hear the owners of a new home in the country boast of their deep well of pure cold water. In all probability, they have not for one moment considered it necessary to have the water 


\section{PRACTICAL BOOK OF GARDEN ARCHITECTURE}

examined. Even though chemically pure water does not exist in nature, analysis will readily determine its constituent parts. The feeling of safety resulting will be well worth the slight expense involved. When there is an extra well at the barn, for supplying the stock with water, the water of this should also be carefully analyzed, as it is important to have this well equally free from impurities.

It is generally supposed that a well of great depth is always an advantage, as there is no danger of pollution from surface water or drainage. Frequently, however, these deep wells that are free from objectionable matter of an organic nature may become subject to the introduction of mineral elements. We often hear the complaint of the housewife that the water is "hard." It should be remembered that while the mineral elements that make it "hard" may be entirely healthful, there is a possibility that they will prove otherwise. When an artesian well situated on high ground has been drilled down to a good source of water that has been pronounced dependably pure, the owner will be free from further anxiety, and can proceed to set up his well curb or pump, with a rustic shelter or any other form of decorative convenience that his fancy may dictate or his purse allow.

Probably the greatest danger of impure water 


\section{ORNAMENTAL WELLS}

lies in the well provided for decorative purposes. For the suburban home or the country seat thoroughly equipped with water towers or windmills, and an adequate water supply within the house and grounds and outbuildings, the shallow well that is dug to supply a pool for the imported well head will be simply an ornamental accessory. The charm of novelty and the pleasant memories of foreign travel clustering about the Italian well, with its richly carved marble curb, will centre considerable interest at this point. Here the admiring friends and visitors will come to study the object of beauty representing a type that for generations has lorded it over formal gardens across the sea. On being assured that a genuine well supplies the water within the quaint curb, this water may be used more frequently during outdoor duties and pastimes than the water from the house supply. Here lies the danger. For the ornamental well curbs, the well is seldom dug to a safe depth; and shallow well water is never entirely free from impurities. A well of from fifteen to twenty-five feet in depth, for instance, is almost certain to be contaminated with surface water which flows directly into it, instead of being filtered into it. Especially is this true after a drought has cracked and dried the soil about the well, giving the surface water of the next rain a chance to flow 


\section{PRACTICAL BOOK OF GARDEN ARCHITECTURE}

through the cracks, without filtering through the soil to a greater depth.

The majority of the shallow well heads of elaborate carving are simply set in some decorative point in the garden, surrounded by other charming types of Florentine pottery, and allowed to serve the same purpose in garden beautifying, without any attempt to connect the well head with water. This is the safest plan, unless there can be a certainty of sufficient depth and purity to make the water safe for drinking purposes.

An attractive method of utilizing old Roman well heads is found on the Houston estate, "Druim Moir," at Chestnut Hill, Pennsylvania, where the carved importation is attractively covered to keep out dust and other impurities, and a deep, pure well has been dug from which the water is brought to the surface by a quaint iron pump. The safety devices for rendering the water pure and wholesome have added to the ornamental value. A little ingenuity in the placing of decorative garden wells may be made to bring about the same result in every instance, in connecting with a practical water supply.

What is known as the "gushing well" is a novelty that is sometimes introduced by artificial means -by piping a good flow of water to the imported well head set on the edge of a pool which receives the 


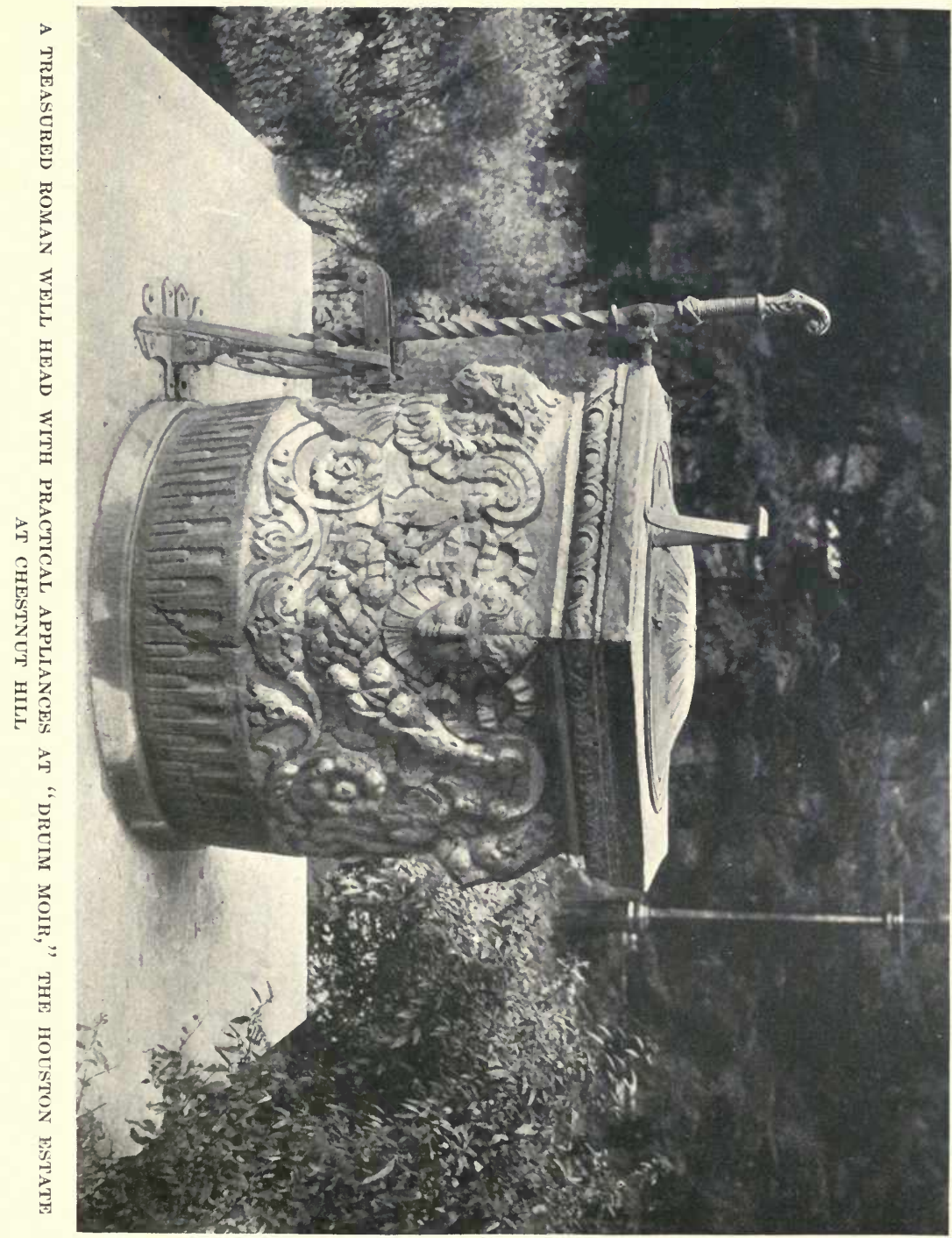


等 


\section{ORNAMENTAL WELLS}

overflow. The type is patterned after the California gushers which are used for irrigation purposes. The famous artesian well at Paso Robles, California, was driven deeper and deeper into the earth until it reached a hidden force of water stored under tremendous pressure.- It is not unusual for these gushers of California to flow six thousand gallons a minute, making them of untold value for irrigation.

Along the eastern shores of the United States we do not find gushers of similar capacity, but there are very creditable ones in various sections. On the north shore of Long Island, near Cold Spring Harbor, is one of the most famous of these everflowing wells. In passing along the quiet road, the visitor scarcely notices the shimmery pool that lies under a group of willows. When its novel attraction is pointed out, one notices that there is a living fountain in the centre of the pool. It is an unpretentious affair, simply a four-inch pipe extending out of the pool, from which spouts a living stream. This spouting or gushing well was secured simply by driving the pipe sixty feet into the earth, until it tapped the abundant underground stream. After spouting up through the pipe, and forming the deep pool, the outlet rushes down at one side of the pool in a little stream, making the surrounding vegetation luxuriantly beautiful by means of irrigation. 


\section{PRACTICAL BOOK OF GARDEN ARCHITECTURE}

The piping of little gushers from driven wells or abundant springs is possible for many gardens with a natural water supply. In connection with imported well heads, these gushers are made extremely decorative; or without the well head the drinking water may be collected into a concrete basin with a rustic shelter built above it.

Shelters of rough cedar logs or field stones, cobbles, and concrete are variously used for well houses. When set in the midst of the garden purely for ornamental value, combinations of field stones and thatching form attractive types. For the well and the pump house, used for the house supply, the shelter is built in keeping with the garden arbors and the porch lattice and trellises. 


\section{XXXIII}

\section{ATTRACTIVE GARDEN STAIRWAYS}

CLEVER DESIGNS FOR CLIMBING TERRACES AND FOR SECURING PICTORIAL VIEWPOINTS IN OUTDOOR LIVING ROOMS

Did you ever stop to think that the principal charm of sunken gardens, which are rapidly gaining popularity, lies in our ability to study the flowers and garden furnishings from an unusual view-point? Looking down, over, and into the garden discloses varied beauties and fascinations that are seldom visible when the garden is studied from its usual flat levels. The famous terraces of the old Roman and Alban hill gardens are supposed to have been cut and graded chiefly for the purpose of preventing washouts on the steep slopes; but a closer study into the work of the old masters in garden building, who constructed these terraces, discloses the fact that their utilitarian purposes were not the only reason for their careful construction. The numerous broad, level terraces were ingeniously continued to form pictorial features of the gardens. Looking up from the lower levels into the overhanging beauty of flowers and trailers on the succession of terraces, 


\section{PRACTICAL BOOK OF GARDEN ARCHITECTURE}

or looking down over a broad expanse, to gaze into the upturned faces of flowers and into fountains and pools, or studying different levels from the stairs leading from one terrace to another, will soon convince the owner of a large estate that he has achieved one of the principal fascinations of the old gardens of the Renaissance when he has introduced into his domains the poetry of changing view-points.

The changing levels necessitate steps and balustrades and quaint winding stairways. The most important feature in building rustic stairways is their suitability. Their construction should be conscientiously kept in harmony with their surroundings. It would be absurd to find stately formal marble steps, mounted by costly statuary, leading from an untamed woodland thicket into an upper level of wild gardening. Such stairs obviously belong only in formal gardening. Irregular stairs of logs and rough stones are equally out of place in stately formal gardens, when their every feature calls for unpruned garden thickets, secluded nooks and corners, and terraces leading to garden retreats.

Rustic stairways (the term "rustic" is here used in its broad sense) are most appropriately formed of the material of the surrounding walks and terrace boundaries. Whether built of stone, brick, concrete, rough wooden branches, or huge logs, the choice of 


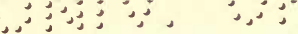

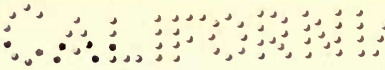

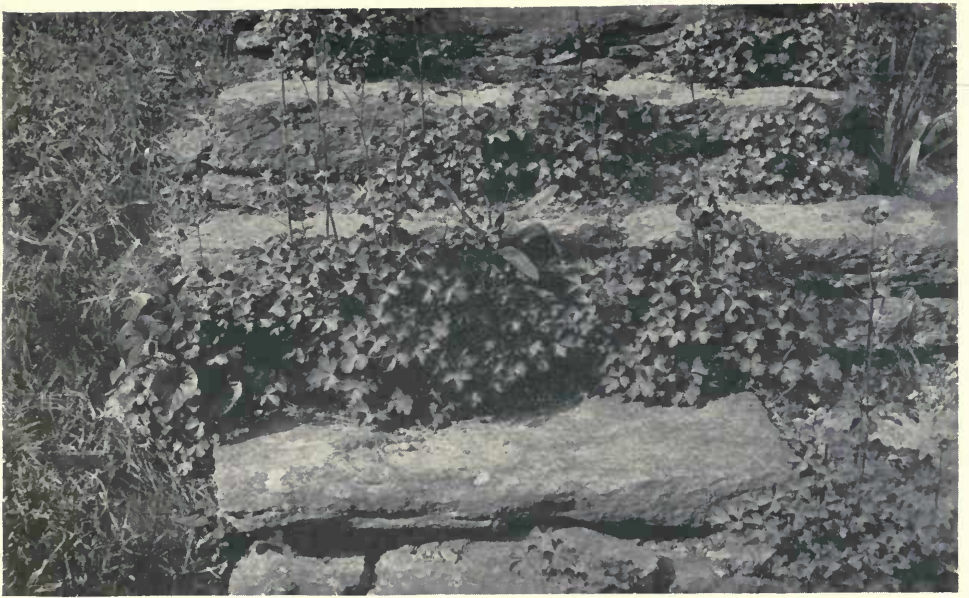

AN ENGLISH METHOD OF DECORATING ROCKY STAIRS WITH ALPINE PLANTS

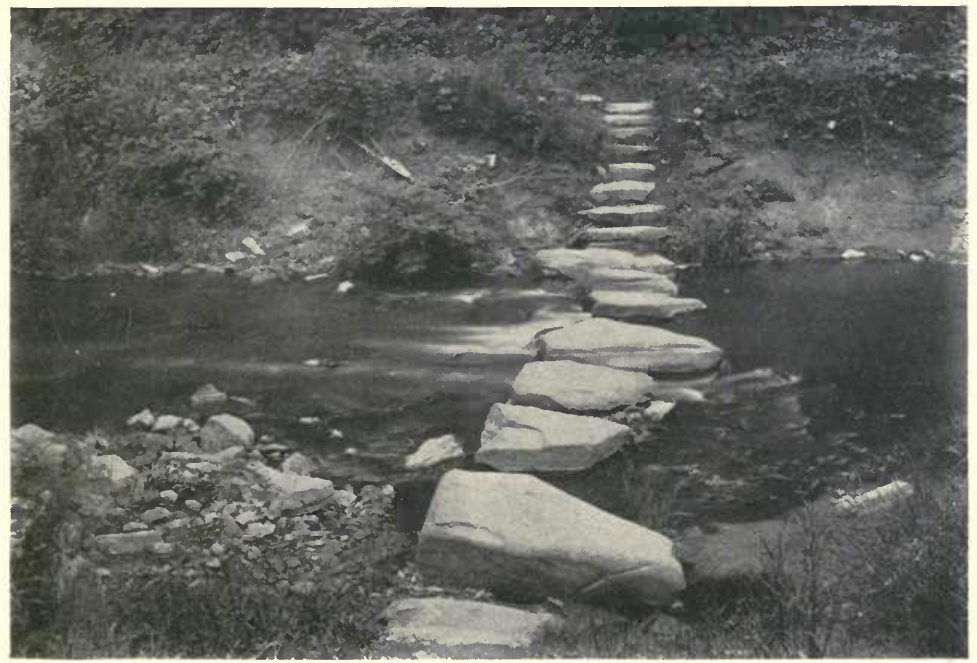

AN IDEAL FORM OF CROSSING A STREAM TO CLIMB THE GARDEN TERRACE 


\section{ATTRACTIVE GARDEN STAIRWAYS}

material must depend largely on the treatment of surrounding garden spaces.

A winding stairway making frequent curves and angles, when leading up a steep slope, serves a double purpose in providing an air of mystery as to what may be discovered in pictorial beauty beyond each bend and curve; and in furnishing varied levels along the winding flight of stairs for rustic seats and enchanting resting places. One can scarcely realize the charm of these winding stairs until the borders and boundaries are planted with masses of shrubbery and blooming trailers. Instead of balustrades for outlining and for support in building these winding rustic stairs, big stones and bowlders may appropriately edge their winding course, to keep the rough logs or stone steps firmly fixed in the soil and provide unique railings for the support of the boundary planting. These winding stairs with stone borders are especially appropriate where the climbing terraces are cut through rocky soil.

Steep flights of stone steps should be avoided wherever it is possible to lay out the stairways in graceful curves that are easy to climb. After climbing to an upper terrace, the short-winded visitor may resent the feeling that he has been required to perform a gymnastic feat. The result will take away half the pleasure of the changing view-points. Unless 


\section{PRACTICAL BOOK OF GARDEN ARCHITECTURE}

the garden space is limited, and the contracted terrace is very steep, there is no excuse for building straight, steep flights of rustic stairs that are as uncomfortable as they are inappropriate. Wherever comparatively steep arrangements are a necessity, the subject of easy tread and practical borders must be carefully studied.

Formal balustrades should not be built even for the steeper stairways when the surroundings are rustic in effect. A single upper railing, supported at regular intervals, and covered with open-mesh wire to encourage the growth of vines, will be less expensive, and more beautiful, because more appropriate. A railing of rustic branches also may be used for supporting the vines and forming a picturesque boundary of green. Where a lint of big rocks borders the steps built into the terraces, a bed of trailers should be arranged next to the stone-work, as grass sod is inclined to become untidy because of the difficulty of keeping it well trimmed where it joins the rocky border.

Broad easy treads and short risers are desirable in any form of rustic stairways for out of doors. Experienced garden architects claim that the stairs that give the greatest satisfaction in easy climbing have from four- to five-inch risers and from fifteento eighteen-inch width in treads. For any form of 


\section{ATTRACTIVE GARDEN STAIRWAYS}

rustic stairs, whether built rather steeply up a sharp incline, or by easy grades around a curving terrace, the height of the risers must be in correct proportion to the breadth of the tread. When the treads are formed of wood or flagstone, the width or breadth may be slightly increased by using a nosing of about an inch to project over the step immediately below. When built of logs, stone, or concrete, with risers and treads of the same material, the advantages of nosing will be lost, and the grades should therefore be less steep and the treads broader.

Where the space is limited and the grade rather steep, a bend in the stairs may be made to provide easy climbing and better pictorial effect. The bend must not be too sharp and sudden, but made to give a changing view-point, and a resting place in the centre of the stairs. It must be kept in mind that a limited space for terrace and stair building does not always necessitate a cramped stairway. This is one instance when the sense of proportion and fitness in garden-building demands special treatment. When space is limited, first try to hide its cramped outlines by architectural devices in building screened retreats and shrubbery banking. Then instead of a cramped, mean stairway, that would immediately give the impression of lack of space, have the flight of steps built on broad lines, of ample proportion and easy 


\section{PRACTICAL BOOK OF GARDEN ARCHITECTURE}

tread, and one will immediately be impressed with the effect of breadth in the visible spaces and an agreeable air of mystery in supposed broader spaces beyond the vine and the shrubbery screening.

It is a mistake to use narrow stone slabs for building the stairs up steep terraces in exposed positions. They may seem more appropriate than any other material, because of the rocky formation of the soil in which they are imbedded, and the wild, woodsy surroundings; but when set sufficiently far back into the soil to keep them firmly in position, with the ends secured in place, these shallow stone steps are almost certain to be injured by frost heavings, that will displace and often crack them during severe winters. Big rustic logs, with bark-covered faces and smooth upper surfaces, firmly set in the same positions, will give better satisfaction at less expense; and should they be occasionally misplaced by frost, there will be no unsightly eracking, and nothing to prevent their long-continued usefulness.

Stone steps are more appropriate where short lengths are used in winding up the foliage-screened paths of woodland terraces, or among secluded garden retreats. These short-length steps possess an advantage in the fact that they may be carried off the line of the direct slope in making the winding ascent. 

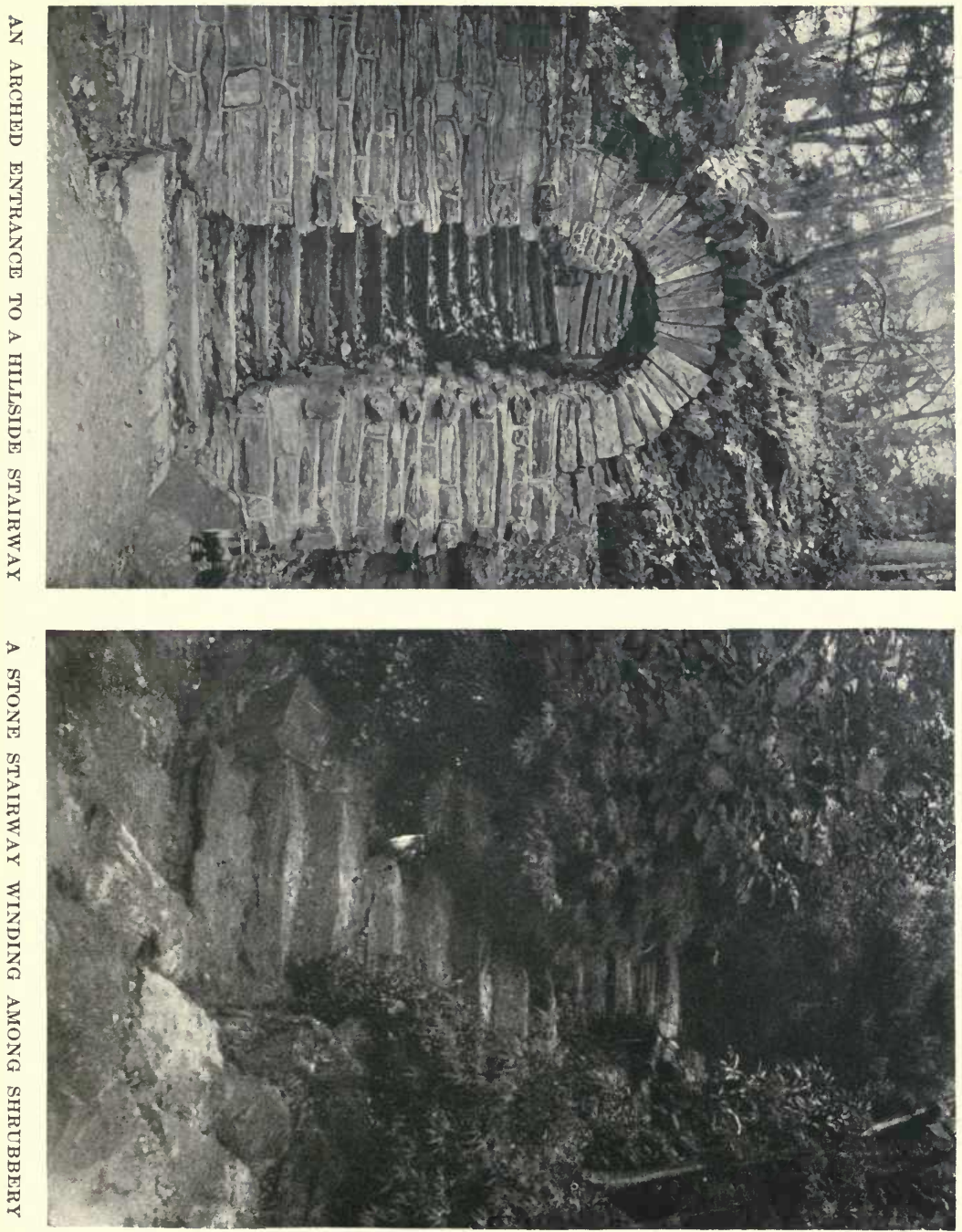


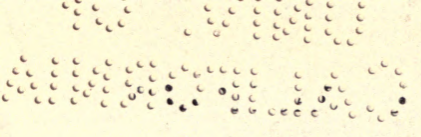




\section{ATTRACTIVE GARDEN STAIRWAYS}

All stiff formality is thus avoided, and the picturesque value is increased.

When garden walls confine a steep upper terrace, the stairs are most appropriately formed within the wall. The first step should stand on the lower level, and ascend by easy grade through the rough stone entrance, and on up the slope. An arch of stone gives an effective entrance-way; and the risers should be either of small stones set in mortar or of carefully placed loose stones after the manner of dry-wall building, making the stairway of the same type as the wall through which it enters the garden terrace.

When the garden stairs wind in circular fashion around the terrace planting on steep slopes, it will give pictorial value to set four or five well-placed stone or log steps, of irregular outline, at the beginning of the flight. Then carry a little winding pathway around a screened level. After rounding the curve, a few more steps may lead to another curved pathway. This plan, continued to the top of the incline, will give the impression of a well-planned walk of easy ascent, with a changing vista at every turn, instead of a difficult climb up a flight of stone steps.

The stairway climbing any sort of steep grade requires an architectural finish that will give an 


\section{PRACTICAL BOOK OF GARDEN ARCHITECTURE}

impression of safety. When it is not desirable to flank its borders with rustic balustrades or vinedraped railings, and there is not sufficient space for winding stairs bordered with protective shrubbery, the object must be accomplished by some special device. An inexpensive form of treatment, that possesses a certain decorative value, consists in spreading out the flight of stairs from top to bottom. When each step extends farther to the sides than the one above it, so that a pyramidal effect is formed by the stair mass, the appearance of safety is much greater than when the steps are all of the same length up a steep flight. The arrangement of pyramidal stairs is especially appropriate for a formal garden terrace.

A distinctive effect is produced when the stairs may be formed at a bend or curve in the terrace. There is then a good excuse for introducing a circular flight of stairs, which will add greatly to the decorative value. When the circular steps extend well around the bend, or the terrace corner, they may simply end in a border of bloom, or in the sod on either side. No balustrades will be required, as the safety feature is satisfied in the broad formation. For additional charm in ornamental finish, short stone pillars, surmounted by flower vases, may be 


\section{ATTRACTIVE GARDEN STAIRWAYS}

built at the top of the circular stairs, where it gives access to the broad walk of the upper level.

Where stone or brick-walled terraees are used instead of grassy banks, a stairway may wind around the curve of the wall, with an outer wall to form the protective balustrade. The stairs in this instance should be built of the same material that is used in the wall building. Vine draperies are not required for such walls and stairs, built on an elaborate scale for formal gardens; but they will have a softening and decorative effect that is pleasing. For informal and unpretentious devices in stair building, vines and trailers are always useful. Mere cost is not essential in achieving stairway dignity and beauty. 



\section{INDEX}

Andalusia spring house, 202

Arched bridges, 221

Arches for curved walks, 135

in imposing series, 136, 137

misplaced, 135

of old Colonial gardens, 134 over garden seats, 136

Belgium bath house, 97

Bermuda garden bath houses, 88

gateways, 15

walled gardens, 31,32

water supply and tank houses, 110

Bernardsville, New Jersey, spring house, 203

Bernardsville, New Jersey, well head, 307

Bird basins, concrete, 159, 160

attractive garden pottery, 156

home-made, 157-159

house to protect, 151

old world types, 157, 158

Bird feeding houses, arrangement of, 155

Bird feeding tables, Colonial food house, 154 evolution of food house, 154 food bells, 152

food trees, 153

"hangers," 153

in Germany, 153

Bird houses, guard for, 139

in trees, 140

on poles, 140
Bird houses, ornate structures, 141 picturesque contrivances, 146 safety before decoration, 141 structural details, 142 thatched roofs for, 143 treatment of entrance, 147, 148

Bridges, appropriate, 215, 216 good foundations, 220 rustic, for wooded sections, 220

screening, rough masonry, 217 value of the high arch, 221

Bryn Mawr spring house, 203

"Burholme" spring house, 199

California gateways, 14

gushers, 313

lake tea room, 67

porch pergola, 271

state bird farm, 151

wall fountain, 238

waterfalls over concrete dams, 207

Cap-stones, 13

Chicago bird houses, 145

Colonial garden temples, 289

Combination bath house, tea room and pergola, 94

"Compton" garden bridges, 218 garden temple, 290

Crows'-nests, finishing and furnishing, 124 open shelters, 123 


\section{INDEX}

Crows'-nests, over garden ravine, 130

in woods garden, 194

"Druim Moir" well head, 312

Dry walls, for terraces, 44

plant crevices, 34

English espalier walls of masonry, 256

espaliers on Laughlin estate, 254

garden fountains, 224-227

gardens, stepping stones, 21

ha-ha wall, 49

pleached alley, 131

ridge finish of thatched roofs, 284

tennis courts, 241

walled garden, 29

Espaliers, fan shapes and cordons, 253

pruning the trees, 259

training cordons, 260,261

training fan shapes, 260

training vase forms, 262

Espalier trellises, dwarfing the trees, 258

iron with self-fixing bases, 263 wire and metal work, 257

Espalier walls, for use and decoration, 252

of glass, 255

Florida gateways, 17

lake house of W. J. Matheson, 71

porch pergolas, 273

"savannah," 72

sea wall, 72

thatched roof of palmetto, 276
Florida water towers, 112

Foot-stones, 12

French espaliers, 254, 255

French ideals, coolness, shade and mystery, 187

French furnishings, conceptions of

Andre Le Nôtre on American country seats, 188,189

for formal spaces, 179

for wall treatment, 181

on New York country seats, 180

screening garden corners, 186 treatment of water gardens, 185

Frost heaving, how to prevent, 11, 43

Garden bath houses, rustic, 94

of Roman villas, 89

of sea-coast estates, 89

of Wyncote, Pennsylvania, 92

Garden fountains, appropriate designs, 223

backgrounds for, 229

elaborate types, 223

iron, concrete and stone, 228

fountain basin as lily pond, 229

at Oyster Bay, Long Island, 231,232

treatment of iron basins, 230

use of hydraulic ram, 222

Gateposts with flower receptacles, 14

High wall enclosures, 30

best situation, 34

as windbreaks, 33 


\section{INDEX}

Holland windmills, 119

Hydraulic ram for garden fountains, 222

Iron fencing and gateway, 10

Italian belvederes, 290

Japanese gardens, Burk estate, 169 by oriental craftsmen, 167

Homer estate, 168

Pilling estate, 169

practical construction, 177

stepping stones, 21

study of manners and customs, 168

symbolic details, 173

with appropriate flowers, 170

without flowers, 171

utilizing small spaces, 175 , 176

Japanese paving, 23

Japanese treatment of ridge poles, 284

"Kathaleen Farm," bath house, 95 porch pergola, 271

swimming pool, 95

"Krisheim," French wall treatment, 182

watering device, 48

Lakes, best plants for, 60

dredging for, 55

dyking for, 55

excavating, 56

location and treatment, 54

prevention of mosquito breeding, 56

shelters for water fowl, 62

to aerate water, 60

treatment of algæ, 57
Lanterns, an acetylene plant, 300

best light producers, 298

best vine background, 304

decorative hanging, 303

gasoline generators, 298

harnessing streams for power

in light producing, 299

inexpensive types, 302

Japanese types, 305

ornamental setting for posts, 302

the useful turbine, 299

Long Island garden fountain, 231, 232

gushing wells, 313

water tower, 111

Layout of walks, 19

Lure of the "antique" temple, 291

"Lyndanwalt" pergolas, 264

studio, 162

"Lynhurst" water-fall and dam, 208

"Lynnewood Hall" terrace treatment, 48

New England bird protection, 150 bath house at Rippowan, 96 historic gateways, 16 ideas of French gardening on coast of Maine, 184

lake pavilions, 68

old walls of, 37

terrace walls, 49

woods gardens, 190, 191

New Jersey espaliers, 254

New York, first bird census, 152

"Ogontz" bridges, 215, 216

"Old Gate" at Farmington, Connecticut, 17 


\section{INDEX}

Pavilions appropriate for lake tea rooms, 66

decorative accessories, 73

floating and stationary, 71

flower barge for, 69

gliding by cable, 67

rope ferry for, 69

thatched roof for, 70

Pergola court of Roman type, 265

Pergolas, how they differ from arbors, 266

how to make concrete columns, 269

in harmony with home, 267

rafters and girders, 270

on rocky Maine coast, 268

Pleached alleys of Italian villas, 132

Pleaching, methods of, 133

Porch pergola, appropriate furnishings, 275

evolution of, 272

terraced, 274

Reservoirs, place for, 100

Retaining wall of bowlders, 52, 53 "Rose Valley Farm" pergolas, 267

water tower, 111

Rotterdam treatment of water, 206

Spring house built by owner, 198 two-story types, 201, 202 treatment of interior, 200

Stairways, advantages of winding stairs, 317

charm of changing viewpoints, 315
Stairways, circular flights, 322

for climbing steep grades, 321 pyramidal stairs, 322

of rustic logs, 320

picturesque railings, 318

sense of proportion and fitness, 319

steep flights objectionable, 317

of stone, 320

study of treads and risers, 318 suitable steps and balustrades, 316

through wall and terrace, 321 Streams, shallow dams for, 219 Street parking, 30

Swimming pools, construction and cost of, 79-86

best form for, 77

inexpensive in garden, 75,76 in conservatories, 74

lining for, 77

Tempietto for commanding positions, 293

Temples, care required in setting up, 296

follow classic reproductions, 295

furnishing, 294

Grecian and Egyptian types, 289

Tennis courts, best position for, 245

clay courts, 246,247

decorative features, 240

"dirt" courts, 248

drainage devices, 245

the grassy court, 242

Tennis court "trenching," 243 


\section{INDEX}

Tennis court, seats, balustrades, terraces, etc., 250, 251

Terrace retaining walls, 42 walls of logs, 43 of sod and trailers, 43

Thatched roofs, best materials, 277 "combing" and trimming, 281

of England, Holland, and Japan, 277

finishing peaks and ridges, 282,283

fire precautions, 287

heather-covered roofs of old world gardens, 286

home-made mallets and needles, 279

methods of laying, 280

old world methods, 278

pine thatching, 285

practical features, 278

treatment of eaves, 282

Tree house construction, 125

in Catskill Mountains, 126

roofing, 128

vine-draped stairs, 130

Tree rooms, wall finish, 128

"Thorn hedge" espaliers, 253

wall fountain, 234

woods garden, 191

Transforming old houses, a charming studio, 165

"antique" doorway, 164

Colonial designs, 165

treatment of interior, 164

various uses, 161

Walk paving, common forms, 20 gravel, brick and concrete, 24,25
Walk, layout, 19

picturesque treatment, 26

ramping, 27

rustic logs, 27

Wall fountains in concrete, 236

duplicates of Italian designs, 235

inexpensive installation, 237

in series of basins, 239

practical features, 238

Wall plants, succulents and alpines, 45,46

with decorative foliage, 46

Walls, buttresses and pilasters, 40,41

of cobbles and fieldstone, 36 earth pockets for plants, 45 of historic Haddonfield, 38 stone and brick, 35

Water-falls, artificial introduction of water, 207

and dams in Blue Ridge Mountains, 208

dam gates, 213

$\log$ dams, 209

making the most of the water supply, 205, 206

providing the charm of vigor, 211

the serviceable spillway, 211, 212

treatment of leaky dams, 210 utilitarian features, 214

Water fowl, 61

Water summer house, 66

Water supply by electric motor,

102

by gas engine, 103

by gasoline engine, 103

by gravitation, 100 


\section{INDEX}

Water supply by hot-air engine, 104

by hydraulic ram, 101 pneumatic tank system, 107 by pumping, 101 by steam engine, 106 small cost of, 108

Water towers, architectural plans, 109 inexpensive, 99

Wells, guarding against impurities, 310

"gushing wells," 312

Well heads, old world types; 307 quaint oil jar, 307 . their manufacture, 308

Well houses, appropriate types, 314 rustic designs, 309
West Indies tree, to protect birds, 138

Wild-gardening, picturesque, 190 Windmills, decoration of base, 115 devices for utilizing structure, 114

tool house, 116

with children's playhouse, 116 with the slab-finish structure, 117

with spring house, 118

tank requirements, 120-122

thatched, 119

Woods garden, harmonious development, 195

garden surprises, 192

Italian treatment, 196

water treatment, 193 


THIS BOOK IS DUE ON THE LAST DATE STAMPED BELOW

\section{AN INITIAL FINE OF 25 CENTS} WILL BE ASSESSED FOR FAILURE TO RETURN THIS BOOK ON THE DATE DUE. THE PENALTY WILL INCREASE TO 50 CENTS ON THE FOURTH DAY AND TO \$1.00 ON THE SEVENTH DAY - SOVERDUE.

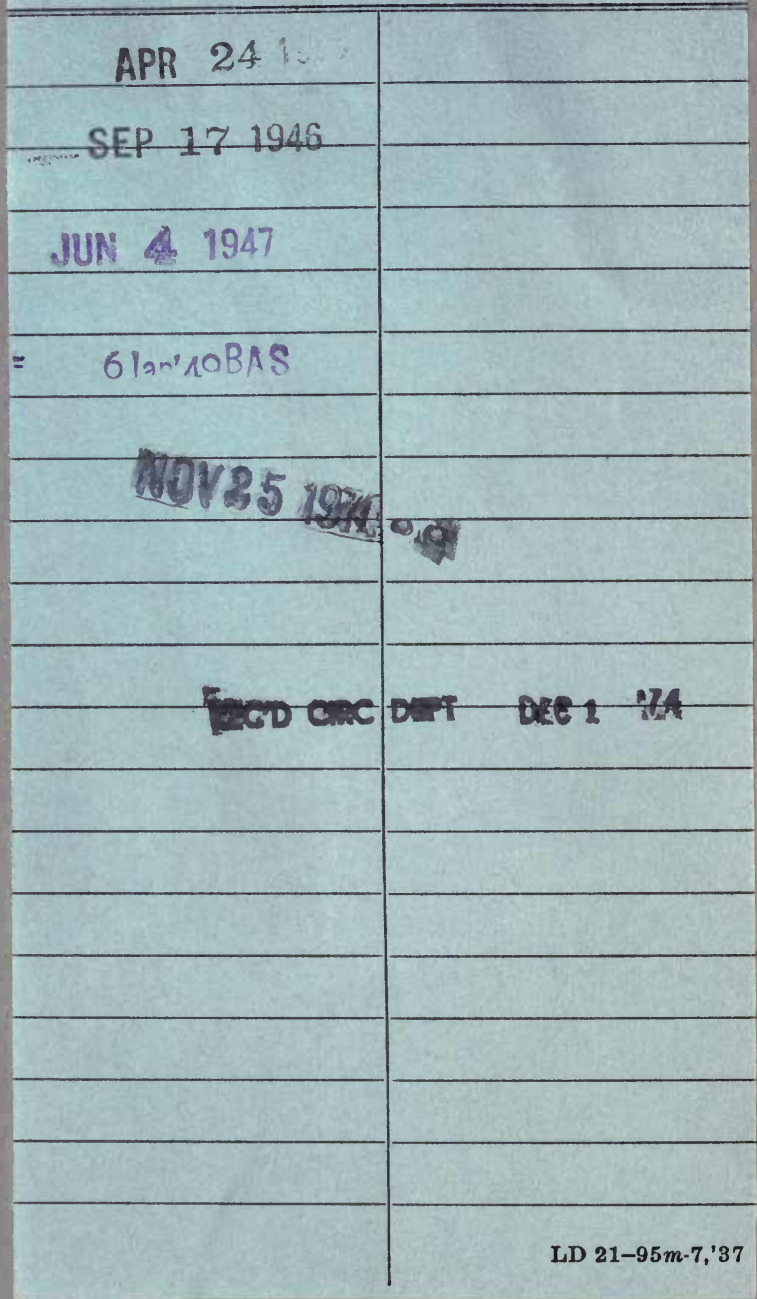



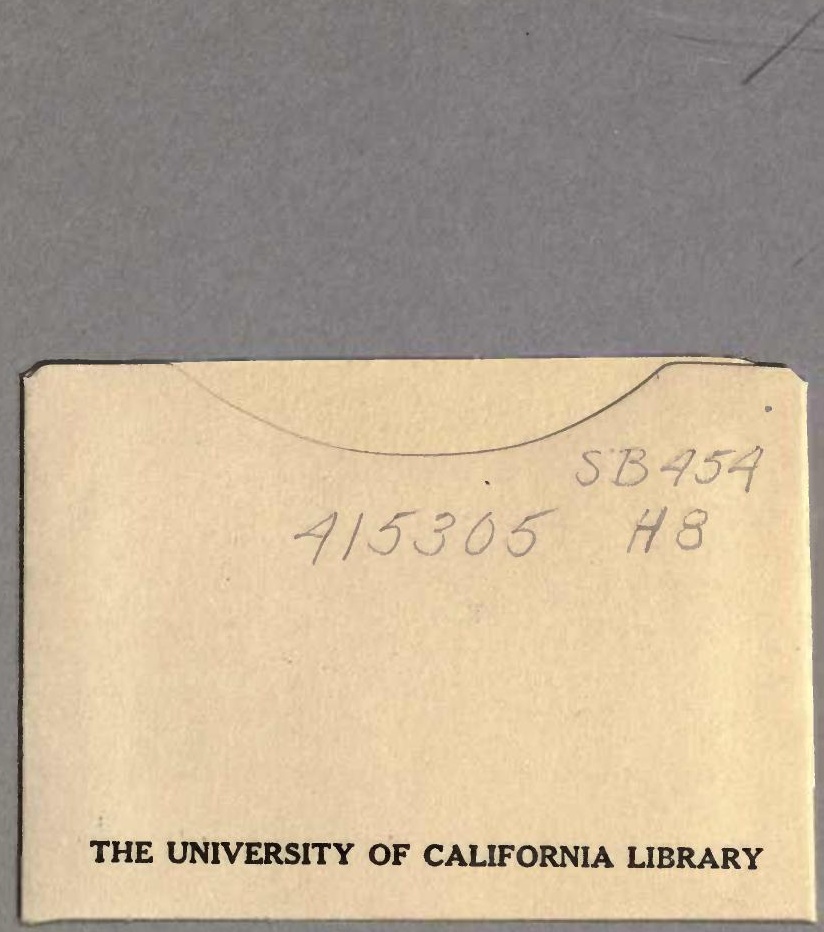
